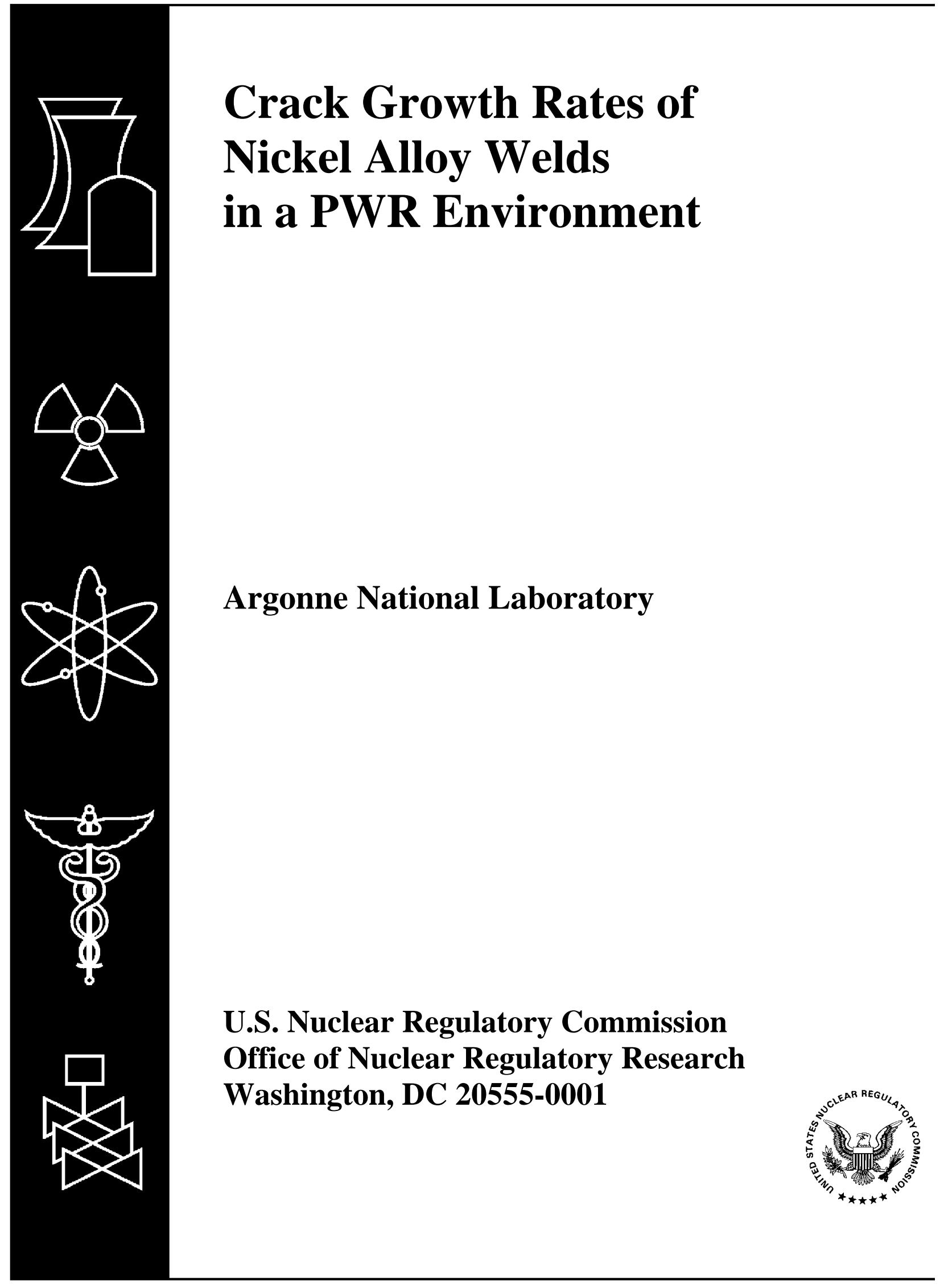




\section{Crack Growth Rates of Nickel Alloy Welds in a PWR Environment}

Manuscript Completed: January 2004

Date Published: May 2006

Prepared by

B. Alexandreanu, O. K. Chopra, and W. J. Shack

Argonne National Laboratory

9700 South Cass Avenue

Argonne, IL 60439

W. H. Cullen, Jr., NRC Project Manager

\section{Prepared for}

Division of Fuel, Engineering and Radiological Research

Office of Nuclear Regulatory Research

U.S. Nuclear Regulatory Commission

Washington, DC 20555-0001

NRC Job Code Y6388

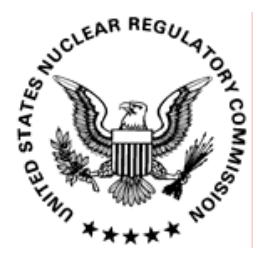


Intentionally Left Blank 


\title{
Crack Growth Rates of Nickel Alloy Welds in a PWR Environment
}

\author{
by
}

\author{
B. Alexandreanu, O. K. Chopra, and W. J. Shack
}

\begin{abstract}
In light water reactors (LWRs), vessel internal components made of nickel-base alloys are susceptible to environmentally assisted cracking. A better understanding of the causes and mechanisms of this cracking may permit less conservative estimates of damage accumulation and requirements on inspection intervals. A program is being conducted at Argonne National Laboratory to evaluate the resistance of $\mathrm{Ni}$ alloys and their welds to environmentally assisted cracking in simulated LWR coolant environments. This report presents crack growth rate (CGR) results for Alloy 182 shielded-metal-arc weld metal in a simulated pressurized water reactor (PWR) environment at $320^{\circ} \mathrm{C}$. Crack growth tests were conducted on 1-T compact tension specimens with different weld orientations from both double-J and deep-groove welds. The results indicate little or no environmental enhancement of fatigue CGRs of Alloy 182 weld metal in the PWR environment. The CGRs of Alloy 182 in the PWR environment are a factor of $\approx 5$ higher than those of Alloy 600 in air under the same loading conditions. The stress corrosion cracking for the Alloy 182 weld is close to the average behavior of Alloy 600 in the PWR environment. The weld orientation was found to have a profound effect on the magnitude of crack growth: cracking was found to propagate faster along the dendrites than across them. The existing CGR data for Ni-alloy weld metals have been compiled and evaluated to establish the effects of key material, loading, and environmental parameters on CGRs in PWR environments. The results from the present study are compared with the existing CGR data for $\mathrm{Ni}$-alloy welds to determine the relative susceptibility of the specific $\mathrm{Ni}$-alloy weld to environmentally enhanced cracking.
\end{abstract}


Intentionally Left Blank 


\section{Foreword}

This report presents crack growth rate data and the results of the corresponding fracture surface and metallographic examinations from cyclic loading and primary water stress-corrosion cracking (PWSCC) tests of two nickel-base Alloy 182 (A182) weldments, which are typical of those used in vessel penetrations and piping butt welds in nuclear power plants. The effect of crack orientation with respect to dendrite orientation is the most significant variable investigated in this study. However, this report also includes a review of data from several laboratories, which describes the effects of material composition, loading characteristics, and chemistry of the aqueous environment. The main conclusion is that the PWSCC growth rates described for A182 specimens in this report are comparable to the crack growth rates that characterize the performance of Alloy 600 (A600).

This report is the first in a series documenting the results of crack growth rate testing in vessel head penetration materials, focusing on the weld metals, A182 and A152, and including results of some tests of the base metals, A600 and (eventually) A690. The results presented in this report were obtained in tests of a laboratory-fabricated, shielded metal arc welding deposit of A182. Testing of A182 weldments continues at Argonne National Laboratory, and substantially more crack growth rate results are anticipated in the next two years.

The impetus for this research on PWSCC comes from User Need Request NRR-2002-018, submitted by the U.S. Nuclear Regulatory Commission, Office of Nuclear Reactor Regulation. This topic may be an especially important consideration in the review of license applications, as well as the disposition of relief requests pertaining to flaw evaluations for vessel penetration and piping butt welds. The data on cyclic loading effects are commonly used in the fatigue analyses that are required for flaw evaluations completed in accordance with the requirements set forth in Section XI, IWB-3660 and Appendix O, of the Boiler and Pressure Vessel Code promulgated by the American Society of Mechanical Engineers.

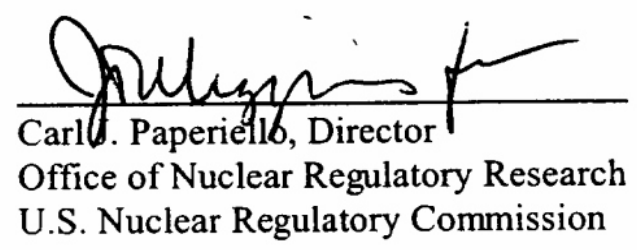


Intentionally Left Blank 


\section{Contents}

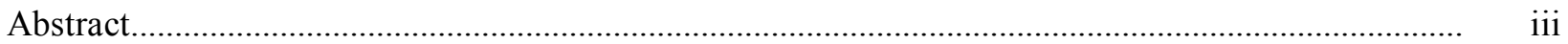

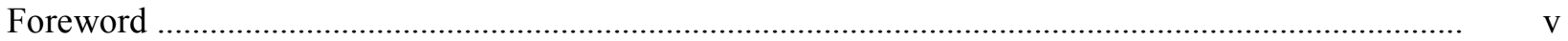

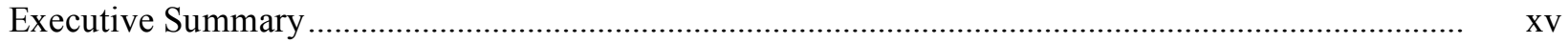

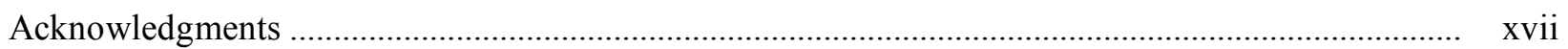

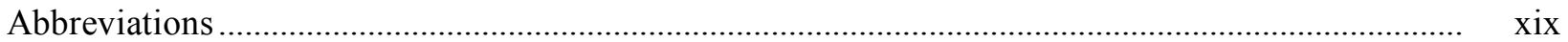

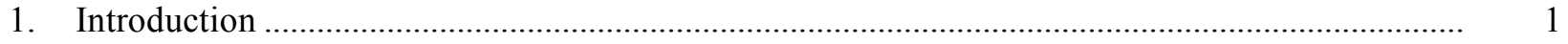

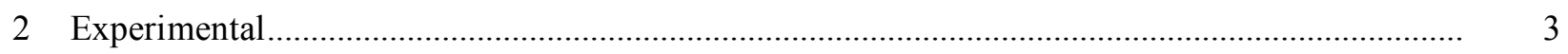

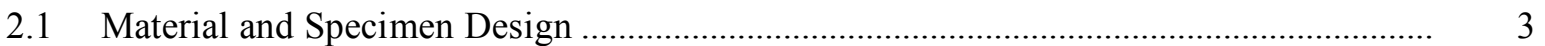

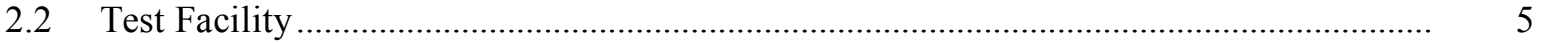

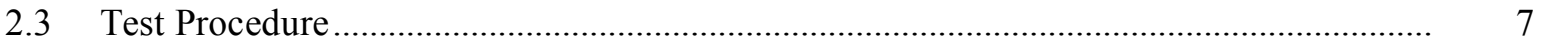

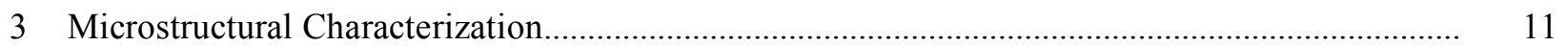

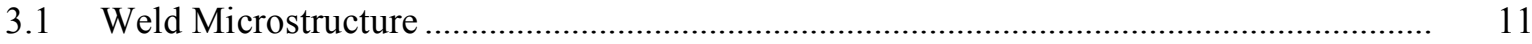

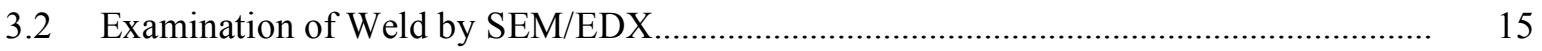

3.3 Examination of Weld Specimens by Orientation Imaging Microscopy …......................... 18

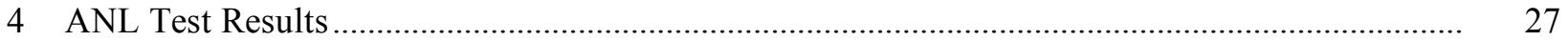

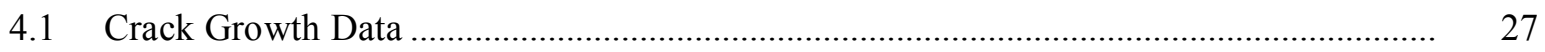

4.1.1 Crack Growth Data for Double-J Weld Specimen CT31-W01 TS .................... 27

4.1.2 Crack Growth Data for Double-J Weld Specimen CT31-W02 TS ................... 34

4.1.3 Crack Growth Data for Deep-Groove Weld Specimen CT933-TS ................... 37

4.1.4 Crack Growth Data for Deep-Groove Weld Specimen CT933-TL................... 42

4.1.5 Crack Growth Data for Deep-Groove Weld Specimen CT933-LS .................... 48

4.2 Effect of Grain Boundary Type and Relative Grain Orientation on Crack

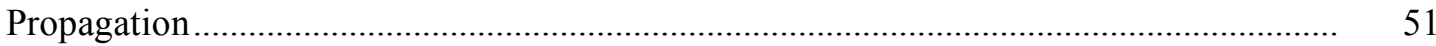

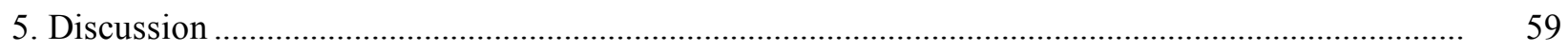

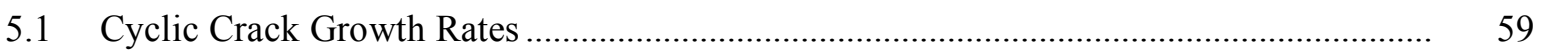

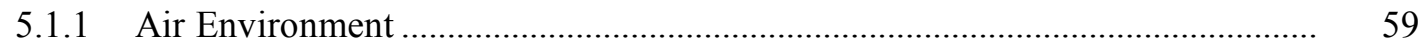

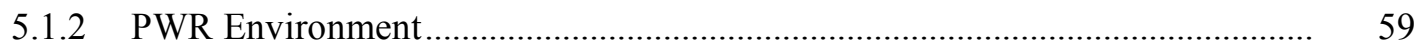




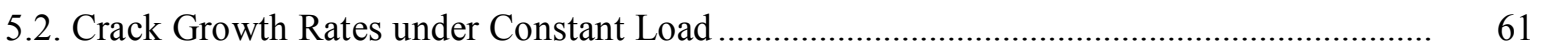

5.3. Effect of Key Parameters on SCC Crack Growth Rates.................................................. 63

5.3.1 Effect of Orientation of Dendrites ................................................................. 63

5.3.2 Effect of Size of the Experimental Crack Advance............................................ 64

5.3.3 Effect of Gentle Cycling and Periodic Unloading ........................................... 66

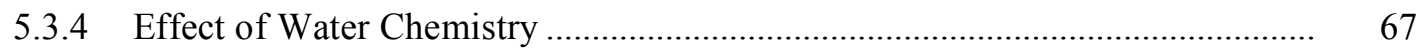

5.3.5 Effect of Temperature ................................................................................... 68

5.3.6 Heat-to-Heat Comparisons of the CGR Data ..................................................... 69

5.3.7 Extrapolation of Available Data to the Population of Alloy 182 and 82 Weld Materials .............................................................................................. $\quad 70$

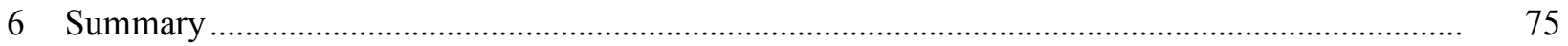

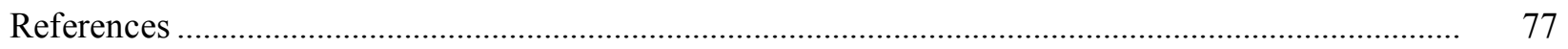




\section{Figures}

1. Configuration of compact-tension specimen used for this study ........................................... 3

2. Schematic of the weld joint design and weld passes. ............................................................ 4

3. Orientation of the CT specimen from the Alloy 182 SMA weld................................................ 4

4. A photograph of the facility for conducting crack growth tests in simulated LWR environments.

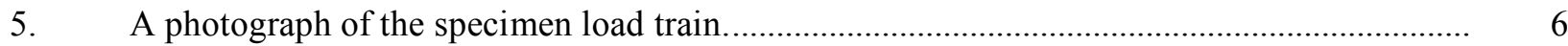

6. Schematic diagram of the recirculating autoclave system used for crack growth rate tests.... 6

7. Schematic showing the locations of the three samples cut from the weld.............................. 11

8. Weld microstructure from Sample 1; transition area between the weld and Alloy 600; and dendritic microstructure in the weld.

9. Large grain microstructure in the HAZ at two opposite positions........................................... 13

10. Dendritic microstructure on sample 3A and at a weld pass. .............................................. 13

11. Dendritic microstructure at weld passes on sample 3B and high magnification micrographs at the respective locations.

12. Dendritic microstructure on sample $3 \mathrm{~B}$ and high magnification of a region.

13. Dendritic microstructure observed on the surface of sample $3 \mathrm{~A}$ at magnifications of $100 \times$, $200 \times$.

14. Micrograph showing one of the matrix precipitates observed on the surface of sample $3 \mathrm{~A}$ and EDX spectra resulting from the bulk and the precipitate.

15. Micrographs showing the microstructure on plane 3A, matrix and grain boundary precipitates, and EDX spectra resulting from the bulk and grain boundary precipitates.

16. Ti-rich precipitates in the weld and maps showing the topography at the locations where the high magnification micrographs were taken.

17. Micrographs showing the heat-affected zone and high magnification micrographs showing precipitates in the heat-affected zone.

18. OIM map of the weld on plane "B", sample 3B; the same OIM map showing the orientation of each grain; and legends for crystal directions and the resulting grain boundary character distribution.

19. OIM map on the surface of sample 3B and the resulting grain boundary character distribution. 
20. The same OIM map as in Fig. 19 showing crystal directions and SEM micrograph illustrating the dendritic microstructure of the weld.

21. Schematic showing the two planes on which the OIM characterization was carried out: plane "A", along the direction of the dendrites, and plane "B", perpendicular to the direction of dendrites.

22. OIM maps from plane "A", parallel to the direction of dendrites, and resulting grain boundary character distributions.

23. OIM maps from plane "A" showing the grain orientations, and legends for grain orientations and grain boundary character distributions.

24. OIM map from plane "B", perpendicular to the direction of dendrites, map showing the grain orientations, and legends for grain orientations and grain boundary character distributions.

25. Grain boundary character distribution for laboratory-prepared welds.

26. OIM map from Alloy 600, map showing the grain orientations, and legends for grain orientations and grain boundary character distributions.

27. Crack length vs. time for Alloy 182 SMA weld-metal specimen CT31-W01 TS in simulated PWR environment at $320^{\circ} \mathrm{C}$ during test periods $1-4 \mathrm{a}, 4 \mathrm{~b}-5,6-8,9$, and 10.

28. Photomicrograph of the fracture surface of specimen CT31-W01 TS.

29. A higher magnification photomicrograph showing entire crack extension in a region in the center of the specimen CT31-W01 TS. Micrographs b, c, and d are from locations 3, 2, and 1 in micrograph.

30. Transition from TG to IG fracture and higher magnification micrograph of the boxed area showing the tip of a few cracks.

31. Mixed TG and IG fracture modes, high magnification micrograph of the boxed area, and micrographs showing the crack tips at locations " 1 " and " 2 " in micrograph.

32. Photomicrographs detailing the fracture in a region during test periods with a hold time and/or a high rise time and high magnification micrographs of positions indicated by arrows.

33. Photomicrographs detailing the fracture in a region during test periods with a hold time and/or a high rise time, and high magnification micrographs.

34. Crack length vs. time for Alloy 182 SMA double-J weld specimen CT31-W02 TS in simulated PWR environment at $320^{\circ} \mathrm{C}$ during test periods $1-3$ and $4-5$.

35. Fracture surface of specimen CT31-W02 TS.

36. Micrographs showing the cross section of CT31-W02 TS. 
37. Crack length vs. time for laboratory-prepared Alloy 182 weld specimen CT933-TS in simulated PWR water at $320^{\circ} \mathrm{C}$ during periods precracking-period 2, 3-4, 5-6, 7-8, and $9-10$.

38. Crack front in cross section of sample CT933-TS. .............................................................

39. Crack front on fracture surface of sample CT933-TS. ............................................................

40. Crack front on sample CT933-TS, where several fracture modes are identified: transition from TG to IG; IG; and ductile rupture in the IG region.

41. Crack length vs. time for Alloy 182 weld specimen CT933-TL in simulated PWR environment at $320^{\circ} \mathrm{C}$ during test periods precracking-1, 2, 3-4, 5, 6-10,11, 12-14, 15, 16-19, and 20-21.

42. Fracture surface of Alloy 182 weld specimen CT933-TL. The regions dominated by IG fracture corresponding to the constant load periods are indicated in the figure.

43. Intergranular fracture on the Alloy 182 weld specimen CT933-TL resulting from the constant-load period CL-5.

44. Higher magnification image of IG fracture on the Alloy 182 weld specimen CT933-TL resulting from the constant load period CL-5.

45. Crack length vs. time for Alloy 182 weld specimen CT933-LS in simulated PWR environment at $320^{\circ} \mathrm{C}$ during precracking and periods $1-2$, constant load period 3 , and constant-load period 4.

46. Crack front on fracture surface of sample CT933-LS. ..................................................... 50

47. Transition from TG to IG observed on the fracture surface of sample CT933-LS................. 51

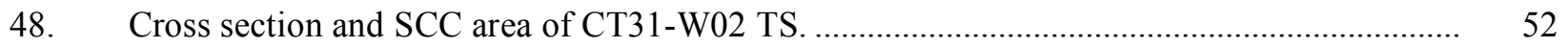

49. SEM image of the cross section of CT31-W02 tilted by $70^{\circ}$ for OIM analysis..................... 53

50. SCC region of specimen CT31-W02 and resulting OIM map........................................... 53

51. Cross sections of the three samples from CT933-TS tilted by $70^{\circ}$ for the OIM analysis: CT933-TS-S1, CT933-TS-S2, and CT933-TS-S3.

52. SCC regions and resulting OIM map for CT933-TS-S1, CT933-TS-S2, and CT933-TS-S3.. 54

53. Fractions of cracked boundaries as a function of boundary type........................................... 56

54. Fractions of cracked boundaries as a function of the relative orientation of the adjacent grains.

55. Experimental values of fatigue crack growth rate of Alloys 182 and 52 in air as a function of those estimated for Alloy 600 under the same loading conditions.

56. Fatigue CGR data for Alloy 82 and Alloy 182 weld metal in PWR environment as a function of the growth rate for Alloy 600 in air under the same loading conditions. 
57. Fatigue CGR data for Ni-alloy welds in PWR environment as a function of the growth rate for Alloy 600 in air under the same loading conditions.

58. CGR data for Alloy 182 SMA weld-metal specimen in simulated PWR environment at $320^{\circ} \mathrm{C}$ as a function of growth rates for Alloy 600 in air.

59. Comparison of the SCC crack growth rate for the Argonne Alloy 182 weld with the available data for Alloy 182 and 82 welds in simulated PWR environment.

60. Experimental crack growth rates in Alloy 182 weld in TL and TS orientations

61. Influence of the orientation of the dendrites on the crack growth rates in Alloy 182 and 82 welds in PWR environments.

62. SCC crack growth data for the Argonne Alloy 182 weld specimens tested.

63. Experimental crack growth rates of Alloy 182 and 82 welds obtained with and without periodic partial unloading.

64. Temperature dependence of the CGR data for Alloy 182 and 82 obtained at Westinghouse, Lockheed Martin, Bechtel Bettis, ETH, and CEA at temperatures between 290 and $360^{\circ} \mathrm{C}$.

65. Experimental crack growth rate normalized to $325^{\circ} \mathrm{C}$ as a function of stress intensity factor $\mathrm{K}$.

66. Estimated cumulative distribution of the normalized parameter $\alpha$ in the CGR relationship for Alloy 182 based on data that satisfy the screening criterion of Ref. 52 and all the data....

67. Distributions of the 95th, 90th, 67th, and 50th percentile values for parameter $\alpha$ for heats of Alloy 182 welds in PWR water at $325^{\circ} \mathrm{C}$.

68. Comparison of the SCC crack growth rate for Alloy 182 and Alloy 82 welds in simulated PWR environment with the 75th percentile curve. 


\section{Tables}

1. Chemical composition of Alloy 600 base metal and Inconel 182 and 82 weld metals............ 3

2. Welding process and conditions for various weld passes........................................................

3. Chemical compositions of the bulk and matrix precipitate resulting from EDX analysis....... 16

4. Chemical compositions of the bulk and grain boundary precipitate resulting from EDX analysis

5. Crack growth data for specimen CT31-W01 TS of Alloy 182 SMA weld in PWR water at $320^{\circ} \mathrm{C}$

6. Crack growth data for specimen CT31-W02 TS of Alloy 182 SMA weld in PWR water at $320^{\circ} \mathrm{C}$.

7. Crack growth data for specimen CT933-TS of Alloy 182 SMA weld in PWR water at $320^{\circ} \mathrm{C}$

8. Crack growth data for specimen CT933-TL of Alloy 182 SMA weld in PWR water at $320^{\circ} \mathrm{C}$

9. Crack growth data for specimen CT933-LS of Alloy 82 SMA weld in PWR water at $320^{\circ} \mathrm{C}$.

10. Cracking data for both CT933-01 and CT31-W02.

11. Fractional errors in the population of cracking susceptible HABs as a function of alloy, orientation, and crack advance.

12. Values of the parameter A in the Scott model for crack growth rate for several Alloy 182, 82, and 132 welds

13. Values of the parameter $\alpha$ for Alloy 182 and 82 at $325^{\circ} \mathrm{C}$ as a function of the percentage of the population bounded and the confidence level. 
Intentionally Left Blank 


\section{Executive Summary}

The Ni-base alloys used as construction material in light water reactors (LWRs) have experienced stress corrosion cracking (SCC). Such cracking was first observed in steam generator tubes, but it has also occurred in Ni alloys used in applications such as instrument nozzles and heater thermal sleeves in the pressurizer and penetrations for control-rod drive mechanisms (CRDMs) in the reactor-vessel closure heads. In operating plants, the weld metal Alloys 82 and 182 are used with Alloy 600 and appear to be more resistant to environmentally assisted cracking than the wrought alloy. However, laboratory tests indicate that in pressurized water (PWR) coolant environments, the SCC susceptibility of Alloy 182 may be greater than Alloy 600, and Alloy 82 may be comparable to Alloy 600. This apparent inconsistency between field and laboratory experience has been an issue that needs further investigation.

A program is being conducted at Argonne National Laboratory (ANL) to evaluate the resistance of $\mathrm{Ni}$ alloys and their welds to environmentally assisted cracking in simulated LWR coolant environments. This report presents crack growth rate (CGR) results for Alloy 182 weld metal alloys in simulated PWR environments at $320^{\circ} \mathrm{C}$. The tests were performed using specimens from both double "J" joint and deepgroove filled laboratory-prepared welds. The total crack extensions estimated by the DC potential method were verified by physical measurements on the fracture surfaces.

Metallographic examinations were performed to characterize the microstructure of the weld. The weld structure consists of vertically aligned columnar grains and dendrites. The weld microstructure was also examined by orientation imaging microscopy (OIM), a diffraction-based technique, to determine the orientations of the grains and the type of grain boundaries present. The results show that a large proportion $(70 \%)$ of the grains boundaries are random or high-angle boundaries (HABs), which are more susceptible to cracking than those in specific orientation relationships, also known as coincident site lattice (CSL) boundaries. In addition, the OIM maps show the presence of clusters of grains that share similar orientations.

The environmental enhancement of CGRs under cyclic loading was determined relative to the CGRs that would be expected under the same loading conditions for Alloy 600 in air. In general, the CGRs of Alloy 182 in the PWR environment are a factor of $\approx 5$ higher than those of Alloy 600 in air under the same loading conditions. This result is independent of rise time or frequency in the test conditions and indicates little or no environmental enhancement of CGRs of the Alloy 182 weld metal in the PWR environment under this type of loading condition. The experimental CGR for the laboratory-prepared Alloy 182 weld under trapezoidal loading (i.e., essentially a constant load with periodic unload/reload) is close to the mean value of CGR for Alloy 600 for the corresponding value of stress intensity factor (K) in a PWR environment. Most of the existing CGR data for Alloy 182 and 82 welds are a factor of $1-10$ greater than the median value for Alloy 600.

Crack growth tests were conducted on 1-T compact tension specimens in TS, LS, and TL orientations, i.e., crack plane along or perpendicular on the columnar grains. The results show that the effect of sample orientation on the crack growth rate can be as high as a factor of four.

Metallographic examination of the fracture surface revealed relatively straight crack fronts. The fracture modes correlated well with the test conditions. High rise times or long hold periods favor intergranular (IG) SCC. Also, IG cracking apparently advanced more readily along some grain orientations than others, resulting in crack fronts with occasional unbroken ligaments and few regions of transgranular (TG) cracking. 
The effects of grain boundary type and grain orientation on the cracking behavior of Alloy 182 weldments were examined. It was hypothesized that a boundary with a weak Taylor-factor mismatch, as would be the case for two neighboring grains that share a similar orientation, would be less susceptible to deformation and, ultimately, to cracking. By contrast, a strong mismatch in the Taylor factor across a grain boundary would tend to result in a strain incompatibility at that boundary, making it susceptible to cracking. To test the hypothesis, OIM maps were obtained along the crack paths in two compact tension specimens of Alloy 182. Comparison of scanning electron microscopy photomicrographs of the cracks with the OIM maps of the same areas enabled the identification of the types of cracked grain boundaries, as well as the relative orientation of the neighboring grains. The results showed that, on average, $90 \%$ of the cracked boundaries are $\mathrm{HAB}$, and $87 \%$ of the cracks occurred along grain boundaries that separated dissimilarly oriented grains.

The existing CGR data for Ni-alloy weld metals (i.e., Alloys 82, 182, 52, 152, and 132) have been compiled and evaluated to establish the effects of material, loading, and environmental parameters on CGRs in PWR environments. The results from the present tests were compared with the existing CGR data.

The data in the literature, while limited, and the results from the present study indicate very little dependence of the environmental enhancement of CGRs on frequency and strain rate under cyclic loading in PWR environments for Alloy 182 and 82 welds. Under similar loading and environmental conditions, strain-rate-dependent environmental enhancement is observed in CGRs for Alloy 600.

In general, the CGRs of Alloy 182 are higher than those of Alloy 82. Although the results have substantial scatter, it is clear that weld orientation has a strong effect on CGRs. Crack growth rates along the plane of the columnar grains are higher in directions parallel to to the columnar grains than in directions perpendicular to the columnar grains. The activation energy for the temperature dependence of SCC CGRs for Alloy 182 and 82 weld metals may be slightly higher than that for Alloy 600 . Individual data sets yield activation energies of $120-250 \mathrm{~kJ} / \mathrm{mol}(28.5-59.5 \mathrm{kcal} / \mathrm{mol})$. Studies on the effect of dissolved hydrogen content indicate that CGRs in Alloy 182 and 82 welds are highest at dissolved hydrogen contents that result in electrochemical potentials close to the $\mathrm{Ni} / \mathrm{NiO}$ phase transition.

The dependence of SCC growth rates of Ni-alloy welds on the stress intensity factor $\mathrm{K}$ can be represented by the Scott model. Material heat-to-heat variations of the CGR are considered and represented in terms of variability in the parameter A in the Scott model. The available data was used to estimate the cumulative distribution of A for the population of Alloy 182 and 82 welds. Values of the parameter $\mathrm{A}$ as a function of the percentage of the population bounded and the confidence level are presented. The results suggest that under similar loading and environmental conditions, the mean CGRs for $\mathrm{Ni}$-alloy welds appear to be a factor of $\approx 2$ higher than the mean CGRs for Alloy 600 . 


\section{Acknowledgments}

The authors thank E. J. Listwan J. Tezak, R. Clark, and T. M. Galvin, for their contributions to the experimental effort. This work is sponsored by the Office of Nuclear Regulatory Research, U.S. Nuclear Regulatory Commission, under Job Code Y6388; Program Manager: W. H. Cullen, Jr. 
Intentionally Left Blank

xviii 


\section{Abbreviations}

\begin{tabular}{|c|c|}
\hline ANL & Argonne National Laboratory \\
\hline ASME & American Society of Mechanical Engineers \\
\hline ASTM & American Society for Testing and Materials \\
\hline BWR & Boiling Water Reactor \\
\hline $\mathrm{C}$ & Circumferential \\
\hline $\mathrm{CF}$ & Corrosion Fatigue \\
\hline CGR & Crack Growth Rate \\
\hline CRDM & Control Rod Drive Mechanism \\
\hline CSLB & Coincident Site Lattice Boundary \\
\hline $\mathrm{CT}$ & Compact Tension \\
\hline DO & Dissolved Oxygen \\
\hline ECP & Electrochemical Potential \\
\hline EDX & Energy Dispersive X-ray \\
\hline GBC & Grain Boundary Coverage \\
\hline GBCD & Grain Boundary Character Distribution \\
\hline HAB & High Angle Boundary \\
\hline IG & Intergranular \\
\hline $\mathrm{L}$ & Longitudinal \\
\hline LWR & Light Water Reactor \\
\hline MRP & Materials Reliability Performance \\
\hline NRC & Nuclear Regulatory Commission \\
\hline NWC & Normal Water Chemistry \\
\hline OIM & Orientation Imaging Microscopy \\
\hline PWSCC & Primary Water Stress Corrosion Cracking \\
\hline PWR & Pressurized Water Reactor \\
\hline $\mathrm{R}$ & Radial \\
\hline $\mathrm{RCS}$ & Reactor Coolant System \\
\hline RPV & Reactor Pressure Vessel \\
\hline RTZ & Rolled Transition Zone \\
\hline SA & Solution Annealed \\
\hline $\mathrm{SCC}$ & Stress Corrosion Cracking \\
\hline SEM & Scanning Electron Microscopy \\
\hline SHE & Standard Hydrogen Electrode \\
\hline SS & Stainless Steel \\
\hline TG & Transgranular \\
\hline
\end{tabular}


Intentionally Left Blank 


\section{Introduction}

The Ni-base alloys used as construction material in light water reactors (LWRs) have experienced stress corrosion cracking (SCC). Primary-water SCC of Alloy 600 steam generator tubes in pressurized water reactors (PWRs) has been studied intensively. ${ }^{1-3}$ Stress corrosion cracking has also occurred in Ni alloys used in applications such as instrument nozzles and heater thermal sleeves in the pressurizer ${ }^{4}$ and penetrations for the control-rod drive mechanism (CRDM) in the reactor vessel closure heads. ${ }^{5}$ In the fall of 1991, during an over-pressurization test, a leak was discovered in the pressure-vessel head penetration at the Bugey 3 plant in France. Metallurgical evaluations indicated that the leak was caused by primary-water SCC. ${ }^{6}$ The main crack had initiated in Alloy 600 base metal and propagated into the Alloy 182 weld metal. Subsequent inspections of CRDM penetrations in domestic and foreign PWRs identified a small number of penetrations ( $<5 \%$ of the penetrations inspected) with axial cracks. None of the cracks was through-wall, and until recently, no more leaks occurred in pressure-vessel head penetrations.

Leaks from axial through-wall cracks were identified at Oconee unit 1 in November 2000 and at Arkansas Nuclear One unit 1 in February 2001. ${ }^{7}$ During the next 15 months, inspections at Oconee units 2 and 3 and followup inspection at unit 1 identified both axial and circumferential cracks in reactor-vessel head penetrations. ${ }^{8}$ The presence of circumferential cracks, in particular, raised concerns regarding structural integrity. 9,10 Also, in October 2000, significant boron deposits were discovered near the Loop "A" reactor vessel nozzle to hot-leg reactor coolant pipe weld at the V. C. Summer plant. ${ }^{11}$ Ultrasonic inspection of the pipe revealed an axial crack and a short, intersecting circumferential crack, in the dissimilar metal weld at the top of the pipe. Earlier in 2000, two shallow axial flaws were found in the outlet nozzle-to-safe-end weld of Ringhals unit 3, and four axial indications were found in the same region of Ringhals unit 4, in Sweden. ${ }^{12}$ Cracks have also been found in pressure-vessel head penetrations at North Anna unit 2, ${ }^{13}$ the Davis-Besse nuclear power plant, ${ }^{14}$ and more recently, in the bottom-mounted instrumentation nozzles at South Texas unit 1.15,16 Long-term operating experience indicates that, although wrought Ni-base Alloy 600 is susceptible to SCC, until recently, the weld metal Alloys 82 and 182 used with Alloy 600 were perceived to be less susceptible. However, laboratory tests indicate that in PWR coolant environments, the SCC susceptibility of Alloy 182 is greater than Alloy 600, and Alloy 82 is comparable to Alloy 600. This apparent inconsistency between field and laboratory experience has been an issue that needs further investigation.

The objective of the experimental program being conducted at Argonne National Laboratory (ANL) is to evaluate the resistance of $\mathrm{Ni}$ alloys and their welds to environmentally assisted cracking in simulated LWR coolant environments. The present report is focused on the cracking behavior of laboratoryprepared Alloy 182 welds as a function of loading and sample orientation.

In order to meet the objective, CGR tests on samples of Alloy 182 were conducted in a PWR environment. The approach was to precrack the samples in water and continue with loading cycles with increasing load ratios, $\mathrm{R}$, and increasing rise times. Finally, the samples were set at constant load to determine SCC CGRs. This approach assured a complete SCC engagement and a uniform crack front. Each test was complemented by a detailed fractographic examination. One notes that the ANL approach is different from the commonly used practice in that, at ANL, precracking was conducted in water as opposed to air. One important advantage is that major experimental difficulties such as incomplete intergranular fracture mode engagement and finger-like crack growth were never encountered in our program. 
The resulting cyclic crack growth rate (CGR) data in water for Alloy 182 was compared with the CGR in air for Alloy 600 obtained previously to determine the effect of the PWR environment. The effect of key parameters on both cyclic and constant load CGRs were determined previously. ${ }^{17-21}$ As such, correlations describing the fatigue CGRs of Alloys 600 and 690 as a function of the stress intensity factor range $\Delta \mathrm{K}$, load ratio $\mathrm{R}$, and temperature were developed. ${ }^{22}$ The results indicated that in air, the CGRs of these materials are relatively insensitive to changes in the test frequency. The CGR (da/dN in $\mathrm{m} /$ cycle) of Alloy 600 in air is best expressed as

$$
\mathrm{da} / \mathrm{dN}=\mathrm{C}_{\mathrm{A} 600}(1-0.82 \mathrm{R})^{-2.2}(\Delta \mathrm{K})^{4.1},
$$

where $\Delta \mathrm{K}$ is in $\mathrm{MPa} \cdot \mathrm{m}^{1 / 2}$, and constant $\mathrm{C}_{\mathrm{A} 600}$ is given by a third-order polynomial of temperature $\mathrm{T}\left({ }^{\circ} \mathrm{C}\right)$ expressed as

$$
\mathrm{C}_{\mathrm{A} 600}=4.835 \times 10^{-14}+\left(1.622 \times 10^{-16}\right) \mathrm{T}-\left(1.490 \times 10^{-18}\right) \mathrm{T}^{2}+\left(4.355 \times 10^{-21}\right) \mathrm{T}^{3} .
$$

In high-dissolved-oxygen (DO) water, the CGRs of Alloy 600 showed frequency-dependent enhancement under cyclic loading conditions. Nevertheless, in high-DO water, the environmental enhancement of growth rates did not appear to depend strongly on the material condition. In contrast, environmental enhancement of CGRs of Alloy 600 in low-DO water seemed to be strongly dependent on material conditions. In the literature ${ }^{23-27}$ such variability has been attributed to thermo-mechanicallycontrolled parameters such as yield strength and grain boundary coverage of carbides, although the evidence for this dependence is more substantial for steam generator tubing than thicker structural materials.

In the earlier ANL work, correlations were also developed to estimate the enhancement of CGRs in LWR environments relative to the CGRs in air under the same loading conditions. The best-fit curve for Alloy 600, either in the solution annealed (SA) condition or the SA plus thermally treated condition, in $\approx 300 \mathrm{ppb}$ DO water is given by the expression ${ }^{19}$

$$
\mathrm{CGR}_{\mathrm{env}}=\mathrm{CGR}_{\mathrm{air}}+4.4 \times 10^{-7}\left(\mathrm{CGR}_{\mathrm{air}}\right)^{0.33} \text {. }
$$

Experimental results showed that some materials in PWR environments show little enhancement, while others show enhancement at $320^{\circ} \mathrm{C}$ comparable to that predicted by Eq. 3. The SCC of Alloy 600 has been reviewed by Chopra et al. ${ }^{22}$ and more recently in Ref. 28, and was found that frequencydependent environmental enhancement is usually associated with susceptibility to SCC under constant loading conditions.

Finally, the existing SCC CGR data for Ni-alloy weld metals (e.g., Alloys 82, 182, 52, 152, and 132) have been compiled and evaluated to establish the effects of key material, loading, and environmental parameters on CGRs in PWR environments. The CGR data generated at ANL on laboratory-prepared Alloy 182 welds are compared with the existing CGR data for Ni-alloy welds to determine their relative susceptibility to environmentally enhanced cracking under a variety of loading conditions. 


\section{Experimental}

\subsection{Material and Specimen Design}

Crack growth rate tests have been conducted on Alloy 182 weld metal samples in simulated PWR environments at $320^{\circ} \mathrm{C}$ in accordance with ASTM Designation E 647, "Standard Test Method for Measurement of Fatigue Crack Growth Rates." The tests were performed on 1-T compact tension (CT) specimens; configuration of the CT specimen is shown in Fig. 1. Crack extensions were determined by the reversing DC potential drop technique.

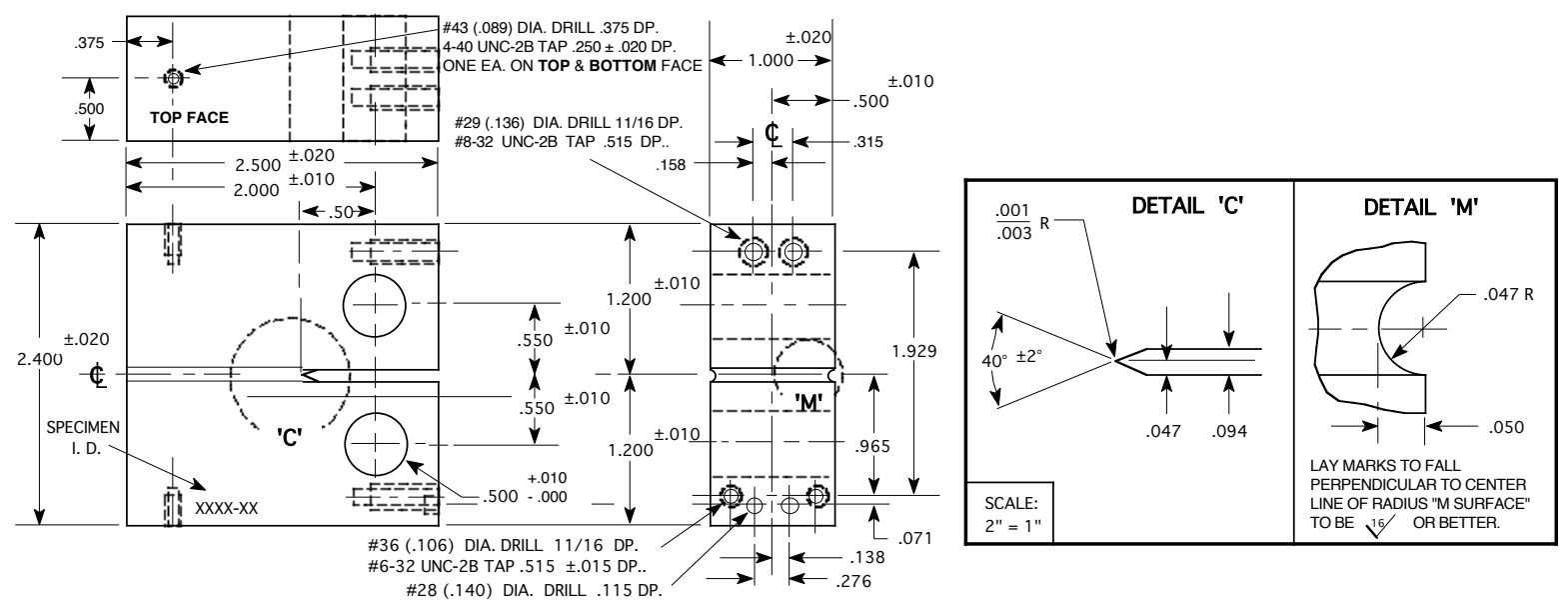

Figure 1. Configuration of compact-tension specimen used for this study (dimensions in inch)

The 1-T CT specimens were machined from laboratory-prepared double-J weld (Fig. 2a) and deepgroove filled weld (Fig. 2b). The double-J weld was prepared by joining two $152 \times 305 \mathrm{~mm}(6 \times 12$ in.) pieces of 38-mm-thick (1.5-in.-thick) plate (Heat NX1310). It was produced by 48 weld passes, root passes 1-5 involved gas tungsten arc (GTA) welding with Alloy 82 filler/electrode, and the other passes, SMA welding with Alloy 182 filler. A schematic of the weld design and various passes is shown in Fig. 2a, and the conditions for each weld pass are listed in Table 2. During welding the maximum interpass temperature was $\approx 120^{\circ} \mathrm{C}\left(250^{\circ} \mathrm{F}\right)$, and the weld surfaces were cleaned by wire brushing and grinding and were rinsed with de-mineralized water or alcohol. The deep-groove filled weld was prepared by using a 51-mm thick Alloy 600 plate (Heat NX1933) with a deep groove that was filled by several passes of SMA welding with Alloy 182 filler/electrode (size 1/8 or 5/32 in.) (Fig. 2b). The chemical compositions of the base and weld metals are given in Table 1.

Table 1. Chemical composition (wt.\%) of Alloy 600 base metal and Inconel 182 and 82 weld metals.

\begin{tabular}{cccccccccccccc}
\hline Alloy ID (Heat) & Analysis & $\mathrm{C}$ & $\mathrm{Mn}$ & $\mathrm{Fe}$ & $\mathrm{S}$ & $\mathrm{P}$ & $\mathrm{Si}$ & $\mathrm{Cu}$ & $\mathrm{Ni}$ & $\mathrm{Cr}$ & $\mathrm{Ti}$ & $\mathrm{Nb}$ & $\mathrm{Co}$ \\
\hline A 600 (NX1310) & Vendor & 0.07 & 0.22 & 7.39 & 0.002 & 0.006 & 0.12 & 0.05 & 76.00 & 15.55 & 0.24 & 0.07 & 0.058 \\
& ANL & 0.07 & 0.22 & 7.73 & 0.001 & - & 0.18 & 0.06 & 75.34 & - & - & - & - \\
A 600 (NX1933) & Vendor & 0.08 & 0.26 & 9.55 & 0.003 & - & 0.15 & 0.10 & 73.31 & 15.90 & - & - & - \\
A 182 & Spec. & $0.10^{*}$ & $5.0-9.5$ & $6.0-10.0$ & $0.015^{*}$ & - & $1.0^{*}$ & $0.5^{*}$ & $\mathrm{Bal}$ & $13.0-17.0$ & $1.0^{*}$ & $1.0-2.5$ & $0.12^{*}$ \\
A 182 Double-J & ANL & 0.04 & 6.58 & 6.48 & 0.005 & 0.022 & 0.33 & 0.04 & 70.62 & 14.34 & 0.36 & 1.13 & 0.03 \\
A 182 Deep Groove & ANL & 0.04 & 7.08 & 6.82 & 0.005 & 0.025 & 0.35 & 0.03 & 70.44 & 13.81 & 0.30 & 1.06 & 0.02 \\
A 82 & Spec. & $0.10^{*}$ & $2.5-3.5$ & $3.0^{*}$ & $0.015^{*}$ & - & $0.5^{*}$ & $0.5^{*}$ & $67.00^{*}$ & $18.0-22.0$ & $0.75^{*}$ & $2.0-3.0$ & $0.75^{*}$ \\
\hline
\end{tabular}




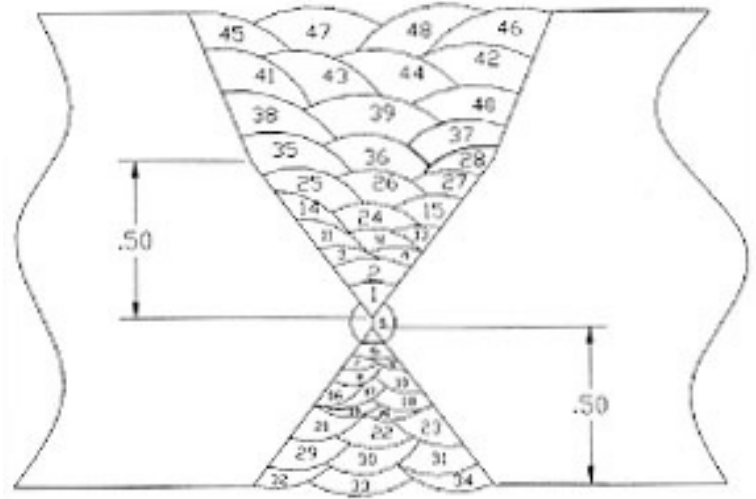

(a)

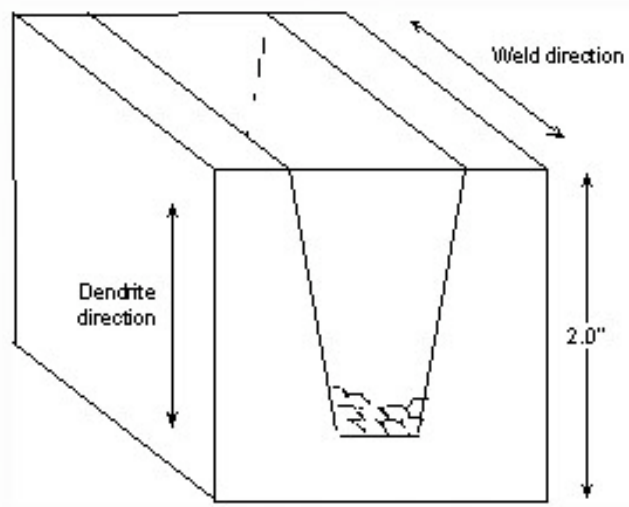

(b)

Figure 2. Schematic of the weld joint design and weld passes for (a) Alloy 182 SMA double-J weld and (b) the deep-groove weld (dimensions are in inches).

Table 2. Welding process and conditions for various weld passes.

\begin{tabular}{ccccccc}
\hline $\begin{array}{c}\text { Weld } \\
\text { Pass }\end{array}$ & Process & Filler & $\begin{array}{c}\text { Filler/Electrode } \\
\text { Size (in.) }\end{array}$ & $\begin{array}{c}\text { Current } \\
(\text { A) }\end{array}$ & $\begin{array}{c}\text { Voltage } \\
\text { (V) }\end{array}$ & $\begin{array}{c}\text { Travel Speed } \\
\text { (in./min) }\end{array}$ \\
\hline $1-5$ & GTA & Alloy 82 & $3 / 32$ & $185-215$ & $21-22$ & $2-4$ \\
$6-10$ & SMA & Alloy 182 & $3 / 32$ & $140-155$ & $24-26$ & $6-7$ \\
$11-27$ & SMA & Alloy 182 & $1 / 8$ & $155-170$ & $25-27$ & $6-7$ \\
$28-48$ & SMA & Alloy 182 & $5 / 32$ & $170-180$ & $26-28$ & $6-7$ \\
\hline
\end{tabular}

Two 1-T CT specimens were cut from the double-J Alloy 182 SMA weld in the TS orientation, ${ }^{*}$ as shown schematically in Fig. 3a. Three additional 1-T CT specimens, in TS, TL and LS orientations, were prepared from a deep-groove Alloy 182 weld (Fig. 3b). All 1-T CT specimens were 25.4-mm (1-in.) thick as shown in Fig. 1, except the deep-groove specimen in LS orientation that had to be thinned to a thickness of $19.4 \mathrm{~mm}$ to ensure that the entire crack front would be exclusively in the weld alloy.

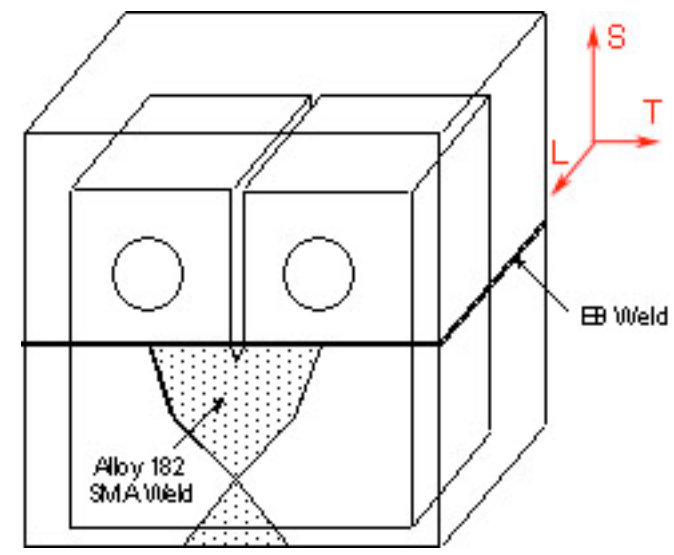

(a)

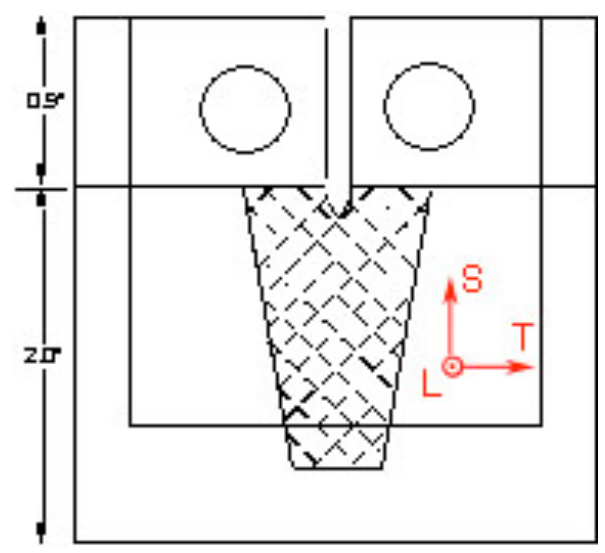

(b)

Figure 3. Orientation of the CT specimens from (a) the Alloy 182 SMA double-J weld and (b) the deepgroove weld.

\footnotetext{
* The first letter represents the direction normal to the fracture plane and the second represents the direction of crack advance. The three directions are: $\mathrm{T}=$ transverse, $\mathrm{L}=$ longitudinal, and $\mathrm{S}=$ side.
} 


\subsection{Test Facility}

The facility for conducting CGR tests in water at elevated temperature and pressure consists of the following: an MTS closed-loop electro-hydraulic material test system equipped with an extra-high-load frame rated at $89 \mathrm{kN}(20,000 \mathrm{lb})$ maximum and MTS 810 (or equivalent) control console; hydraulic pump; commercial autoclave with a recirculating or once-through water system; temperature control unit; DC potential control console; two computers for elastic unloading compliance and DC potential measurements; and strip chart recorder. The autoclave, mounted within the load frame, has been modified to permit a $\approx 19-\mathrm{mm}(0.75-\mathrm{in}$.) shaft to load the test specimen through a "Bal-Seal" gland in the top of the autoclave cover. Up to three 25.4- mm (1-in.) thick (1-T) CT specimens can be tested in series inside the autoclave. Figure 4 shows a photograph of the MTS load frame with the autoclave, temperature control unit and strip chart recorder (on the right), MTS 810 control console (on the left), and DC potential control console (above the MTS 810 system). Two such systems were used for this program; the systems differ only slightly in terms of design and materials of construction.

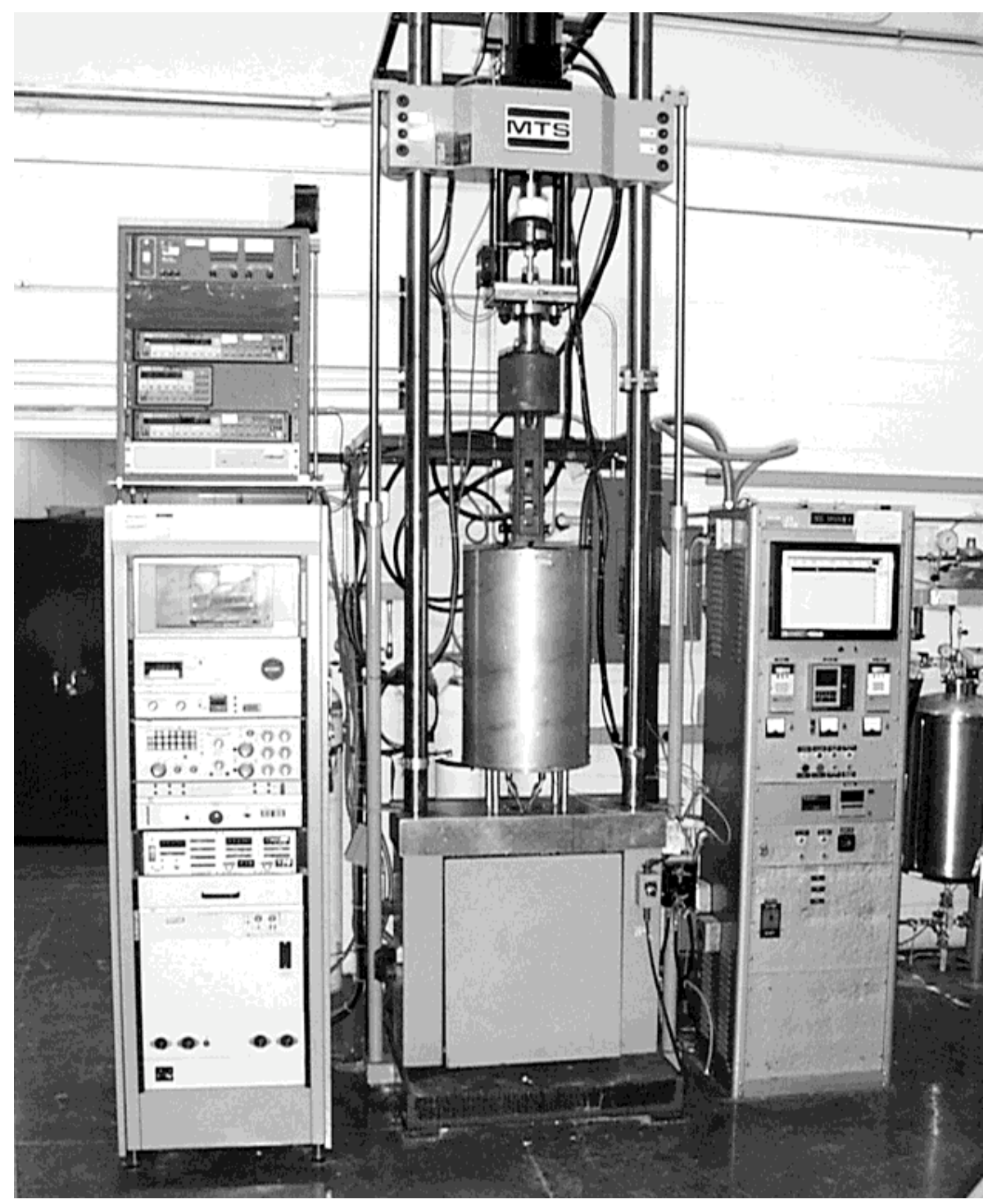

Figure 4. A photograph of the facility for conducting crack growth tests in simulated LWR environments. 


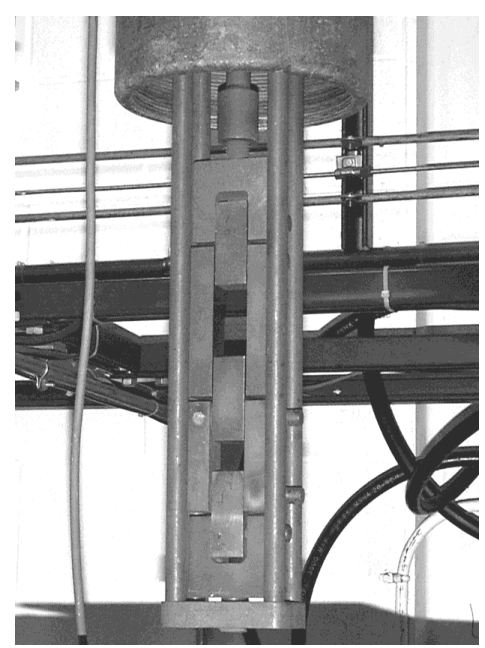

Figure 5.

A photograph of the specimen load train

The test facility is designed for easy access to the specimens during assembly of the test train. The MTS load frame stands $\approx 3.7 \mathrm{~m}(12 \mathrm{ft}$ ) high. The actuator assembly, consisting of the hydraulic actuator, load cell, autoclave plug, and the internal specimen load train, may be raised and lowered hydraulically to position the specimens at a convenient height. A photograph of the specimen load train is shown in Fig. 5. A 1-T CT specimen may be substituted for any or all of the three central in-line blocks.

The autoclave is continuously supplied with the test water solution from a feedwater tank. Figure 6 shows a schematic diagram of the water system. It consists of a feedwater storage tank, high pressure pump, regenerative heat exchanger, autoclave preheater, test autoclave, electrochemical potential (ECP) cell, regenerative heat exchanger, back-pressure regulator, and return line to the feedwater tank. In the
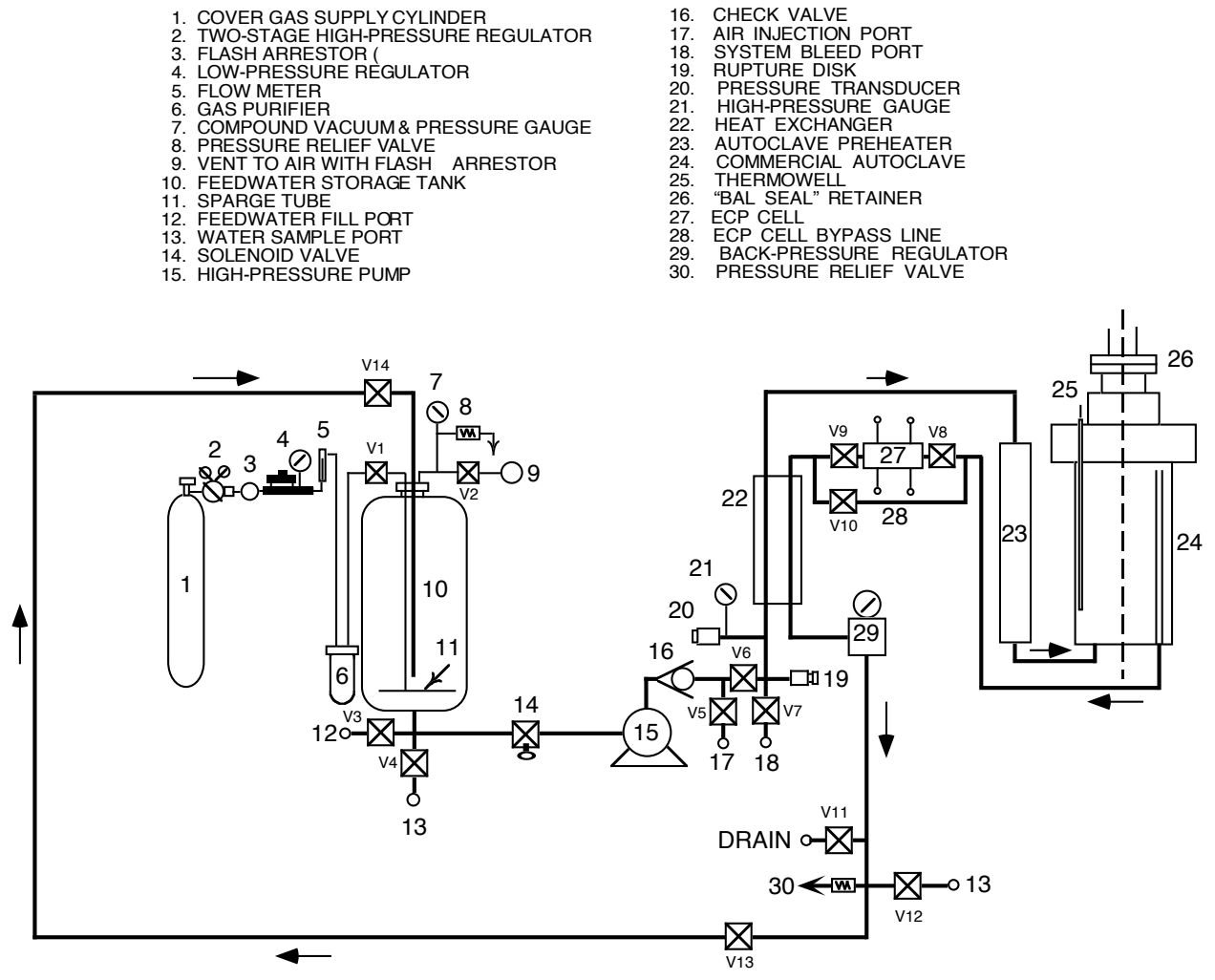

Figure 6. Schematic diagram of the recirculating autoclave system used for crack growth rate tests. 
once-through mode, the return line is connected to the drain. During recirculation the ECP cell in the return line from the autoclave to the feedwater supply tank is bypassed. The 5.7-liter Type 316 stainless steel autoclave has a $175-\mathrm{mm}(6.875-\mathrm{in}$.) OD and is rated for a working pressure of $5050 \mathrm{psig}(35 \mathrm{MPa})$ at $343^{\circ} \mathrm{C}\left(650^{\circ} \mathrm{F}\right)$. The system uses Types 316 or 304 stainless steel (SS) tubing. Water is circulated at relatively low flow rates, i.e., $5-15 \mathrm{~mL} / \mathrm{min}$.

The feedwater storage tank, manufactured by Filpaco Industries, has $130-\mathrm{L}$ capacity and is constructed of either Type 304 or 316 SS. The tank is designed for vacuum and over-pressure to 60 psig $(414 \mathrm{kPa})$. The storage tank has a hydrogen cover gas to maintain a desired dissolved hydrogen concentration in the water.

The simulated PWR feedwater contains less than $10 \mathrm{ppb}$ DO, $2 \mathrm{ppm} \mathrm{Li}, 1000 \mathrm{ppm} \mathrm{B}$, and $\approx 2 \mathrm{ppm}$ dissolved hydrogen $\left(\approx 23 \mathrm{~cm}^{3} / \mathrm{kg}\right)$. It is prepared from the laboratory supplies of deionized water by first passing this water through a local filtration system that includes a carbon filter, an Organex-Q filter, two ion exchangers, and a $0.2-\mathrm{mm}$ capsule filter. The DO in the deionized water is reduced to $<10 \mathrm{ppb}$ by bubbling/sparging a mixture of $\mathrm{N}_{2}+5 \% \mathrm{H}_{2}$ through the water. To speed deoxygenation, a vacuum may be applied to the feedwater tank at the vent port (item 9). The PWR water is prepared by dissolving boric acid and lithium hydroxide in $20 \mathrm{~L}$ of deionized water before adding the solution to the supply tank. The hydrogen gas pressure in the feedwater tank is maintained at $34 \mathrm{kPa}$. The dissolved hydrogen in water is calculated from the tank hydrogen pressure and temperature.

Water samples are taken periodically to measure $\mathrm{pH}$, resistivity, and $\mathrm{DO}$ concentration both upstream and downstream from the autoclave. An Orbisphere meter and CHEMetrics ${ }^{\mathrm{TM}}$ ampules are used to measure the DO concentrations in the supply and effluent water. The redox and open-circuit corrosion potentials are monitored at the autoclave outlet by measuring the ECPs of platinum and an Alloy 600 electrode, respectively, against a $0.1 \mathrm{M} \mathrm{KCl} / \mathrm{AgCl} / \mathrm{Ag}$ external (cold) reference electrode. The measured

ECPs, $\mathrm{E}_{\text {(meas) }}(\mathrm{mV})$, were converted to the standard hydrogen electrode (SHE) scale, $\mathrm{E}_{(\mathrm{SHE})}(\mathrm{mV})$, by the polynomial expression 29

$$
\mathrm{E}(\mathrm{SHE})=\mathrm{E}(\text { meas })+286.637-1.0032(\Delta \mathrm{T})+1.7447 \times 10^{-4}(\Delta \mathrm{T})^{2}-3.03004 \times 10^{-6}(\Delta \mathrm{T})^{3},
$$

where $\Delta \mathrm{T}\left({ }^{\circ} \mathrm{C}\right)$ is the temperature difference of the salt bridge in a $0.1 \mathrm{M} \mathrm{KCl} / \mathrm{AgCl} / \mathrm{Ag}$ external reference electrode (i.e., the test temperature minus ambient temperature).

\subsection{Test Procedure}

The CGR tests were conducted in the load-control mode using a triangular, sawtooth, or trapezoidal waveform with load ratio $\mathrm{R}$ of $0.3-0.7$. The $\mathrm{CT}$ specimens were fatigue precracked in the test environment and load ratio $\mathrm{R}=0.3$, frequency $\approx 1 \mathrm{~Hz}$, and maximum stress intensity factor $\mathrm{K}_{\max }$ of 20 $25 \mathrm{MPa} \cdot \mathrm{m}^{1 / 2}$. After $\approx 0.5-\mathrm{mm}$ extension, $\mathrm{R}$ was increased incrementally to 0.7 , and the loading waveform changed to a slow/fast sawtooth with rise times of 30-1000 s. The SCC growth rates were determined using a trapezoidal waveform with $\mathrm{R}=0.5$ or $0.7,12-1000 \mathrm{~s}$ rise time, $3600-\mathrm{s}$ hold period at peak, and $12-\mathrm{s}$ unload time. This loading sequence is considered to result in reproducible CGRs. ${ }^{30}$ During individual test periods, $\mathrm{K}_{\max }$ was maintained approximately constant by periodic load shedding (less than $2 \%$ decrease in load at any given time).

Crack extensions were monitored by the reversing DC potential difference method. The current leads were attached to the holes on the top and bottom surfaces of the specimen (Fig. 1), and potential leads were welded on the front face of the specimen across the machined notch but on diagonal ends. Also, to compensate for the effects of changes in resistivity of the material with time, an Alloy 600 
internal reference bar was installed near the test specimen. The CT specimen and reference bar were connected in series, and the DC potential across the specimen as well as the reference bar was monitored continuously during the test. The results for the reference bar were used to normalize potential drop measurements for the CT test specimen.

Under cyclic loading, the CGR $(\mathrm{m} / \mathrm{s})$ can be expressed as the superposition of the rate in air (mechanical fatigue) and the rates due to corrosion fatigue (CF) and stress corrosion cracking (SCC), given as

$$
\dot{\mathrm{a}}_{\mathrm{env}}=\dot{\mathrm{a}}_{\mathrm{air}}+\dot{\mathrm{a}}_{\mathrm{cf}}+\dot{\mathrm{a}}_{\mathrm{scc}} \text {. }
$$

During crack growth tests in high-temperature water, environmental enhancement of CGRs does not occur from the start of the test. Under more rapid cyclic loading, the crack growth is dominated by mechanical fatigue. The CGRs during precracking and initial periods of cyclic loading were primarily due to mechanical fatigue. In general, environmental enhancement is typically observed under loading conditions that would lead to CGRs between $10^{-10}$ and $10^{-9} \mathrm{~m} / \mathrm{s}$ in air. The stress intensity factor range $\Delta \mathrm{K}$ was calculated as follows:

$$
\begin{aligned}
& \Delta \mathrm{K}=\frac{\Delta \mathrm{P}}{\left(\mathrm{BB}_{\mathrm{N}} \mathrm{W}\right)^{1 / 2}} \frac{\left(2+\frac{\mathrm{a}}{\mathrm{W}}\right)}{\left(1-\frac{\mathrm{a}}{\mathrm{W}}\right)^{3 / 2}} \mathrm{f}\left(\frac{\mathrm{a}}{\mathrm{W}}\right) \\
& \Delta \mathrm{P}=\mathrm{P}_{\max }-\mathrm{P}_{\min } \quad \text { for } \mathrm{R}>0 \\
& \mathrm{f}\left(\frac{\mathrm{a}}{\mathrm{W}}\right)=0.886+4.64\left(\frac{\mathrm{a}}{\mathrm{W}}\right)-13.32\left(\frac{\mathrm{a}}{\mathrm{W}}\right)^{2}+14.72\left(\frac{\mathrm{a}}{\mathrm{W}}\right)^{3}-5.6\left(\frac{\mathrm{a}}{\mathrm{W}}\right)^{4},
\end{aligned}
$$

where $\mathrm{P}_{\max }$ and $\mathrm{P}_{\min }$ are maximum and minimum applied load, a is crack length, $\mathrm{W}$ is the specimen width, and effective thickness $\mathrm{B}_{\text {eff }}=\left(\mathrm{B} \mathrm{B}_{\mathrm{N}}\right)^{0.5}$. The applied $\mathrm{K}$ for the tests was in accordance with the specimen size criteria of ASTM E 1681 and E 647. These criteria are intended to ensure applicability and transferability of the cracking behavior of a component or specimen of a given thickness under a specific loading condition to a crack associated with a different geometry, thickness, and loading condition. The $\mathrm{K} /$ size criteria require that the plastic zone at the tip of a crack is small relative to the specimen geometry. For constant load tests, ASTM E 1681 requires that

$$
\mathrm{B}_{\text {eff }} \text { and }(\mathrm{W}-\mathrm{a}) \geq 2.5\left(\mathrm{~K} / \sigma_{\mathrm{ys}}\right)^{2} \text {, }
$$

and for cyclic loading ASTM 647 requires that

$$
(\mathrm{W}-\mathrm{a}) \geq(4 / \pi)\left(\mathrm{K} / \sigma_{\mathrm{ys}}\right)^{2} \text {, }
$$

where $\mathrm{K}$ is the applied stress intensity factor, and $\sigma_{\mathrm{ys}}$ is the yield stress of the material. In hightemperature water, because the primary mechanism for crack growth during continuous cycling is not mechanical fatigue, Eq. 9 is probably the more appropriate criterion, but Eq. 10 may give acceptable 
results. For high-strain hardening materials, i.e., materials with an ultimate-to-yield stress ratio $\left(\sigma_{\mathrm{ult}} / \sigma_{\mathrm{ys}}\right) \geq 1.3$, both criteria allow the use of the flow stress defined as $\sigma_{\mathrm{f}}=\left(\sigma_{\mathrm{ult}}+\sigma_{\mathrm{ys}}\right) / 2$ rather than the yield stress.

After the test the specimen was fractured in liquid nitrogen, and the fracture surfaces were examined by optical or electron microscopy to measured the final crack length using the $9 / 8$ averaging technique; that is, the two near-surface measurements were averaged, and the resultant value was averaged with the remaining seven measurements. The number of measurements was increased for irregular crack fronts. 



\section{Microstructural Characterization}

The microstructures of Ni-alloy weld metals such as Alloys 182 and 82 are similar in composition to those of wrought Alloys 600 and 690. Under certain thermal treatments, Cr-rich carbides can precipitate at both interdendrite and intradendrite grain boundaries. ${ }^{31}$ Chromium depletion also occurs at the boundaries that are covered with such carbides. The precipitate phases are predominantly $\mathrm{M}_{23} \mathrm{C}_{6}$ and Ti-rich MC carbide. During the welding process, only the $\mathrm{M}_{23} \mathrm{C}_{6}$ carbide precipitates because of the rapid cooling of the weld metal from fusion temperature. Nucleation of $\mathrm{M}_{7} \mathrm{C}_{3}$ carbides requires long periods at relatively high temperatures, whereas nucleation of $\mathrm{M}_{23} \mathrm{C}_{6}$ is quite rapid and cannot be avoided even during water quenching from solution treatment temperatures. The matrix also contains a uniform dispersion of spherical $\gamma^{\prime}$ phase $\left(\mathrm{Ni}_{3} \mathrm{Ti}\right)$.

The greater susceptibility of Alloy 182 to SCC than Alloy 82 has been attributed to differences in $\mathrm{Cr}$ depletion observed in the two alloys because of differences in their composition. Alloy 182 contains higher concentrations of $\mathrm{C}$ and $\mathrm{Fe}$ and a lower concentration of $\mathrm{Cr}$, all of which enhance $\mathrm{Cr}$ depletion during carbide precipitation.

The current section presents the metallography of the weld alloys used in the CGR tests. The SEM and EDX investigations focused on the double-J weld, while the OIM analysis was conducted on both double-J and deep-groove laboratory prepared welds.

\subsection{Weld Microstructure}

A metallographic examination was performed to characterize the microstructure of the weld. For this purpose, three $1 \mathrm{~cm} \times 2 \mathrm{~cm}$ rectangular pieces, designated 1,2 , and 3 , were cut from the weld, as shown in Fig. 7. The thickness of all three samples was $0.5 \mathrm{~cm}$. Sample 3 was further cut in half to enable the examination of both surfaces A and B, normal to the plane of Fig. 7 .

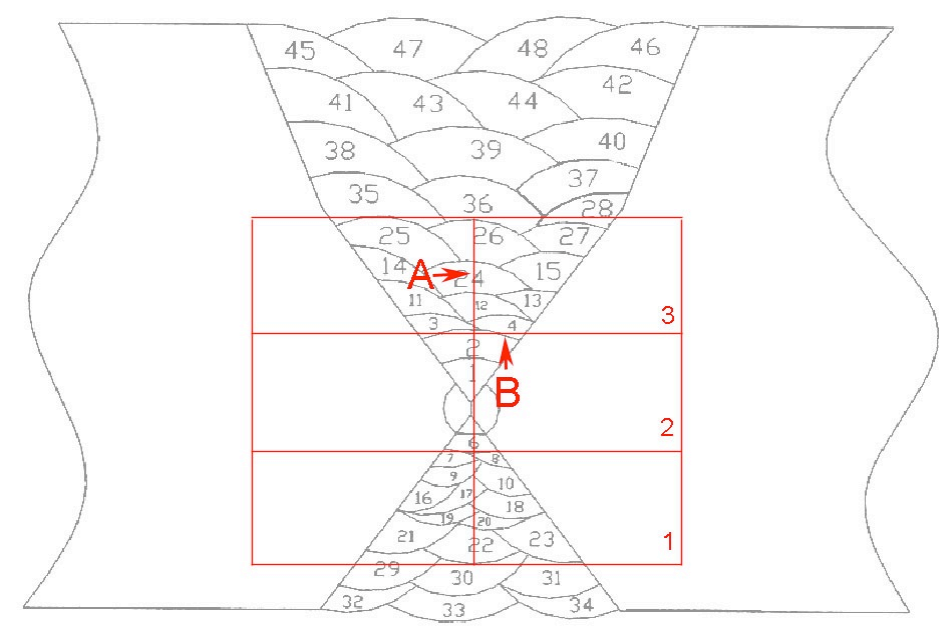

Figure 7. Schematic showing the locations of the three samples cut from the weld.

All samples were mechanically polished through $1-\mu \mathrm{m}$ diamond paste, followed by electrolytic etching for $10-20 \mathrm{~s}$ in a $70 \% \mathrm{H}_{3} \mathrm{PO}_{4}$ and water solution at $5 \mathrm{~V}$ to reveal the dendritic structure and carbides. The samples were then examined in a JEOL scanning electron microscope. Figure 8a shows the entire span of the weld microstructure on Sample 1 (the picture shown here was rotated by $90^{\circ}$ 
counter clockwise with respect to the schematic shown in Fig. 7 to fit in the page). The elongated grains with dendritic features are easily discernible from the regular microstructure of Alloy 600 (upper-left and bottom-left corners). This difference is also visible in Fig. 8b. Figures $8 \mathrm{c}$ and $8 \mathrm{~d}$ also show the dendritic microstructure in the weld. Large variations in grain size can be observed between the different passes.
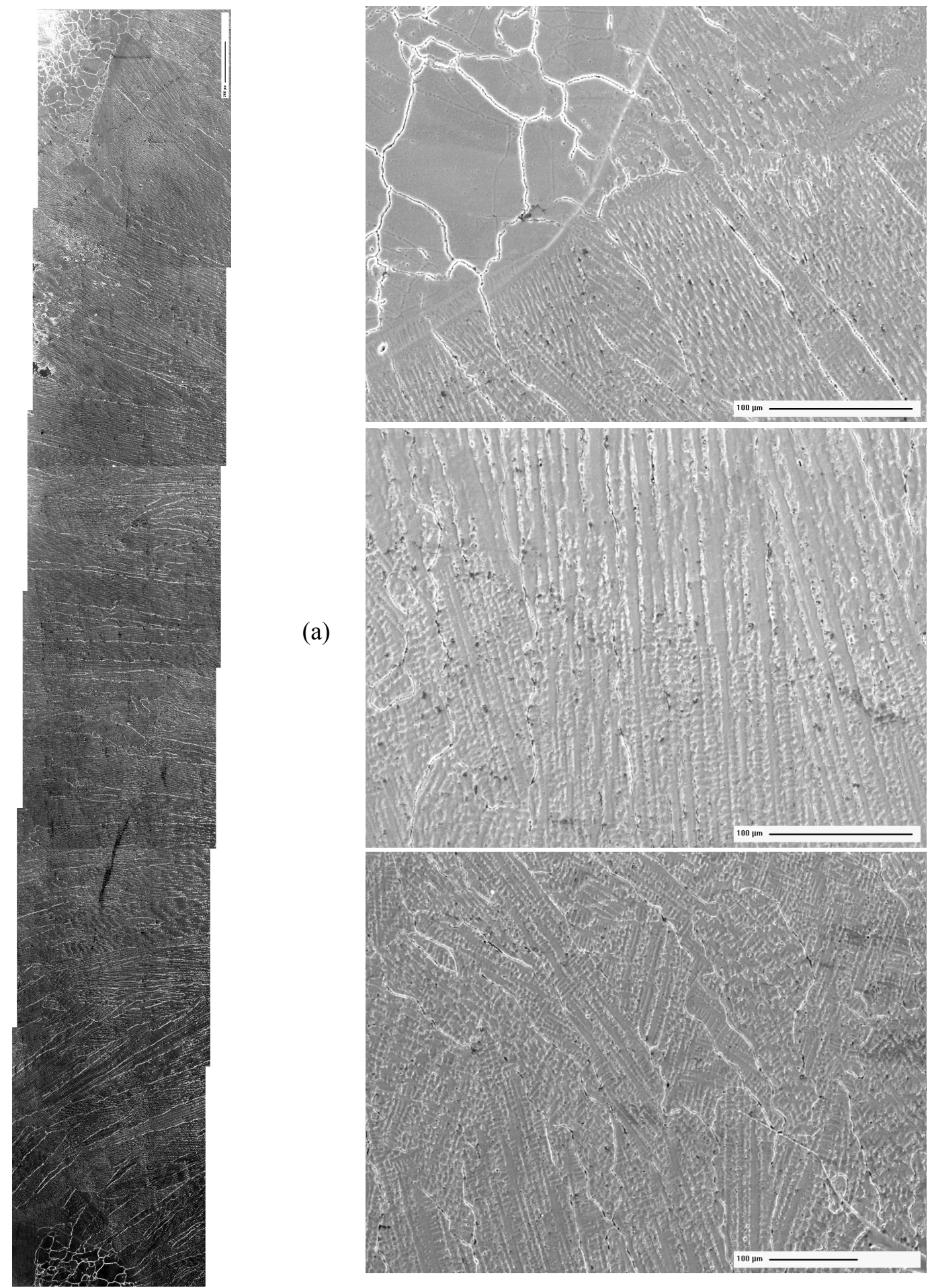

(b)

(a)

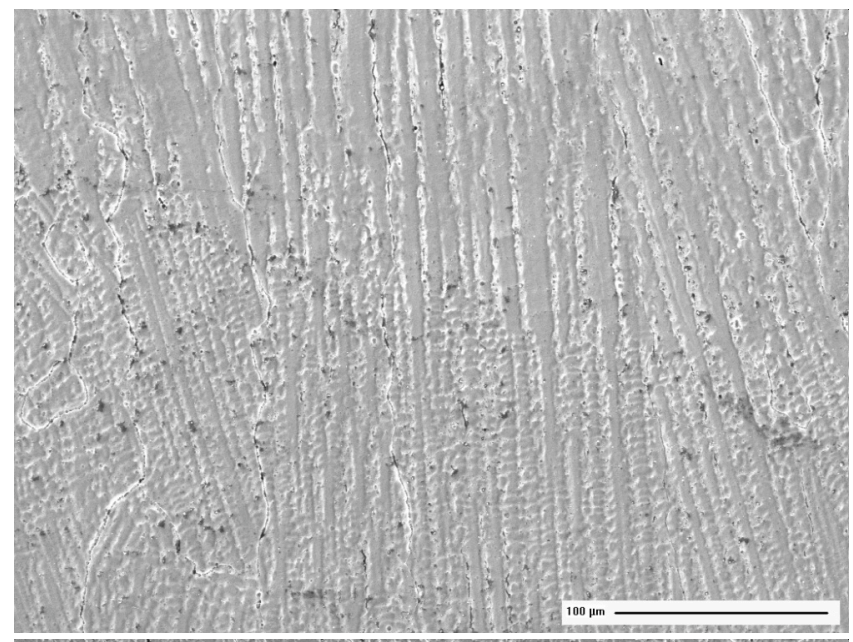

(c)

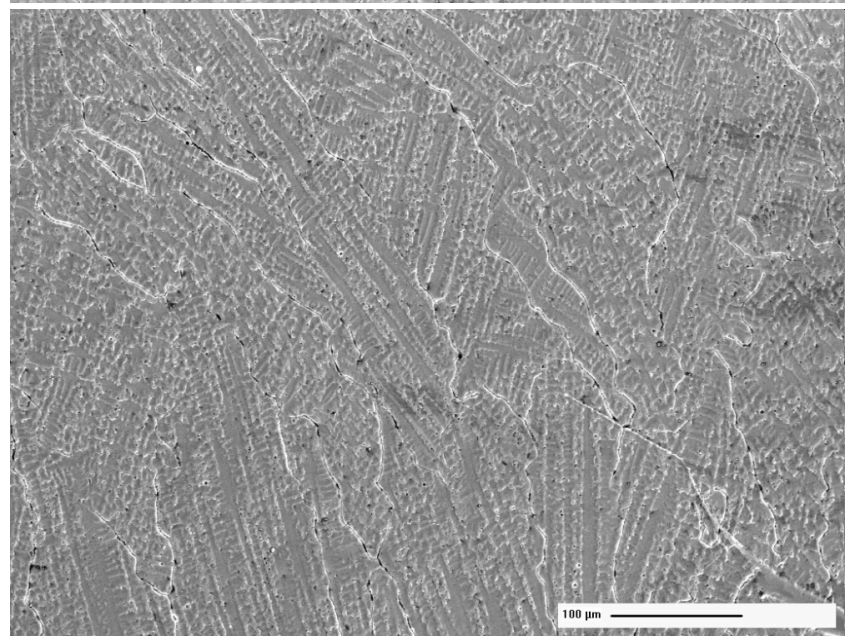

(d)

Figure 8. (a) Weld microstructure from Sample 1 (rotated $90^{\circ}$ with respect to Fig. 7); (b) transition area between the weld and Alloy 600; and (c, d) dendritic microstructure in the weld. 
Figure 9 focuses on the transition area between the weld and the base material, i.e., the heat affected zone (HAZ). A larger grain size than that of the base material is observed in the immediate vicinity of the well in both Figs. 9a and 9b. These micrographs were obtained from opposite locations on Sample 1. A dendritic microstructure was observed on the plane 3A (Fig. 7), and examples are shown in Fig. 10. The picture shown in Fig. 10a was taken at a location where the grain is still visible, although with internal dendritic features. Figure $10 \mathrm{~b}$ was obtained at a weld pass, showing the different structure of the two weld layers.

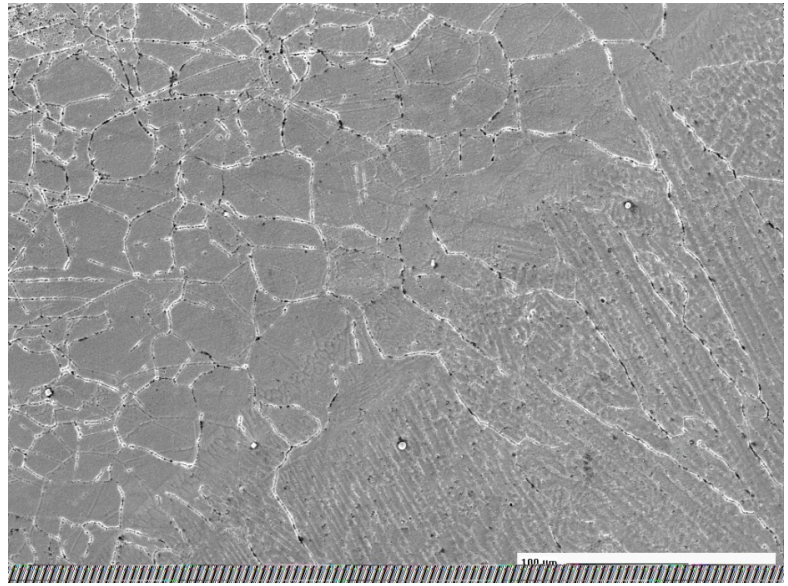

(a)

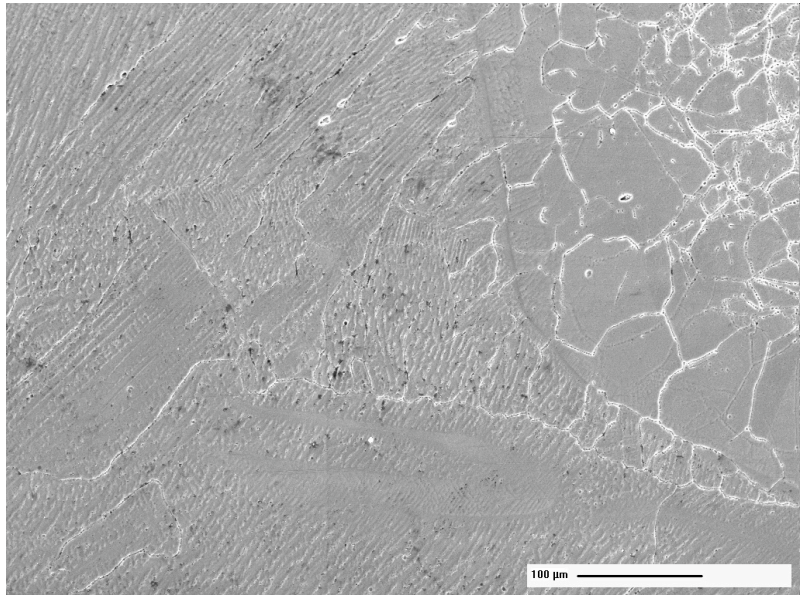

(b)

Figure 9. Large grain microstructure in the HAZ at two opposite positions ( $a$ and b).

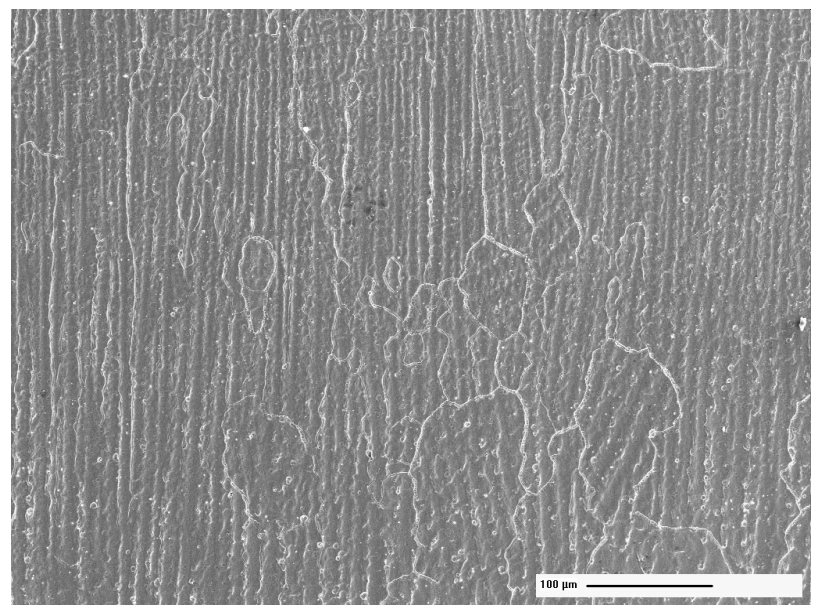

(a)

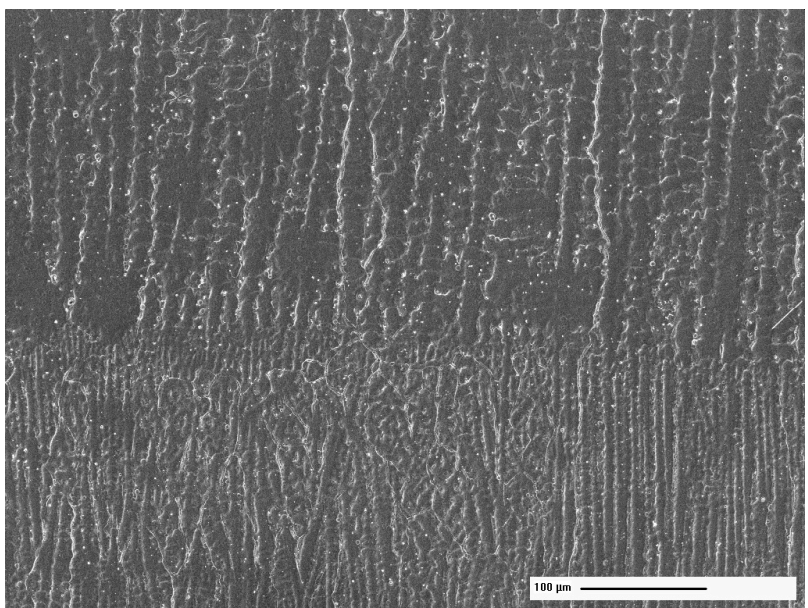

(b)

Figure 10. Dendritic microstructure (a) on sample 3A and (b) at a weld pass.

Figure $11 \mathrm{a}$ and $11 \mathrm{~b}$ are micrographs obtained on plane $3 \mathrm{~B}$ at weld passes. Figure $11 \mathrm{c}$ and $11 \mathrm{~d}$ are higher magnification micrographs obtained at locations shown in Figs. 11a and 11b, respectively. The grain and dendritic microstructures are visible; however, as expected, the grains are more regular and the dendrites are perpendicular to the plane of observation. 


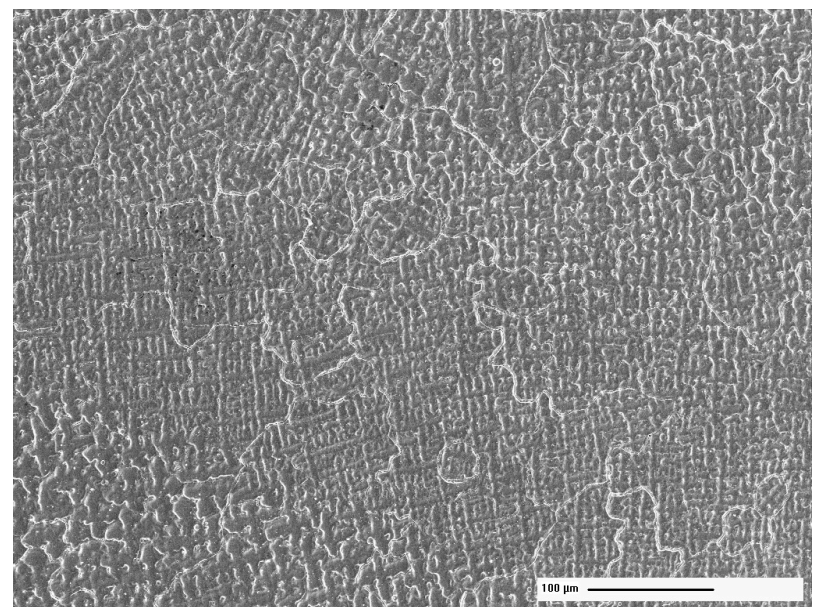

(a)

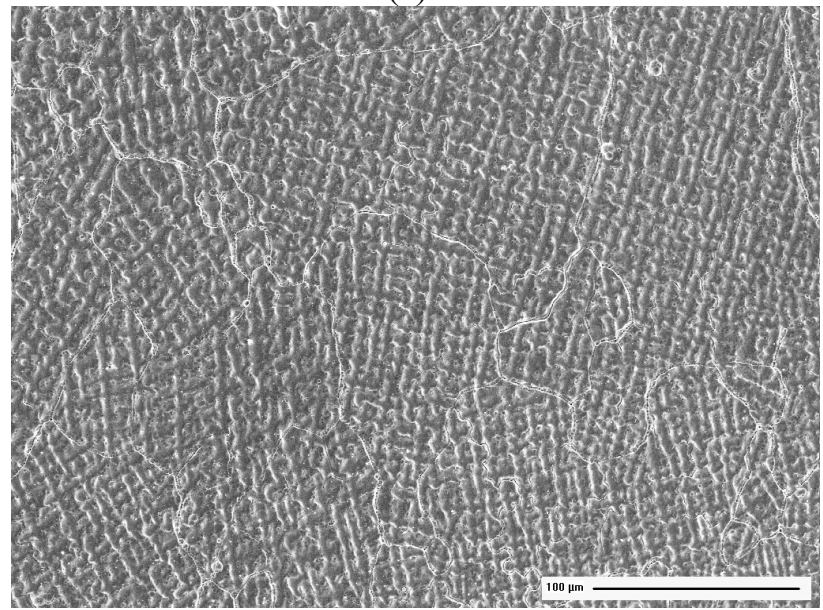

(c)

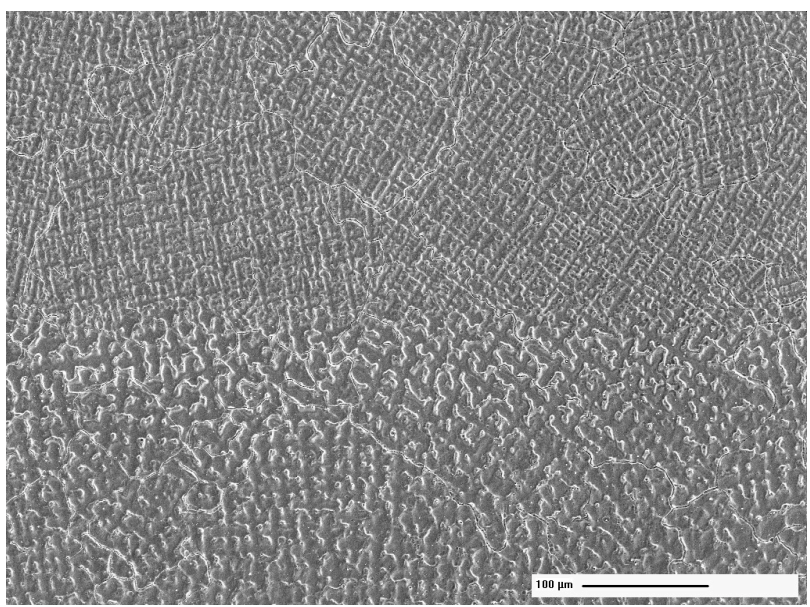

(b)

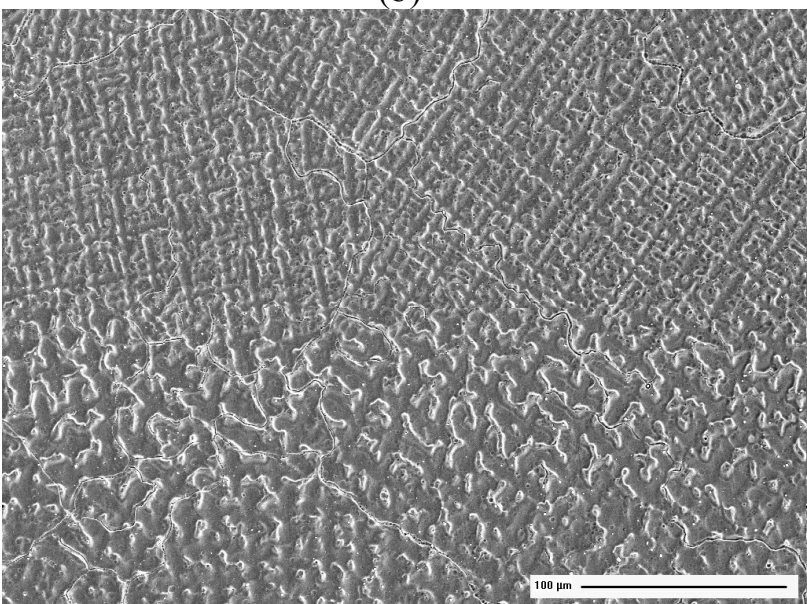

(d)

Figure 11. Dendritic microstructure at weld passes on sample $3 \mathrm{~B}(\mathrm{a}, \mathrm{b})$ and high magnification micrographs at the respective locations (c, d).

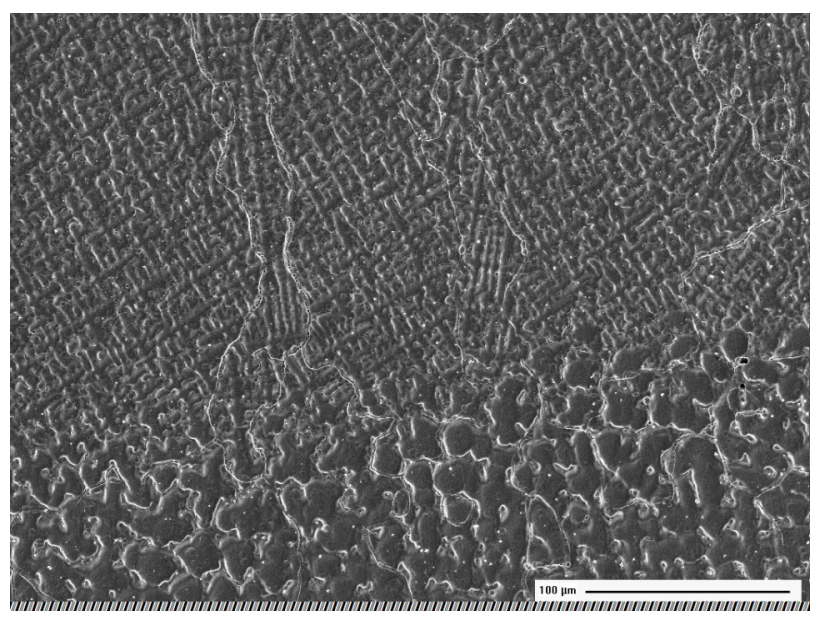

(a)

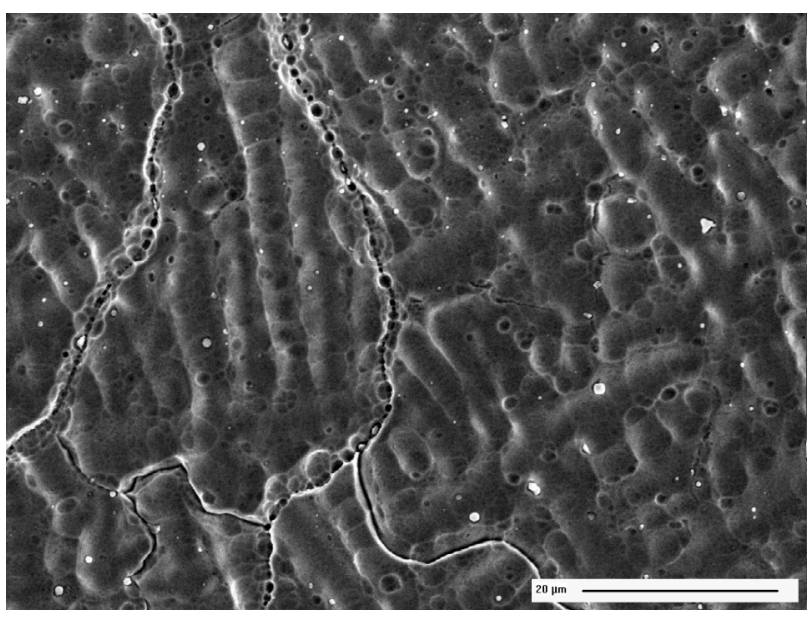

(b)

Figure 12. (a) Dendritic microstructure on sample 3B and (b) high magnification of a region from (a). 
Figure $12 \mathrm{a}$ is another example of the microstructure obtained on plane $3 \mathrm{~B}$ at a weld pass, and Fig. $12 \mathrm{~b}$ is a higher magnification micrograph obtained at a location in Fig. 12a. From the manner in which the phosphoric acid attacked the grain boundaries it appears that grain boundary precipitates were present. Additional precipitates or particles were also observed in grain boundaries and matrix, which had not been attacked by the phosphoric-acid etch.

\subsection{Examination of Weld by SEM/EDX}

Scanning electron microscopy and energy dispersive $\mathrm{x}$-ray (SEM/EDX) analysis was conducted on sample 3A in a Philips XL30 FEG SEM. This sample was mechanically polished to $1-\mu \mathrm{m}$ diamond paste, followed by electrolytic etching in a phosphoric-acid solution to reveal the dendritic structure and carbides. Figures $13 \mathrm{a}-\mathrm{b}$ show the microstructure observed on the surface of sample $3 \mathrm{~A}$, at several magnifications. The elongated grains with dendritic features can be seen in both micrographs.

The objective of this part of the analysis was to investigate the nature of both matrix and grain boundary precipitates. Figure 14a shows one of the matrix precipitates on the surface of sample $3 \mathrm{~A}$. In Fig. 14b the EDX spectra resulting from the bulk and the precipitate are shown. The comparison of the two spectra indicates that both the $\mathrm{Ti}$ and $\mathrm{O}$ peaks are higher in the spectrum resulting from the precipitate, suggesting that the particle composition is $\mathrm{TiO}_{2}$. The results of the analysis are shown in Table 3, confirming that indeed the precipitates are $\mathrm{TiO}_{2}$.

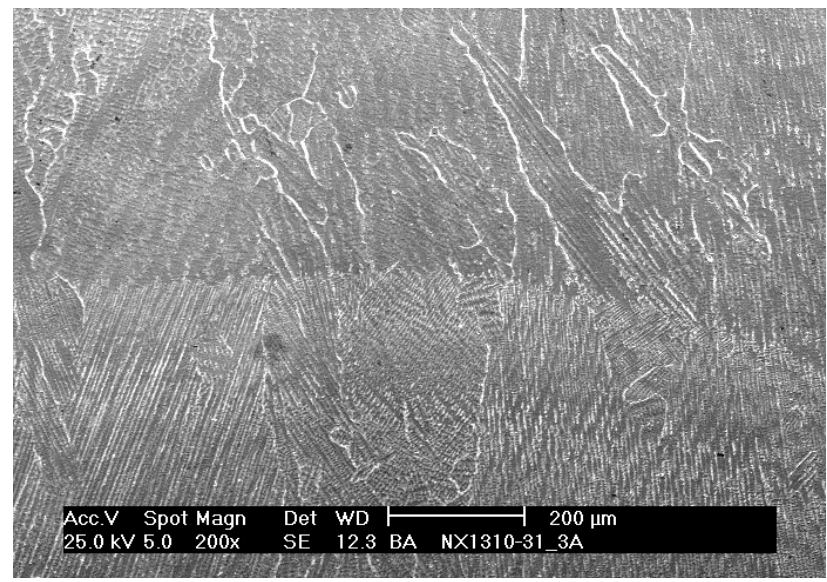

(a)

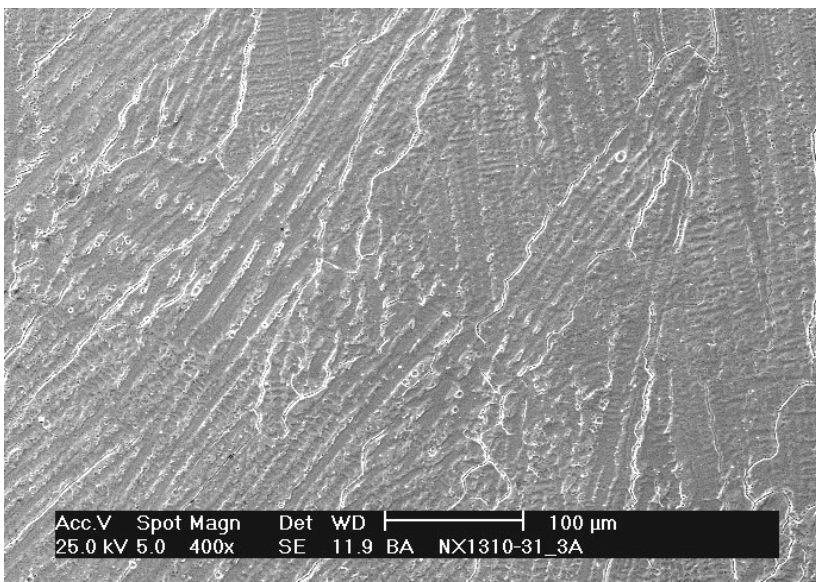

(b)

Figure 13. Dendritic microstructure observed on the surface of sample $3 A$ at magnifications of (a) $100 \times$, (b) $200 \times$.

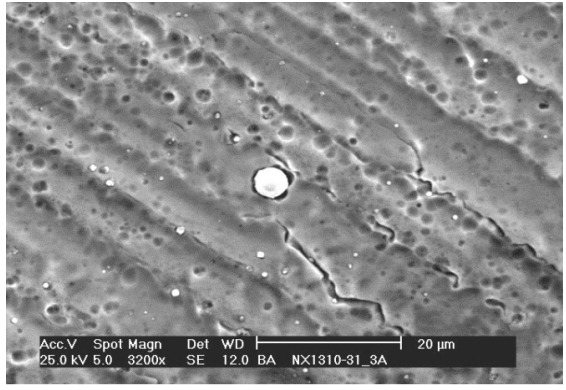

(a)

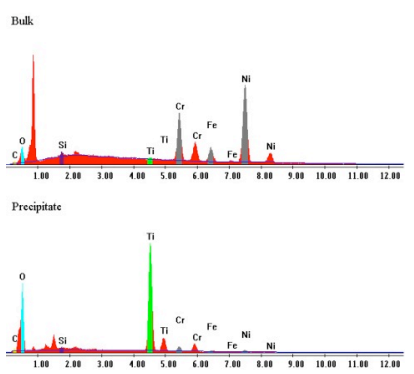

(b)

Figure 14. (a) Micrograph showing one of the matrix precipitates observed on the surface of sample $3 \mathrm{~A}$ and (b) EDX spectra resulting from the bulk and the precipitate shown in (a). 
Table 3. Chemical compositions of the bulk and matrix precipitate resulting from EDX analysis.

\begin{tabular}{|c|r|r|r|r|}
\hline \multirow{2}{*}{ Element } & \multicolumn{2}{|c|}{ Bulk } & \multicolumn{2}{c|}{ Matrix precipitate } \\
\cline { 2 - 5 } & wt. \% & at. \% & wt. \% & at. \% \\
\hline $\mathrm{C}$ & 1.53 & 6.56 & 1.66 & 3.63 \\
\hline $\mathbf{O}$ & $\mathbf{1 . 7 7}$ & $\mathbf{5 . 7 2}$ & $\mathbf{3 9 . 0 8}$ & $\mathbf{6 4 . 2 4}$ \\
\hline $\mathrm{Si}$ & 0.60 & 1.10 & 0.56 & 0.52 \\
\hline $\mathbf{T i}$ & $\mathbf{0 . 4 8}$ & $\mathbf{0 . 5 2}$ & $\mathbf{5 0 . 1 5}$ & $\mathbf{2 7 . 5 4}$ \\
\hline $\mathrm{Cr}$ & 15.20 & 15.08 & 3.83 & 1.94 \\
\hline $\mathrm{Fe}$ & 7.30 & 6.74 & 1.06 & 0.50 \\
\hline $\mathrm{Ni}$ & 73.12 & 64.27 & 3.67 & 1.64 \\
\hline $\mathrm{Total}$ & 100.00 & 100.00 & 100.00 & 100.00 \\
\hline
\end{tabular}

Next, the nature of the grain boundary precipitates was investigated. Figure 15a shows the microstructure on plane "A" (Fig. 7), while Fig. 15b is a higher magnification micrograph showing both matrix and grain boundary precipitates. In Fig. 15c EDX spectra resulting from the bulk and from one the grain boundary precipitate are shown. Again, the comparison of the two spectra and the quantitative results shown in Table 4 suggest that the grain boundary precipitate is $\mathrm{TiO}_{2}$.

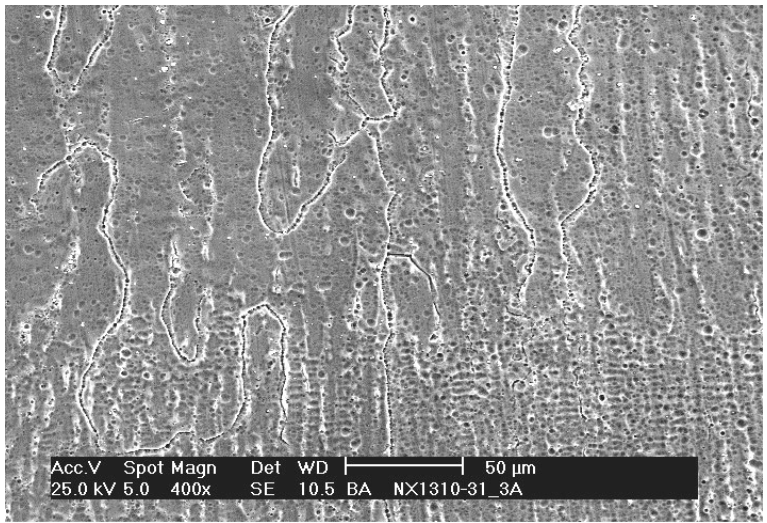

(a)

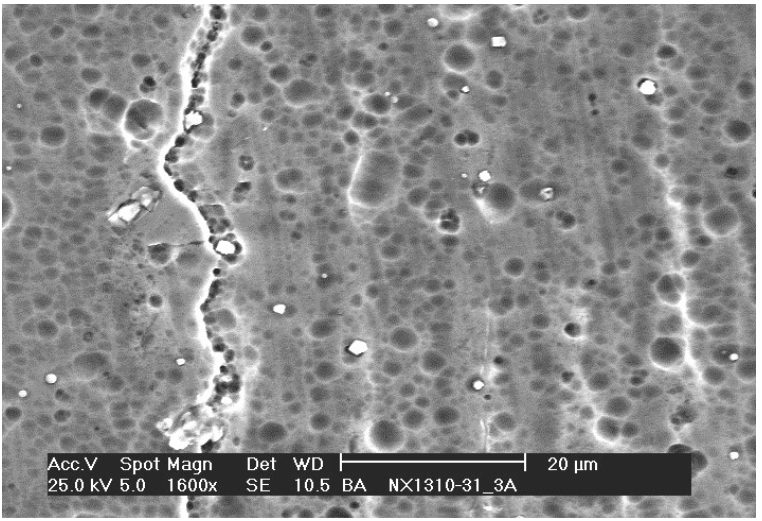

(b)
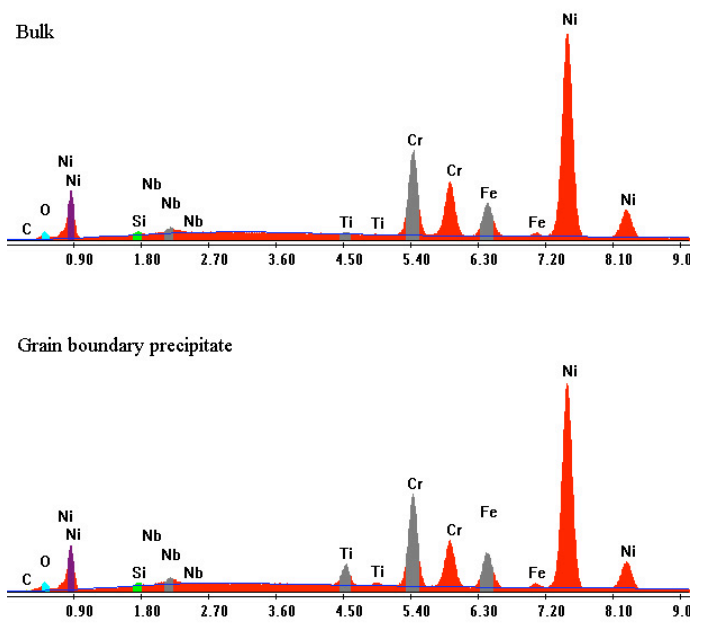

(c)

Figure 15. Micrographs showing (a) the microstructure on plane $3 \mathrm{~A}$, (b) matrix and grain boundary precipitates, and (c) EDX spectra resulting from the bulk and grain boundary precipitates. 
Table 4. Chemical compositions of the bulk and grain boundary precipitate resulting from EDX analysis.

\begin{tabular}{|c|r|r|r|r|}
\hline \multirow{2}{*}{ Element } & \multicolumn{2}{|c|}{ Bulk } & \multicolumn{2}{c|}{ GB precipitate } \\
\cline { 2 - 5 } & wt. \% & at. \% & wt. \% & at. \% \\
\hline $\mathrm{C}$ & 1.34 & 5.82 & 1.65 & 6.99 \\
\hline $\mathbf{O}$ & $\mathbf{1 . 9 4}$ & $\mathbf{6 . 3 3}$ & $\mathbf{2 . 2 5}$ & $\mathbf{7 . 1 8}$ \\
\hline $\mathrm{Si}$ & 0.75 & 1.39 & 0.62 & 1.13 \\
\hline $\mathrm{Nb}$ & 2.14 & 1.20 & 2.26 & 1.24 \\
\hline $\mathbf{T i}$ & $\mathbf{0 . 3 0}$ & $\mathbf{0 . 3 2}$ & $\mathbf{2 . 7 0}$ & $\mathbf{2 . 8 7}$ \\
\hline $\mathrm{Cr}$ & 14.23 & 14.26 & 14.73 & 14.44 \\
\hline $\mathrm{Fe}$ & 7.27 & 6.78 & 7.41 & 6.76 \\
\hline $\mathrm{Ni}$ & 72.03 & 63.90 & 68.38 & 59.38 \\
\hline Total & 100.00 & 100.00 & 100.00 & 100.00 \\
\hline
\end{tabular}

The microstructure on plane "A" (Fig. 7) was further examined in a Hitachi S-4700 field emission gun SEM, allowing a close inspection of the precipitates and grain boundary continuity across the HAZ. Figures 16a, c are high magnification micrographs showing Ti-rich precipitates in the weld material, in both matrix and grain boundaries. Figures $16 \mathrm{~b}, \mathrm{~d}$, are maps showing the topography at the locations where the high magnification micrographs were taken. One observes that both grain boundary and matrix precipitates appear to stick out from the sample surface, thus were not attached by the etch.

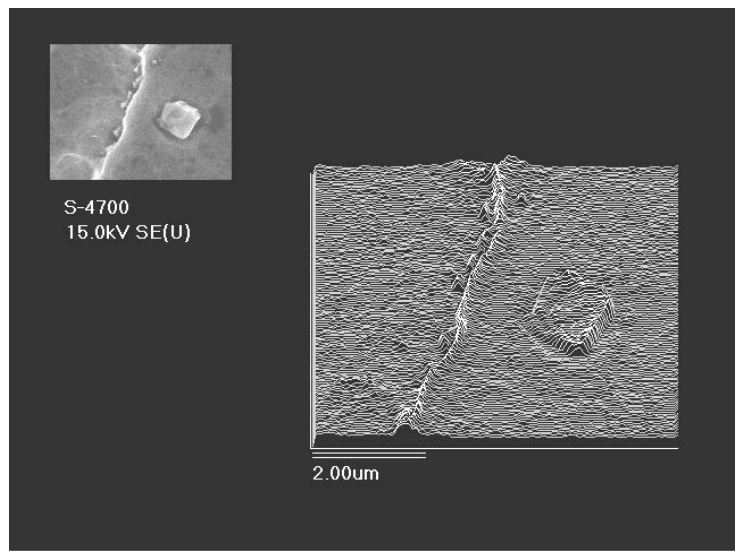

(a)

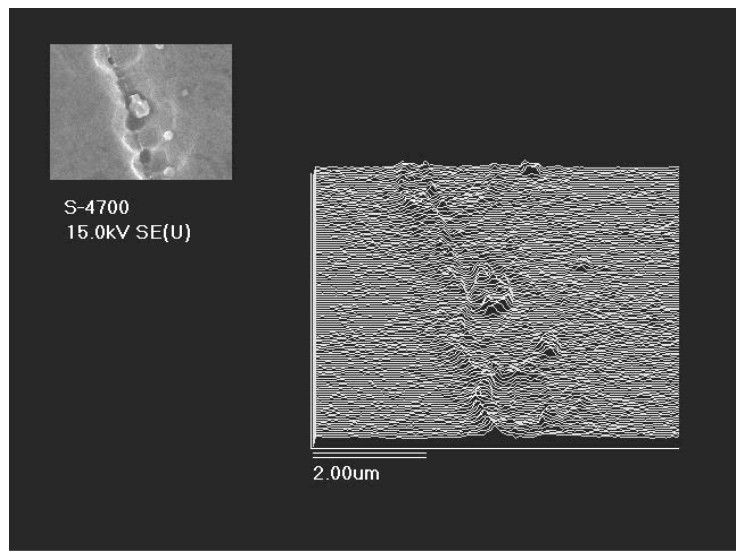

(b)

Figure 16. Examples of Ti-rich precipitates in the weld (top left) and maps showing the topography at the locations where the high magnification micrographs were taken.

Figures $17 \mathrm{a}$ and $\mathrm{c}$ show areas on the HAZ where the dendritic microstructure (lower left) is replaced by the large grains of the HAZ. Figures $17 \mathrm{~b}$ and $\mathrm{d}$ are high magnification micrographs of the precipitates observed in Figs. 17a and c, respectively. Figure 17 also shows that, as suggested by the depth of the etch attack, random boundaries from the weld extend into the HAZ.

In summary, the metallographic examination of the weld alloy has found that there exists a large variation in grain size between the different weld passes. Both matrix and grain boundary precipitates were observed, and these were identified to be $\mathrm{TiO}_{2}$. The effect of $\mathrm{TiO}_{2}$ precipitates on the $\mathrm{SCC}$ behavior is unknown. High angle boundaries were observed to extend from the weld into the HAZ, and the implication of this observation is that once a crack initiates in the HAZ, it can then readily extend into the weld via such continuous, cracking-susceptible boundaries. 


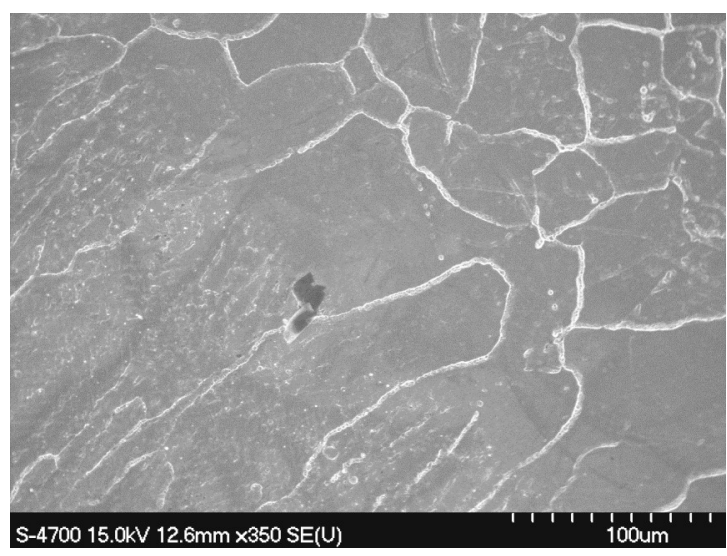

(a)

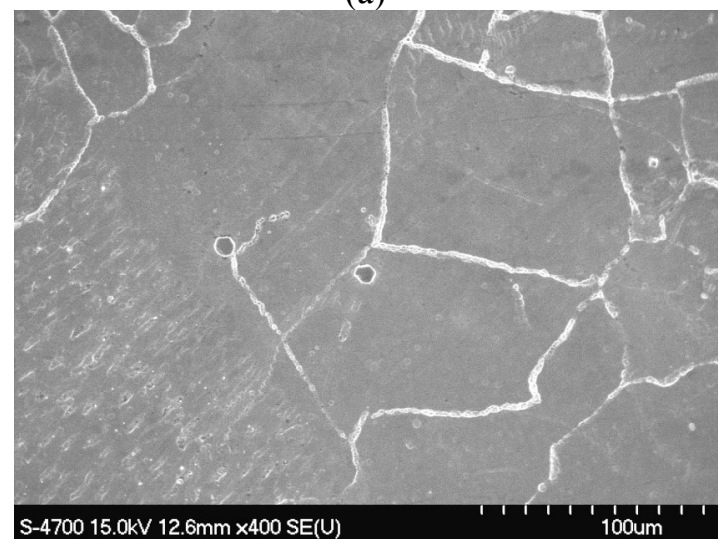

(c)

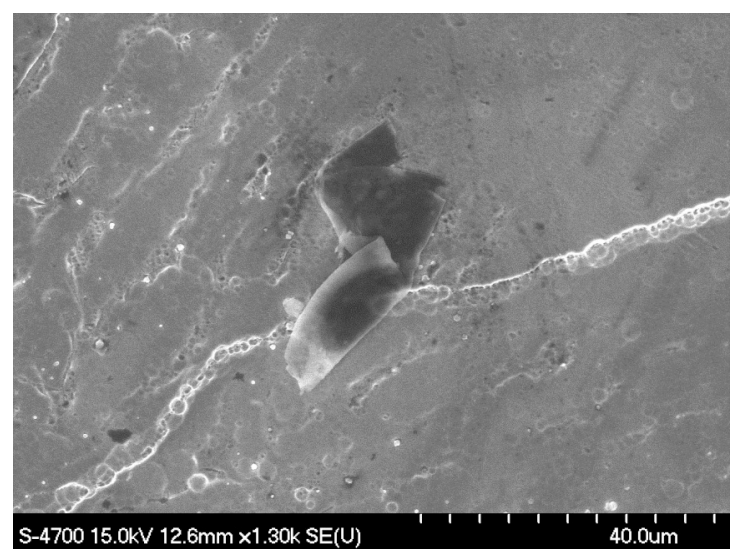

(b)

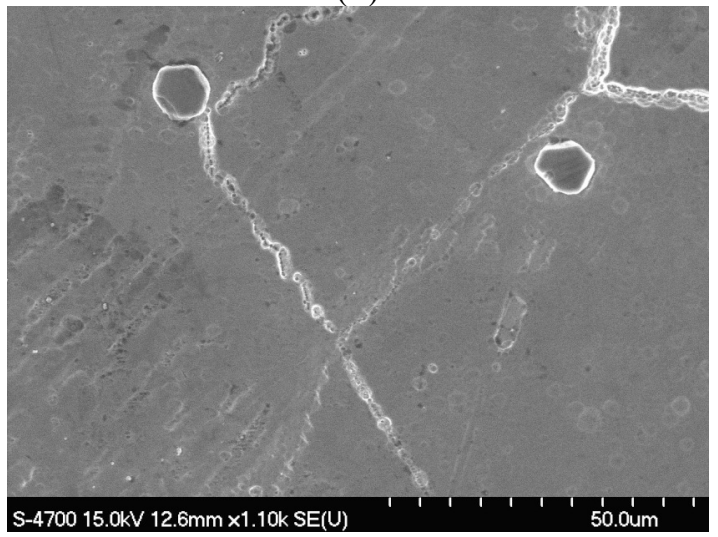

(d)

Figure 17. Micrographs showing the heat-affected zone $(a, c)$ and high magnification micrographs showing precipitates in the heat-affected zone $(b, d)$.

\subsection{Examination of Weld Specimens by Orientation Imaging Microscopy}

Orientation imaging microscopy (OIM) is a diffraction-based technique by which maps of the crystal structure of a material can be obtained, thus determining both the orientations of the grains and the types of grain boundaries present. Intergranular SCC behavior of austenitic alloys in high-temperature aqueous environments is known to be strongly influenced by the proportions of boundaries in special orientation relationships and the magnitude and location of residual stress. ${ }^{32-35}$ Thus the information provided by the OIM analysis can give insights into the relative susceptibility of specific welds or components.

First, specimens from the double-J weld were examined by OIM. A specimen was cut and polished to reveal both the surface plane and plane "B" (see Fig. 7). The sample was polished with 1- $\mu \mathrm{m}$ diamond paste and electro-polished in a perchloric acid $(10 \%)$ and methanol solution at $-50^{\circ} \mathrm{C}$. Repeated double polishing cycles of $5 \mathrm{~s}$ at $40 \mathrm{~V}$ provided the best surface finish.

Figure 18a shows an OIM map resulting from the weld, plane B. In this analysis, the grain boundaries were classified as either low angle boundaries (LAB, $\Sigma=1$ ), coincident site lattice boundaries (CSLB, $3 \leq \Sigma<29$ ), or high angle boundaries (HAB, $\Sigma \geq 29$ ), where $\Sigma$ represents the reciprocal of the density of coincident sites. For example, a $\Sigma 3$ boundary designates a boundary where 1 in every 3 sites on one grain coincides with a site from the adjacent grain. In terms of angle/axis misorientation, to achieve this particular coincidence, one grain must be rotated by $60^{\circ}$ around the [111] direction. For the 
current work Brandon's criterion ${ }^{36}$ was used to determine the maximum allowed deviation from exact coincidence: $\delta \theta=15^{\circ} \Sigma^{1 / 2}$. According to Brandon's criterion the maximum allowed misorientation for a $\Sigma 1$ boundary is $15^{\circ}$, and for a $\Sigma 3$ is $8.6^{\circ}$.

Cracking would be expected along the high angle boundaries, identified as such in the OIM map, Fig. 18a. Also displayed (Fig. 18b) is a map showing the crystal directions parallel $\left( \pm 15^{\circ}\right)$ to the normal to the sample surface. We first noticed that the dendritic structure does not appear in the OIM maps, suggesting that the dendrites are coherent and, therefore, very unlikely to crack. Overall, the appearance is that plane B exhibits little or no texture (Fig. 18b). Figure 18c consists of two tables. The upper table shows the legend for the grain directions as well as the resulting fractions of grains having a certain direction. The lower table shows the legend for CSL boundaries, resulting boundary fractions of each type, and the misorientation distribution function (MDF) values, and are a distribution of misorientations measured at grain boundaries and area-weighted.

We observed that the fraction of cracking-resistant CSLBs is very low, 26\%. For comparison, solution-annealed Alloy 600 has a CSLB fraction of approximately 50\%. If this last observation holds true for a larger area - where a statistically significant number of boundaries are analyzed - it would suggest a high degree of susceptibility of the weld.

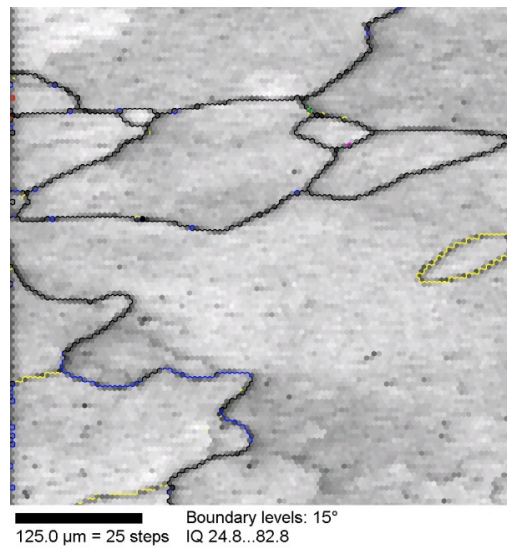

(a)

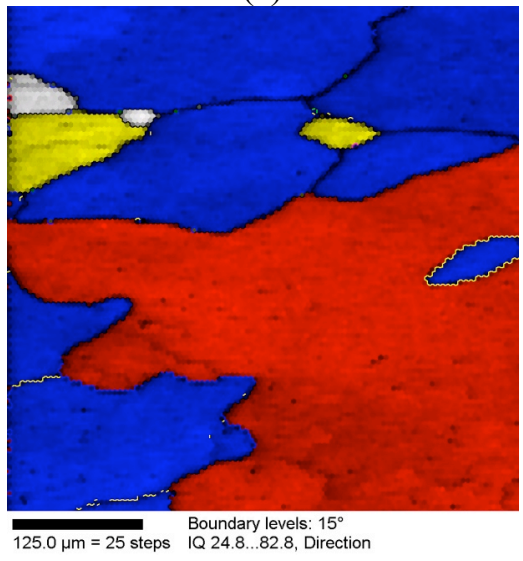

(b)

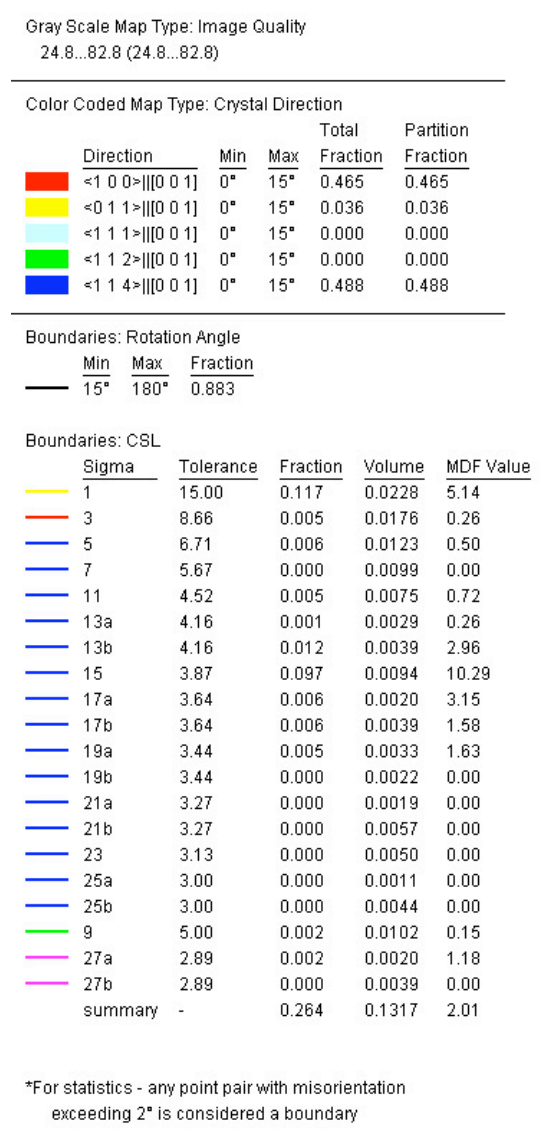

(c)

Figure 18. (a) OIM map of the weld on plane "B", sample 3B; (b) the same OIM map showing the orientation of each grain; and (c) legends for crystal directions and the resulting grain boundary character distribution. 


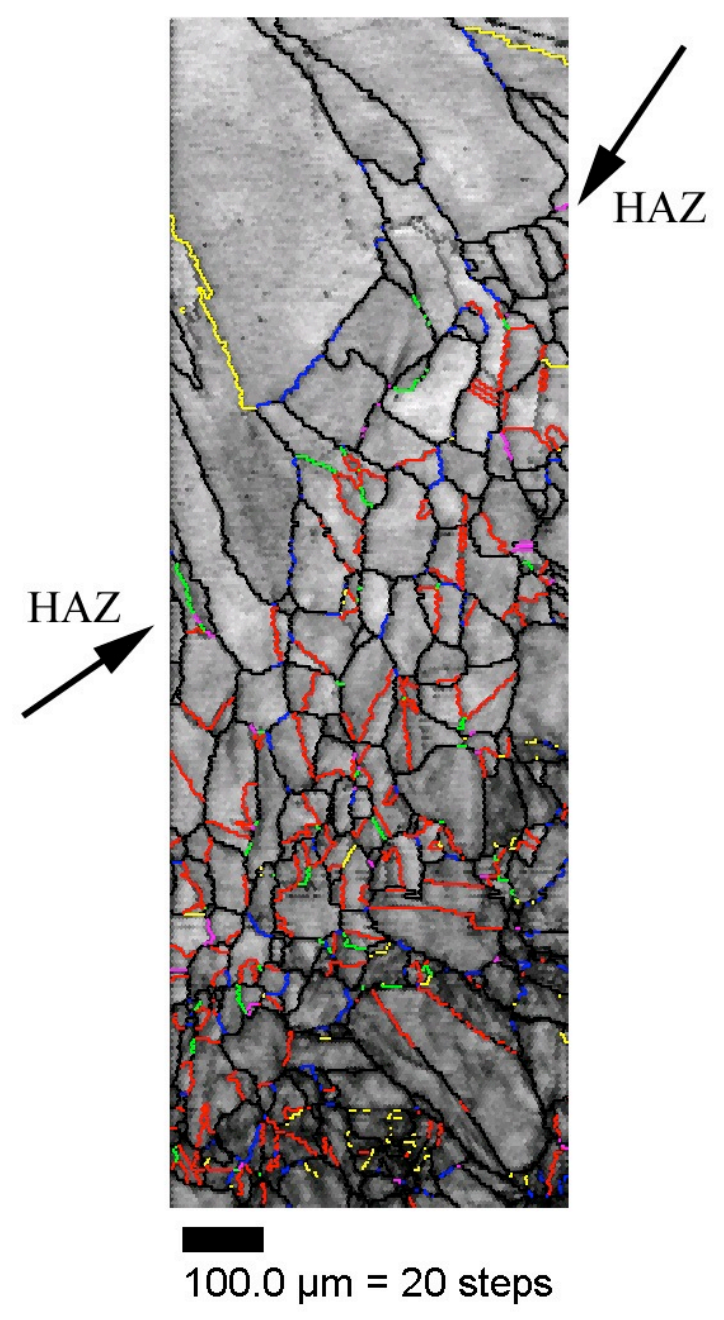

(a)

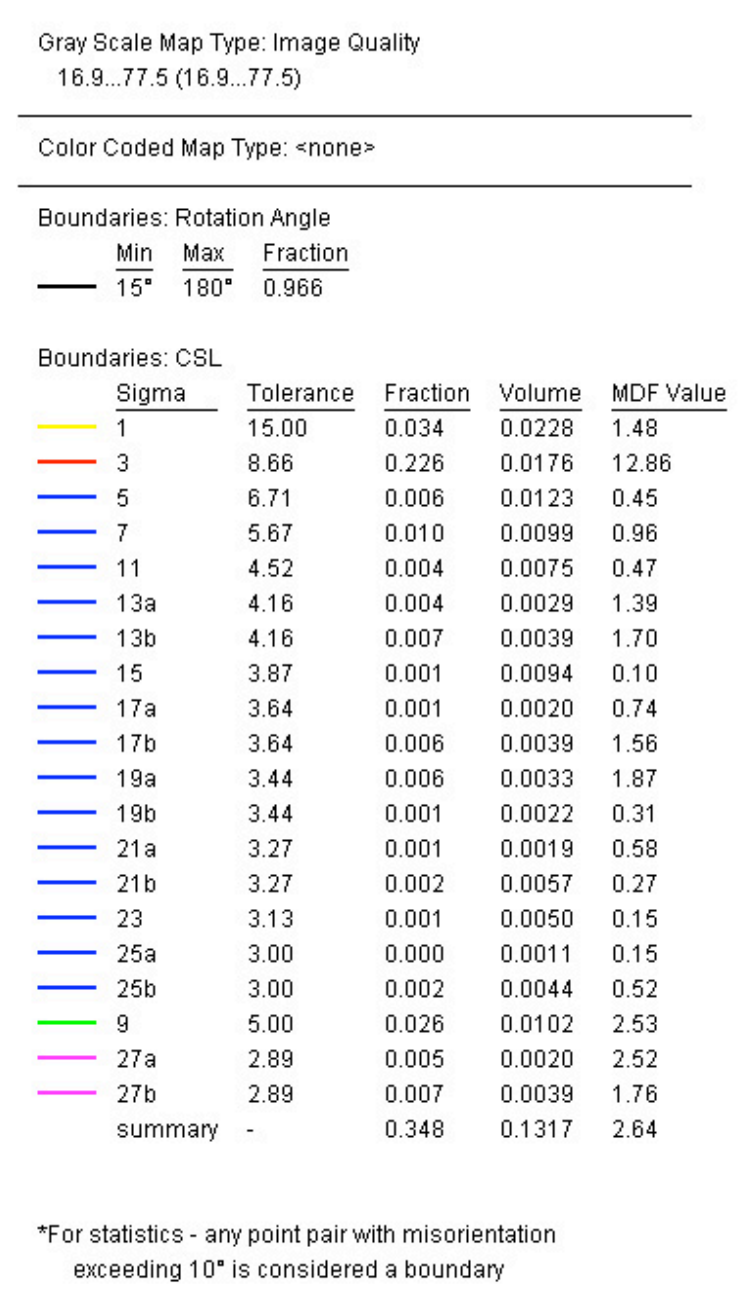

(b)

Figure 19. (a) OIM map on the surface of sample 3B and (b) the resulting grain boundary character distribution. The OIM map covers the weld (upper part), the HAZ (indicated by arrows), and Alloy 600 (lower part).

Next, an area on the surface of the sample was mapped by OIM in the vicinity of the HAZ. The area included the weld, HAZ, and part of the Alloy 600 (Fig. 19a). The resulting proportion of CSLBs was $35 \%$. Although somewhat larger than in the previous example, this proportion appears to be attributable to the inclusion of the area from Alloy 600 in the total count.

Figure 20a shows the same OIM map as Fig. 19a but with the grain directions included. Again, no definitive conclusion can be drawn with respect to the presence or absence of texture in the weld due to the small weld area analyzed. Nevertheless, as in Fig. 18, the OIM did not distinguish the dendritic structure (the SEM micrograph of Fig. 20b was included for comparison). Thus, the grain boundary character distribution will likely determine the cracking behavior of the weld.

The second model weld, the deep-groove weld, was examined by OIM to determine (a) the grain boundary character distribution and (b) any texture in the microstructure. Both these parameters are known to influence the SCC behavior of austenitic alloys in high temperature water environments. ${ }^{32-40}$ Specifically, the OIM analysis allows a classification of boundaries according to the coincident site lattice (CSL) model as either CSLB or HAB. The CSLBs are formed when the neighboring grains are in 


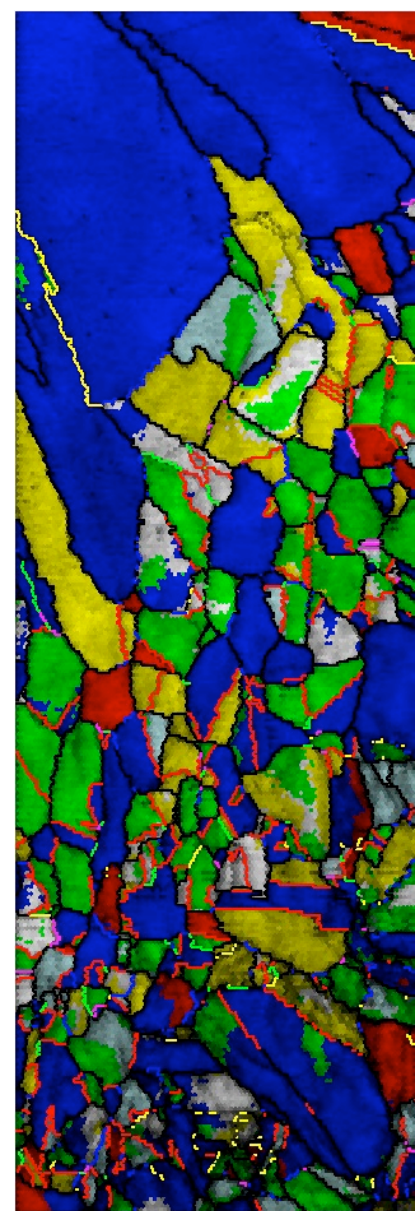

$100.0 \mu \mathrm{m}=20$ steps

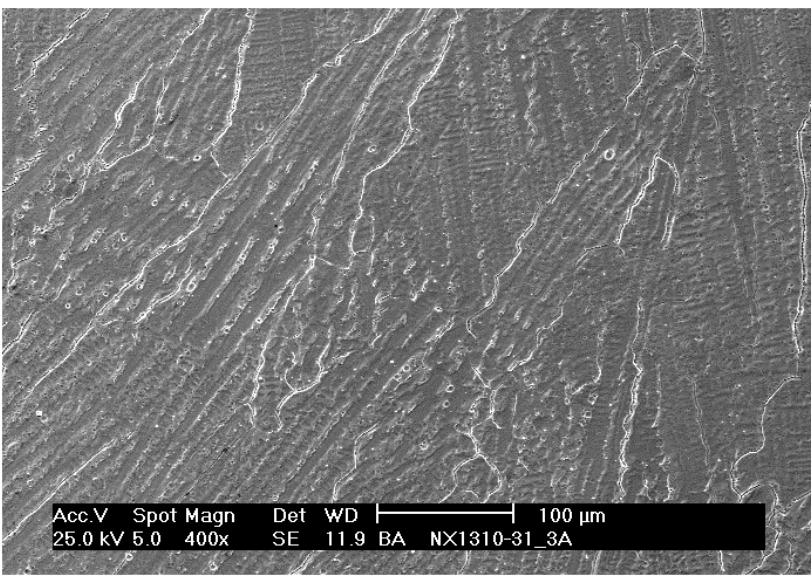

(b)

Color Coded Map Type: Crystal Direction

\begin{tabular}{|c|c|}
\hline Direction & Min \\
\hline 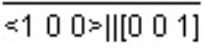 & $\overline{0^{\circ}}$ \\
\hline$\leq \begin{array}{lll}0 & 1 & 1\end{array} \Rightarrow \|\left[\begin{array}{lll}0 & 0 & 1\end{array}\right]$ & $0^{\circ}$ \\
\hline$\Leftrightarrow \begin{array}{lll}1 & 1 & 1\end{array}=\|\left[\begin{array}{lll}0 & 0 & 1\end{array}\right]$ & $0^{\circ}$ \\
\hline$\leq 1 \begin{array}{lll}1 & 1 & 2\end{array}$ & $0^{\circ}$ \\
\hline$\Leftrightarrow \begin{array}{lll}1 & 1 & 4\end{array}=\|\left[\begin{array}{lll}0 & 0 & 1\end{array}\right]$ & $0^{\circ}$ \\
\hline
\end{tabular}

(a)

Figure 20. (a) The same OIM map as in Fig. 19a showing crystal directions and (b) SEM micrograph illustrating the dendritic microstructure of the weld.

specific orientation relationships and have been shown to possess an increased resistance to SCC over HABs. ${ }^{37}$ In addition, texture affects the high-temperature deformation behavior of a polycrystalline material and is thus expected to play a role in the SCC behavior as well.

The OIM analysis was carried out on plane "A", along the direction of the dendrites, and "B", perpendicular to the direction of dendrites (Fig. 21). In preparation for the OIM analysis, the weld

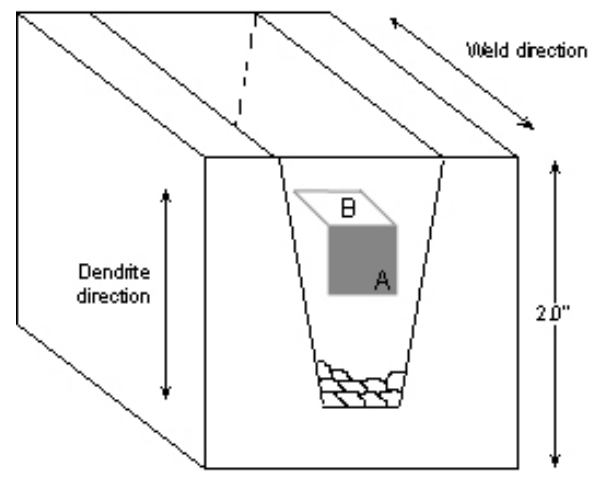

Figure 21.

Schematic showing the two planes on which the OIM characterization was carried out: plane "A", along the direction of the dendrites, and plane "B", perpendicular to the direction of dendrites. 
specimens were mechanically polished through $1-\mu \mathrm{m}$ diamond paste, and electro-polished in a perchloric acid $(10 \%)$ and methanol solution at $-50^{\circ} \mathrm{C}$. The OIM characterization was performed in a Philips XL30 FEG SEM equipped with a TexSem OIM system.

Two OIM maps from plane " $\mathrm{A}$ " and the corresponding boundary character distributions are shown in Fig. 22. The microstructure (a, c) consists of columnar grains, typical of those observed on this plane. Also, note the absence of dendrites from the OIM map. The boundary character distributions resulting from the two scans (Figs. 22b, d) give CSL fractions of $27.5 \%$ and $22.7 \%$.

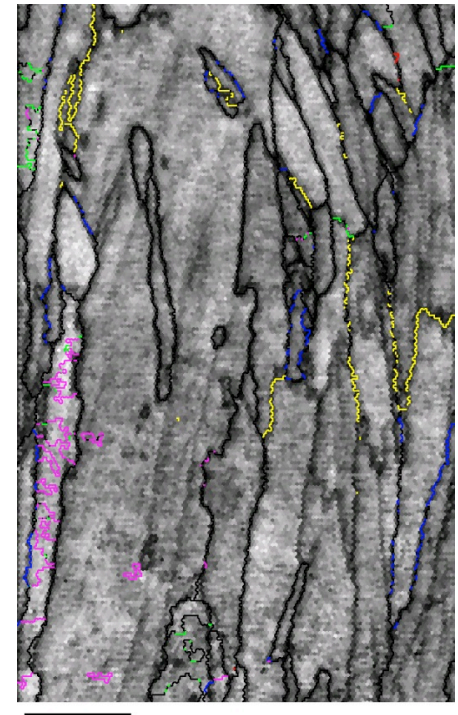

$240.0 \mu \mathrm{m}=30$ steps

(a)

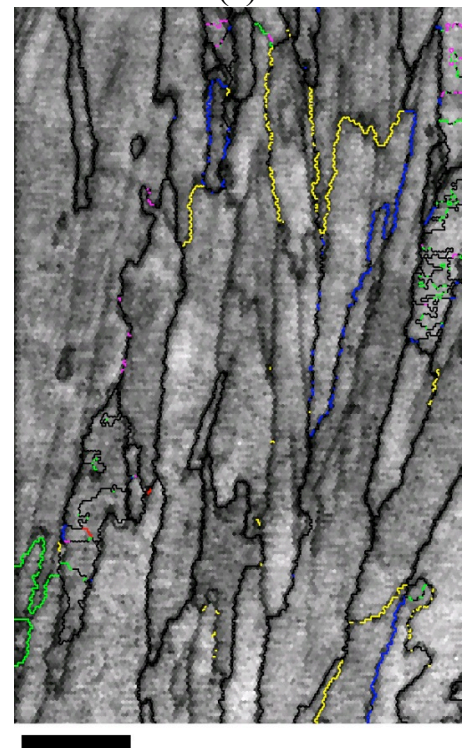

$240.0 \mu \mathrm{m}=30$ steps

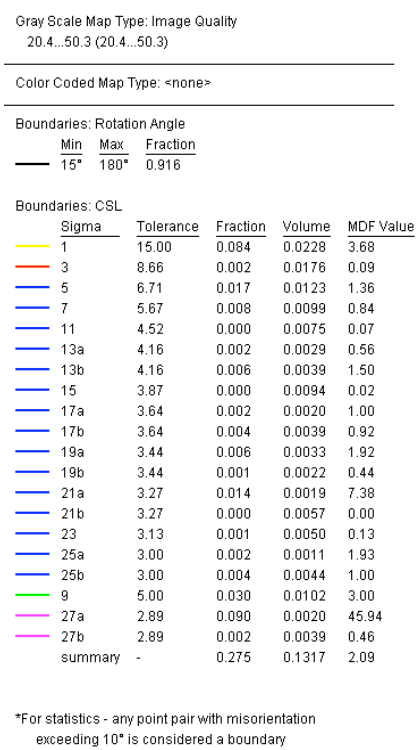

(b)

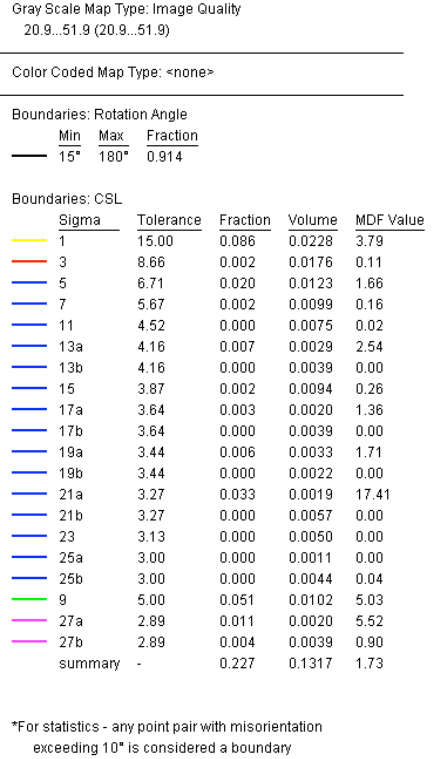

(d)

Figure 22. OIM maps from plane "A", parallel to the direction of dendrites $(a, c)$, and resulting grain boundary character distributions (b, d). 


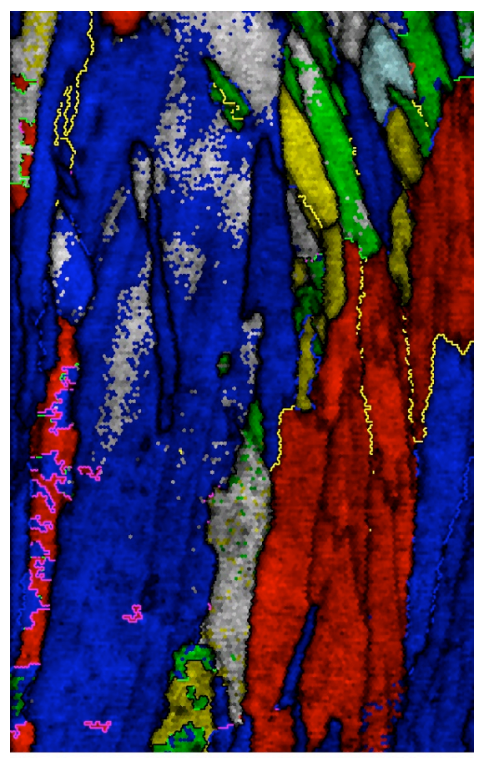

$240.0 \mu \mathrm{m}=30$ steps

(a)

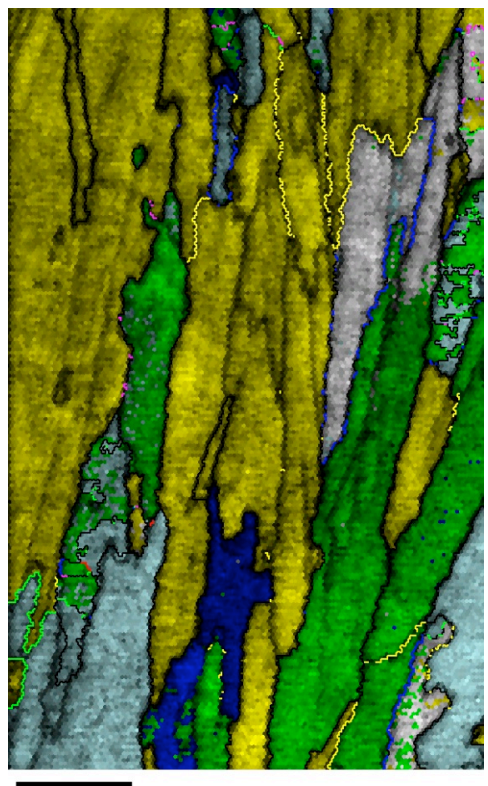

$240.0 \mu \mathrm{m}=30$ steps

(c)

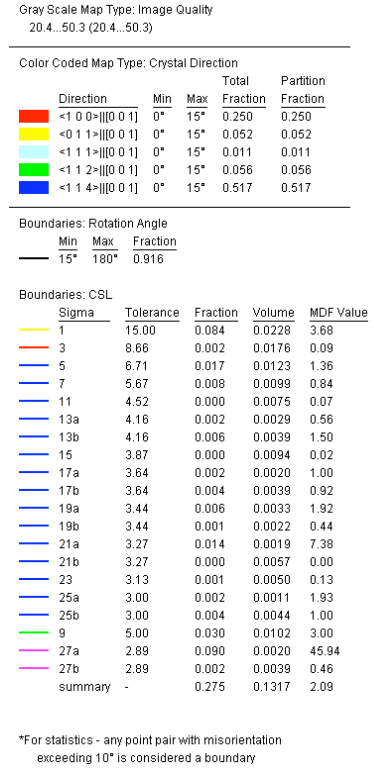

(b)

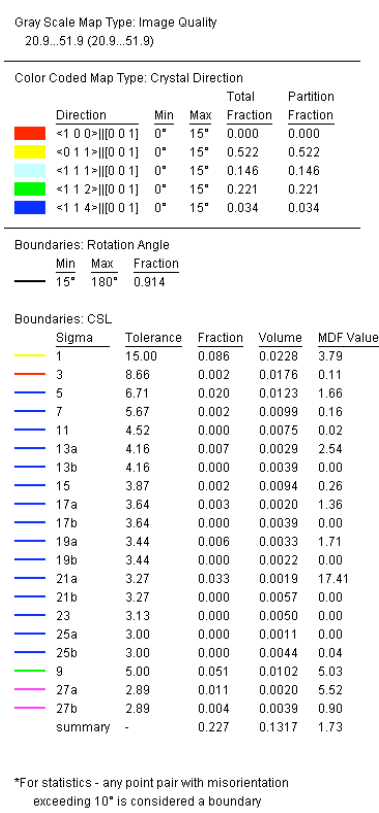

(d)

Figure 23. OIM maps from plane " $A$ " (parallel to the direction of dendrites) showing the grain orientations $(a, c)$, and legends for grain orientations and grain boundary character distributions $(b, d)$.

Figure 23a and c present the same OIM maps as Fig. 22, but this time the grain directions are specified. The orientation legend for each map is given next to it $(b, d)$ along with the grain boundary character distributions. For example, a grain shown in red has the [100] direction perpendicular to the plane of the figure, while a grain shown with blue has the [114] direction perpendicular to the plane of the figure. The tolerance angle is $15^{\circ}$. We notice that most of the grains in Fig. 23a have either [100] or [114] directions perpendicular to the sample surface. In addition, the grains sharing similar orientations are also neighbors. A similar observation can be made for the second scan (Fig. 23c). However, in this 
Figure 25 shows the grain boundary character distribution (GBCD) of the weld alloys. This appears to be dominated by LABs $(\Sigma 1)$. This feature of the weld GBCD is actually consistent with the clustering of grains of similar orientations: one may envision that the higher the proportion of neighboring grains that share some particular orientation, the higher becomes the probability that these grains have parallel crystal structures. The fact that the weld GBCD is dominated by $\Sigma 1$ boundaries makes it also significantly different from that of Alloy 600 , which is dominated by twin-related $\Sigma 3, \Sigma 9$, and $\Sigma 27$ boundaries (of which approximately half are coherent). ${ }^{41}$

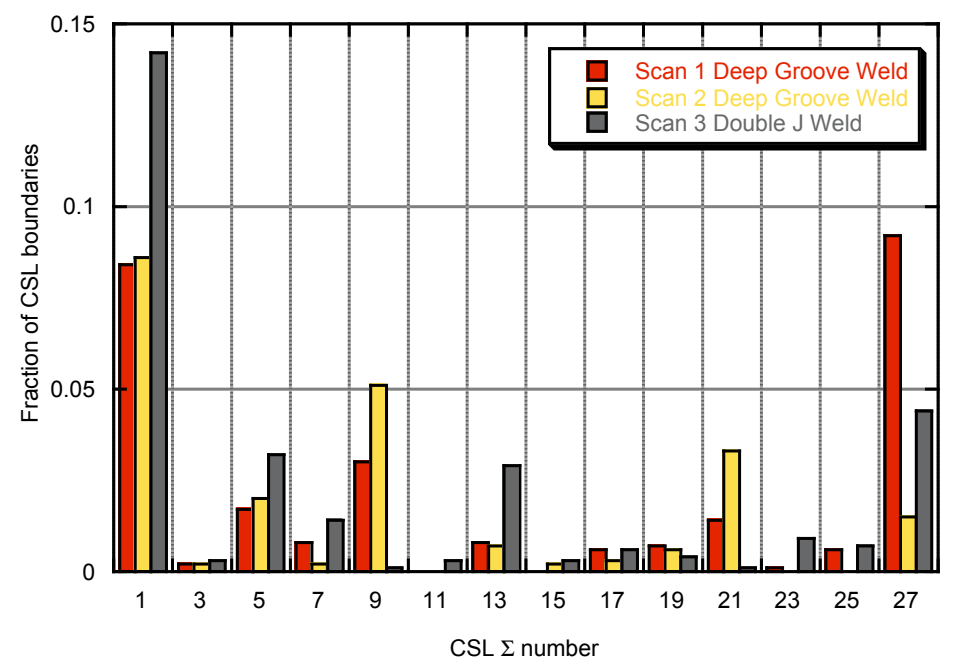

Figure 25.

Grain boundary character distribution for laboratory-prepared welds.

For comparison, the base Alloy 600 was also analyzed by OIM. Figure 26a is an OIM map from this alloy, and Fig. 26b maps the grain orientation. The legend for grain orientation and the corresponding boundary character distributions are shown in Fig. 26c. Unlike the weld alloy, the microstructure shown in Fig 26a is typical of isotropic, solution-annealed Alloy 600. The resulting CSL fraction is $47.1 \%$, close to that generally reported (about $50 \%$ ) for this alloy in the solution-annealed condition.

In summary, the OIM analysis presented in this section has shown that the intragranular dendrites are coherent and are, therefore, expected to be resistant to cracking. In consequence, it appears that the grain boundary character distribution (along with residual deformation) will determine the cracking behavior of the welds. The proportion of cracking-resistant CSL boundaries in the weld was found to be relatively small; however, the clustering of grains having similar orientations was observed. 


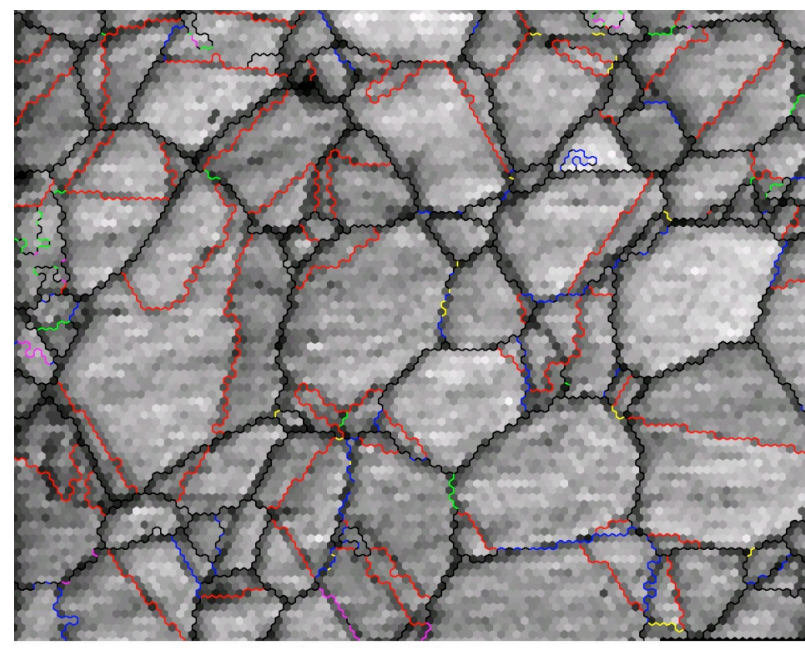

Boundary levels: $15^{\circ}$

(a)

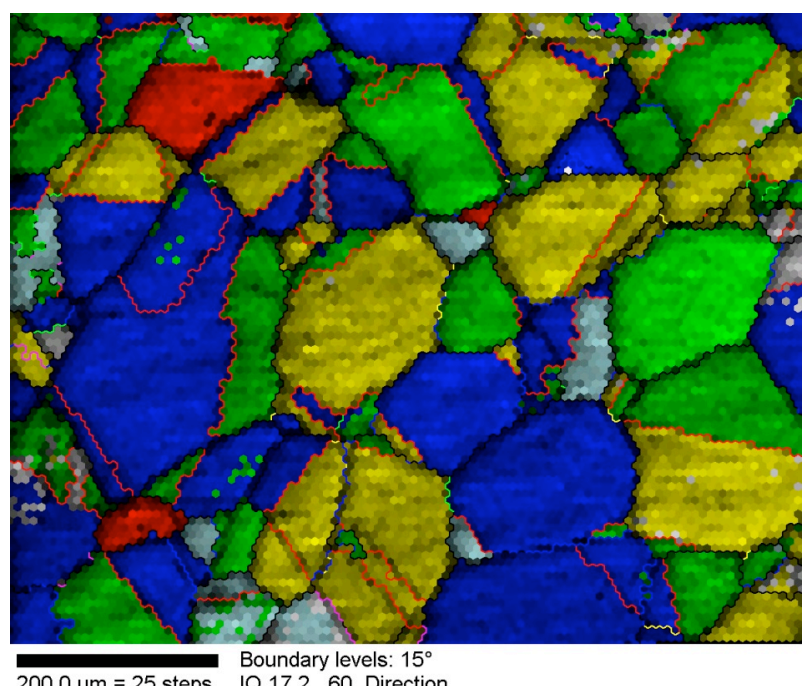

(b)
Gray Scale Map Type: Image Quality $17.2 \ldots 60(17.2 \ldots 60)$

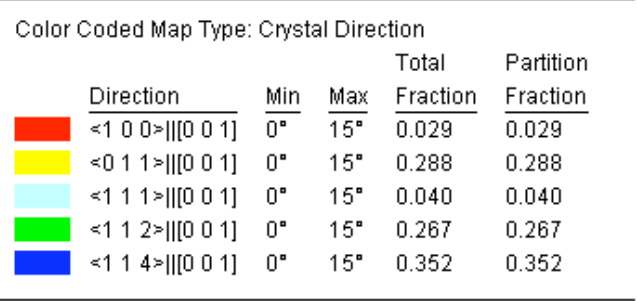

Boundaries: Rotation Angle $-\frac{\text { Min }}{15^{\circ}} \frac{\text { Max }}{180^{\circ}} \frac{\text { Fraction }}{0.982}$

Boundaries: CSL

\begin{tabular}{|c|c|c|c|c|}
\hline Sigma & Tolerance & Fraction & Volume & MDF Value \\
\hline 1 & 15.00 & 0.018 & $\overline{0.0228}$ & 0.80 \\
\hline 3 & 8.66 & 0.340 & 0.0176 & 19.38 \\
\hline 5 & 6.71 & 0.019 & 0.0123 & 1.57 \\
\hline 7 & 5.67 & 0.003 & 0.0099 & 0.33 \\
\hline 11 & 4.52 & 0.005 & 0.0075 & 0.61 \\
\hline $13 a$ & 4.16 & 0.004 & 0.0029 & 1.47 \\
\hline $13 b$ & 4.16 & 0.003 & 0.0039 & 0.84 \\
\hline 15 & 3.87 & 0.011 & 0.0094 & 1.15 \\
\hline $17 a$ & 3.64 & 0.000 & 0.0020 & 0.00 \\
\hline $17 \mathrm{~b}$ & 3.64 & 0.004 & 0.0039 & 0.97 \\
\hline $19 a$ & 3.44 & 0.003 & 0.0033 & 0.92 \\
\hline $19 b$ & 3.44 & 0.002 & 0.0022 & 0.69 \\
\hline $21 a$ & 3.27 & 0.002 & 0.0019 & 0.80 \\
\hline $21 b$ & 3.27 & 0.006 & 0.0057 & 1.02 \\
\hline 23 & 3.13 & 0.007 & 0.0050 & 1.32 \\
\hline $25 a$ & 3.00 & 0.009 & 0.0011 & 8.52 \\
\hline $25 b$ & 3.00 & 0.002 & 0.0044 & 0.40 \\
\hline 9 & 5.00 & 0.020 & 0.0102 & 2.02 \\
\hline $27 a$ & 2.89 & 0.007 & 0.0020 & 3.36 \\
\hline $27 \mathrm{~b}$ & 2.89 & 0.007 & 0.0039 & 1.81 \\
\hline summary & - & 0.471 & 0.1317 & 3.58 \\
\hline
\end{tabular}

(c)

Figure 26. OIM map from Alloy 600 (a), map showing the grain orientations (b), and legends for grain orientations and grain boundary character distributions (c). 


\section{ANL Test Results}

\subsection{Crack Growth Data}

This section presents the crack growth data obtained from five 1-T CT specimens. Two of these specimens, CT31-W01 TS and CT31-W02 TS, were cut from a double-J weld, while the remaining three, CT933-TS, CT933-TL, and CT933-LS, were machined from a deep-groove weld.

\subsubsection{Crack Growth Data for Double-J Weld Specimen CT31-W01 TS}

The CGR test on Specimen CT31-W01 TS of Alloy 182 SMA weld was conducted in simulated PWR water at $320^{\circ} \mathrm{C}$, in recirculating mode at a flow rate of $\approx 60 \mathrm{cc} / \mathrm{min}$. The environmental conditions stabilized after about a week. The ECPs, measured at $289^{\circ} \mathrm{C}$ at the exit of the autoclave, of a Alloy 600 sample and Pt electrode were -686 and $-690 \mathrm{mV}$ (SHE), respectively; the water system was switched to the once-through mode during ECP measurements to prevent possible contamination of the test solution. The specimen was fatigue precracked at $\mathrm{R}=0.3, \mathrm{~K}_{\max }=23 \mathrm{MPa} \mathrm{m}{ }^{1 / 2}$, triangular waveform, and $0.5 \mathrm{~Hz}$ frequency. After $\approx 0.3-\mathrm{mm}$ extension, $\mathrm{R}$ was increased incrementally to 0.7 and the frequency decreased to $0.005 \mathrm{~Hz}$. The experimental conditions and results for the test are given in Table 5; the changes in crack length and $\mathrm{K}_{\max }$ with time during various test periods are shown in Fig. 27. Note that at 140, 250, 380 , and $580 \mathrm{~h}$, the DC potential measurements were not recorded for short periods extending 10-20 h.

The test was interrupted at $407 \mathrm{~h}$ and $593 \mathrm{~h}$ because of large fluctuations in the system pressure. The problem was identified to be caused by $\mathrm{Al}(\mathrm{OH})_{3}$ deposits in the cooler regions of the water system. Alumina beads used to insulate the DC potential and current leads were the source for Al. In the recirculating system, the concentration of $\mathrm{Al}$ gradually built up during operation, eventually leading to plugging of the high pressure letdown line. The entire return line from the autoclave to the supply feedwater tank, including the back-pressure regulator, was replaced or cleaned by back flushing. The test was restarted under the loading conditions prior to the interruption, but the system was operated in a once-through mode at a lower flow rate of $\approx 10 \mathrm{cc} / \mathrm{min}$. In the case of both interruptions, the CGRs existing before the interruption were restored after restart.

Table 5. Crack growth data for specimen CT31-W01 TS of Alloy 182 SMA weld in PWR water ${ }^{\mathrm{a}}$ at $320^{\circ} \mathrm{C}$.

\begin{tabular}{|c|c|c|c|c|c|c|c|c|c|c|c|c|}
\hline $\begin{array}{c}\text { Test } \\
\text { Period }\end{array}$ & $\begin{array}{c}\text { Test } \\
\text { Time, } \\
\mathrm{h}\end{array}$ & $\begin{array}{l}\text { Conduc- } \\
\text { tivity, } \\
\mu \mathrm{S} / \mathrm{cm}\end{array}$ & $\begin{array}{c}\mathrm{O}_{2} \\
\text { Conc., } \\
\text { ppb }\end{array}$ & $\begin{array}{c}\text { Load } \\
\text { Ratio } \\
\text { R }\end{array}$ & $\begin{array}{c}\text { Rise } \\
\text { Time, } \\
\text { s }\end{array}$ & $\begin{array}{c}\text { Down } \\
\text { Time, } \\
\text { s }\end{array}$ & $\begin{array}{c}\text { Hold } \\
\text { Time, } \\
\text { s }\end{array}$ & $\begin{array}{c}\mathrm{K}_{\max }, \\
\mathrm{MPa} \cdot \mathrm{m}^{1 / 2}\end{array}$ & $\begin{array}{c}\Delta \mathrm{K}, \\
\mathrm{MPa} \cdot \mathrm{m}^{1 / 2}\end{array}$ & $\begin{array}{c}\mathrm{CGR}_{\text {env }} \\
\mathrm{m} / \mathrm{s}\end{array}$ & $\begin{array}{c}\text { Estimated } \\
\text { CGR }_{\text {air }} \\
\mathrm{m} / \mathrm{s}\end{array}$ & $\begin{array}{c}\text { Crack } \\
\text { Length, } \\
\mathrm{mm}\end{array}$ \\
\hline 1 & 25 & 25.0 & $<10$ & 0.3 & 1 & 1 & 0 & 23.22 & 16.25 & $5.62 \mathrm{E}-08$ & $1.55 \mathrm{E}-08$ & 12.976 \\
\hline 2 & 40 & 25.0 & $<10$ & 0.3 & 10 & 10 & 0 & 24.00 & 16.80 & $1.72 \mathrm{E}-08$ & $1.78 \mathrm{E}-09$ & 13.523 \\
\hline 3 & 90 & 25.0 & $<10$ & 0.6 & 10 & 10 & 0 & 23.86 & 9.55 & $1.94 \mathrm{E}-09$ & 4.17E-10 & 13.718 \\
\hline $4 a$ & 135 & 25.3 & $<10$ & 0.7 & 10 & 10 & 0 & 24.64 & 7.39 & $1.59 \mathrm{E}-09$ & $2.15 \mathrm{E}-10$ & 13.832 \\
\hline $4 b$ & 281 & 25.3 & $<10$ & 0.7 & 10 & 10 & 0 & 25.26 & 7.58 & $1.26 \mathrm{E}-09$ & $2.38 \mathrm{E}-10$ & 14.371 \\
\hline 5 & 407 & 24.4 & $<10$ & 0.7 & 100 & 100 & 0 & 25.43 & 7.63 & $2.55 \mathrm{E}-10$ & $2.45 \mathrm{E}-11$ & 14.394 \\
\hline 6 & 498 & 23.9 & $<10$ & 0.7 & 100 & 100 & 0 & 25.59 & 7.68 & $2.73 \mathrm{E}-10$ & $2.52 \mathrm{E}-11$ & 14.497 \\
\hline 7 & 552 & 22.7 & $<10$ & 0.7 & 500 & 500 & 0 & 25.57 & 7.67 & negligible & $5.02 \mathrm{E}-12$ & 14.497 \\
\hline 8 & 593 & 23.0 & $<10$ & 0.7 & 1000 & 12 & 0 & 28.55 & 8.56 & $2.40 \mathrm{E}-10$ & $3.94 \mathrm{E}-12$ & 14.588 \\
\hline 9 & 858 & 20.0 & $<10$ & 0.7 & 1000 & 12 & 0 & 28.86 & 8.66 & $5.25 \mathrm{E}-11$ & $4.12 \mathrm{E}-12$ & 14.687 \\
\hline 10 & 1214 & 20.5 & $<10$ & 0.7 & 1000 & 12 & 3600 & 29.03 & 8.71 & $9.79 \mathrm{E}-11^{\mathrm{c}}$ & $4.22 \mathrm{E}-12$ & 14.790 \\
\hline
\end{tabular}

${ }^{a}$ Simulated PWR water with $2 \mathrm{ppm} \mathrm{Li}, 1100 \mathrm{ppm} \mathrm{B}$, and $2 \mathrm{ppm}$ dissolved hydrogen $(\approx 23 \mathrm{cc} / \mathrm{kg})$.

${ }^{b}$ Represents values in the effluent; conductivity was $\approx 21.5 \mu \mathrm{S} / \mathrm{cm}$ in feedwater.

${ }^{c}$ Represents the SCC component of the CGR. 


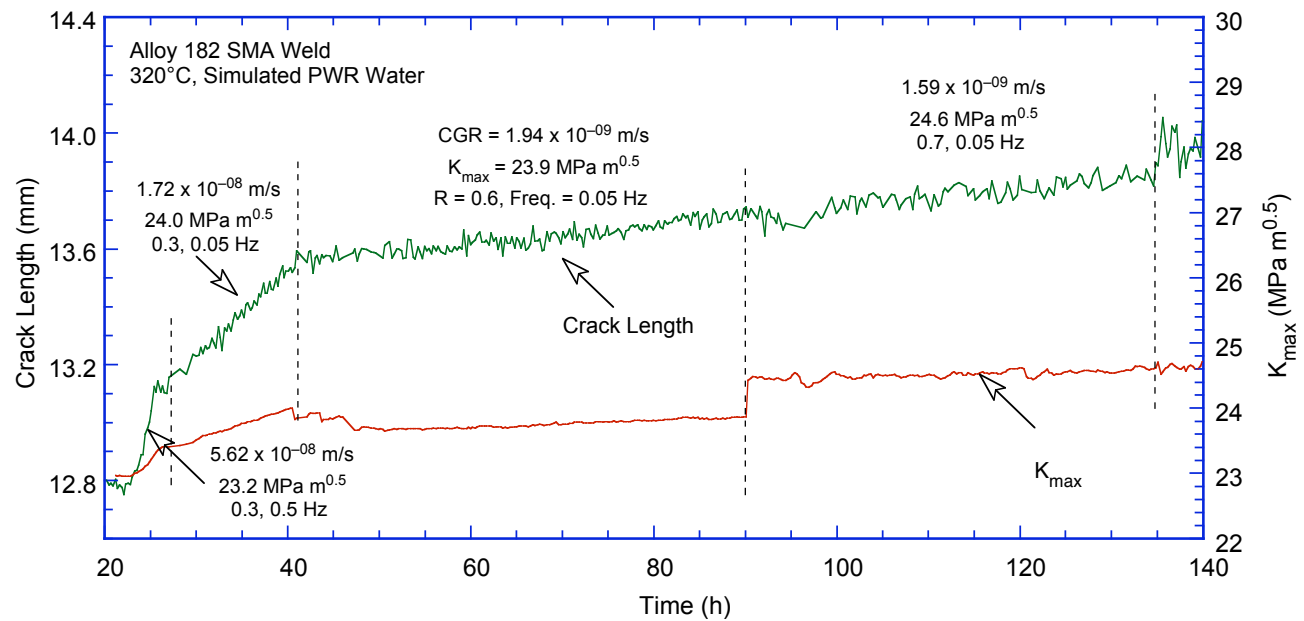

(a)

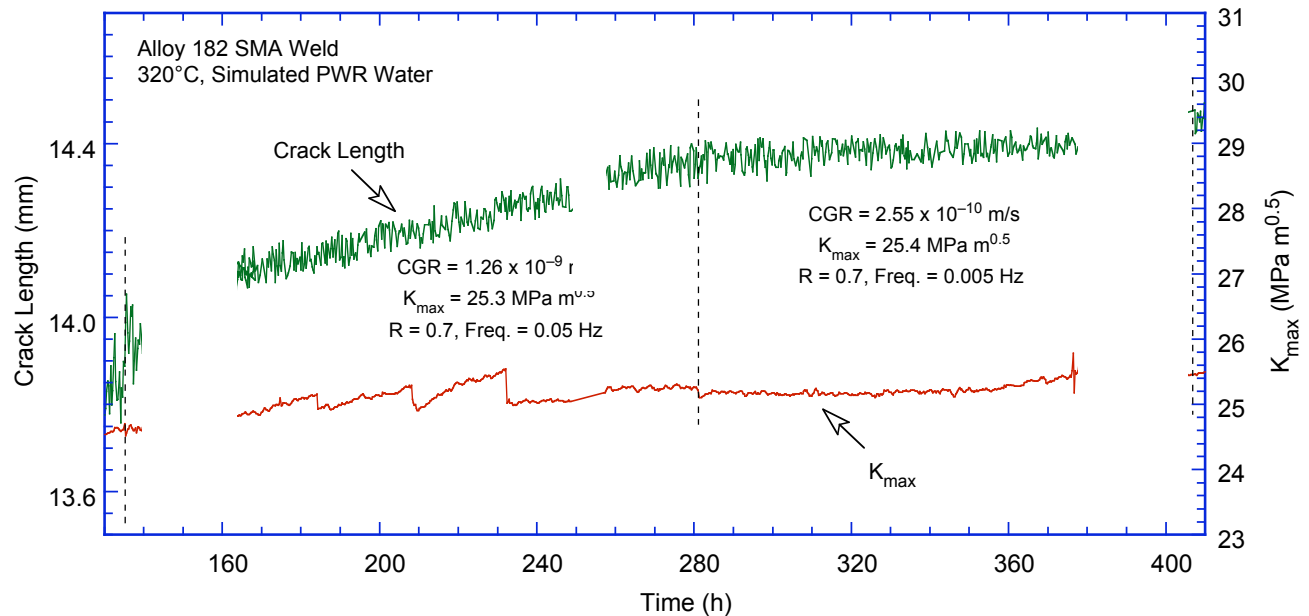

(b)

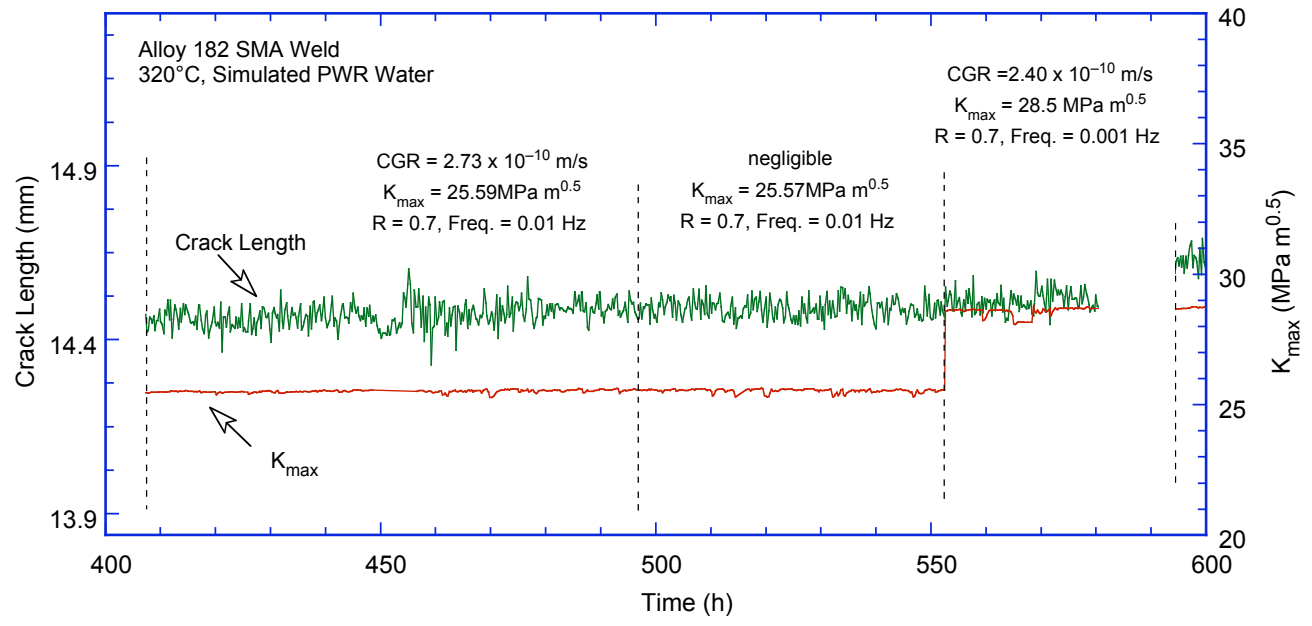

(c)

Figure 27. Crack length vs. time for Alloy 182 SMA weld-metal specimen CT31-W01 TS in simulated PWR environment at $320^{\circ} \mathrm{C}$ during test periods (a) 1-4a, (b) 4b-5, (c) 6-8, (d) 9, and (e) 10. 


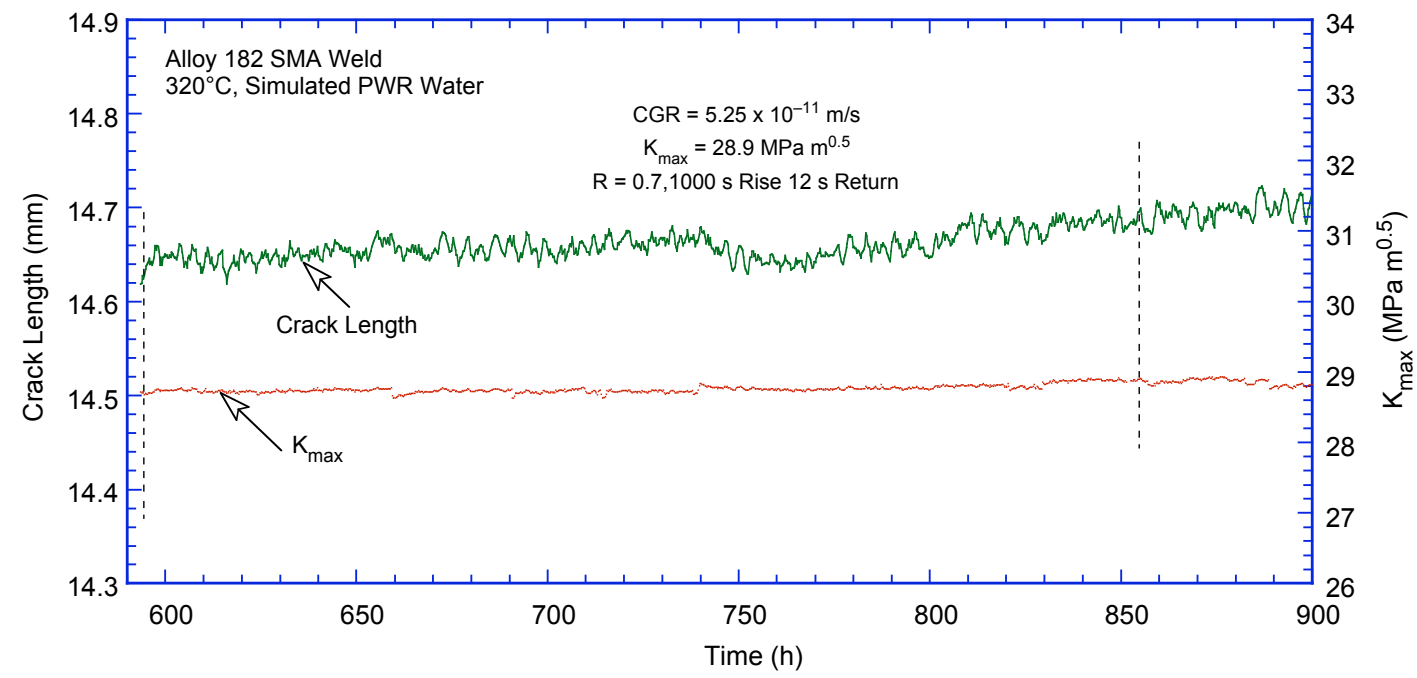

(d)

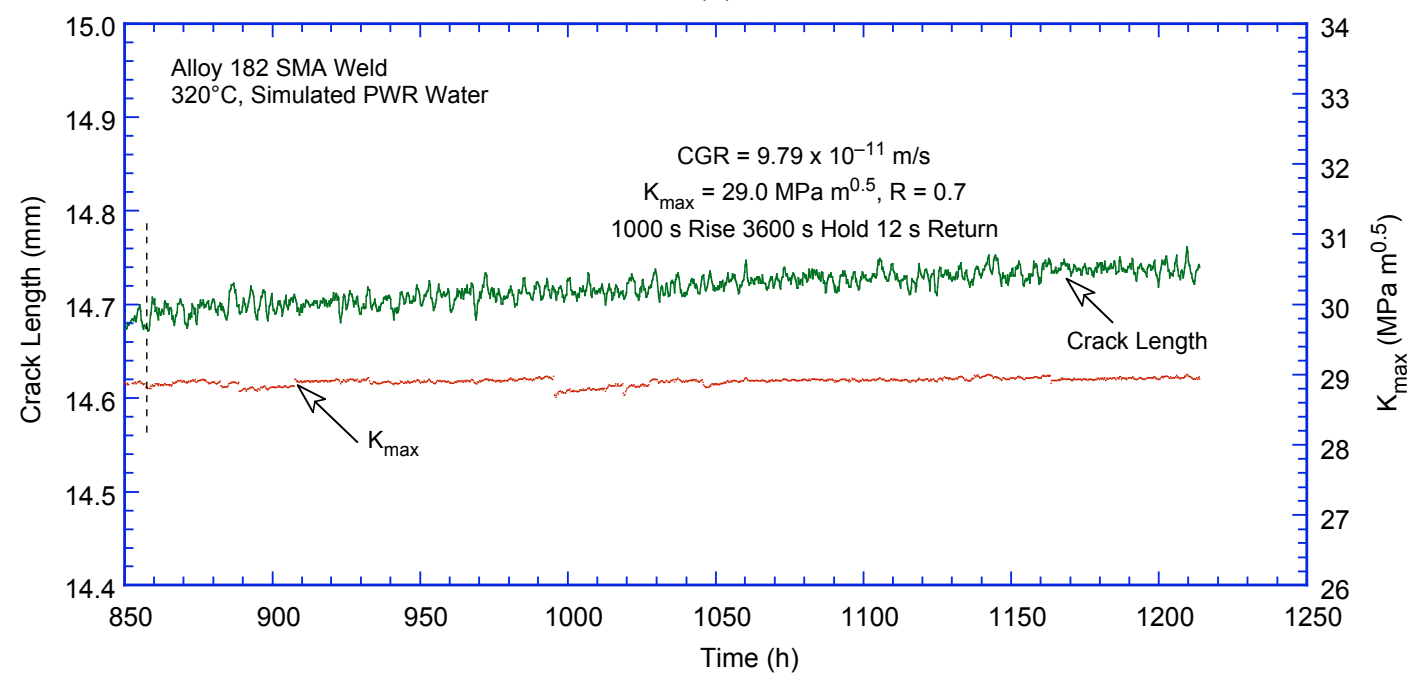

(e)

Figure 27. (Contd.)

After the test, the specimen was fractured in liquid nitrogen. A photomicrograph of the fracture surface of one-half of the specimen is shown in Fig. 28; the crack front is relatively straight. The average crack extension for the transgranular region and the total crack advance were determined by taking $\approx 20$ measurements across the width of the specimen. The measured total crack extension was greater than the value determined from the DC potential measurements, most likely because of several unbroken ligaments in the intergranular region. Thus, using the common assumption that ligaments have little

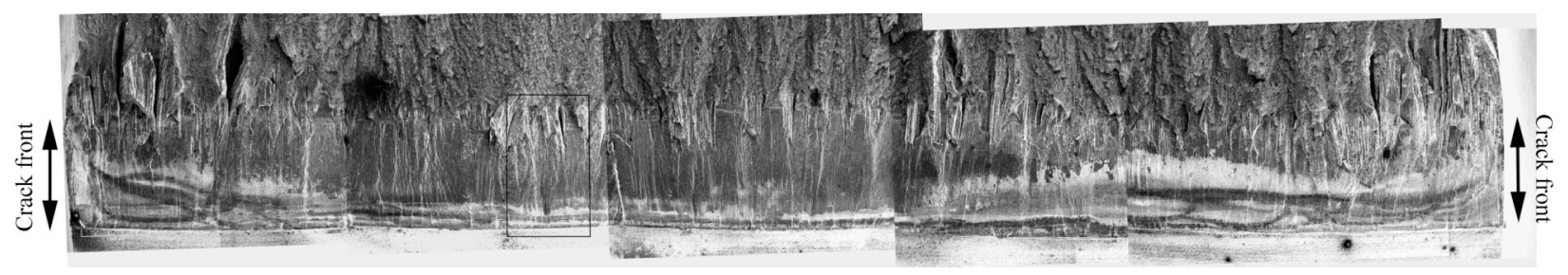

Figure 28. Photomicrograph of the fracture surface of specimen CT31-W01 TS. 


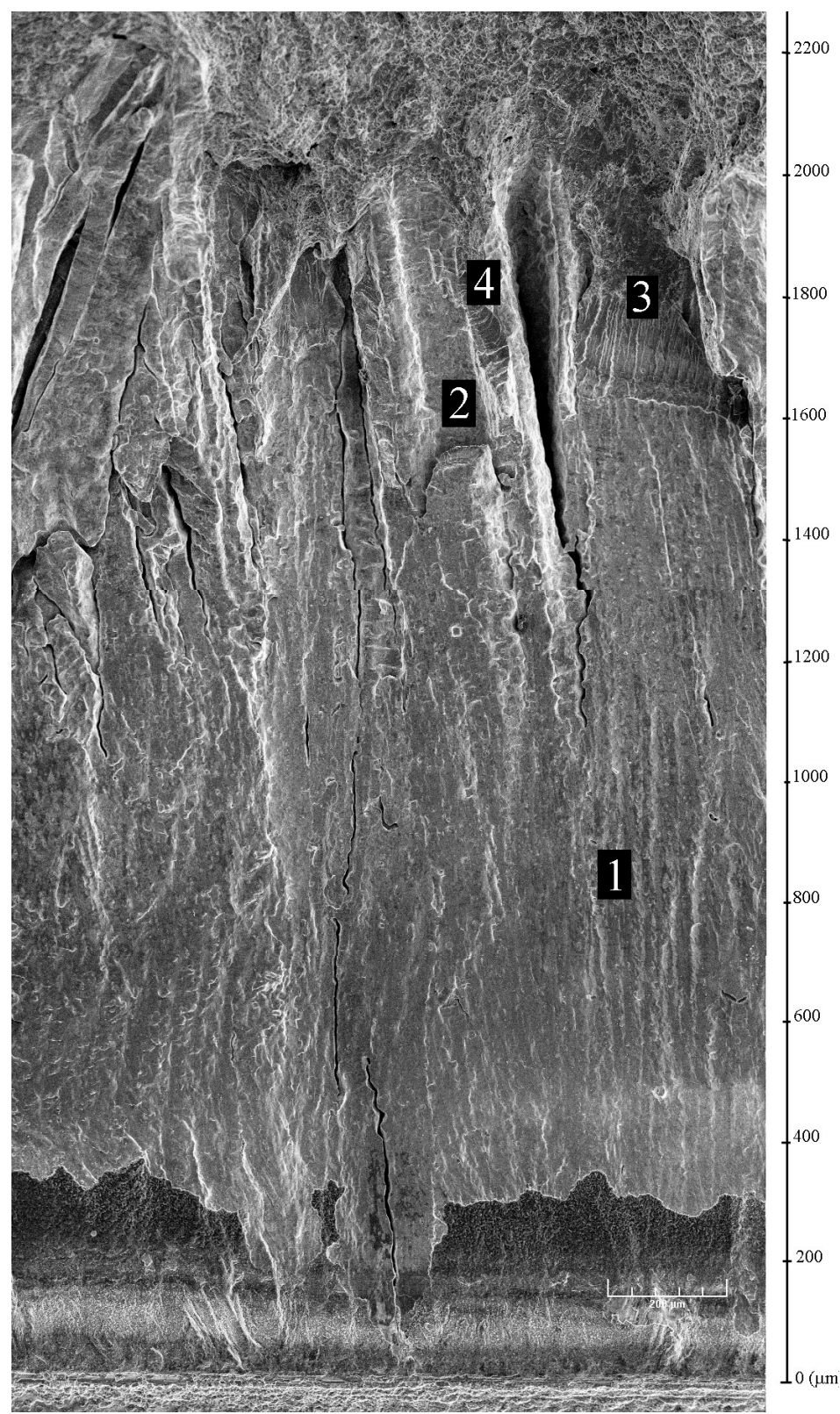

(a)

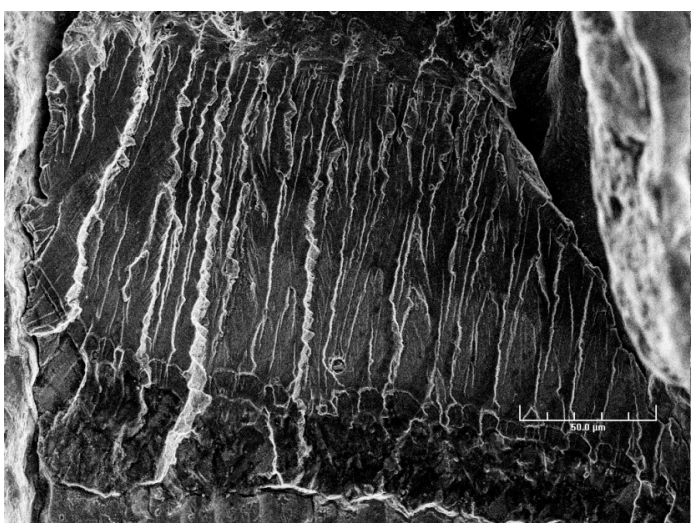

(b)

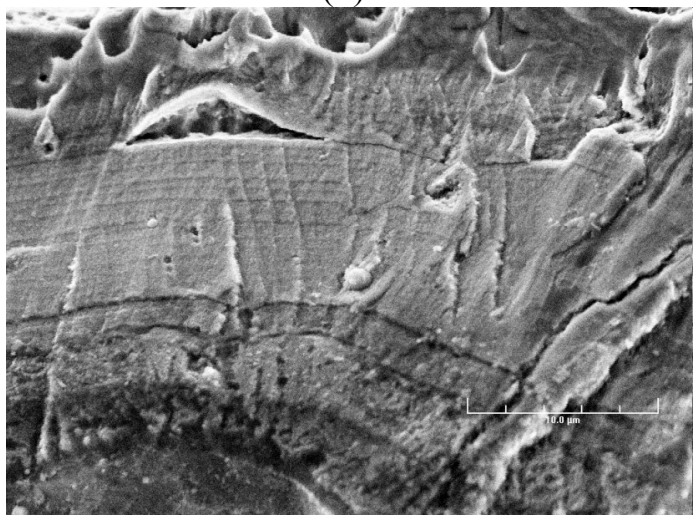

(c)

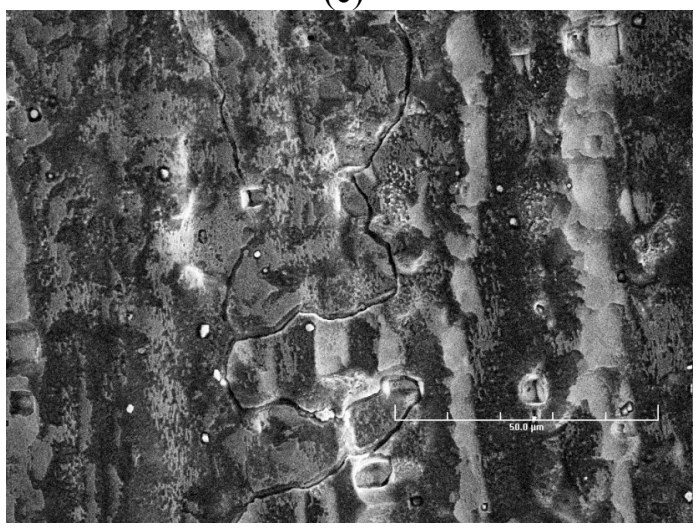

(d)

Figure 29. A high magnification micrograph showing entire crack extension in the center of specimen CT31-W01 TS. Micrographs b, c, and d are from locations 3, 2, and 1 in micrograph.

tendency to develop during cyclic loading the transgranular data was not corrected, and a factor 2.1 was applied to the DC potential data for the intergranular region; the corrected data are given in Table 5.

To correlate different fracture modes with the test parameters (Table 5), the fracture surface of the specimen was also investigated by high magnification SEM. Figure 29 is a collage of micrographs showing the entire crack extension in a region corresponding to the boxed area of Fig. 28. High magnification micrograph of locations designated 3, 2, and 1 in Fig. 29a are shown in Figs. 29b, c, and d, respectively. 
The results indicate that cracking initiated and progressed in a transgranular (TG) mode along the columnar grains and through the dendritic microstructure up to approximately 1300-1400 $\mu \mathrm{m}$. At longer crack extensions, the fracture mode is predominantly intergranular (IG) with significant secondary IG cracks parallel to the direction of crack advance (Fig. 29a). Table 5 indicates that the change to an IG fracture mode occurred during test period 5 when the rise time was increased from 10 to $100 \mathrm{~s}$. Nevertheless, secondary IG cracks apparently are observed quite early during the test (Figs. 29a and d), but, as shown later in this section, evidence suggests that the secondary IG cracking most likely occurred during the high rise-time testing and extended back into the already cracked region. Figure 29c (location "2" in Fig. 29a) is a high magnification micrograph from the area corresponding to the high rise time testing, and shows the highly deformed facet of an IG crack. Further, close to the end of the crack front, Fig. 29b (location "3" in Fig. 29a) shows a TG stepped fracture surface.

The transition from TG to IG fracture is shown in Fig. 30a. The top-center brighter area of the figure shows IG cracks with the dendrites oriented perpendicular to the direction of crack advance, whereas the adjacent grain with the dendrites oriented parallel to the direction of crack advance shows TG fracture. The existing CGR data for Ni-alloy welds indicate that in PWR environments, the growth rates parallel to the columnar grain structure (TS orientation) are generally a factor of two greater than those perpendicular to the columnar grain structure (TL orientation). This conclusion may not be true in all cases. The onset of IG cracking seems to have occurred sooner for the perpendicular grains.

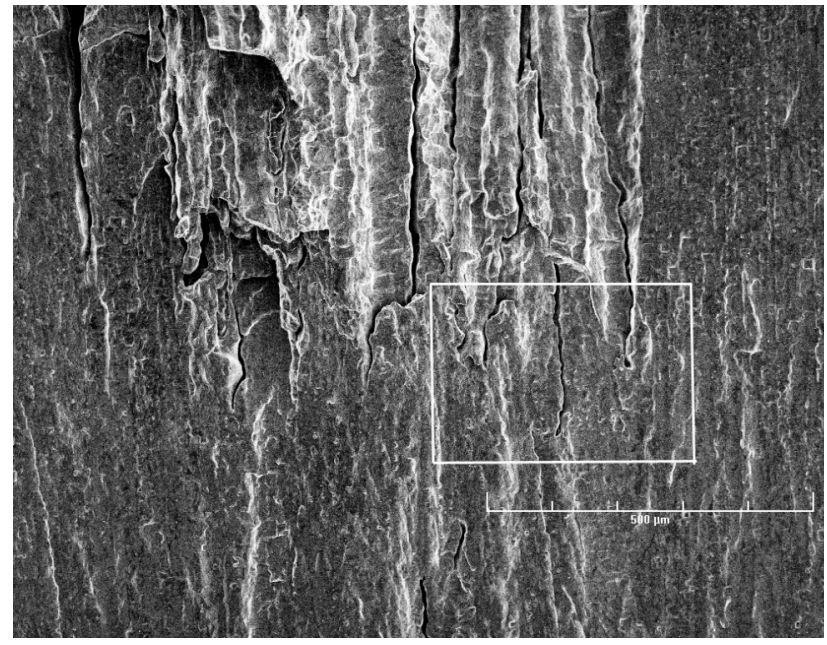

(a)

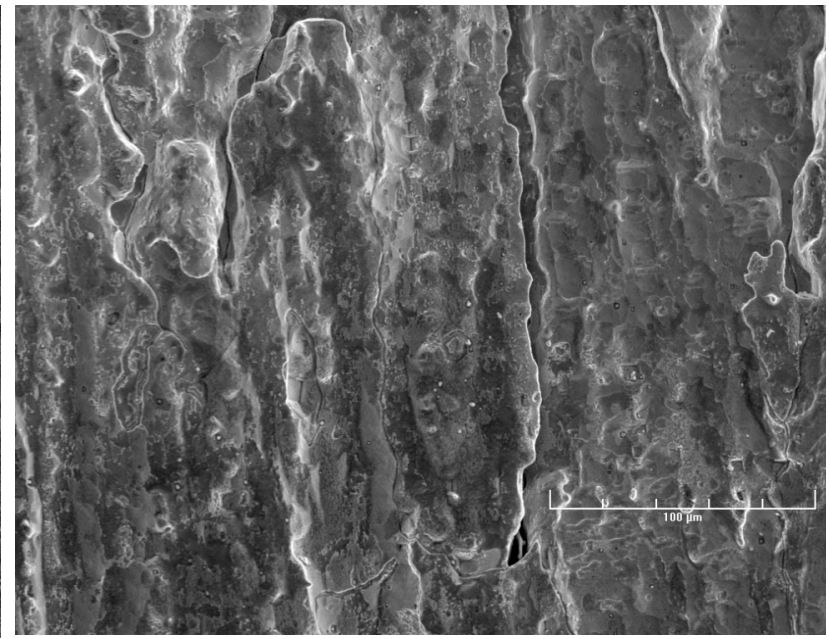

(b)

Figure 30. (a) Transition from TG to IG fracture and (b) higher magnification micrograph of the boxed area showing the tip of a few secondary cracks. Crack extension from bottom to top of the figure.

Another significant observation concerns the apparent formation of secondary IG cracks quite early during the test. A few examples are shown in the boxed area of Fig. 30a, and at higher magnification in Fig. 30b. The cracks seem to blunt in the TG region, suggesting that they had actually originated in the IG region and propagated back into the TG region. This behavior is substantiated further by additional micrographs in Fig. 31.

Figure 31a identifies an area in the TG region where IG cracks were observed (boxed area). A high magnification micrograph of the region is shown in Fig. 31b, where the two most prominent cracks are designated " 1 " and " 2 ". The two cracks appear to shrink as they advance in the TG region; furthermore, the tips appear blunt, as shown in Figs. 31c and d. Such observations lend further support to the 


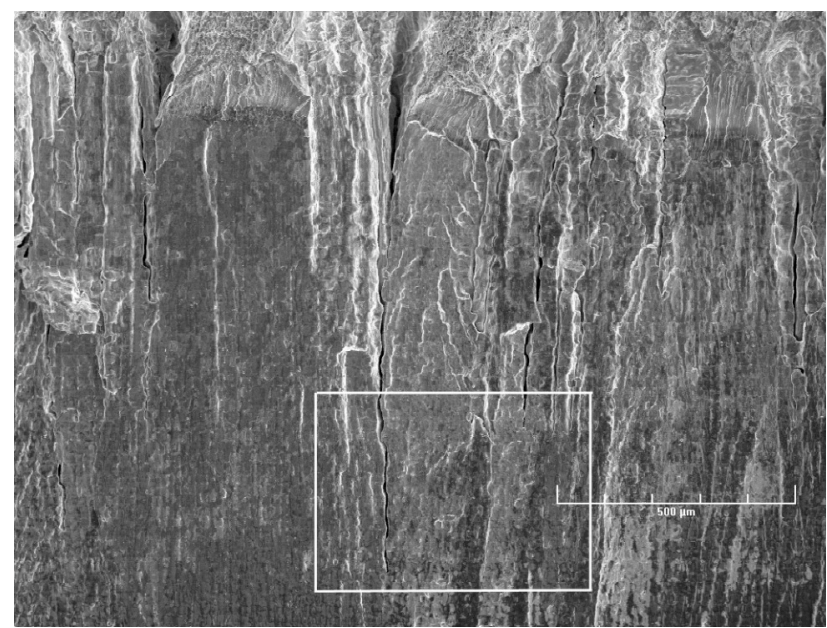

(a)

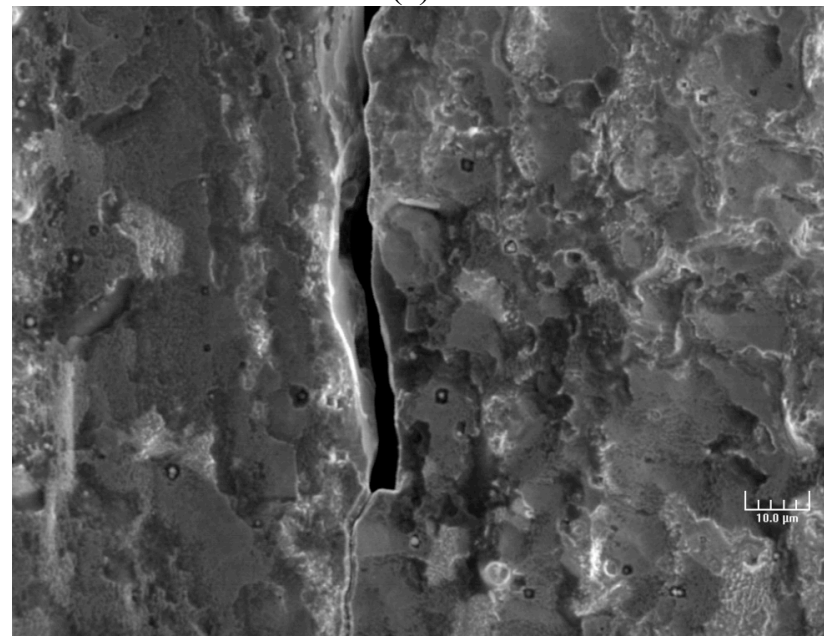

(c)

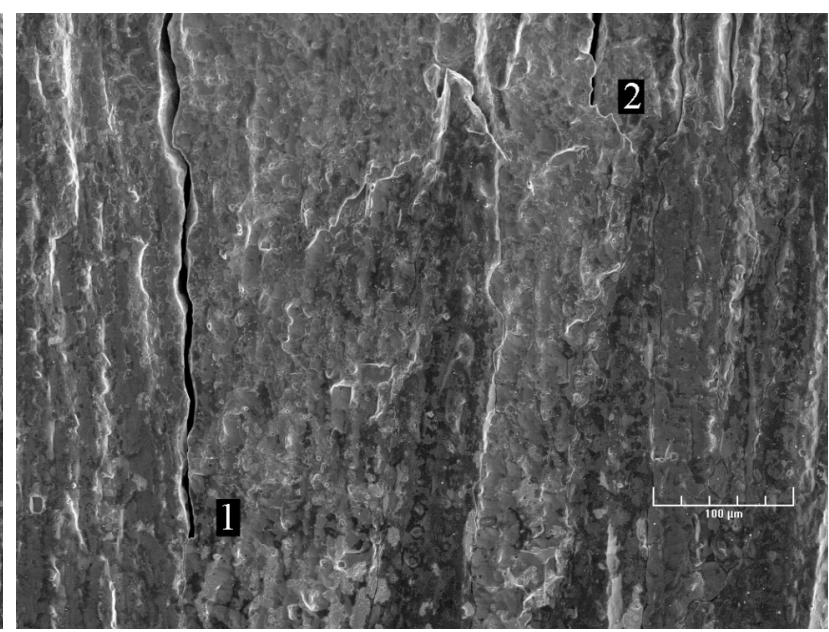

(b)

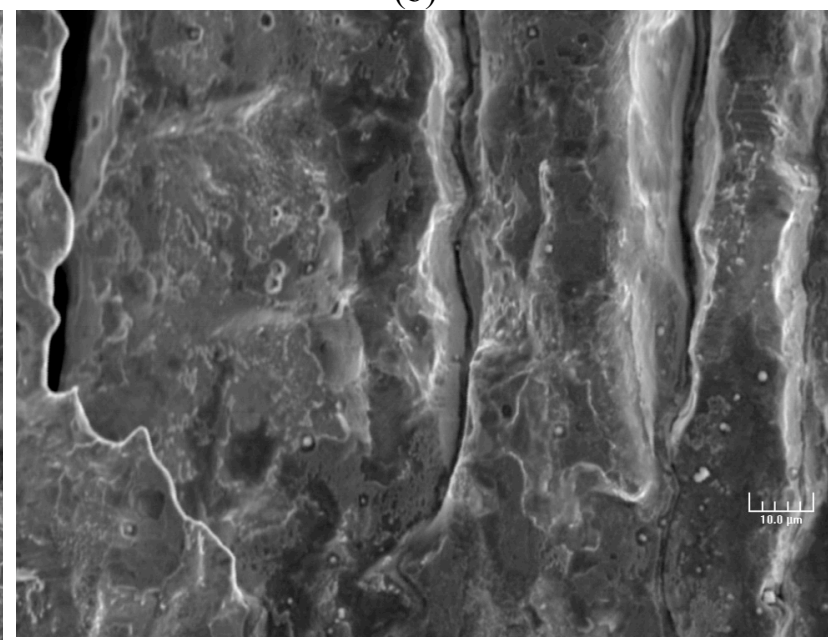

(d)

Figure 31. (a) Mixed TG and IG fracture modes, (b) high magnification micrograph of the boxed area, and (c, d) micrographs showing the crack tips at locations "1" and "2" in micrograph b. Crack extension from bottom to top of the figure.

hypothesis that the secondary IG cracks most likely originated in the IG region and propagated opposite to the direction of crack advance into the TG region.

The next two sets of micrographs focus on the region obtained near the end of the test during periods with a hold time and/or a high rise time. As mentioned earlier the crack extension measured after the test was $\approx 35 \%$ greater than that determined by the DC potential measurements. The present results indicate that the crack front might have advanced in a nonuniform manner, faster along some grain orientations, leaving behind more-resistant, unbroken ligaments. In turn these ligaments would cause the DC potential technique to underestimate the crack length. The first set of micrographs, Figs. 32a and c, show two examples where ductile fracture is adjacent to IG cracking. The high magnification micrographs (Figs. 32b, d) were obtained at the positions indicated by arrows in Figs. 32a and c. It thus appears very likely that some IG crack fronts propagated independently of each other, and the unbroken ligament ruptured when the specimen was fractured in air. 
By contrast, the second set of micrographs, Fig. 33, documents cases of various TG fracture morphologies observed in the last test region. These micrographs show stepped TG (Figs. 33a, b) and quasi-cleavage with cleavage steps and crack arrest markings (Figs. 33c, d). These cases of TG in a test condition favoring IG are probably similar to those described in Fig. 32, i.e., grains of unfavorable orientation for crack advance situated between two faster propagating regions. It can thus be envisaged that high local stresses combined with the effect of environment caused these grains to crack in a TG mode.

In summary, the examination of the fracture surface of the CT31-W01 TS specimen revealed that the fracture mode correlates well with the testing condition. Specifically, high rise times or long hold periods favor IGSCC. Also, IG cracking apparently advanced more readily along some grain orientations than others, resulting in a crack front with occasional unbroken ligaments and few regions of TG cracking.

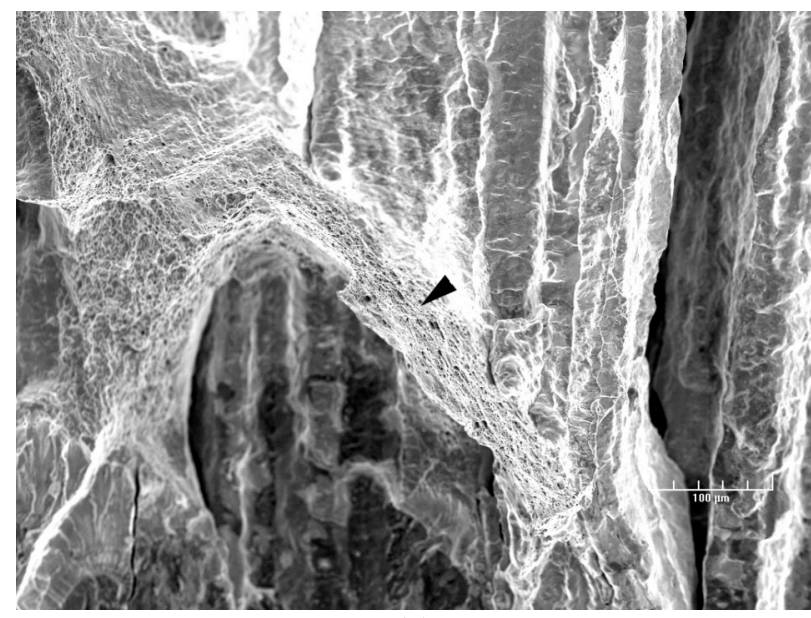

(a)

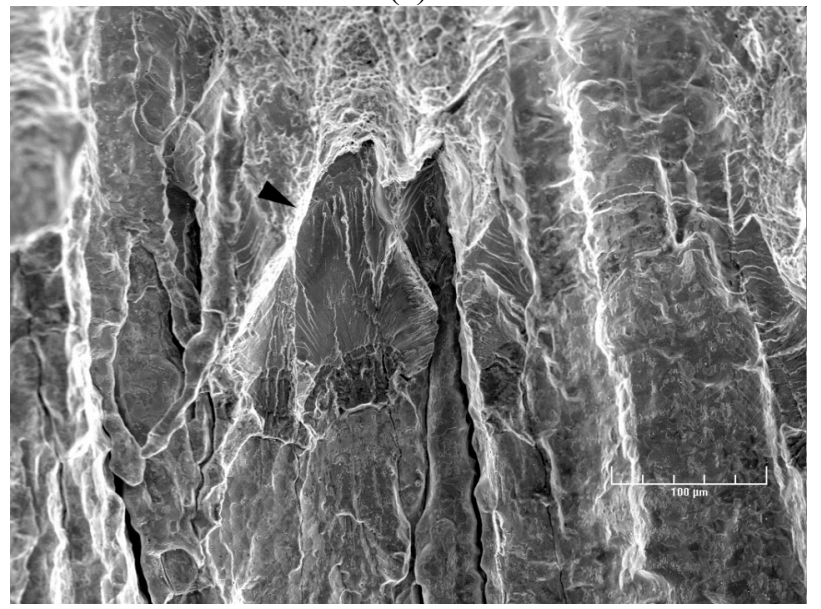

(c)

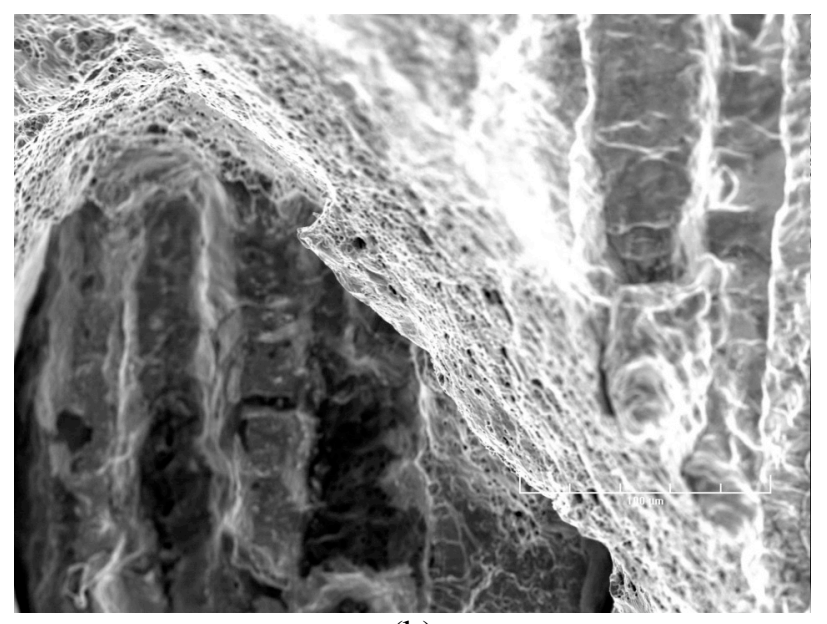

(b)

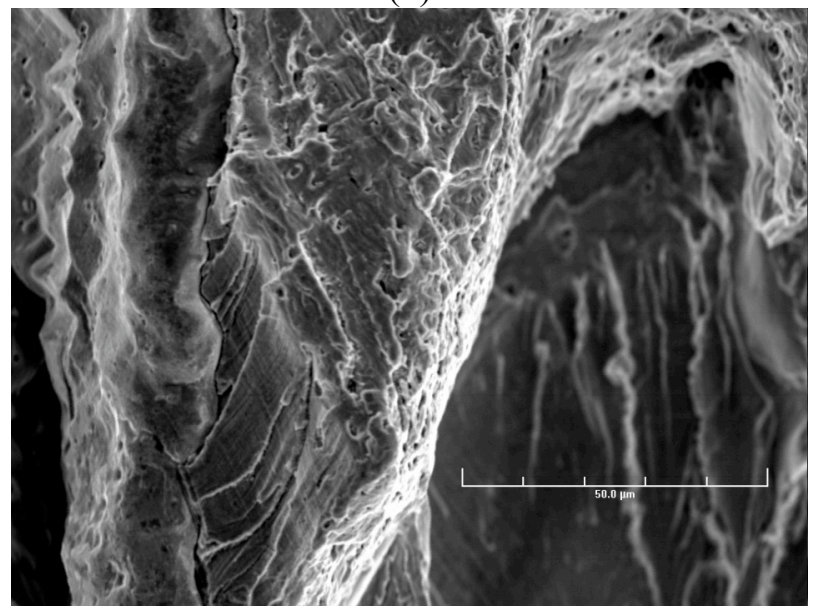

(d)

Figure 32. (a, c) Photomicrographs detailing the fracture in a region during test periods with a hold time and/or a high rise time and (b, d) high magnification micrographs of positions indicated by arrows. Crack extension from bottom to top of the figure. 


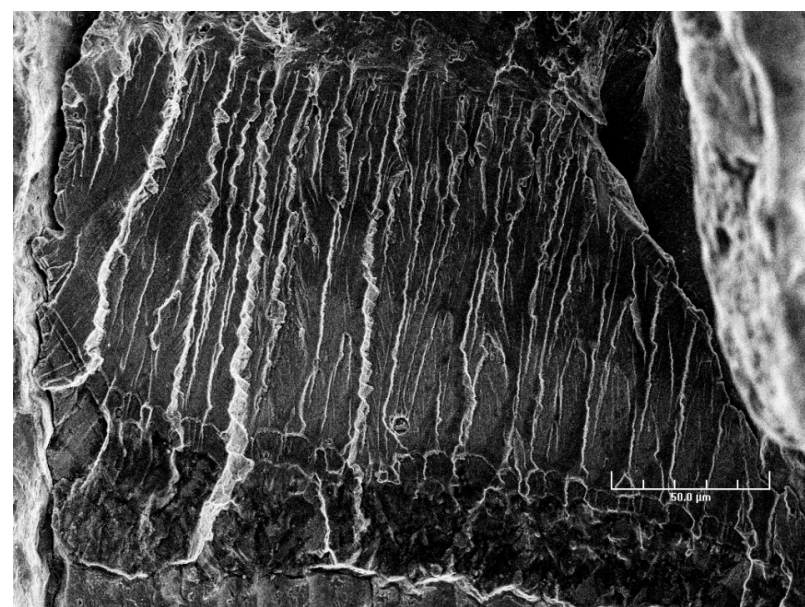

(a)

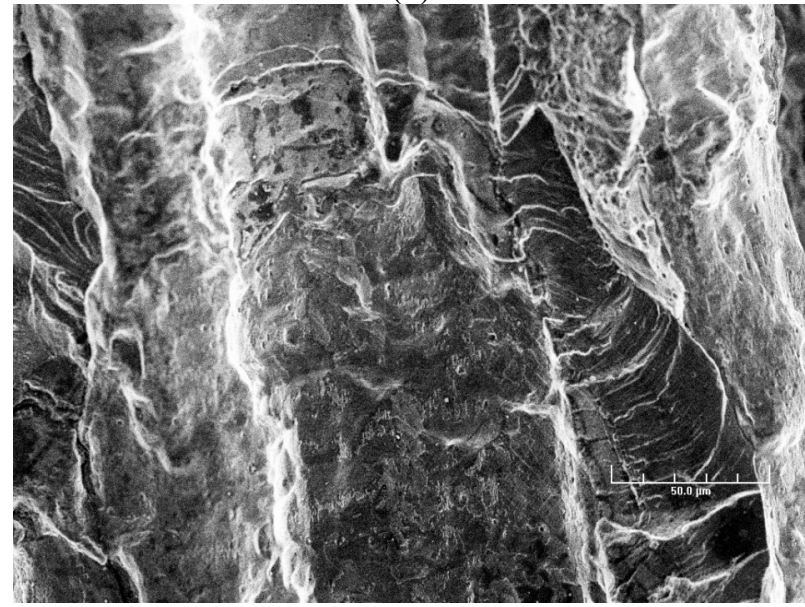

(c)

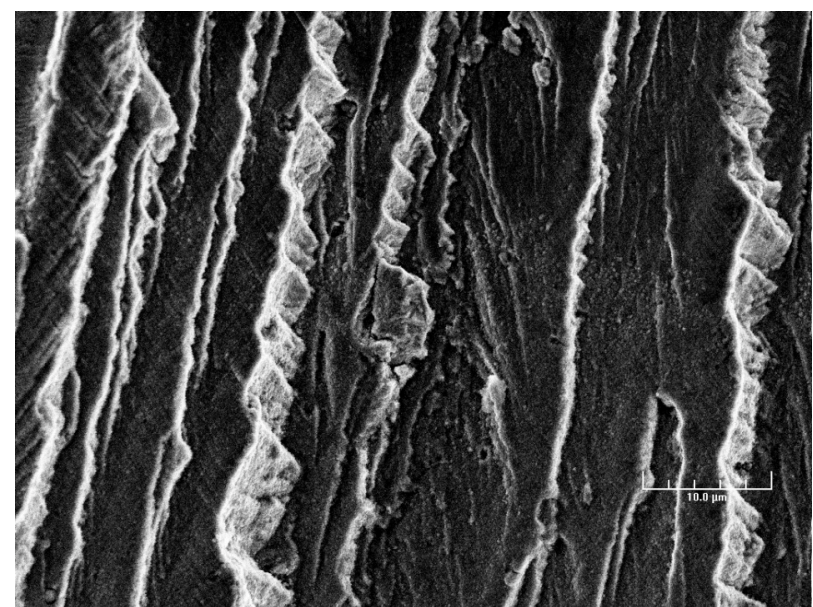

(b)

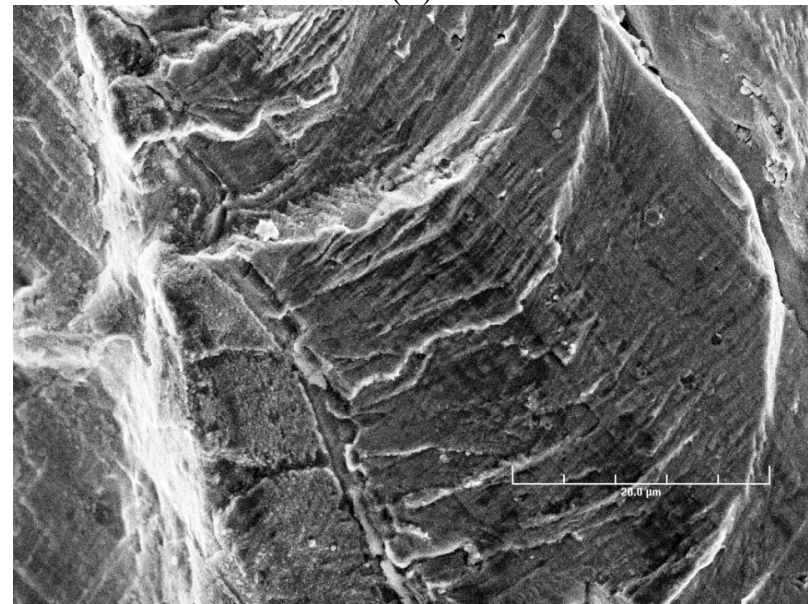

(d)

Figure 33. (a, c) Photomicrographs detailing the fracture in a region during test periods with a hold time and/or a high rise time, and (b, d) high magnification micrographs.

\subsubsection{Crack Growth Data for Double-J Weld Specimen CT31-W02 TS}

A second CGR test was conducted on a double- $\mathrm{J}$ weld specimen in the PWR environment at $320^{\circ} \mathrm{C}$ to verify the earlier results. The test was started with the water system operating in the once-through mode at a flow rate of $\approx 10 \mathrm{cc} / \mathrm{min}$. The system was operated for about a week for the environmental conditions to stabilize. The specimen was fatigue precracked at $\mathrm{R}=0.3$, initial $\mathrm{K}_{\max }=23 \mathrm{MPa} \mathrm{m}^{1 / 2}$, triangular waveform, and $0.5 \mathrm{~Hz}$ frequency. Under these conditions, crack growth was relatively fast, the crack extended by $\approx 12.5 \mathrm{~mm}$ in $\approx 14 \mathrm{~h}$, and $\mathrm{K}_{\text {max }}$ increased from $\approx 23$ to $43 \mathrm{MPa} \mathrm{m}^{0.5}$, which is higher than intended. To emerge from the plastic zone associated with the high $\mathrm{K}_{\max }$, the specimen was cycled at a $\mathrm{K}_{\max }$ of $\approx 29 \mathrm{MPa} \mathrm{m}^{0.5}$ using a saw-tooth waveform with a $12-\mathrm{s}$ rise time. The sample was then set at constant load and $\mathrm{K}_{\max }$ of $30.5-49.5 \mathrm{MPa} \mathrm{m}^{1 / 2}$. The experimental conditions and results for the test are given in Table 6; the changes in crack length and $\mathrm{K}_{\max }$ with time are shown in Fig. 34. 
Table 6. Crack growth data for specimen CT31-W02 TS of Alloy 182 SMA weld in PWR water a $320^{\circ} \mathrm{C}$.

\begin{tabular}{|c|c|c|c|c|c|c|c|c|c|c|c|c|}
\hline $\begin{array}{c}\text { Test } \\
\text { Period }\end{array}$ & $\begin{array}{c}\text { Test } \\
\text { Time, } \\
\mathrm{h}\end{array}$ & $\begin{array}{c}\mathrm{ECPb} \\
\text { (SHE) } \\
\mathrm{mV}\end{array}$ & $\begin{array}{c}\mathrm{O}_{2} \\
\text { Conc., } \\
\text { ppb }\end{array}$ & $\begin{array}{c}\text { Load } \\
\text { Ratio } \\
\text { R } \\
\end{array}$ & $\begin{array}{c}\text { Rise } \\
\text { Time, } \\
\mathrm{s}\end{array}$ & $\begin{array}{c}\text { Down } \\
\text { Time, } \\
\mathrm{s}\end{array}$ & $\begin{array}{c}\text { Hold } \\
\text { Time, } \\
\mathrm{s}\end{array}$ & $\begin{array}{c}\mathrm{K}_{\max }, \\
\mathrm{MPa} \cdot \mathrm{m}^{1 / 2}\end{array}$ & $\begin{array}{c}\Delta \mathrm{K}, \\
\mathrm{MPa} \cdot \mathrm{m}^{1 / 2}\end{array}$ & $\begin{array}{c}\mathrm{CGR}_{\text {env }} \\
\mathrm{m} / \mathrm{s}\end{array}$ & $\begin{array}{c}\text { Estimated } \\
\mathrm{CGR}_{\text {air }}, \\
\mathrm{m} / \mathrm{s}\end{array}$ & $\begin{array}{c}\text { Crack } \\
\text { Length, } \\
\mathrm{mm}\end{array}$ \\
\hline Pre a & 129 & -679 & $<10$ & 0.3 & 1 & 1 & 0 & 23.7 & 16.6 & $1.83 \mathrm{E}-07$ & $3.37 \mathrm{E}-08$ & 13.928 \\
\hline Pre b & 132 & -679 & $<10$ & 0.3 & 1 & 1 & 0 & 26.4 & 18.5 & $3.10 \mathrm{E}-07$ & $2.62 \mathrm{E}-08$ & 16.026 \\
\hline Pre c & 136 & -679 & $<10$ & 0.3 & 1 & 1 & 0 & 29.7 & 20.8 & $4.55 \mathrm{E}-07$ & $4.24 \mathrm{E}-08$ & 18.356 \\
\hline Pre d & 138 & -679 & $<10$ & 0.3 & 1 & 1 & 0 & 34.9 & 24.4 & $6.10 \mathrm{E}-07$ & $8.24 \mathrm{E}-08$ & 21.470 \\
\hline Pre e & 141 & -679 & $<10$ & 0.3 & 1 & 1 & 0 & 43.3 & 30.3 & $7.48 \mathrm{E}-07$ & $1.99 \mathrm{E}-07$ & 25.274 \\
\hline 1 & 339 & -681 & $<10$ & 0.5 & 12 & 2 & 0 & 28.8 & 14.4 & $2.08 \mathrm{E}-09$ & $1.36 \mathrm{E}-09$ & 25.872 \\
\hline 2 & 359 & -672 & $<10$ & 0.5 & 12 & 2 & 0 & 29.9 & 15.0 & $6.91 \mathrm{E}-09$ & $1.58 \mathrm{E}-09$ & 26.417 \\
\hline 3 & 599 & - & $<10$ & 1.0 & - & - & - & 30.5 & - & $4.22 \mathrm{E}-10$ & - & 26.708 \\
\hline 4 & 812 & - & $<10$ & 1.0 & - & - & - & 36.4 & - & $3.94 \mathrm{E}-10$ & - & 27.097 \\
\hline 5 & 1157 & - & $<10$ & 1.0 & - & - & - & 49.5 & - & $7.29 \mathrm{E}-10$ & - & 28.185 \\
\hline
\end{tabular}

${ }^{\mathrm{a}}$ Simulated PWR water with $2 \mathrm{ppm} \mathrm{Li}, 1100 \mathrm{ppm} \mathrm{B}$, and $2 \mathrm{ppm}$ dissolved hydrogen $(\approx 23 \mathrm{cc} / \mathrm{kg})$.

${ }^{b}$ Represents values in the effluent; ECP values are for Alloy 600 electrode, conductivity was $\approx 22 \mu \mathrm{S} / \mathrm{cm}$ in the effluent.

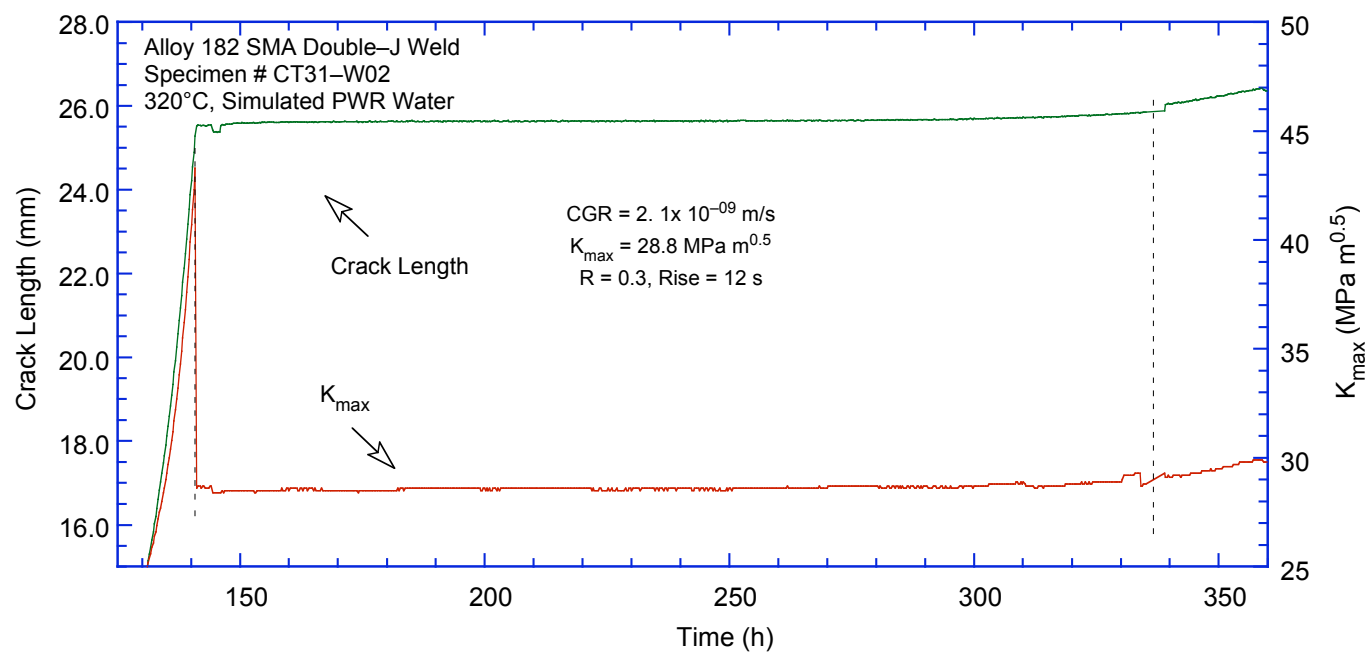

(a)

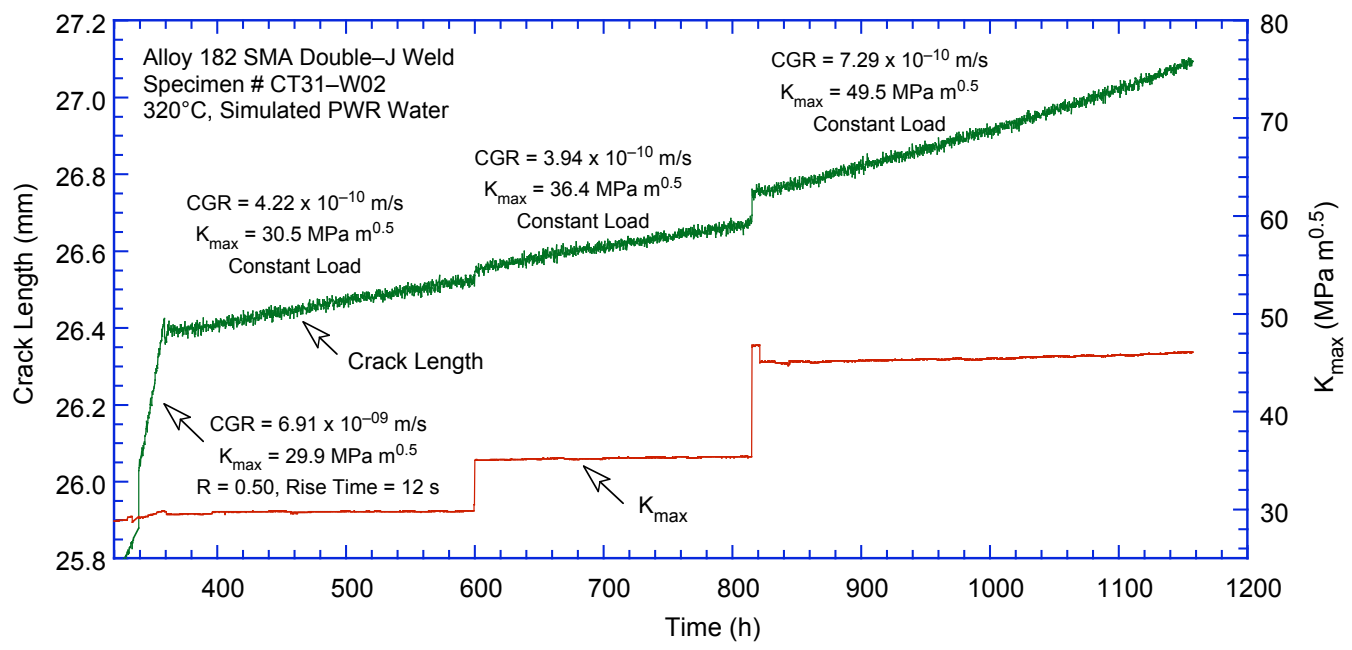

(b)

Figure 34. Crack length vs. time for Alloy 182 SMA double-J weld specimen CT31-W02 TS in simulated PWR environment at $320^{\circ} \mathrm{C}$ during test periods (a) 1-3 and (b) 4-5. 
Figure 35 shows the fracture surface of specimen CT31-W02 TS (approximately 1/4 of the width was cut off prior to breaking the sample apart, to enable the examination of the cross section). The fracture surface was exclusively TG until the constant load testing, at which point the fracture mode switched to IG. The IG fracture area is bound by the green and red lines in Fig. 35. The red line also shows the final crack front. The testing procedure resulted in a relatively straight crack front.

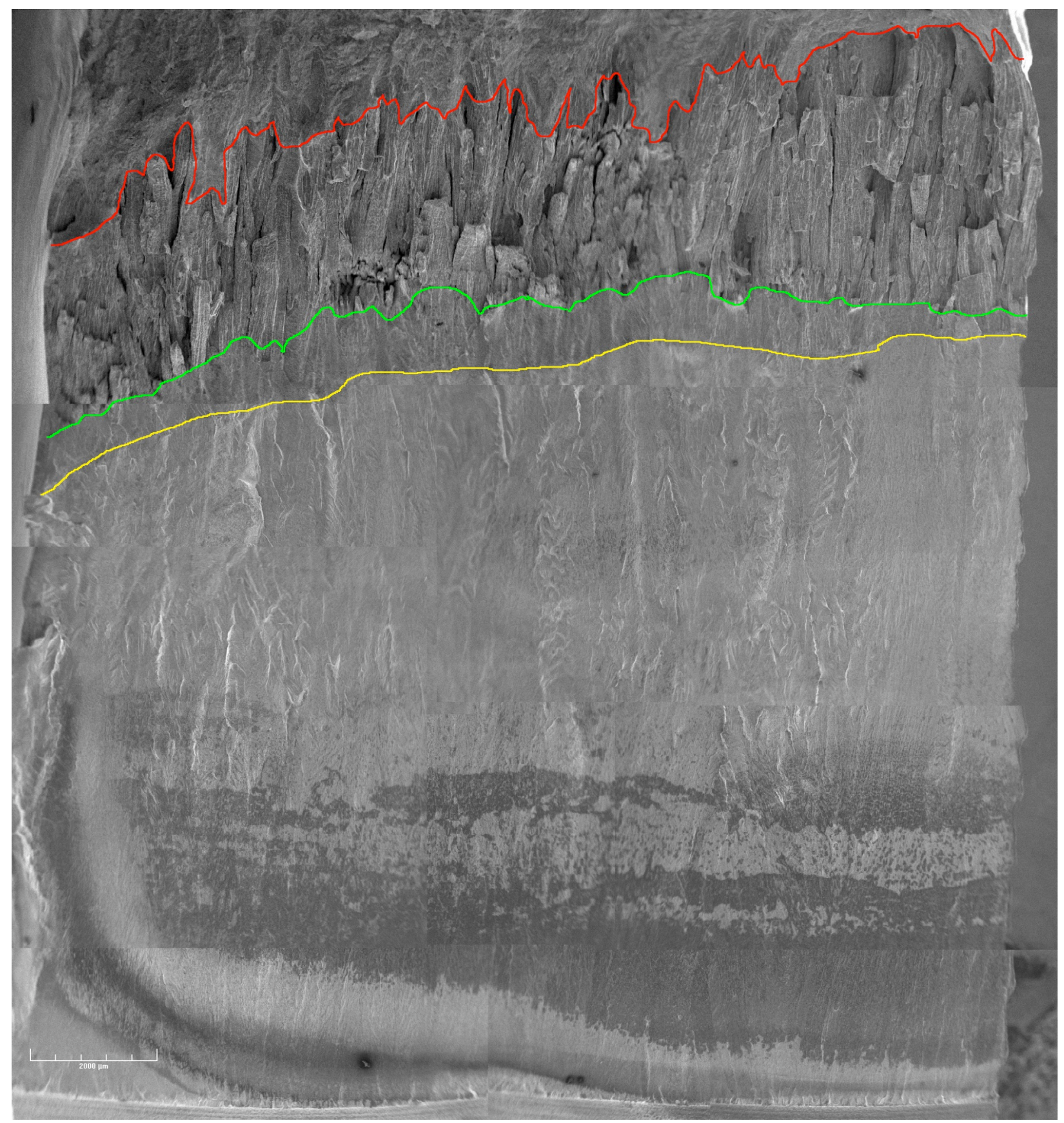

Figure 35. Fracture surface of specimen CT31-W02 TS. Crack extension from bottom to top of the figure.

Figure 36 shows the cross section of CT31-W02 TS. Near the end of the test (boxed area in Fig. 36 a) the crack line becomes discontinuous. This condition, along with possible cases where the two surfaces of the crack touch each other, partially causes the DC potential measurements to underestimate 
the full extent of the crack. However, unlike the previous example, the precrack region in this case is TG; thus it is expected to be measured accurately by the DC potential method. For this test, only CGR data resulting from the IG periods were corrected. As such, based on Fig. 35 the IG region was measured to be $3.31 \mathrm{~mm}$, a factor of 2.6 larger than the value obtained from DC potential measurements (the data in Table 6 have been corrected to be consistent with the fractographic results).

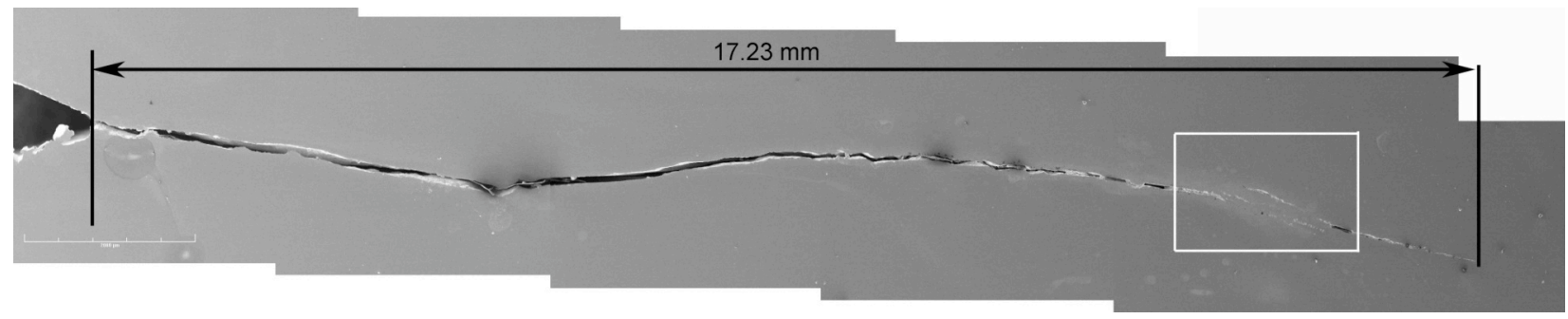

a

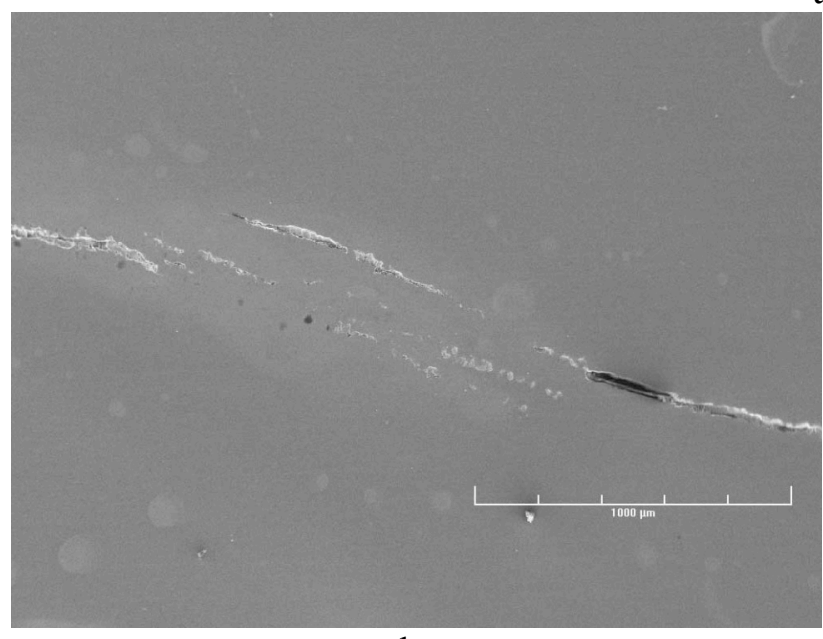

$\mathrm{b}$

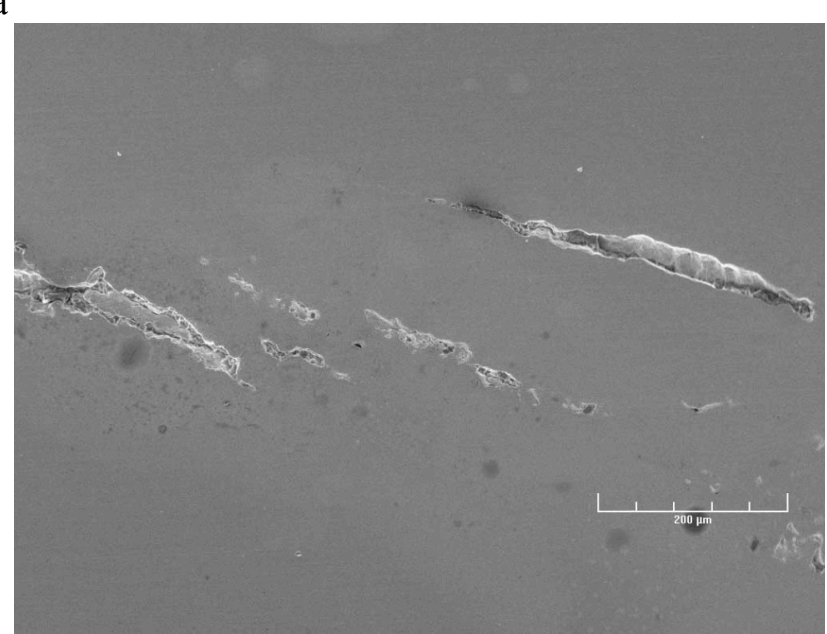

$\mathrm{c}$

Figure 36. Micrographs showing the cross section of CT31-W02 TS.

\subsubsection{Crack Growth Data for Deep-Groove Weld Specimen CT933-TS}

This test was started in PWR water at $320^{\circ} \mathrm{C}$ with the system operating in once-through mode at a flow rate of $\approx 10 \mathrm{cc} / \mathrm{min}$. The system was operated for about a week for the environmental conditions to stabilize. The specimen was fatigue precracked at $\mathrm{R}=0.3, \mathrm{~K}_{\max }=23 \mathrm{MPa} \mathrm{m}^{1 / 2}$, triangular waveform, and $0.5-\mathrm{Hz}$ frequency. After $\approx 1-\mathrm{mm}$ extension, $\mathrm{R}$ was increased incrementally to 0.7 , and the waveform changed to sawtooth with $300-\mathrm{s}$ rise time with or without a $3600-\mathrm{h}$ hold period to transition to IG cracking. Finally, the test was conducted at constant load $\left(\mathrm{K}_{\max } \approx 30 \mathrm{MPa} \mathrm{m}^{1 / 2}\right)$. The specimen was next subjected to a constant load but higher $\mathrm{K}_{\max }\left(\approx 34 \mathrm{MPa} \mathrm{m}^{1 / 2}\right)$; the applied $\mathrm{K}_{\max }$ was increased by fatigue cycling at $\mathrm{R}=0.5$ and rise time of 30 or $300 \mathrm{~s}$ to increase the crack length from $\approx 14$ to $16 \mathrm{~mm}$. The experimental conditions and results for the test are given in Table 7; the changes in crack length and $\mathrm{K}_{\max }$ with time are shown in Fig. 37. 
Table 7. Crack growth data for specimen CT933-TS of Alloy 182 SMA weld in PWR water ${ }^{\mathrm{a}}$ at $320^{\circ} \mathrm{C}$.

\begin{tabular}{|c|c|c|c|c|c|c|c|c|c|c|c|c|}
\hline $\begin{array}{c}\text { Test } \\
\text { Period }\end{array}$ & $\begin{array}{c}\text { Test } \\
\text { Time, } \\
\mathrm{h}\end{array}$ & $\begin{array}{l}\text { Conduc- } \\
\text { tivity, } \\
\mu \mathrm{S} / \mathrm{cm}\end{array}$ & $\begin{array}{l}\mathrm{DO},{ }^{\mathrm{b}} \\
\mathrm{ppb}\end{array}$ & $\begin{array}{c}\mathrm{R} \\
\text { Load } \\
\text { Ratio } \\
\end{array}$ & $\begin{array}{c}\text { Rise } \\
\text { Time, } \\
\text { s }\end{array}$ & $\begin{array}{c}\text { Down } \\
\text { Time, } \\
\text { s }\end{array}$ & $\begin{array}{c}\text { Hold } \\
\text { Time, } \\
\mathrm{s}\end{array}$ & $\begin{array}{c}\mathrm{K}_{\max }, \\
\mathrm{MPa} \cdot \mathrm{m}^{1 / 2}\end{array}$ & $\begin{array}{c}\Delta \mathrm{K}, \\
\mathrm{MPa} \cdot \mathrm{m}^{1 / 2}\end{array}$ & $\begin{array}{c}\text { CGR, } \\
\mathrm{m} / \mathrm{s}\end{array}$ & $\begin{array}{c}\text { CGR } \\
\text { in Air, } \\
\mathrm{m} / \mathrm{s}\end{array}$ & $\begin{array}{c}\text { Crack } \\
\text { Length, } \\
\mathrm{mm}\end{array}$ \\
\hline Pre a & 30 & 25.0 & $<10$ & 0.3 & 1 & 1 & 0 & 23.18 & 16.23 & $2.07 \mathrm{E}-09$ & $1.54 \mathrm{E}-08$ & 12.609 \\
\hline Pre b & 40 & 25.0 & $<10$ & 0.3 & 10 & 10 & 0 & 23.32 & 16.32 & $5.80 \mathrm{E}-09$ & $1.58 \mathrm{E}-09$ & 12.708 \\
\hline $1 \mathrm{a}$ & 70 & 25.0 & $<10$ & 0.3 & 10 & 10 & 0 & 23.87 & 16.71 & $1.05 \mathrm{E}-08$ & $1.74 \mathrm{E}-09$ & 13.148 \\
\hline $1 b$ & 90 & 25.3 & $<10$ & 0.3 & 10 & 10 & 0 & 24.57 & 17.20 & $1.47 \mathrm{E}-08$ & $1.96 \mathrm{E}-09$ & 13.686 \\
\hline 2 & 142 & 25.3 & $<10$ & 0.6 & 10 & 10 & 0 & 25.29 & 10.11 & $1.88 \mathrm{E}-09$ & $5.29 \mathrm{E}-10$ & 13.889 \\
\hline 3 & 243 & 25.3 & $<10$ & 0.7 & 10 & 10 & 0 & 25.89 & 7.77 & $6.97 \mathrm{E}-10$ & $2.64 \mathrm{E}-10$ & 14.027 \\
\hline 4 & 506 & & $<10$ & 0.7 & 100 & 100 & 0 & 25.71 & 7.71 & $2.43 \mathrm{E}-10$ & $2.57 \mathrm{E}-11$ & 14.234 \\
\hline 5 & 704 & & $<10$ & 0.7 & 300 & 12 & 0 & 28.46 & 8.54 & $1.18 \mathrm{E}-10$ & $1.30 \mathrm{E}-11$ & 14.313 \\
\hline 6 & 964 & & $<10$ & 0.7 & 300 & 12 & 3600 & 28.60 & 8.58 & $1.15 \mathrm{E}-10$ & $1.32 \mathrm{E}-11$ & 14.428 \\
\hline 7 & 1132 & & $<10$ & 1.0 & - & - & - & 28.72 & 0.00 & $1.05 \mathrm{E}-10$ & - & 14.491 \\
\hline 8 & 1373 & & $<10$ & 0.5 & 30 & 4 & 0 & 32.61 & 16.30 & 2.66E-09 & $8.99 \mathrm{E}-10$ & 16.568 \\
\hline 9 & 1467 & & $<10$ & 0.5 & 300 & 4 & 0 & 33.34 & 16.67 & 1.37E-09 & $9.85 \mathrm{E}-11$ & 16.990 \\
\hline 10 & & & $<10$ & 1.0 & - & - & - & 36.88 & 0.00 & $2.53 \mathrm{E}-10$ & - & 17.753 \\
\hline
\end{tabular}

${ }^{\mathrm{a}}$ Simulated PWR water with $2 \mathrm{ppm} \mathrm{Li}, 1100 \mathrm{ppm} \mathrm{B}$, and $2 \mathrm{ppm}$ dissolved hydrogen $(\approx 23 \mathrm{cc} / \mathrm{kg})$.

${ }^{b}$ Represents values in the effluent; ECP was measured at $289^{\circ} \mathrm{C}$.

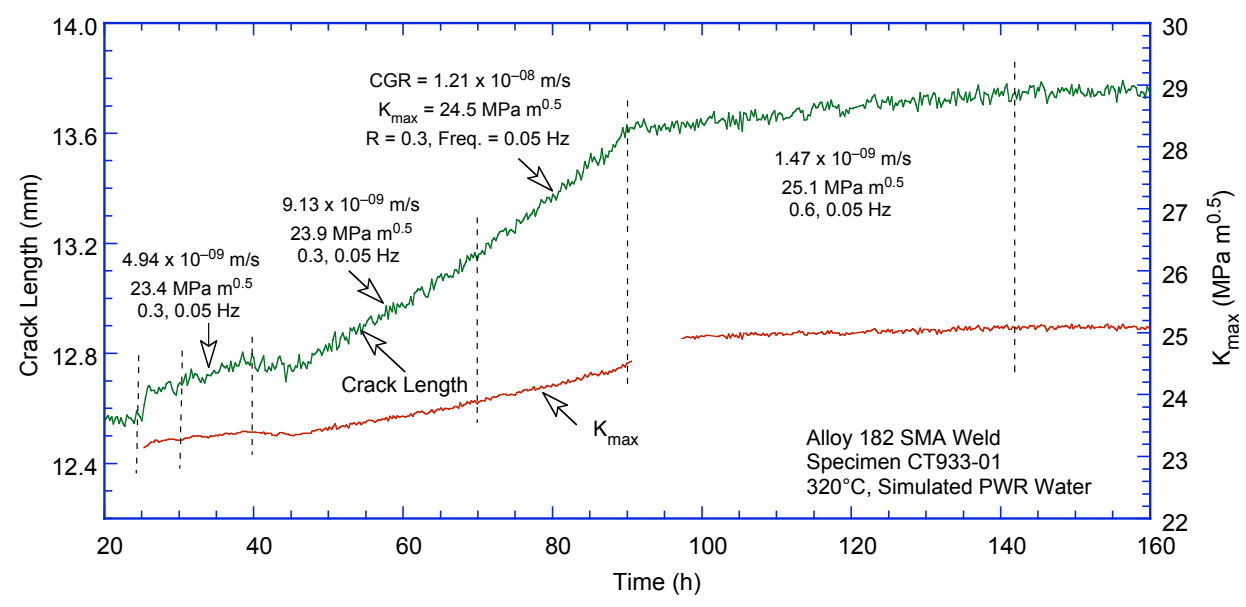

(a)

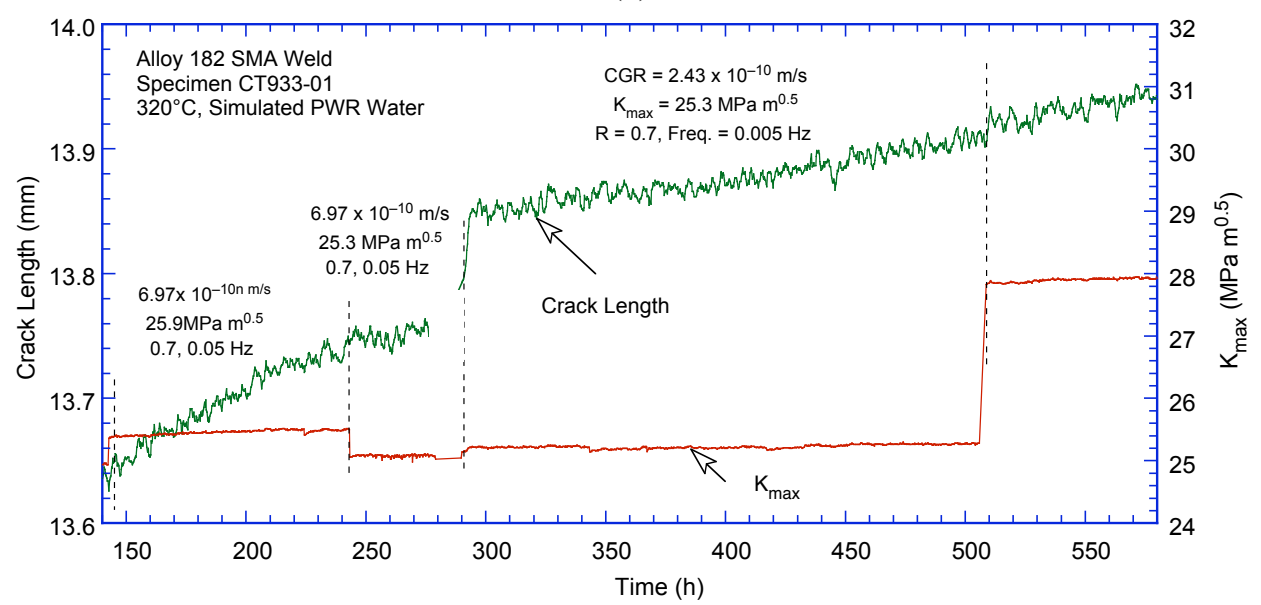

(b)

Figure 37. Crack length vs. time for laboratory-prepared Alloy 182 weld specimen CT933-TS in simulated PWR water at $320^{\circ} \mathrm{C}$ during periods (a) precracking-period 2, (b) 3-4, (c) 5-6, (d) 7-8, and (e) 9-10. 


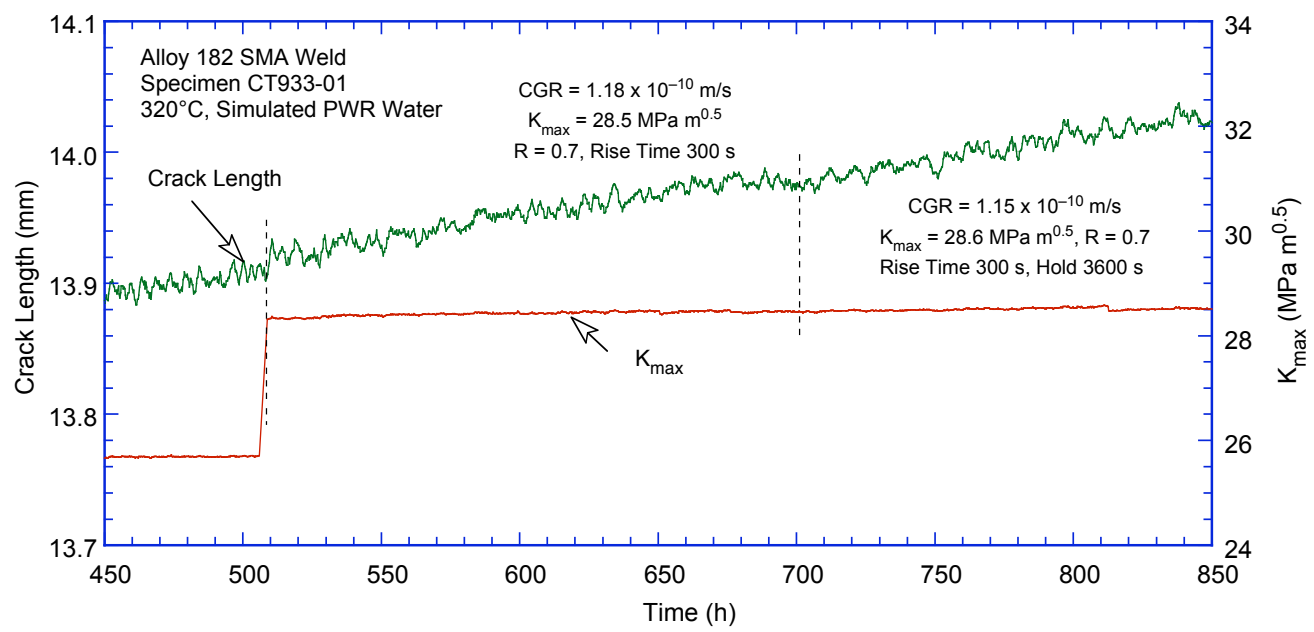

(c)

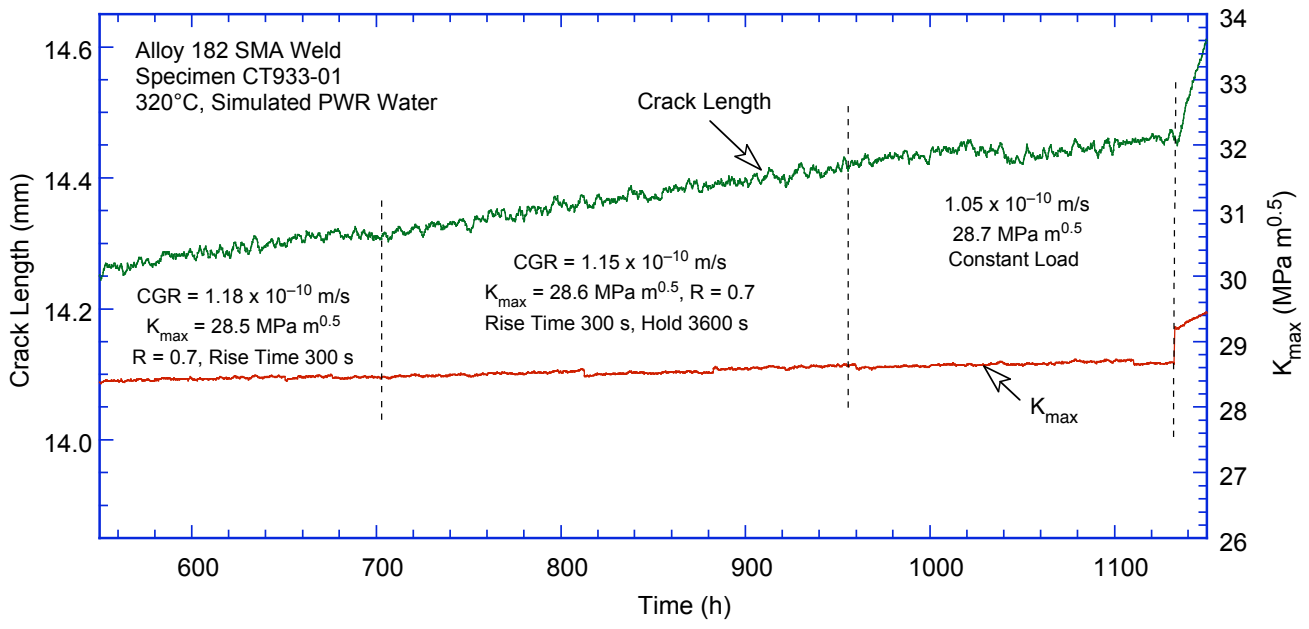

(d)

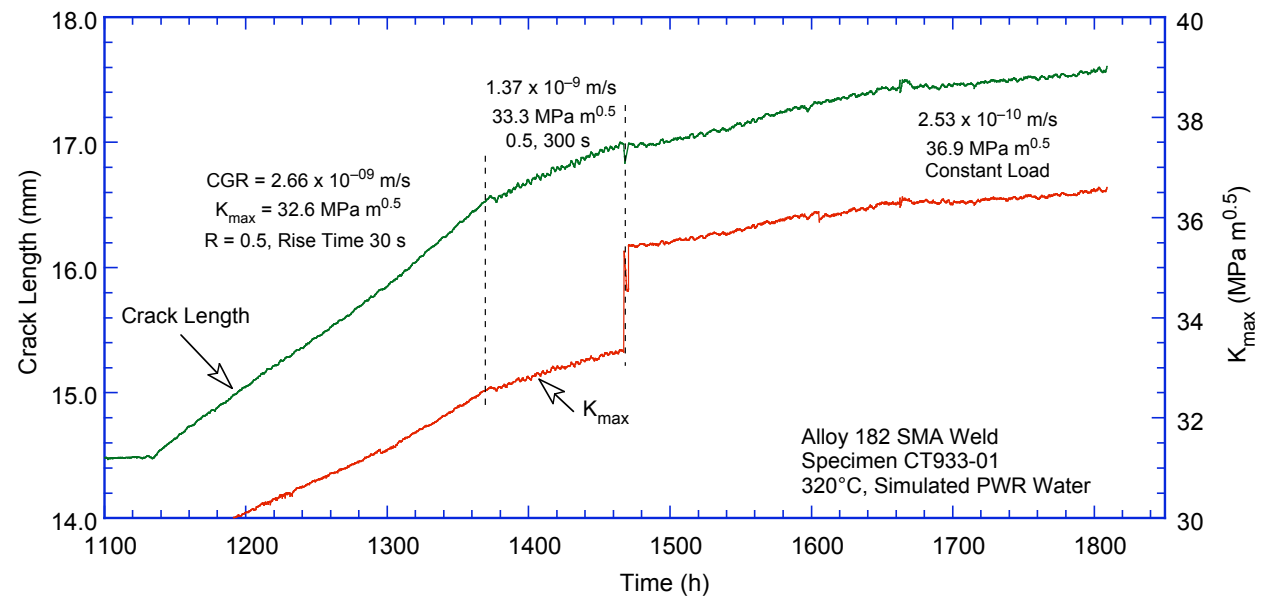

Figure 37. (Contd.)

(e) 
The fractured compact tension specimen CT933-TS was examined by SEM in cross section and on the fracture surface. Figure 38 shows the entire crack length on the cross-section sample. Based on this cross section, the crack length was estimated at approximately $5.05 \mathrm{~mm}$. Also, for this section (close to one side of the sample), the onset of intergranular (IG) fracture was estimated at $2.28 \mathrm{~mm}$.

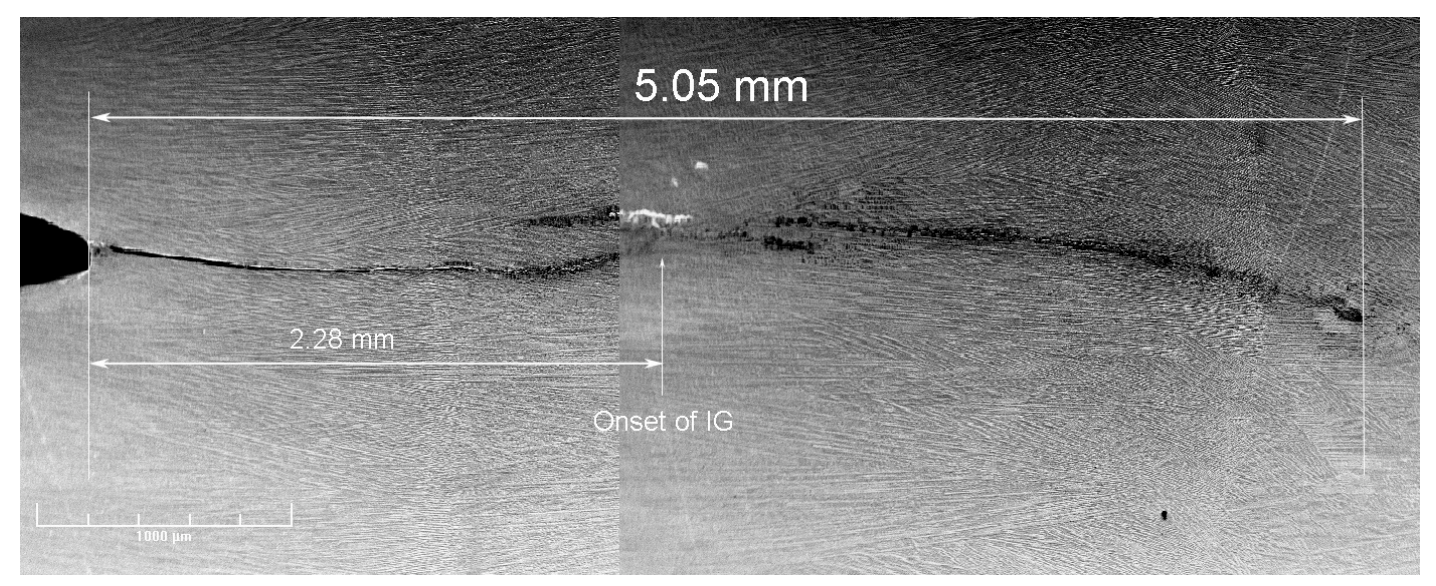

Figure 38. Crack front in cross section of sample CT933-TS.

Figure 39 shows the entire fracture surface of this specimen. Following pre-cracking, the fracture turned into a mainly trangranular (TG) mode, the exception being the center of the sample where the fracture mode is primarily intergranular (IG). Nevertheless, we observe that the testing procedure resulted in a relatively straight crack front. The average crack extension for the transgranular region and the total crack advance were determined by taking $\approx 20$ measurements across the width of the specimen. The measured total crack extension was greater than the value determined from the DC potential measurements. The DC potential data was scaled proportionally: a factor 1.24 was applied to the transgranular data and a factor 1.65 was applied to the DC potential data for the intergranular region; the corrected data are given in Table 7.

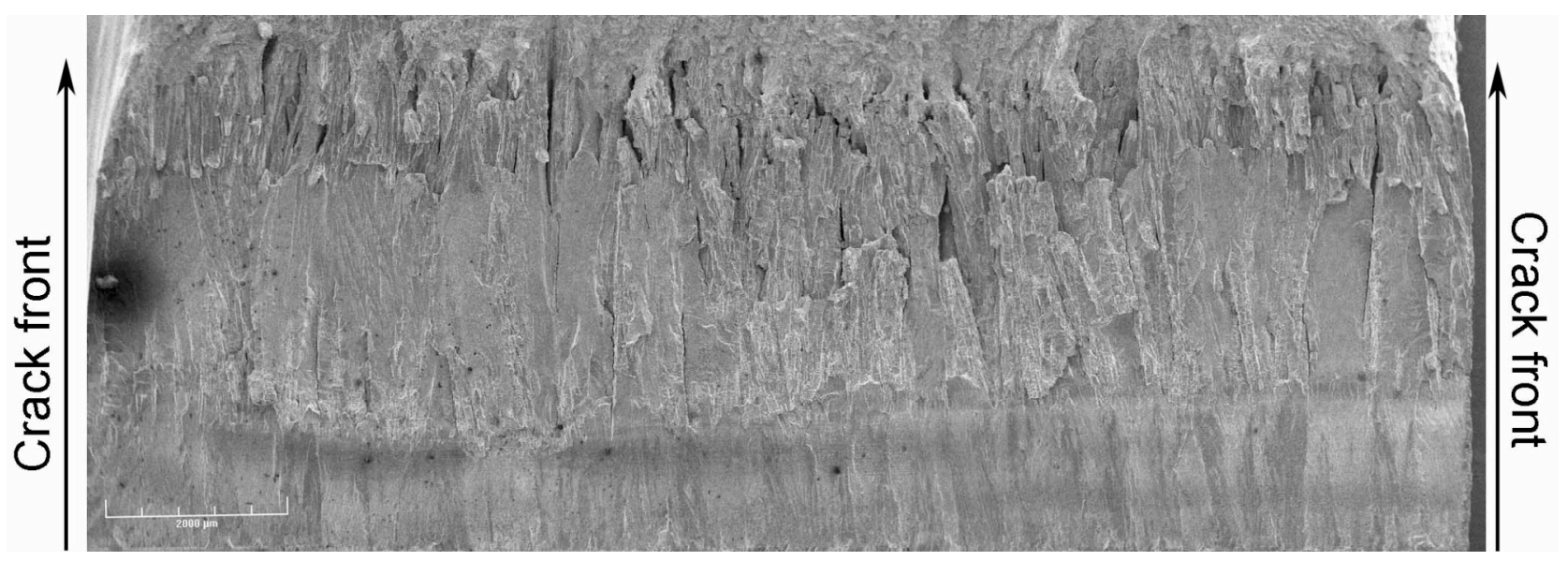

Figure 39. Crack front on fracture surface of sample CT933-TS.

An additional collage from the sample surface was constructed with the purpose of illustrating the fracture modes (Fig. 40). The set of pictures shown in Fig. 40a was taken in the middle of the sample, where the IG cracking mode occurred earlier than close to the sides. Figure 40b shows the co-existence of TG and IG cracking modes in the early stages of the experiment (position 1). Figure 40c illustrates IG 
cracking, typical for the weld microstructure (position 2). Figure 40d shows ductile fracture in the middle of the IG fracture mode (position 3), which was most likely due to an unbroken ligament.

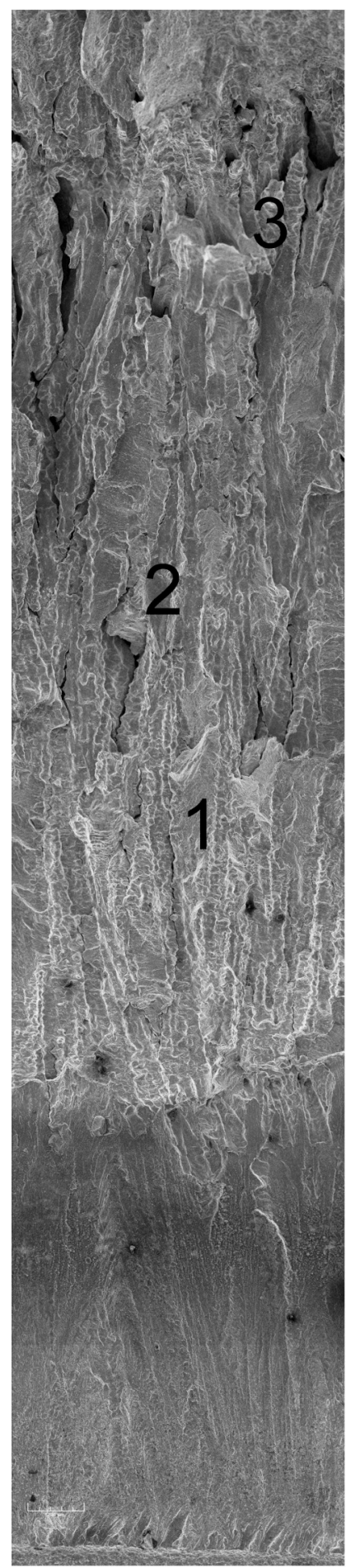

(a)

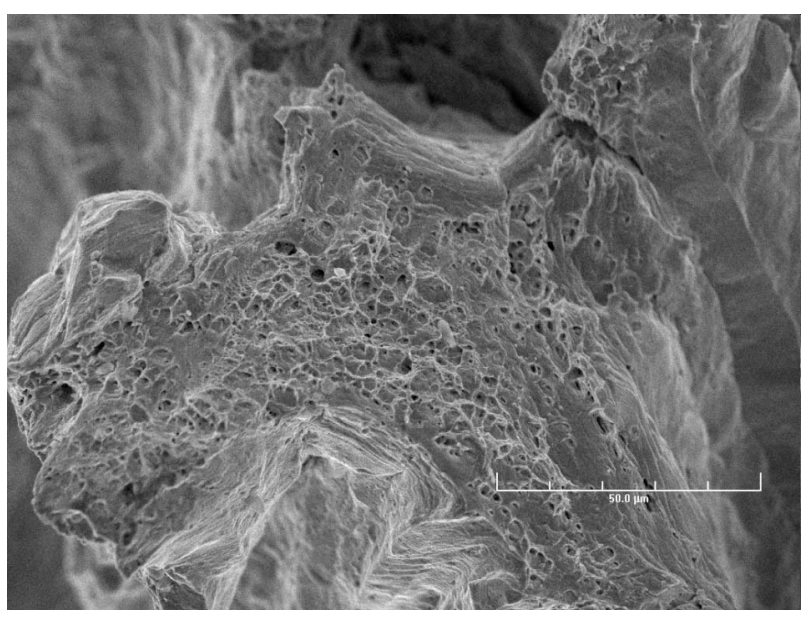

(d)

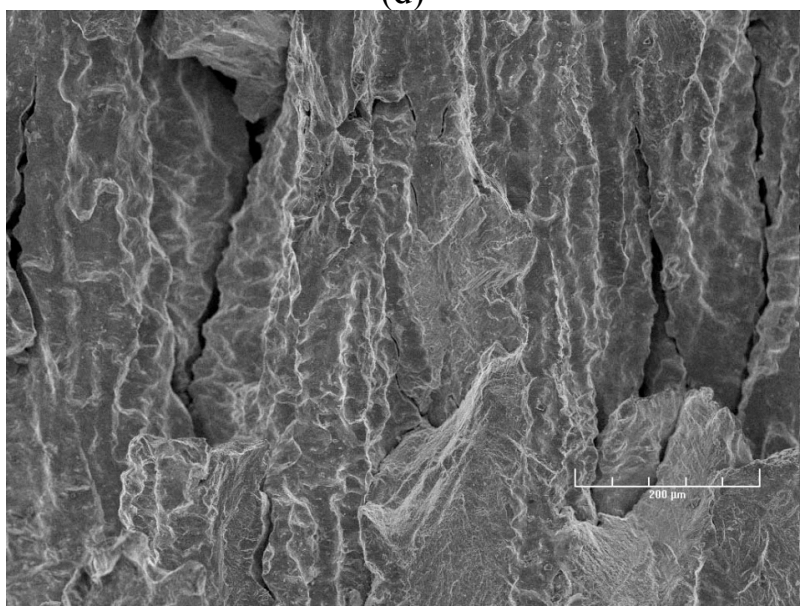

(c)

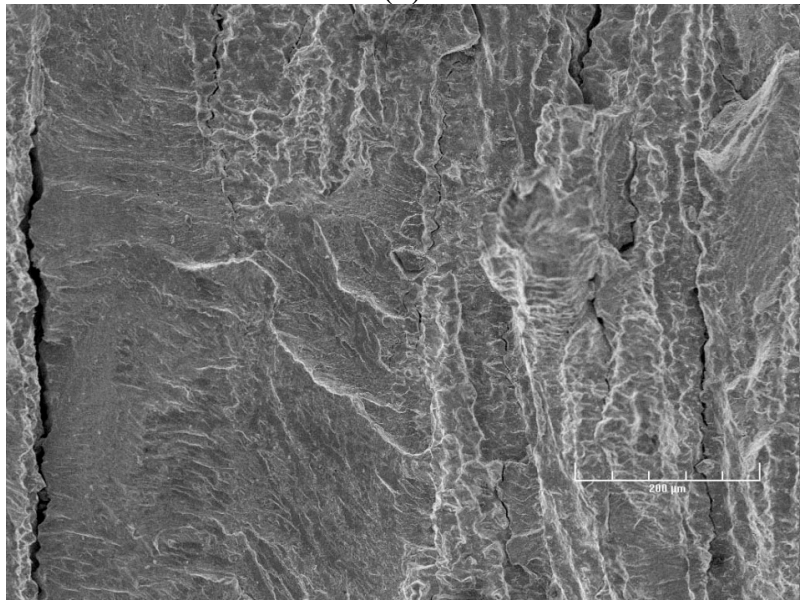

(b)

Figure 40. (a) Crack front on sample CT933-TS, where several fracture modes are identified: (b) transition from TG to IG; (c) IG; and (d) ductile rupture in the IG region. Crack extension is from bottom to top of the figure. 


\subsubsection{Crack Growth Data for Deep-Groove Weld Specimen CT933-TL}

The experimental conditions and results for testing of CT933-TL are shown in Table 8, and the changes in crack length and $\mathrm{K}_{\max }$ with time are shown in Fig. 41. The specimen was fatigue precracked with a triangular waveform at $\mathrm{R}=0.5$ and $\mathrm{K}_{\max }=21 \mathrm{MPa} \mathrm{m}{ }^{1 / 2}$, followed by cycling with a trapezoidal waveform at $\mathrm{R}=0.5$ and $\mathrm{K}_{\max }=21.6 \mathrm{MPa} \mathrm{m}^{1 / 2}$. The specimen was then set at constant load at $\mathrm{K}_{\max }=21.6 \mathrm{MPa} \mathrm{m}{ }^{1 / 2}$ for $\approx 200 \mathrm{~h}$. The specimen was next cycled at $\mathrm{R}=0.5$, at increasing rise times, and set at constant load at $\mathrm{K}_{\max }=21.8$ and $30.9 \mathrm{MPa} \mathrm{m}^{1 / 2}$. The specimen was next cycled with the goal of reaching $\mathrm{K}_{\max }=35 \mathrm{MPa} \mathrm{m}{ }^{1 / 2}$, and set at constant load. Finally, the sample was again cycled to reach approximately $\mathrm{K}_{\max }=49.2 \mathrm{MPa} \mathrm{m}^{1 / 2}$, and set at constant load. The effluent water conductivity was monitored continuously, while the effluent DO and ECPs of a Pt electrode and Alloy 600 electrode downstream from the autoclave were measured periodically. The water flow rate was $\approx 25 \mathrm{cc} / \mathrm{min}$. The ECPs of Pt and Alloy 600 electrodes were -690 and $-693 \mathrm{mV}$ (SHE), respectively.

Table 8. Crack growth data for specimen CT933-TL of Alloy 182 SMA weld in PWR water ${ }^{\mathrm{a}}$ at $320^{\circ} \mathrm{C}$.

\begin{tabular}{|c|c|c|c|c|c|c|c|c|c|c|c|c|}
\hline $\begin{array}{c}\text { Test } \\
\text { Period }\end{array}$ & $\begin{array}{c}\text { Test } \\
\text { Time, } \\
\mathrm{h}\end{array}$ & $\begin{array}{l}\text { Cond,,b } \\
\mu \mathrm{S} / \mathrm{cm}\end{array}$ & $\begin{array}{c}\mathrm{O}_{2} \\
\text { Conc., } \\
\text { ppb }\end{array}$ & $\begin{array}{c}\text { Load } \\
\text { Ratio } \\
\text { R } \\
\end{array}$ & $\begin{array}{c}\text { Rise } \\
\text { Time, } \\
\mathrm{s} \\
\end{array}$ & $\begin{array}{c}\text { Down } \\
\text { Time, } \\
\mathrm{s} \\
\end{array}$ & $\begin{array}{c}\text { Hold } \\
\text { Time, } \\
\mathrm{s} \\
\end{array}$ & $\begin{array}{c}\mathrm{K}_{\max }, \\
\mathrm{MPa} \cdot \mathrm{m}^{1 / 2}\end{array}$ & $\begin{array}{c}\Delta \mathrm{K}, \\
\mathrm{MPa} \cdot \mathrm{m}^{1 / 2}\end{array}$ & $\begin{array}{c}\mathrm{CGR}_{\text {env }} \\
\mathrm{m} / \mathrm{s}\end{array}$ & $\begin{array}{c}\text { Estimated } \\
\text { CGR }_{\text {air }} \\
\mathrm{m} / \mathrm{s}\end{array}$ & $\begin{array}{c}\text { Crack } \\
\text { Length, } \\
\mathrm{mm}\end{array}$ \\
\hline Pre a & 73 & 22 & $<10$ & 0.3 & 0.5 & 0.5 & 0 & 21.2 & 14.8 & $1.12 \mathrm{E}-08$ & $1.07 \mathrm{E}-08$ & 12.791 \\
\hline Pre b & 96 & 22 & $<10$ & 0.3 & 0.5 & 0.5 & 0 & 21.4 & 15.0 & $1.25 \mathrm{E}-08$ & $2.22 \mathrm{E}-08$ & 12.945 \\
\hline 1 & 191 & 22 & $<10$ & 0.5 & 300 & 12 & 0 & 21.6 & 10.8 & $3.61 \mathrm{E}-10$ & $1.65 \mathrm{E}-11$ & 13.110 \\
\hline 2 & 385 & 22 & $<10$ & 1 & - & - & 0 & 21.63 & 0.00 & $2.68 \mathrm{E}-12$ & - & 13.153 \\
\hline 3 & 500 & 22 & $<10$ & 0.5 & 300 & 12 & 0 & 21.67 & 10.83 & $1.08 \mathrm{E}-10$ & $1.68 \mathrm{E}-11$ & 13.164 \\
\hline 4 & 598 & 22 & $<10$ & 0.5 & 1000 & 12 & 0 & 21.70 & 10.85 & $4.03 \mathrm{E}-11$ & $5.07 \mathrm{E}-12$ & 13.181 \\
\hline 5 & 860 & 22 & $<10$ & 1 & - & - & 0 & 21.81 & 0.00 & $4.46 \mathrm{E}-11$ & - & 13.259 \\
\hline $6 a$ & 867.0 & 22 & $<10$ & 0.3 & 1 & 1 & 0 & 23.52 & 16.46 & $6.82 \mathrm{E}-09$ & $1.63 \mathrm{E}-08$ & 13.309 \\
\hline $6 \mathrm{~b}$ & 890.0 & 22 & $<10$ & 0.3 & 1 & 1 & 0 & 23.72 & 16.61 & $1.09 \mathrm{E}-08$ & $1.69 \mathrm{E}-08$ & 13.470 \\
\hline $6 \mathrm{c}$ & 913.0 & 22 & $<10$ & 0.3 & 1 & 1 & 0 & 23.59 & 16.51 & $1.62 \mathrm{E}-08$ & $1.66 \mathrm{E}-08$ & 13.669 \\
\hline $6 \mathrm{~d}$ & 935.0 & 22 & $<10$ & 0.3 & 1 & 1 & 0 & 24.15 & 16.90 & $1.33 \mathrm{E}-08$ & $3.64 \mathrm{E}-08$ & 13.822 \\
\hline 7 & $1,002.0$ & 22 & $<10$ & 0.5 & 12 & 2 & 0 & 24.42 & 12.21 & $7.14 \mathrm{E}-10$ & $6.86 \mathrm{E}-10$ & 14.208 \\
\hline 8 & $1,026.0$ & 22 & $<10$ & 0.5 & 12 & 2 & 0 & 26.50 & 13.25 & $1.40 \mathrm{E}-09$ & $9.60 \mathrm{E}-10$ & 14.321 \\
\hline 9 & $1,073.0$ & 22 & $<10$ & 0.5 & 1 & 1 & 0 & 28.66 & 14.33 & $1.83 \mathrm{E}-08$ & $1.59 \mathrm{E}-08$ & 15.823 \\
\hline 10 & $1,102.0$ & 22 & $<10$ & 0.5 & 300 & 12 & 0 & 30.63 & 15.31 & $1.05 \mathrm{E}-09$ & $6.95 \mathrm{E}-11$ & 15.957 \\
\hline 11 & $1,368.0$ & 22 & $<10$ & 1 & - & - & 0 & 31.01 & 0.00 & $9.04 \mathrm{E}-11$ & - & 16.046 \\
\hline $12 \mathrm{a}$ & $1,374.0$ & 22 & $<10$ & 0.3 & 1 & 1 & 0 & 32.23 & 22.56 & $9.04 \mathrm{E}-08$ & $5.95 \mathrm{E}-08$ & 16.875 \\
\hline $12 b$ & $1,391.0$ & 22 & $<10$ & 0.3 & 1 & 1 & 0 & 32.88 & 23.02 & 7.54E-07 & $6.46 \mathrm{E}-08$ & 17.324 \\
\hline 13 & $1,398.0$ & 22 & $<10$ & 0.5 & 30 & 2 & 0 & 34.91 & 17.45 & 4.29E-08 & $1.19 \mathrm{E}-09$ & 18.431 \\
\hline 14 & $1,439.0$ & 22 & $<10$ & 0.5 & 1000 & 12 & 0 & 35.19 & 17.59 & $5.98 \mathrm{E}-11$ & $3.68 \mathrm{E}-11$ & 18.586 \\
\hline 15 & $1,633.0$ & 22 & $<10$ & 1 & - & - & 0 & 35.43 & 0.00 & $8.10 \mathrm{E}-11$ & - & 18.740 \\
\hline 16 & $1,638.0$ & 22 & $<10$ & 0.3 & 1 & 1 & 0 & 37.36 & 26.16 & $1.98 \mathrm{E}-07$ & $1.09 \mathrm{E}-07$ & 19.769 \\
\hline 17 & $1,651.0$ & 22 & $<10$ & 0.3 & 30 & 1 & 0 & 39.51 & 27.66 & $2.46 \mathrm{E}-08$ & $4.57 \mathrm{E}-09$ & 20.834 \\
\hline 18 & $1,656.0$ & 22 & $<10$ & 0.3 & 1 & 1 & 0 & 46.67 & 32.67 & $3.81 \mathrm{E}-07$ & $2.72 \mathrm{E}-07$ & 23.860 \\
\hline 19 & $1,663.0$ & 22 & $<10$ & 0.5 & 300 & 12 & 0 & 49.16 & 24.58 & $2.15 \mathrm{E}-08$ & $4.84 \mathrm{E}-10$ & 24.778 \\
\hline 20 & $2,137.0$ & 22 & $<10$ & 1 & - & - & 0 & 50.01 & 0.00 & $1.57 \mathrm{E}-10$ & - & 25.048 \\
\hline 21 & $2,141.0$ & 22 & $<10$ & 0.5 & 300 & 12 & 0 & 51.61 & 25.12 & $2.52 \mathrm{E}-08$ & $5.29 \mathrm{E}-10$ & 25.593 \\
\hline
\end{tabular}

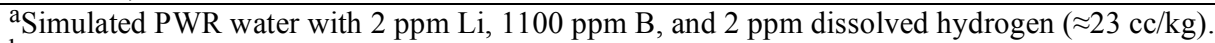

${ }^{\mathrm{b}}$ Represents values in the effluent. 


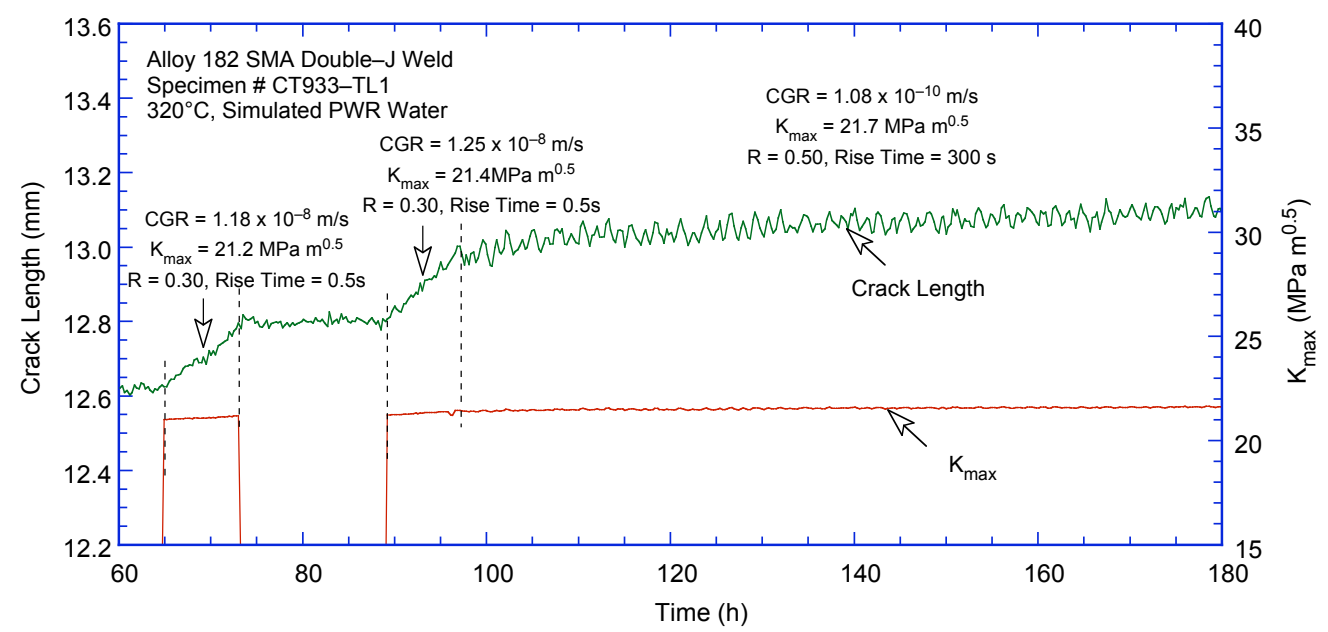

(a)

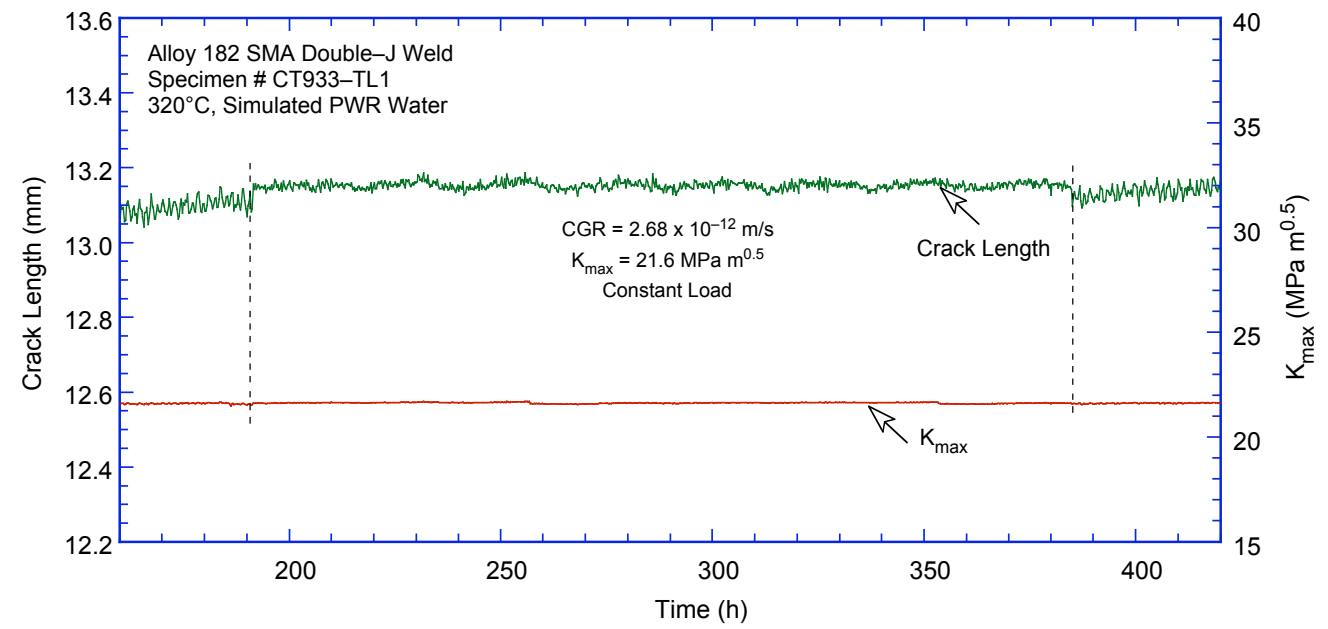

(b)

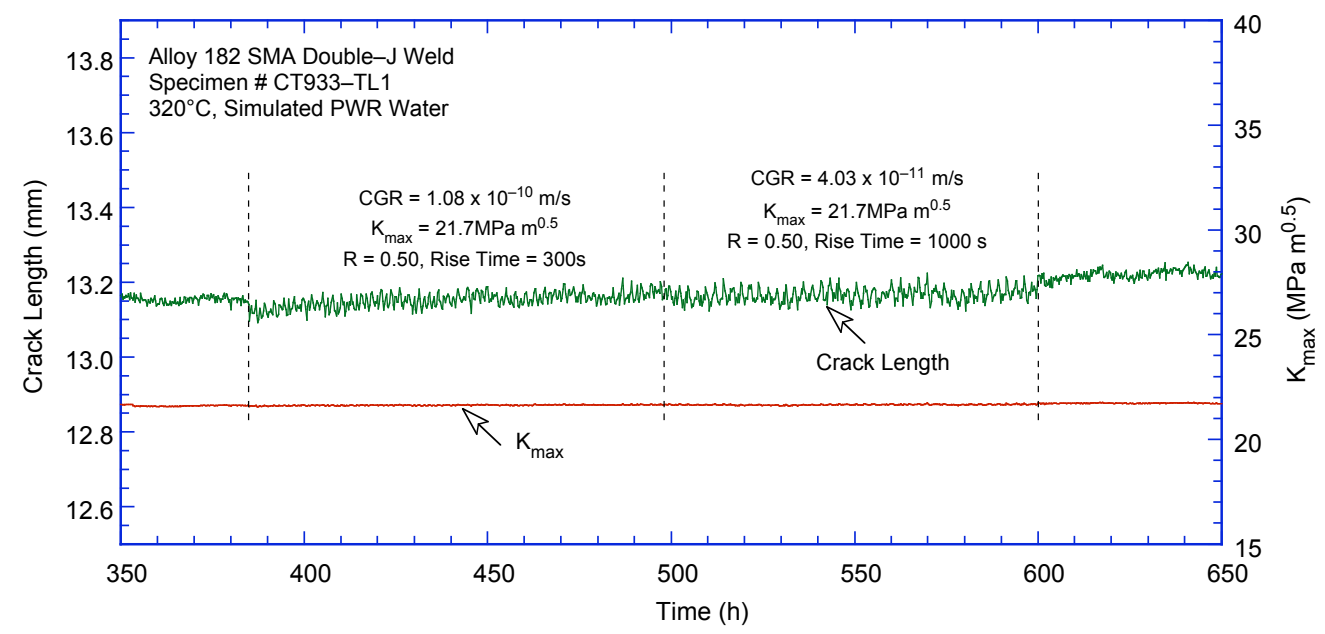

(c)

Figure 41. Crack length vs. time for Alloy 182 weld specimen CT933-TL in simulated PWR environment at $320^{\circ} \mathrm{C}$ during test periods (a) precracking-1, (b) 2 , (c) $3-4$, (d) 5 , (e) $6-10$, (f) 11 , (g) $12-$ 14 , (h) 15 , (i) $16-19$, and (j) 20-21. 


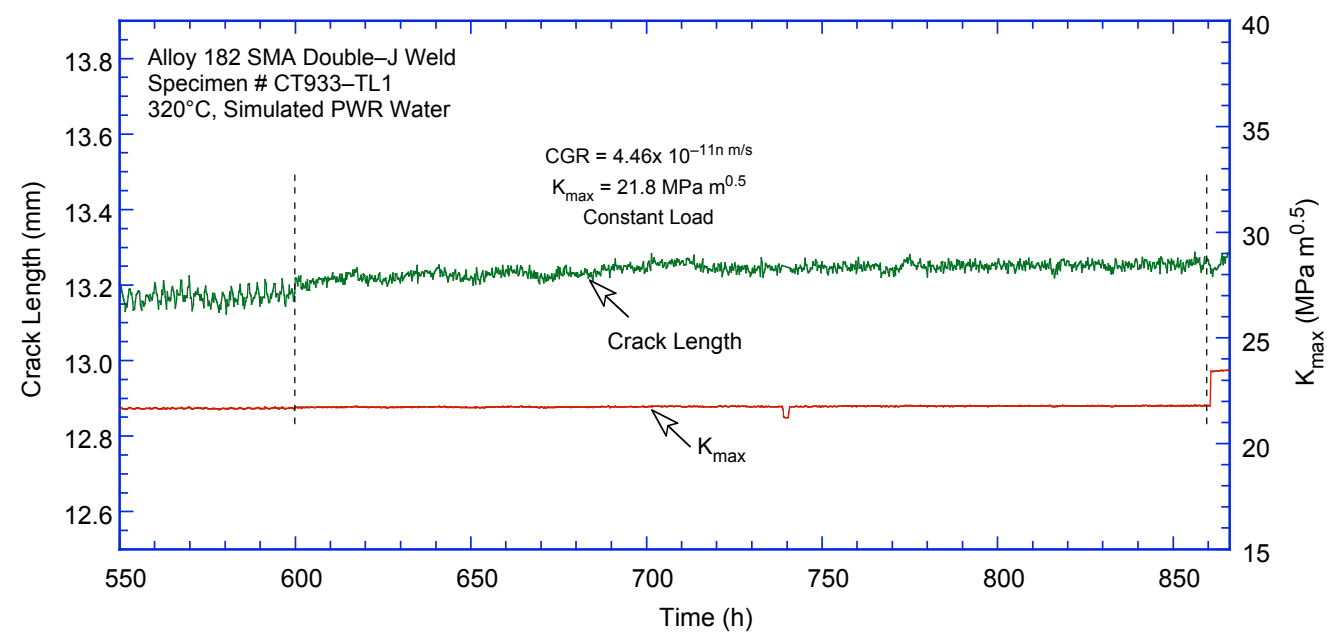

(d)

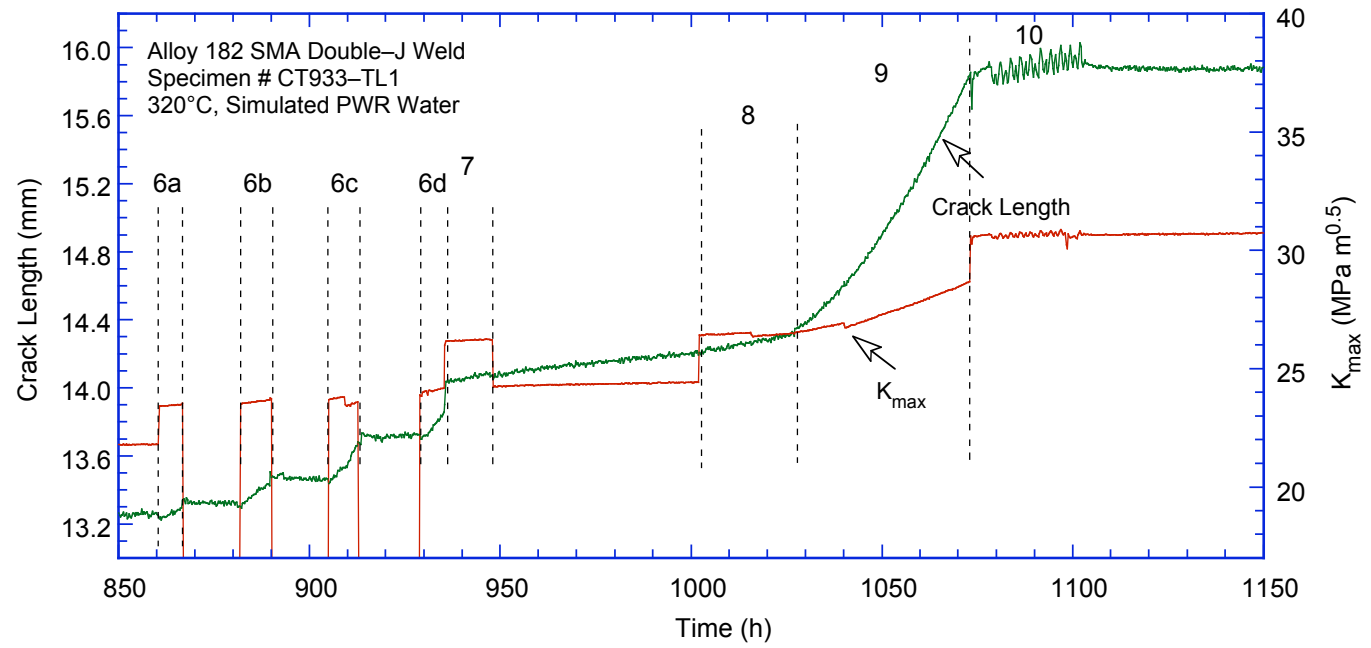

(e)

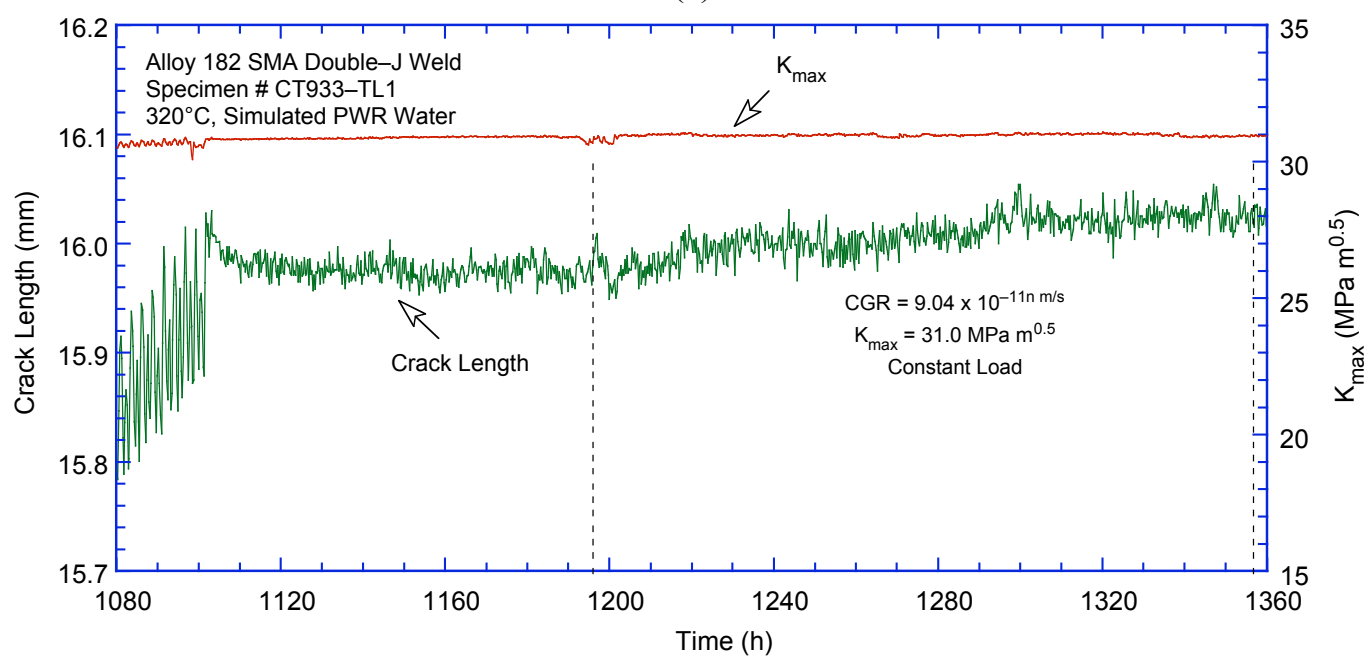

(f)

Figure $41 . \quad$ (Contd.) 


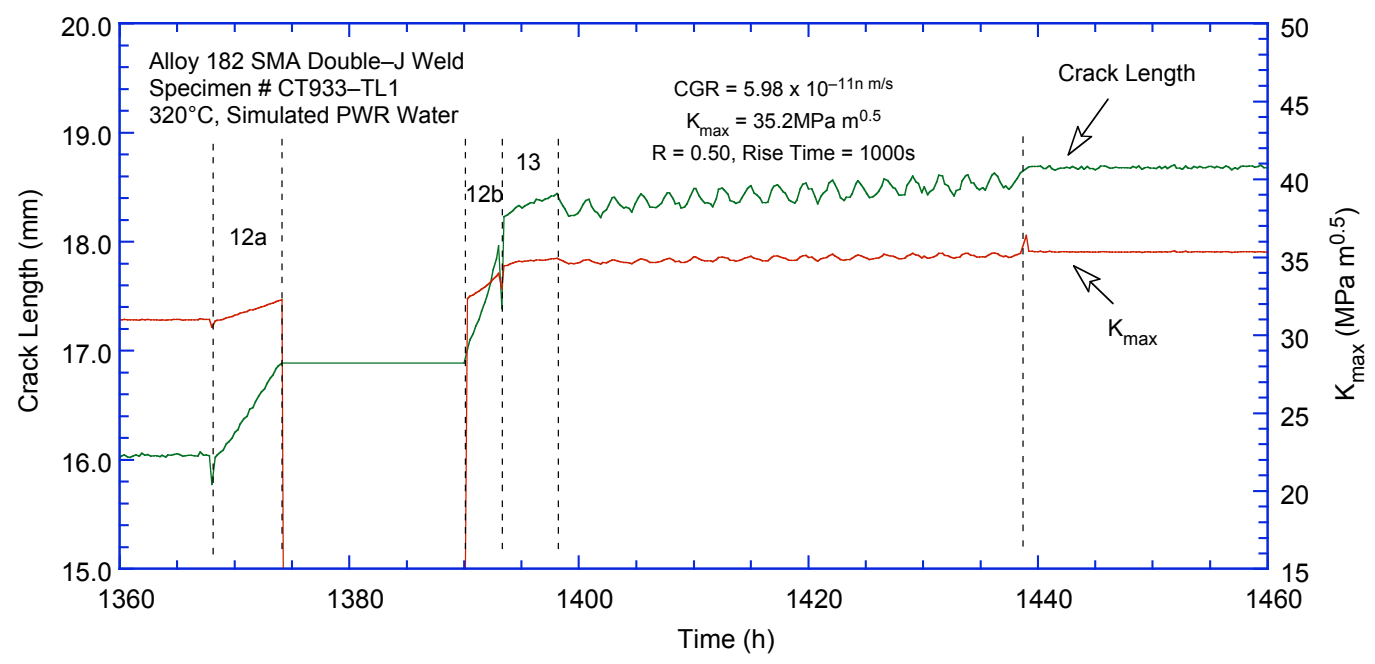

(g)

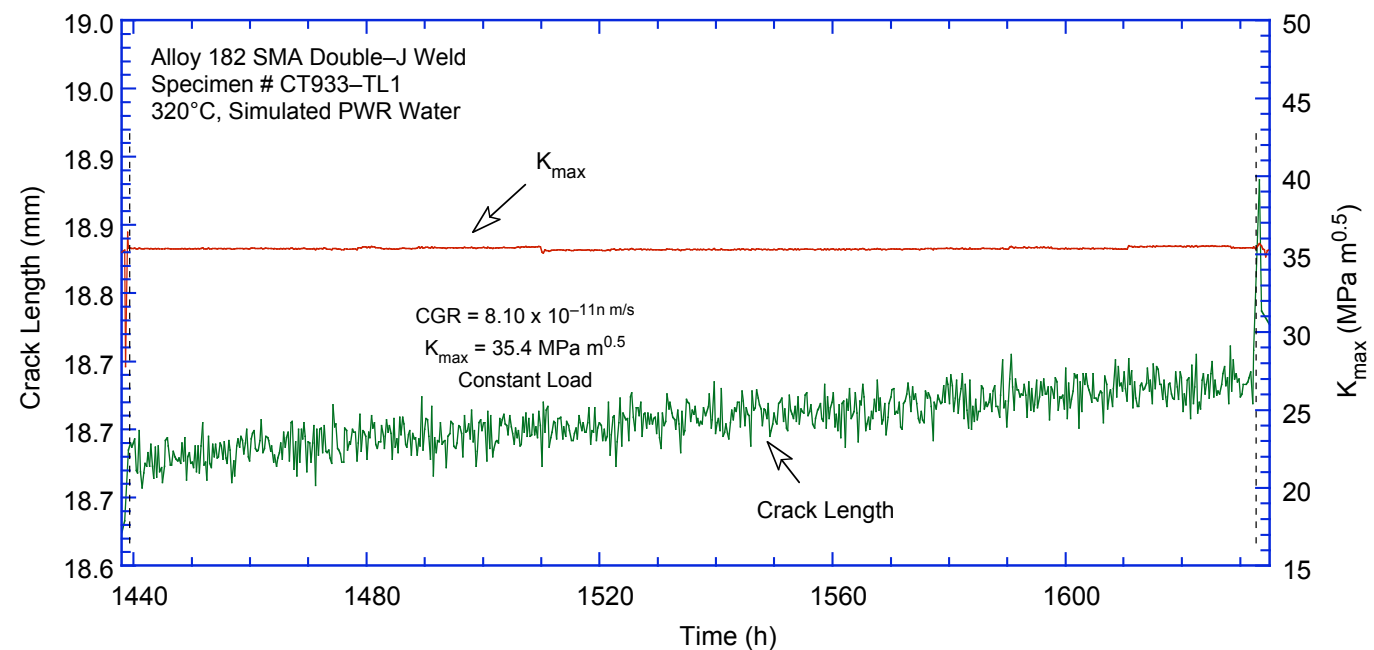

(h)

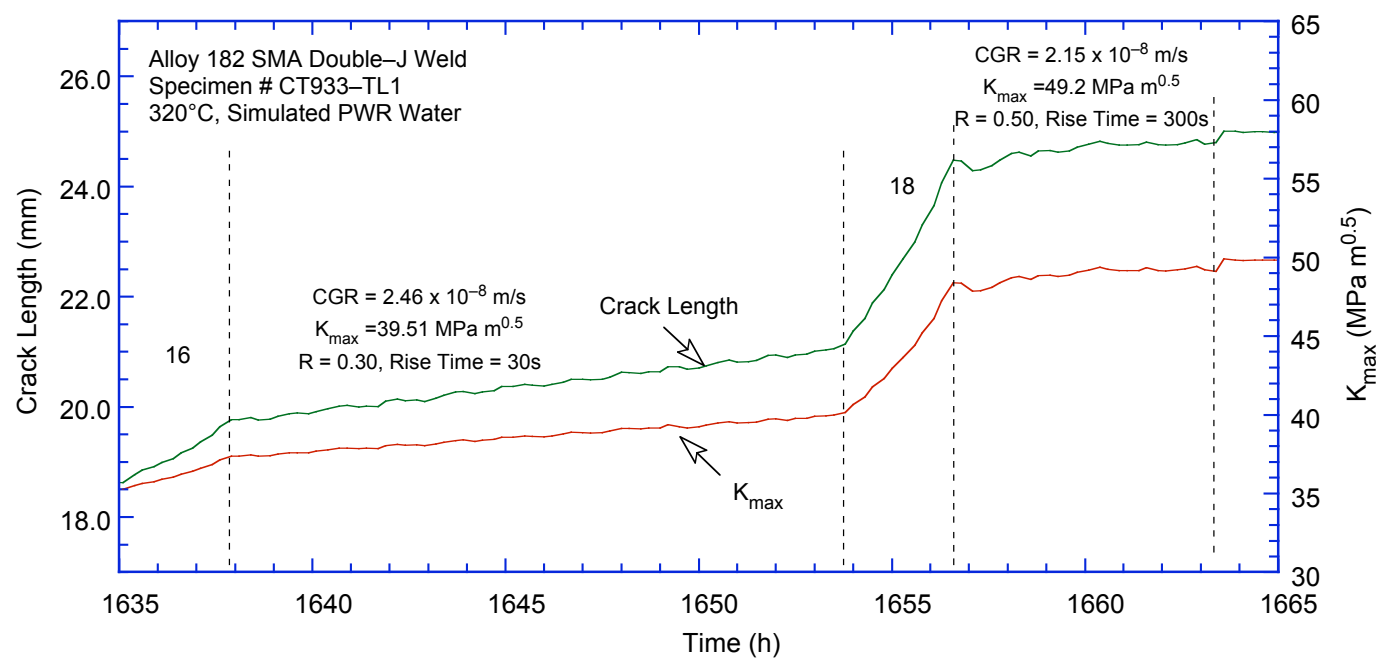

(i)

Figure $41 . \quad$ (Contd.) 


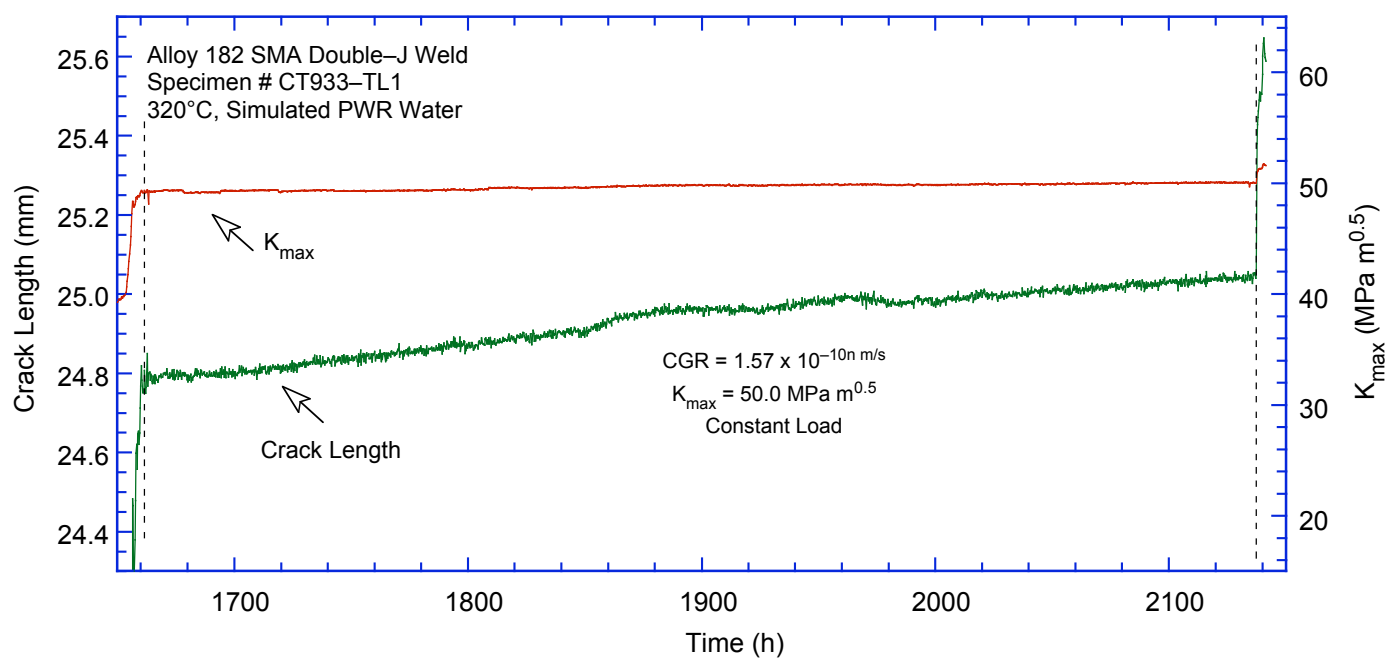

Figure 41 .

(j)

Figure 42 shows the entire fracture surface of CT933-TL, which has a relatively straight crack front. The entire crack length was measured to be $13.86 \mathrm{~mm}$, slightly larger $(6.2 \%)$ than the crack measurement by DC potential. This difference may be due to the fact that most of the fracture surface is transgranular, and each constant load (CL) period was followed by a cycling period, thus breaking off the ligaments that are generally believed to cause the DC potential method to underestimate the crack length.

The constant load periods CL-1 through CL-5, corresponding to the test periods $3,5,11,15$, and 20 (Table 8), are also indicated in Fig. 42. Examination of the fracture surface revealed that, although the fracture mode was IG during the constant load periods, the crack growth rate in this particular orientation was relatively small, causing a non-complete IG engagement during the typical $200 \mathrm{~h}$ of testing time in each constant load period. Nevertheless, the IG engagement was complete during CL-5 (test period 20, Table 8), which lasted approximately $500 \mathrm{~h}$. Figure 43 shows the fracture surface from this last constantload test period, and Fig. 44 shows a high magnification micrograph also from this region. 


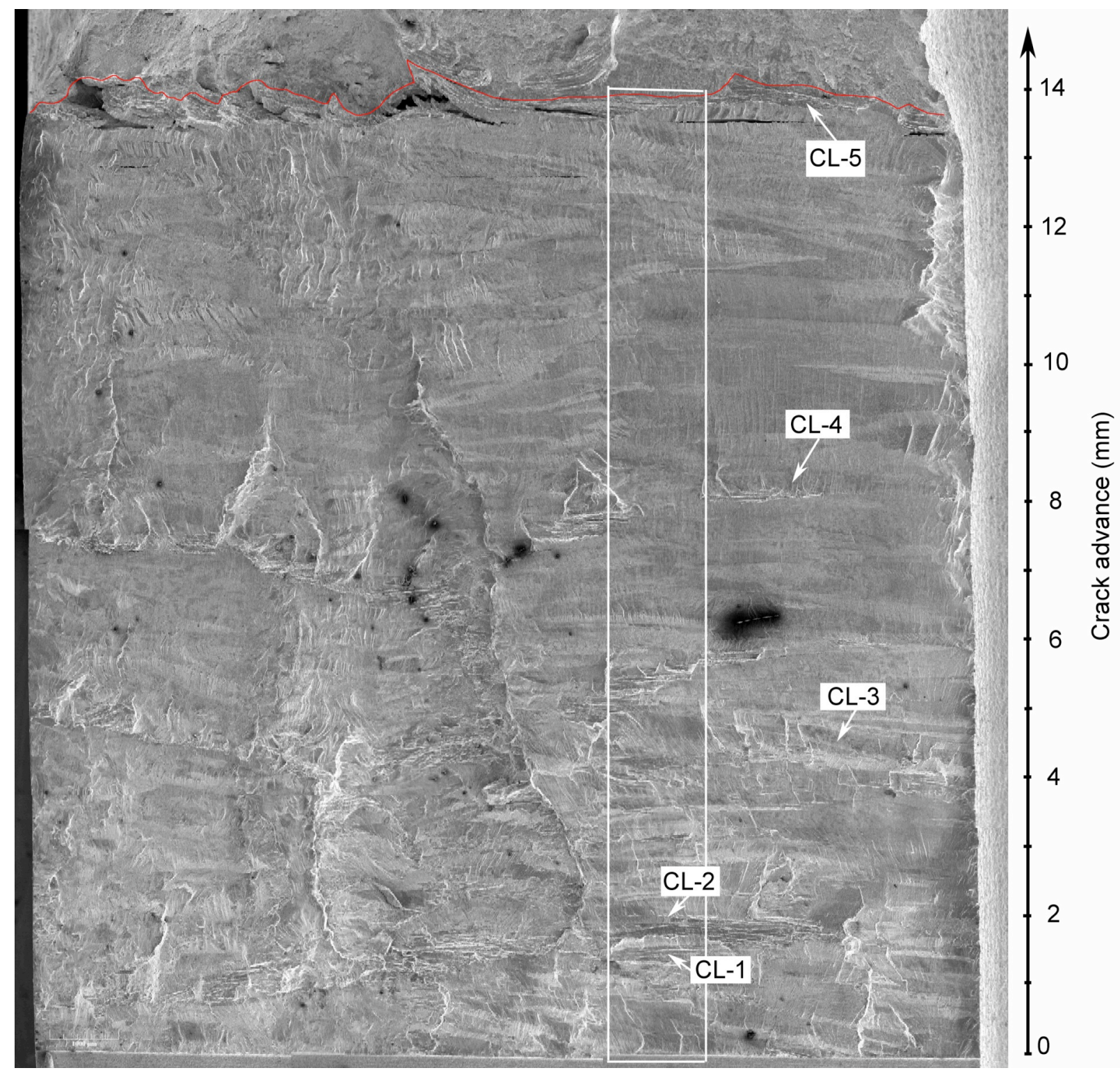

Figure 42. Fracture surface of Alloy 182 weld specimen CT933-TL. The regions dominated by IG fracture corresponding to the constant load $(\mathrm{CL})$ periods are indicated in the figure. The different IG regions are indicated.

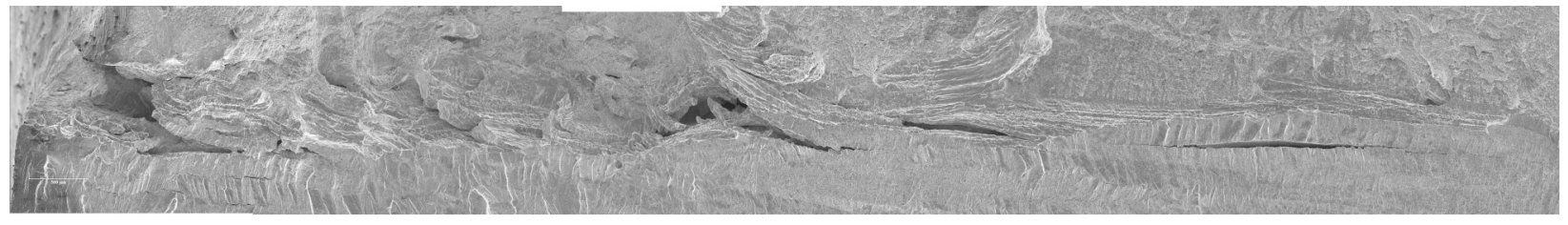

Figure 43. Intergranular fracture on the Alloy 182 weld specimen CT933-TL resulting from the constantload period CL-5 (test period 20). 


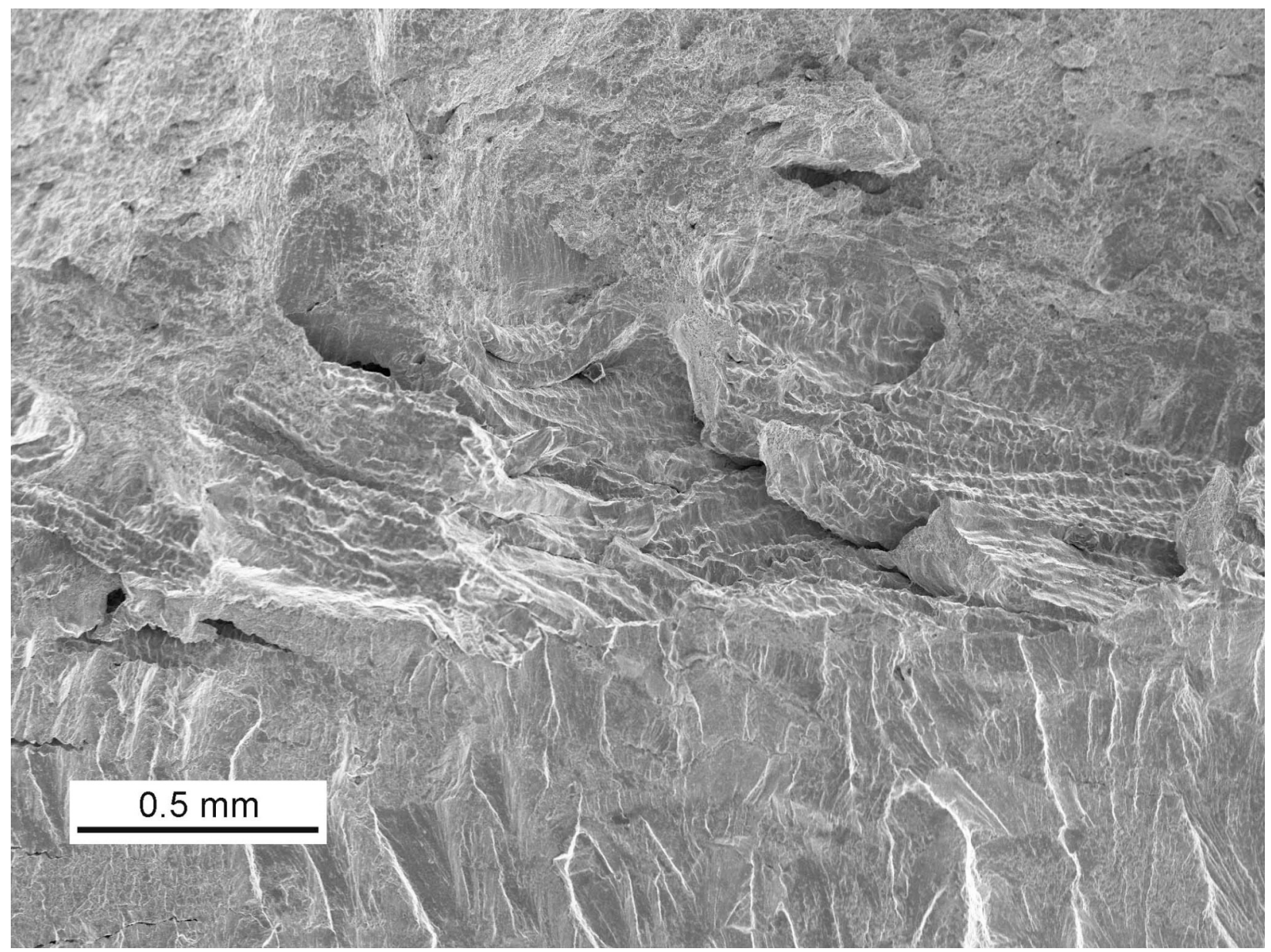

Figure 44. Higher magnification image of IG fracture on the Alloy 182 weld specimen CT933-TL resulting from the constant load period CL-5 (test period 20). Crack extension from bottom to top of the figure.

\subsubsection{Crack Growth Data for Deep-Groove Weld Specimen CT933-LS}

A CGR test was conducted on a deep-groove-filled weld specimen in the LS orientation (Specimen CT933-LS). The specimen had to be thinned by approximately $3 \mathrm{~mm}$ on each side to ensure that the entire crack front (anticipated to extend $15 \mathrm{~mm}$ ) will be exclusively in the weld alloy. Prior to the test, the ECPs of a Pt electrode and a companion Alloy 600 electrode downstream from the autoclave were -650 and $-690 \mathrm{mV}$ (SHE), respectively. The experimental conditions and results are shown in Table 9, and the changes in crack length and $\mathrm{K}_{\max }$ with time are shown in Fig. 45. The sample was fatigue precracked at $\mathrm{K}_{\max }=24 \mathrm{MPa} \mathrm{m}^{1 / 2}, \mathrm{R}=0.3$, and a triangular waveform. Next, the specimen was cycled at $\mathrm{R}=0.5$ at increasing rise times of 50 and $500 \mathrm{~s}$. The system was then set at constant load at $\mathrm{K}_{\max }=28 \mathrm{MPa} \mathrm{m}^{1 / 2}$, followed by constant load at $\mathrm{K}_{\max }=40 \mathrm{MPa} \mathrm{m}^{1 / 2}$. One observes that in Fig. $45 \mathrm{~b}$ the CGR was determined by connecting the initial crack length at the start of test period 3 and the crack length at the start of the next test period at $\mathrm{K}=40.5 \mathrm{MPa} \mathrm{m}{ }^{1 / 2}$ (given by the dotted line). The assumption was that the unbroken ligaments snapped when the increased load was applied (note the sudden jump in crack length in Fig. 45b). A similar approach was undertaken for the next constant load period (Fig. 45c). 
Table 9. Crack growth data for specimen CT933-LS of Alloy 82 SMA weld in PWR water a $320^{\circ} \mathrm{C}$.

\begin{tabular}{|c|c|c|c|c|c|c|c|c|c|c|c|c|}
\hline $\begin{array}{c}\text { Test } \\
\text { Period }\end{array}$ & $\begin{array}{c}\text { Test } \\
\text { Time, } \\
\mathrm{h} \\
\end{array}$ & $\begin{array}{l}\text { Cond, }{ }^{b} \\
\mu \mathrm{S} / \mathrm{cm}\end{array}$ & $\begin{array}{c}\mathrm{O}_{2} \\
\text { Conc., } \\
\text { ppb }\end{array}$ & $\begin{array}{c}\text { Load } \\
\text { Ratio } \\
\mathrm{R} \\
\end{array}$ & $\begin{array}{c}\text { Rise } \\
\text { Time, } \\
\mathrm{s} \\
\end{array}$ & $\begin{array}{c}\text { Down } \\
\text { Time, } \\
\mathrm{s}\end{array}$ & $\begin{array}{c}\text { Hold } \\
\text { Time, } \\
\mathrm{s} \\
\end{array}$ & $\begin{array}{c}\mathrm{K}_{\max } \\
\mathrm{MPa} \cdot \mathrm{m}^{1 / 2}\end{array}$ & $\begin{array}{c}\Delta \mathrm{K}, \\
\mathrm{MPa} \cdot \mathrm{m}^{1 / 2}\end{array}$ & $\begin{array}{c}\mathrm{CGR}_{\text {env }} \\
\mathrm{m} / \mathrm{s}\end{array}$ & $\begin{array}{c}\text { Estimated } \\
\text { CGR }_{\text {air }} \\
\mathrm{m} / \mathrm{s}\end{array}$ & $\begin{array}{c}\text { Crack } \\
\text { Length, } \\
\mathrm{mm}\end{array}$ \\
\hline Pre a & 79 & 26 & $<10$ & 0.30 & 0.5 & 0.5 & 0 & 23.71 & 16.59 & $1.63 \mathrm{E}-08$ & $3.42 \mathrm{E}-08$ & 13.306 \\
\hline Pre $b$ & 91 & 26 & $<10$ & 0.30 & 5 & 5 & 0 & 25.88 & 18.12 & 7.87E-08 & 4.87E-09 & 15.051 \\
\hline Pre c & 97 & 26 & $<10$ & 0.30 & 5 & 5 & 0 & 28.49 & 19.94 & $1.28 \mathrm{E}-07$ & $7.22 \mathrm{E}-09$ & 16.952 \\
\hline 1 & 162 & 26 & $<10$ & 0.50 & 50 & 2 & 0 & 27.67 & 13.84 & 3.69E-09 & $2.77 \mathrm{E}-10$ & 17.816 \\
\hline 2 & 217 & 26 & $<10$ & 0.50 & 500 & 12 & 0 & 27.91 & 13.96 & $7.63 \mathrm{E}-10$ & $2.88 \mathrm{E}-11$ & 18.007 \\
\hline 3 & 836 & 26 & $<10$ & 1.00 & - & - & - & 28.73 & 0.00 & $1.73 \mathrm{E}-10$ & - & 18.373 \\
\hline 4 & 1665 & 26 & $<10$ & 1.00 & - & - & - & 44.81 & 0.00 & $6.54 \mathrm{E}-10$ & - & 20.338 \\
\hline 5 & 1690 & 26 & $<10$ & 0.5 & 500 & 12 & 0 & 46.66 & 23.33 & 3.69E-09 & $2.36 \mathrm{E}-10$ & 21.212 \\
\hline
\end{tabular}

${ }^{\mathrm{a}}$ Simulated PWR water with $2 \mathrm{ppm} \mathrm{Li}, 1100 \mathrm{ppm} \mathrm{B}$, and $2 \mathrm{ppm}$ dissolved hydrogen $(\approx 23 \mathrm{cc} / \mathrm{kg})$.

${ }^{\mathrm{b}}$ Represents values in the effluent.

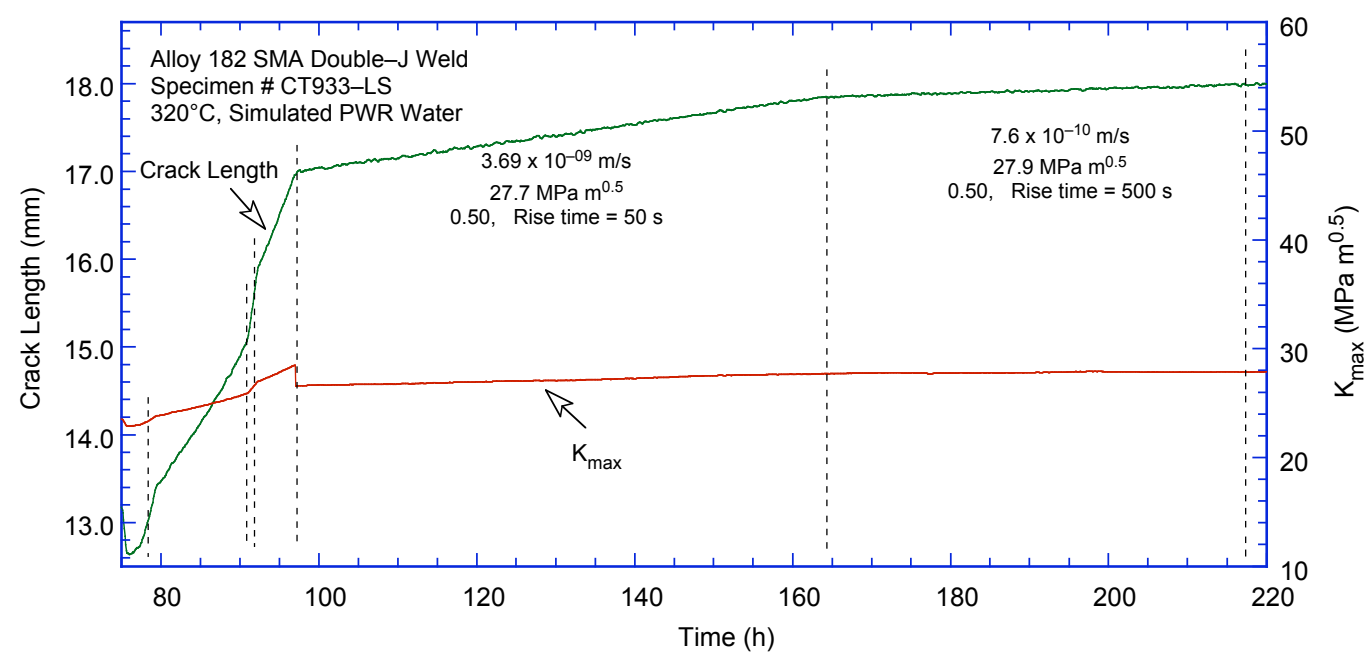

(a)

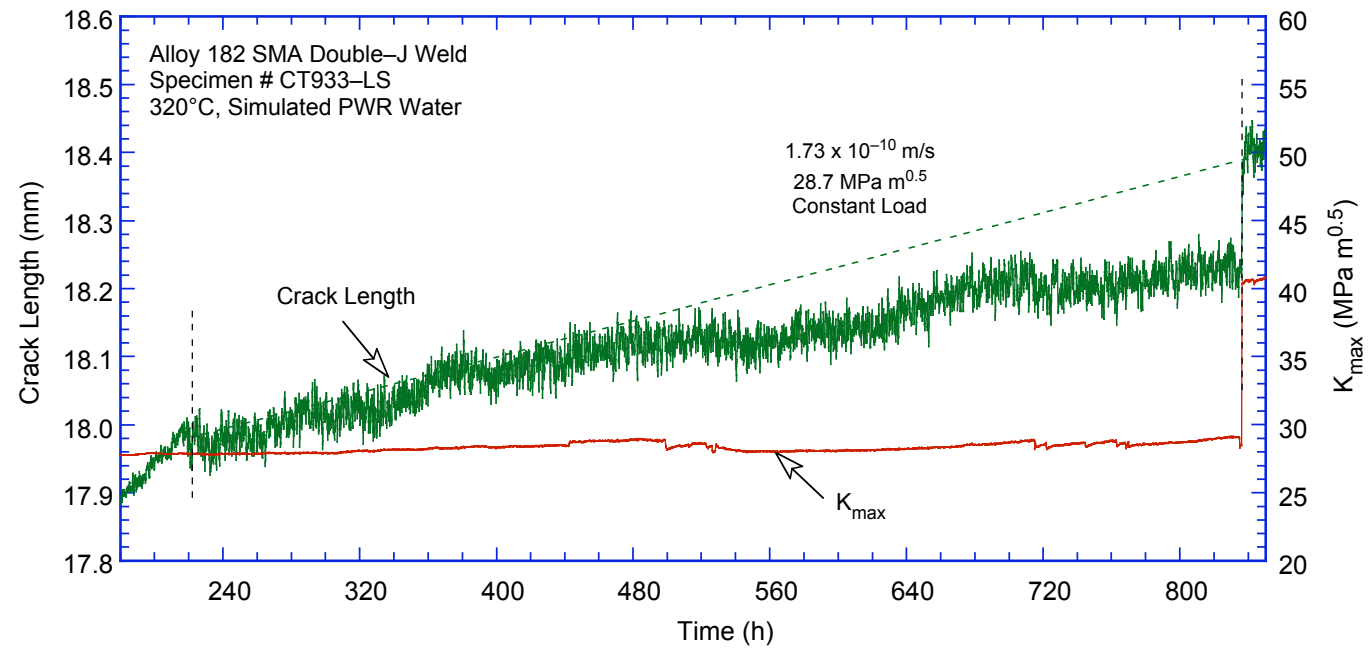

(b)

Figure 45. Crack length vs. time for Alloy 182 weld specimen CT933-LS in simulated PWR environment at $320^{\circ} \mathrm{C}$ during (a) precracking and periods $1-2$, (b) constant load period 3 , and (c) constantload period 4. 


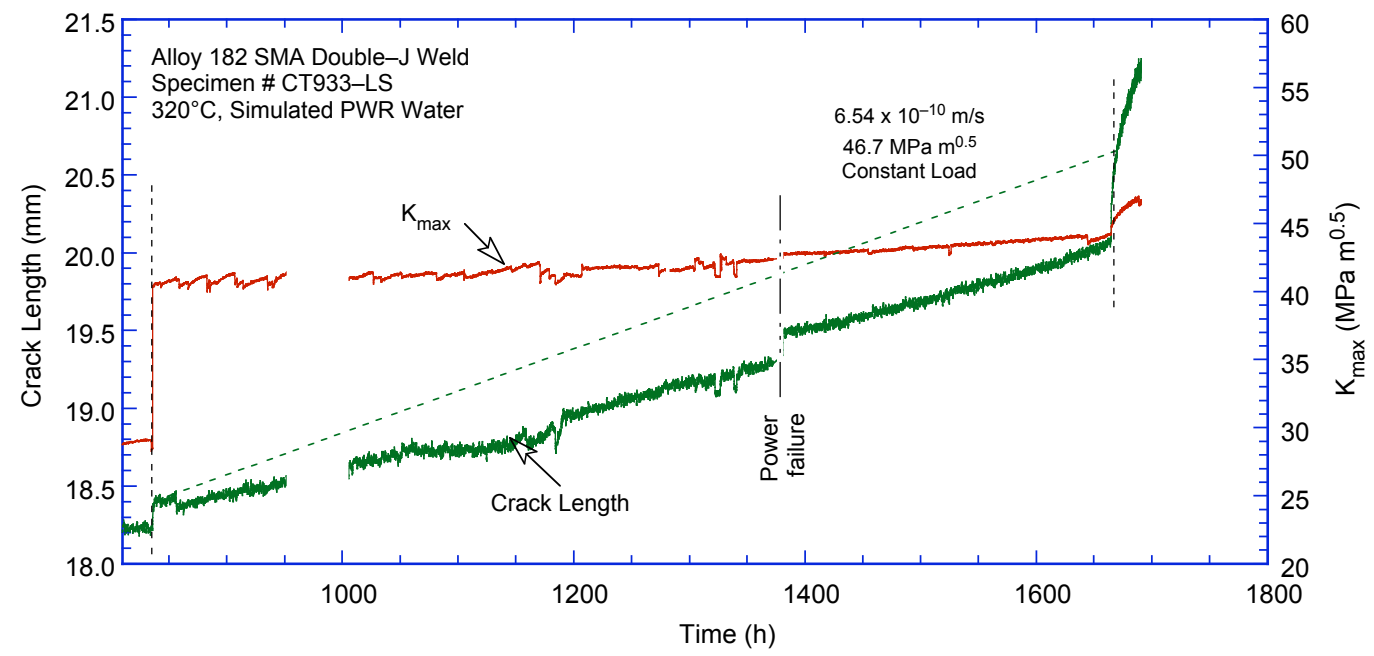

(c)

Figure $45 \quad$ (Contd.)

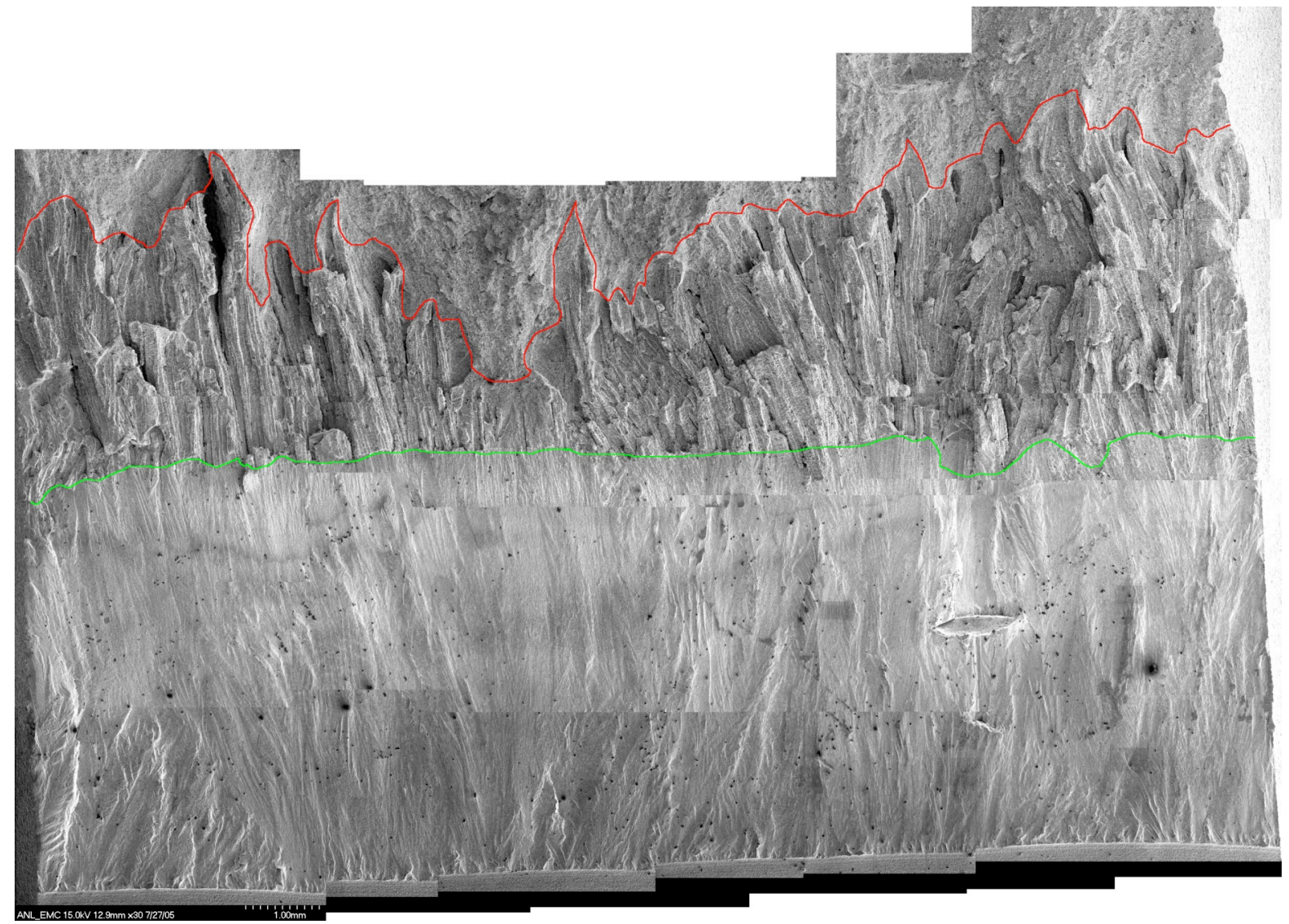

Figure 46. Crack front on fracture surface of sample CT933-LS. Crack extension from bottom to top of the figure.

Figure 46 shows the entire fracture surface of this specimen. Following pre-cracking the fracture turned into a intergranular mode (IG). Nevertheless, we observe that the testing procedure resulted in a relatively straight crack front. The average crack extension for the transgranular region and the total crack advance were determined by taking $\approx 20$ measurements across the width of the specimen. The 
measured total crack extension was greater than the value determined from the DC potential measurements, most likely due to unbroken ligaments in the intergranular region. The DC potential data for the transgranular region was found to be in good agreement with the direct measurements. The intergranular DC potential data was scaled proportionally by a factor 2.30; the corrected data are given in Table 7.

Figure 47 focuses on the transition from TG to IG on the fracture surface of specimen CT933-LS. One observes that following the TG region, elements of IG fracture appear on the fracture surface, most likely during long rise time fatigue periods. Upon transitioning to constant load, the fracture mode changes completely to IG.

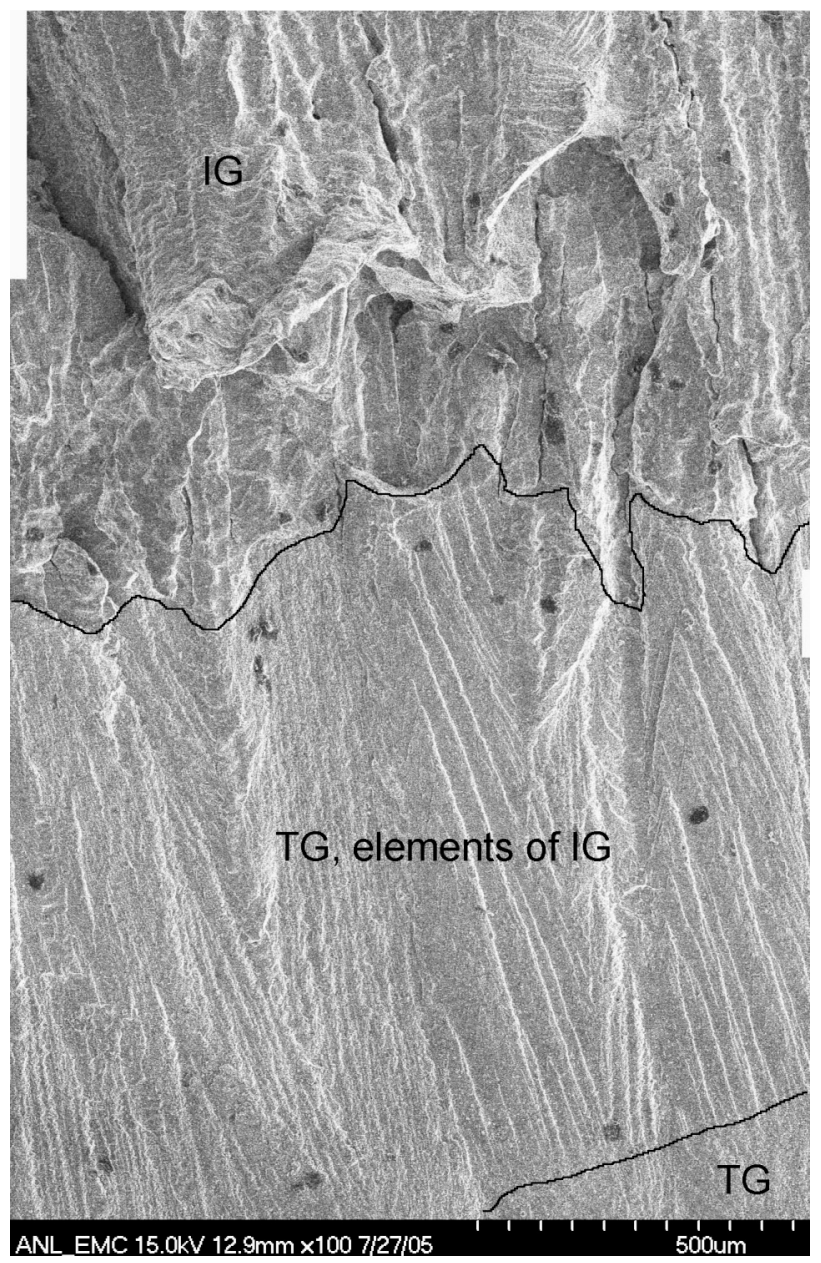

Figure 47. Transition from TG to IG observed on the fracture surface of sample CT933-LS. Crack extension is from bottom to top of the figure.

\subsection{Effect of Grain Boundary Type and Relative Grain Orientation on Crack Propagation}

Several studies have been conducted on the effect of grain boundary type (primarily misorientation) on the cracking behavior of Ni-base alloys in primary water environments. Although there appears to be a consensus on the improved resistance to SCC initiation of CSLBs, $32-35,37,38$ the effect of such boundaries on SCC propagation is not well understood. Palumbo et al. ${ }^{32,37,38}$ have shown that, in Ni- 
base alloys, cracking occurs almost exclusively along random interfaces. Similar behavior was reported by Gertsman and Bruemmer ${ }^{39}$ for Alloy 600 and by Pan et al. ${ }^{40}$ for Alloy X-750. In addition to the experimental observations, quite a few modeling studies have been conducted, based primarily on percolation stochastic methods ${ }^{41,42}$ or on concepts such as "grain boundary connectivity" 43 that attempt to explain the effect of grain boundary type on crack propagation. Although it is not clear whether models based on either method fully explain the available crack growth data, they all appear to have one common premise: that cracking will propagate along the HABs.

The objective of this work was to determine whether a propagating stress corrosion crack in weld Alloy 182 is influenced by the character of the grain boundaries it encounters and by the relative orientation of the adjacent grains. Our previous OIM characterization of the Alloy 182 weld alloys currently used in our CGR experiments has shown these weld alloys to have a much higher proportion of SCC-susceptible boundaries (about 75\%) than typical solution-annealed Alloy 600 (about 50\%). In addition, the OIM data reported previously has shown that, unlike the isotropic Alloy 600, in the weld alloys clusters of grains with similar orientations were observed in the weld microstructure. We hypothesize that a boundary with a weak Taylor factor mismatch - as would be the case for two neighboring grains sharing a similar orientation - would be less susceptible to deformation, thus less susceptible to cracking. ${ }^{44}$ The following experiment was conducted to test this hypothesis.

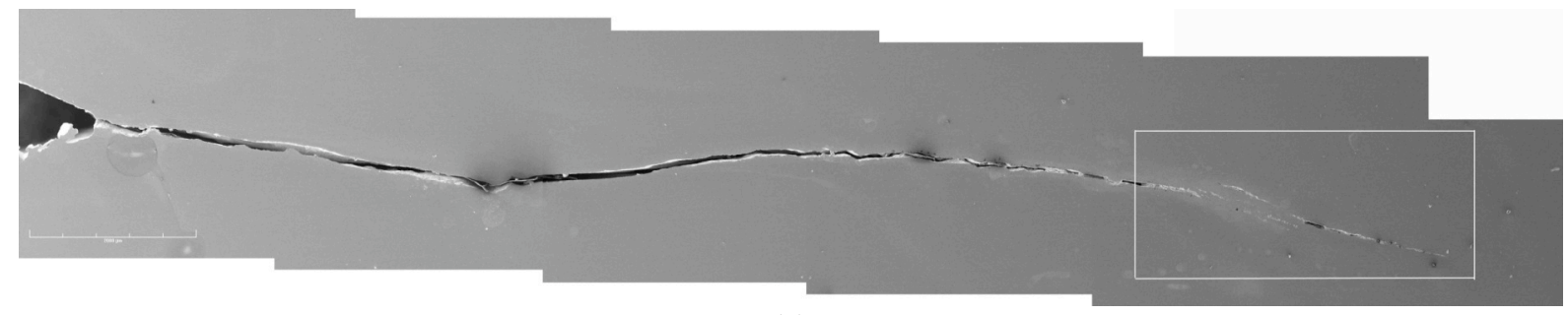

(a)

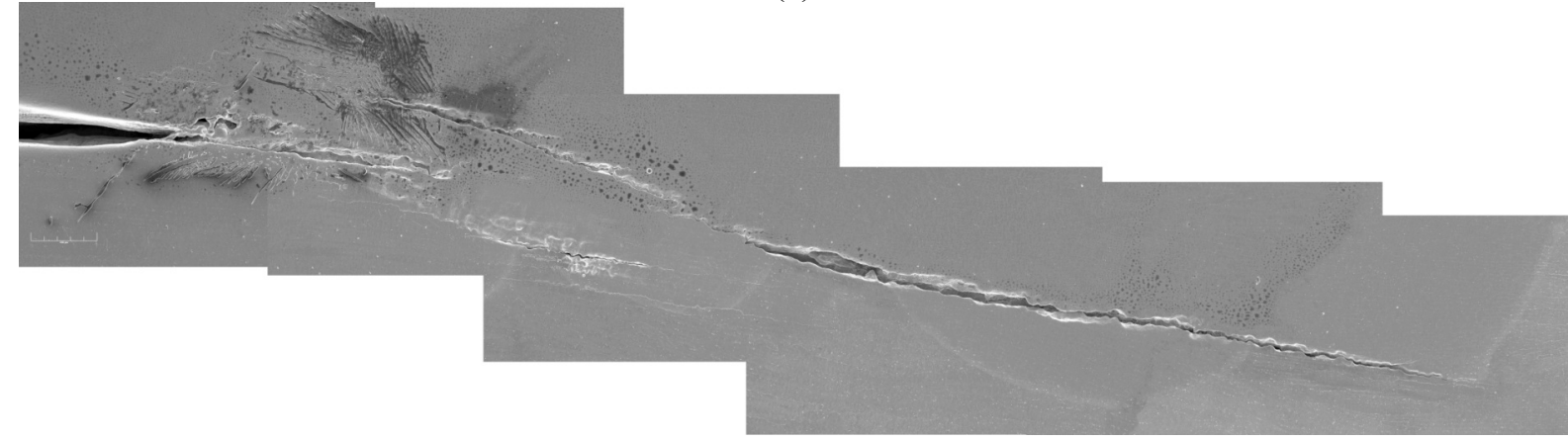

(b)

Figure 48. (a) Cross section and (b) SCC area of CT31-W02 TS (boxed region in (a)).

To determine whether the cracking behavior of a grain boundary is influenced by the relative orientation of the adjacent grains, OIM maps were acquired on the cross sections, along the crack path of two specimens, CT31-W02 TS (deep-groove weld) and CT933-TS (double-J weld), from the SCC regions. For specimen CT31-W02 TS the OIM scan was conducted in the boxed area of Fig. 48a, shown at higher magnification in Fig. 48b. By comparing the SEM images with the resulting OIM scans, the characters and the relative orientations of the neighboring grains were recorded for each cracked grain boundary. The cross section of CT933-TS was further cut into three slices, and each slice was scanned separately to improve the cracked boundary statistics. For the OIM analysis, all the specimens were mechanically polished with $1-\mu \mathrm{m}$ diamond paste and electro-polished in a perchloric acid (10\%) and methanol solution at $-50^{\circ} \mathrm{C}$. The OIM characterization was performed in a Philips XL30 FEG SEM 
equipped with a TexSem OIM system. For the subsequent SEM examination of the OIM-scanned areas, in an effort to reveal the finer cracks, too, the samples were etched in a phosphoric acid solution. Figure 49 shows an SEM image of the cross section of CT31-W02 tilted by $70^{\circ}$ for OIM analysis. This was taken in the SCC region near the end of the crack.

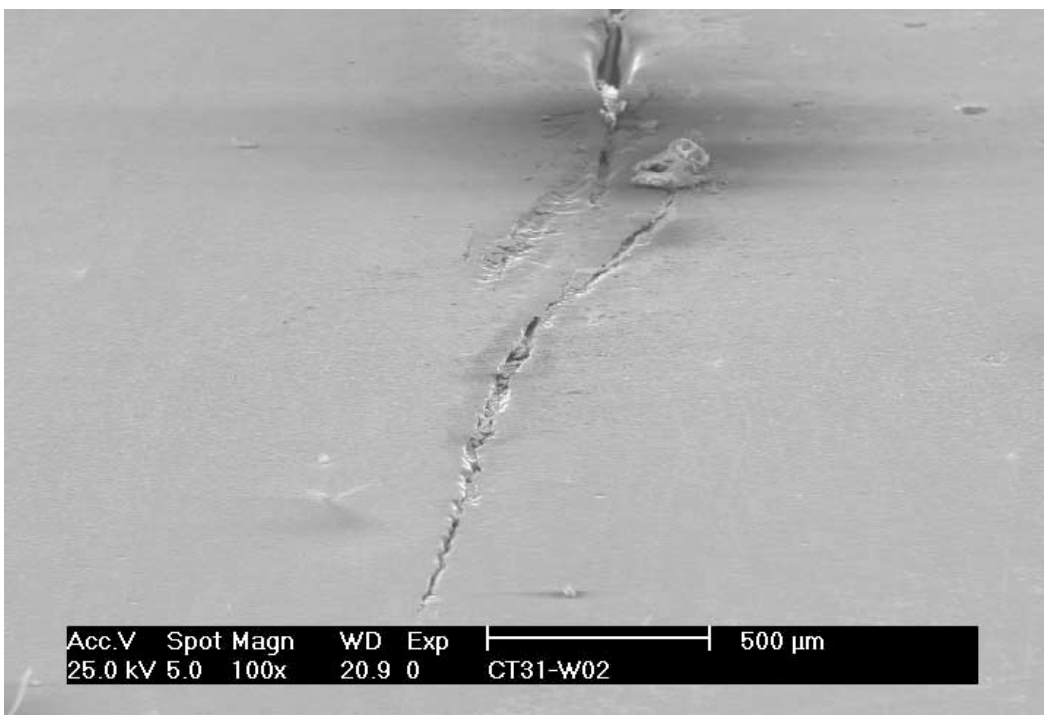

Figure 49. SEM image of the cross section of CT31-W02 tilted by $70^{\circ}$ for OIM analysis.

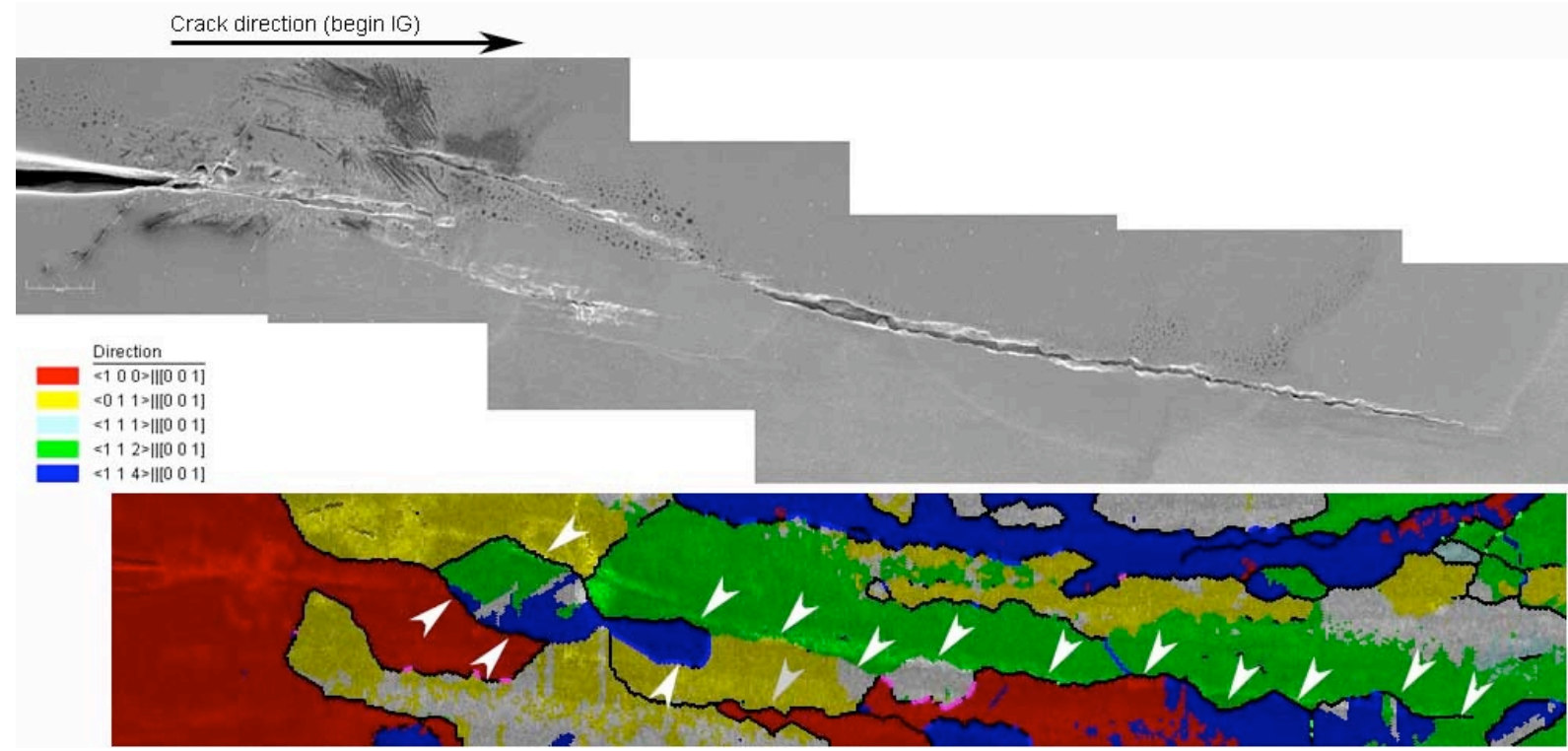

Figure 50. SCC region of specimen CT31-W02 and resulting OIM map. The cracked boundaries are indicated by arrows on the OIM map.

Figure 50 shows the SEM image of the SCC region of specimen CT31-W02 TS and the resulting OIM map. The cracked boundaries are indicated by arrows on the OIM map. One observes that cracking propagated mostly along $\mathrm{HAB}$, as expected, and mostly along grain boundaries separating grains of different orientations (shown with different colors in the OIM map of Fig. 50). Similarly, Fig. 51 shows the SEM images of the cross sections of the three samples from CT933-TS tilted by $70^{\circ}$ for the OIM analysis. 


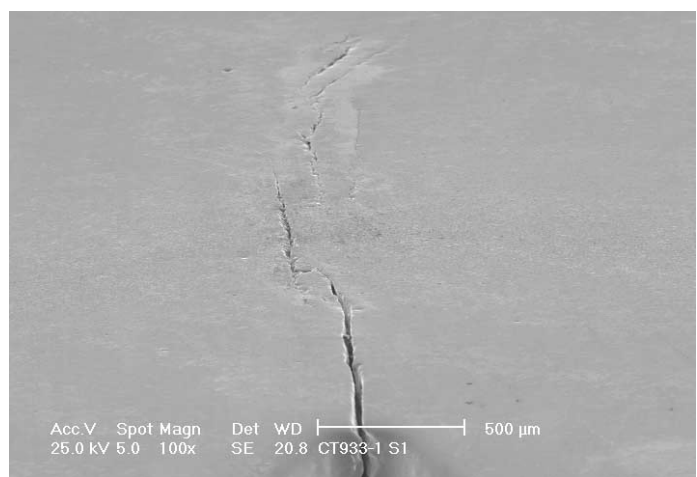

a

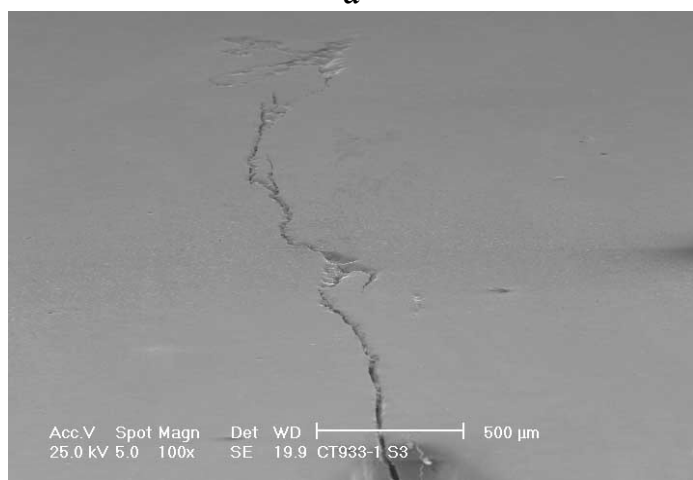

c

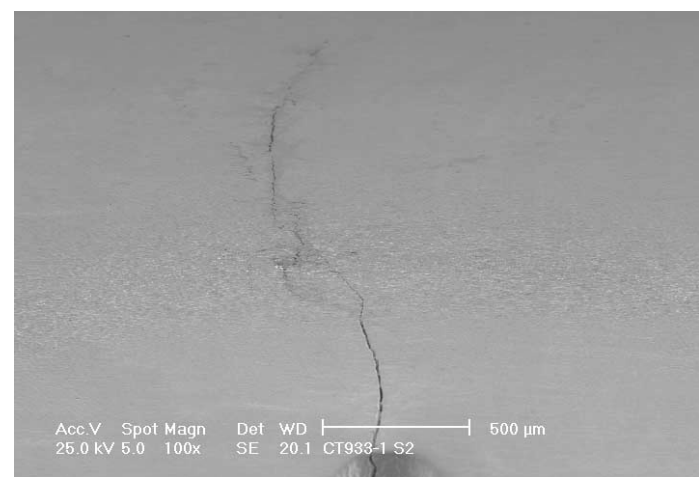

b

Figure 51

Cross sections of the three samples from CT933-TS tilted by $70^{\circ}$ for the OIM analysis:

(a) CT933-TS-S1, (b) CT933-TS-S2, and (c) CT933-TS-S3.

In a similar fashion with CT31-W02 TS, OIM maps were obtained from the SCC regions, and the cracked boundaries were identified in each scan with white arrows, shown in Fig. 52. As in the previous sample, cracking propagated mostly along HABs, and along grain boundaries separating grains of similar orientation.

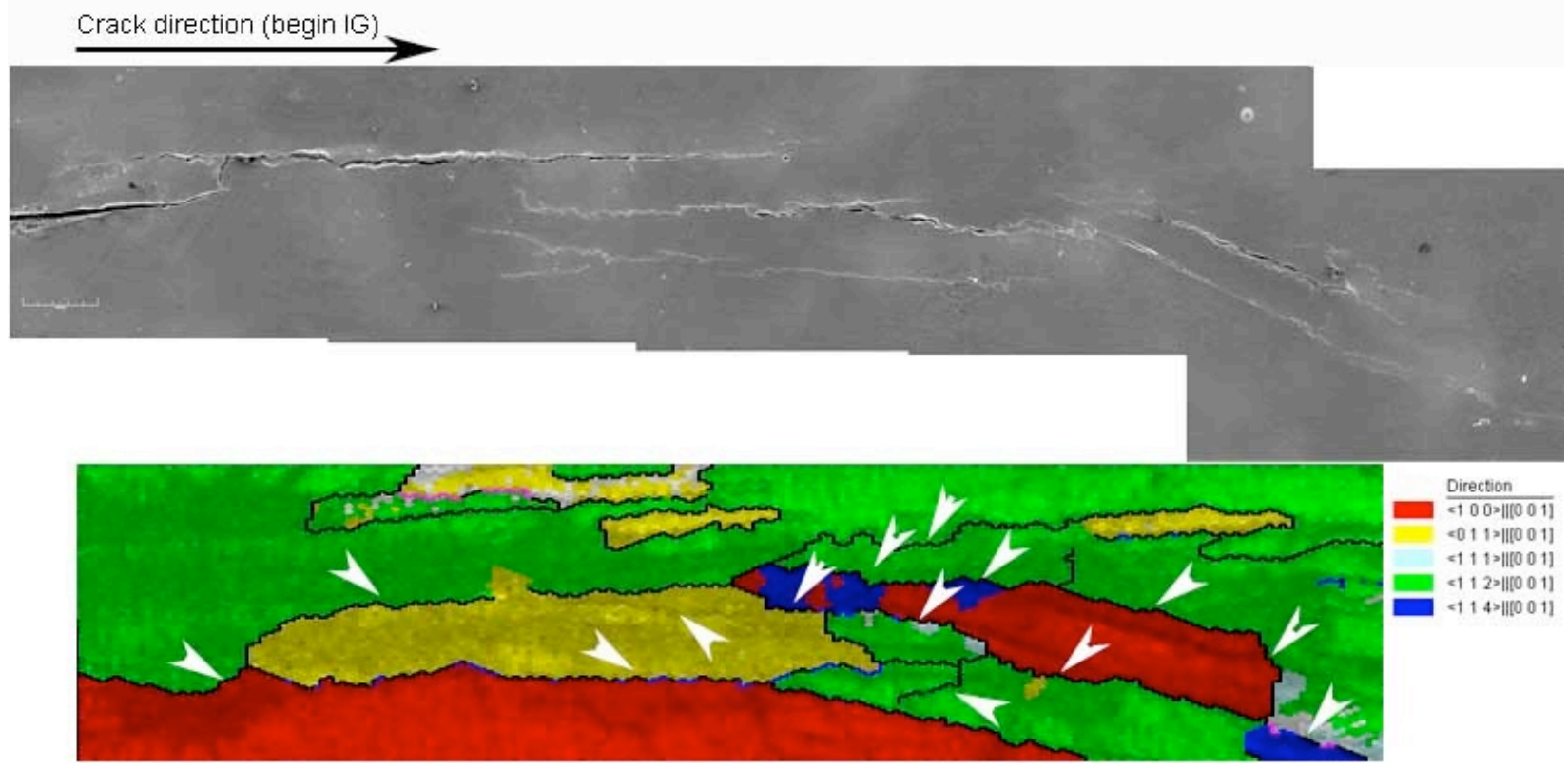

(a)

Figure 52. SCC regions and resulting OIM map for (a) CT933-TS-S1, (b) CT933-TS-S2, and (c) CT933TS-S3. The cracked boundaries are indicated by arrows on the OIM map. 


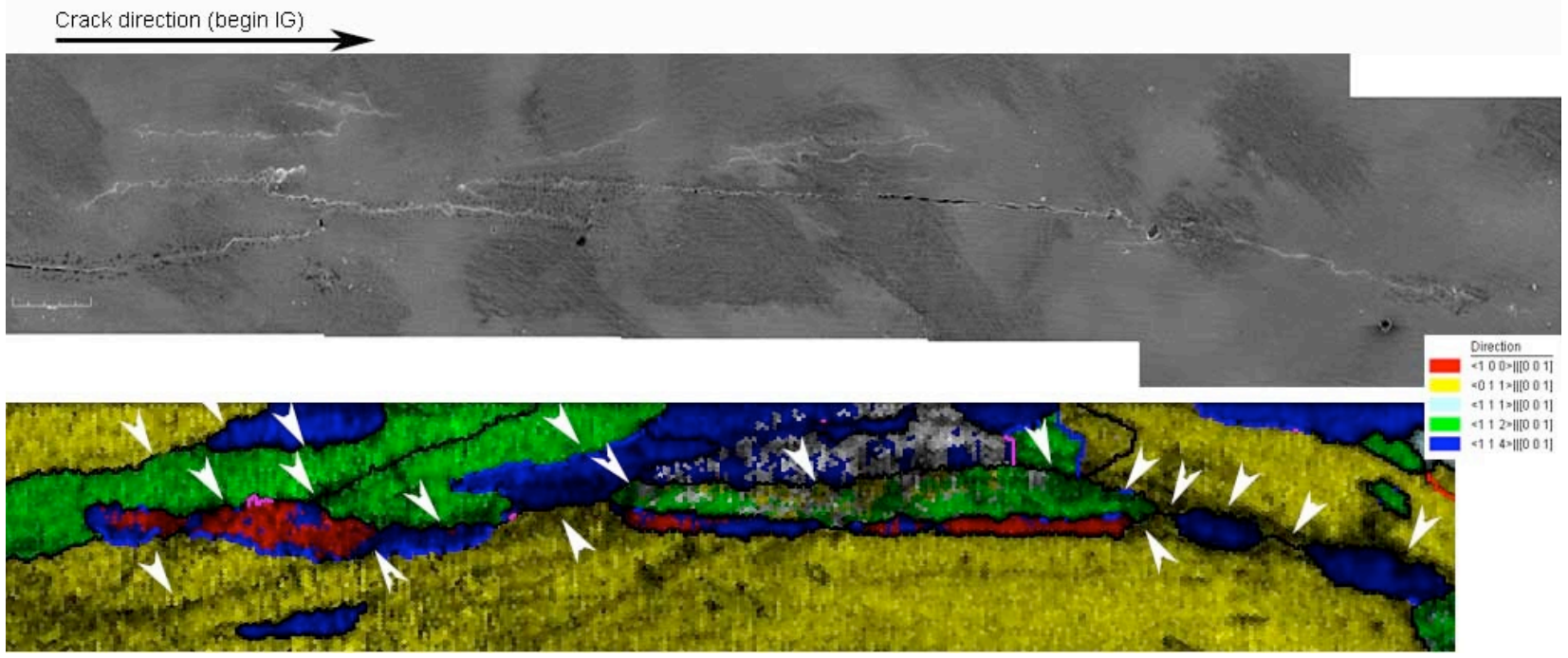

(b)

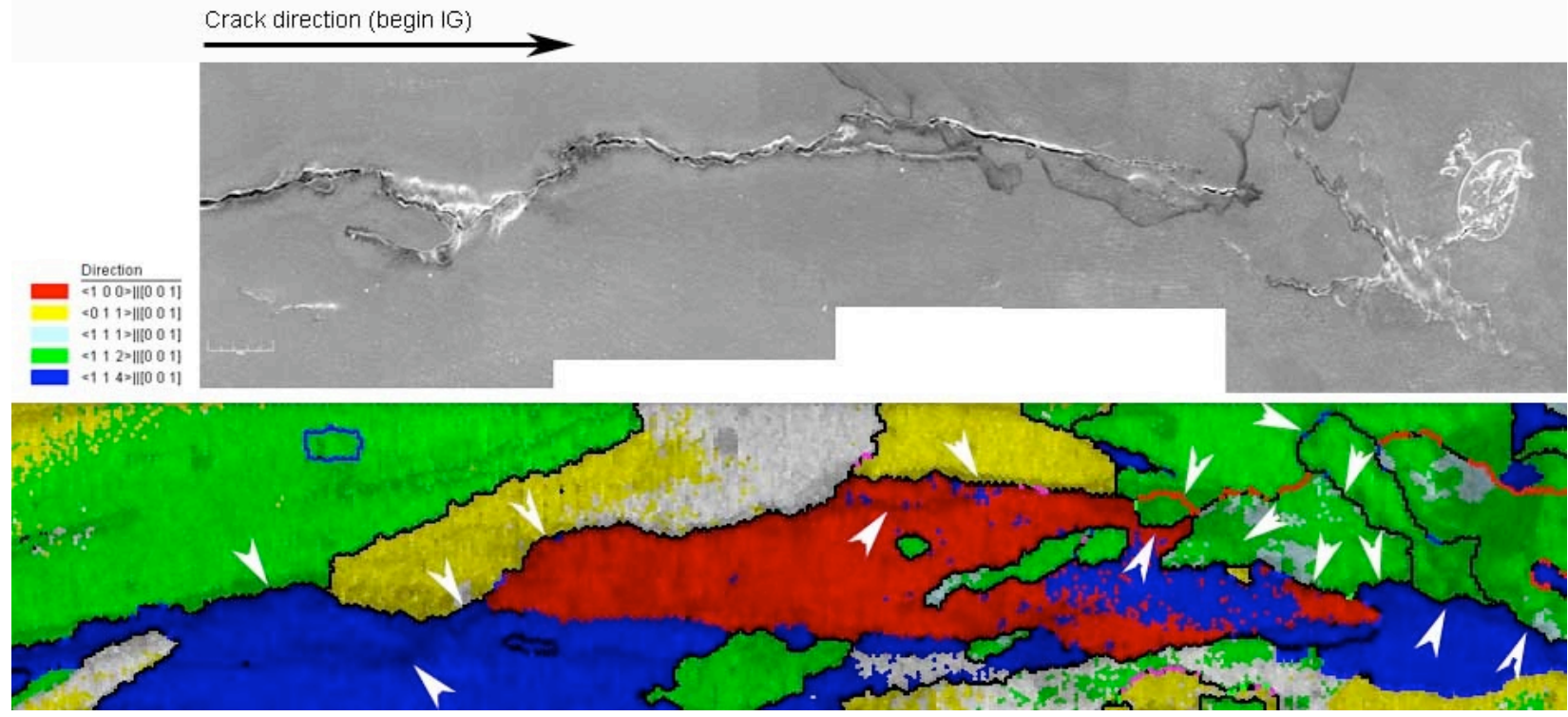

Figure 52. (Contd.)

(c)

The resulting cracking data, broken down by the orientation of adjacent grains and grain boundary (GB) types for both specimens (all four OIM scans), are shown in Table 10.

Table 10. Cracking data for both CT933-01 and CT31-W02 (all four OIM scans).

\begin{tabular}{|c|c|c|c|c|c|}
\hline \multirow[b]{2}{*}{ Specimen } & \multirow{2}{*}{$\begin{array}{c}\text { Total cracked } \\
\text { GBs } \\
\end{array}$} & \multicolumn{2}{|c|}{$\begin{array}{c}\text { Orientation of adjacent } \\
\text { grains }\end{array}$} & \multicolumn{2}{|c|}{ GB type } \\
\hline & & Different & Similar & HAB & CSLB \\
\hline CT933-01-S1 & 14 & 13 & 1 & 13 & 1 \\
\hline CT933-01-S1 & 19 & 16 & 3 & 18 & 1 \\
\hline CT933-01-S1 & 15 & 10 & 5 & 14 & 1 \\
\hline Total CT933-01 & 48 & 39 & 9 & 45 & 3 \\
\hline CT31-W02 & 15 & 14 & 1 & 13 & 1 \\
\hline
\end{tabular}


Using the data in Table 10, the fractions of cracked boundaries were calculated as a function of boundary type for both specimens. The results are plotted in Fig. 53. The uncertainties in the fractions of cracked boundaries $\sigma_{\mathrm{p}}$ were calculated according to:

$$
\frac{\sigma_{p}}{p}=\sqrt{\frac{1}{N} \frac{(1-p)}{p}}
$$

where $p$ is the fraction of cracked boundaries, and $N$ is the population of boundaries based on which the analysis was made. ${ }^{45}$ The fact that a crack is more likely to propagate along HABs was somewhat expected, in light of the numerous studies concluding that crack initiation is more likely to occur at HABs than at CSLBs. ${ }^{37,35}$ This result is in very good agreement with results reported by Gertsman and Bruemmer, ${ }^{39}$ who found that, in Alloy $600, \approx 90 \%$ of the cracked boundaries along a crack path were HABs. Although these authors attributed the increased resistance of the CSLBs to cracking to the relatively high proportions of cracking-immune coherent twins, in the present study, the microstructure does not appear to contain a significant population of twins (see the grain boundary character distribution for welds in Fig. 26). The present results suggest that the CSLBs other than the coherent $\Sigma 3$ s must be more resistant to cracking.

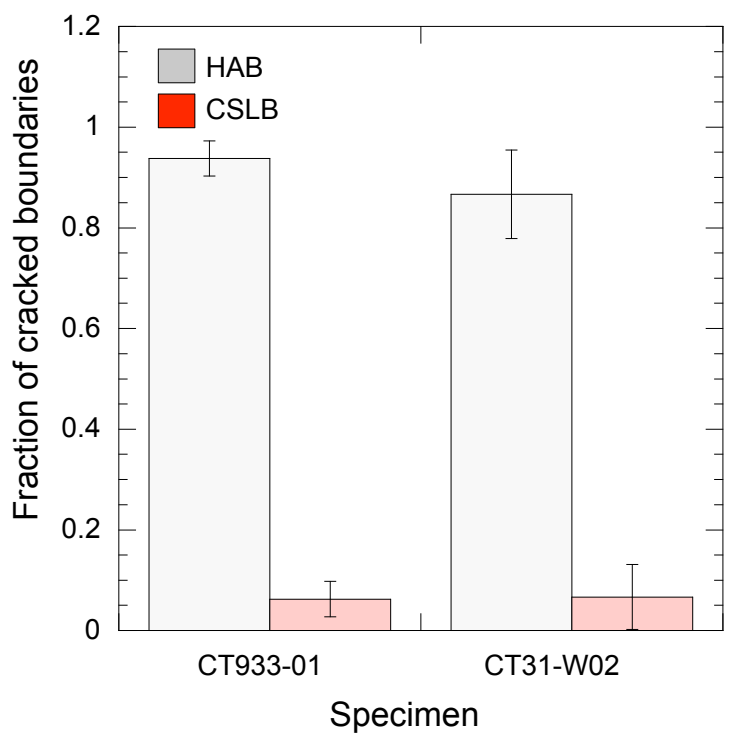

Figure 53

Fractions of cracked boundaries as a function of boundary type.

The fraction of cracked boundaries is plotted as a function of the relative orientation of the adjacent grains for both specimens in Fig. 54. The bars indicate that grain boundaries that separate grains with similar orientation are more resistant to cracking than boundaries that separate grains with different orientations. That is, the clustering of grains with similar orientations in weld alloys leads to a different class of random (HAB) boundaries, more resistant to SCC than "regular" HABs. This result is in very good agreement with that of Wright and Field for fatigue cracking in a Ni-base superalloy. ${ }^{46}$ The authors examined an otherwise-rare cracked $\Sigma 3$ and found a strong mismatch in Taylor factors across the boundary. Based on this finding, the authors suggested that Taylor factors should be included in the description of a grain boundary. 


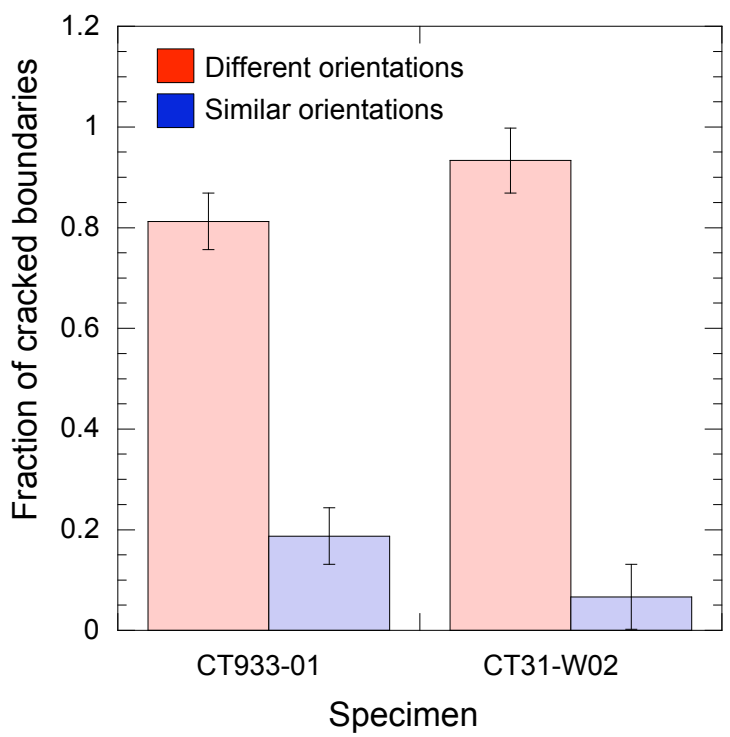

Figure 54.

Fractions of cracked boundaries as a function of the relative orientation of the adjacent grains.

Therefore, while the weld Alloy 182 contains a significantly lower CSLB fraction than a typical Alloy 600, these may not necessarily control the cracking behavior of the weld alloys. The microstructure of Alloy 182 contains clusters of grains with similar orientations, and these were found to be more resistant to cracking than boundaries that separate grains of different orientations; therefore, this information should be included along with misorientation for a better description of an alloy's susceptibility to SCC. 


\section{Discussion}

This section provides an overview of the existing crack growth data for Ni-base weld alloys and discusses in this context the data generated at ANL.

\subsection{Cyclic Crack Growth Rates}

\subsubsection{Air Environment}

The fatigue CGR (da/dN) data on Ni-alloy welds in air are quite limited. ${ }^{47-51}$ Most of the tests have been conducted on Alloy 182 and some on Alloy 52. The results indicate that the effect of temperature on CGRs of the weld metals is similar to that for Alloy 600. Fatigue crack growth data for Alloys 82 and 152 in air are not available. The experimental CGRs obtained under cyclic loading for Alloys 52 and 182 and those predicted in air for Alloy 600 under the same loading conditions are plotted in Fig. 55. In general, the CGRs for Ni-alloy welds are a factor of $\approx 2$ higher (dashed line) than for Alloy 600 under the same loading conditions. Because so few data are available, comparisons of the results for the weld alloys are usually made in terms of the results for Alloy 600 in air, rather than the weld alloys in air.

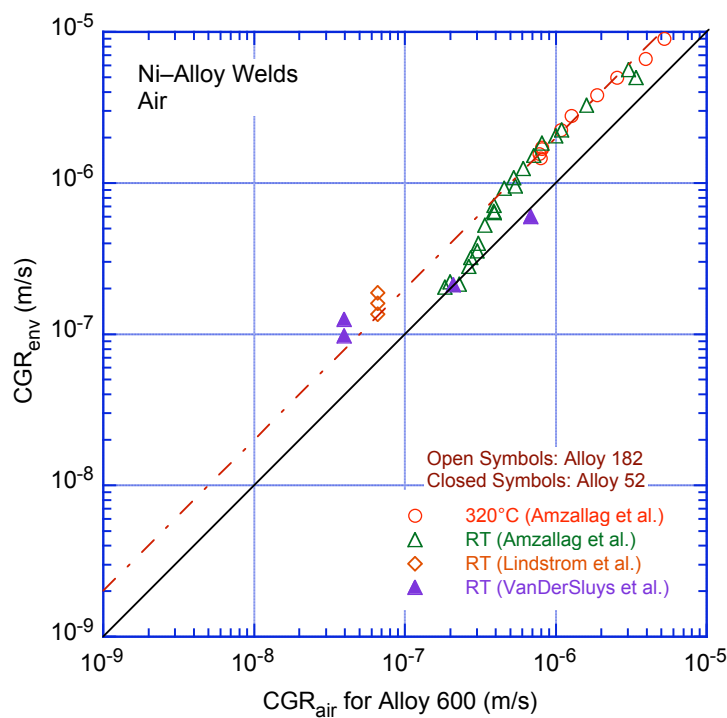

Figure 55.

Experimental values of fatigue crack growth rate of Alloys 182 and 52 in air as a function of those estimated for Alloy 600 under the same loading conditions. Data obtained by Linstrom et al. (Ref. 47), Amzallag et al. (Ref. 48), and Van Der Sluys et al. (Ref. 49).

\subsubsection{PWR Environment}

The fatigue CGR data on Ni-alloy welds in simulated PWR environments are available from $\approx 120$ tests conducted on Alloys $182,82,152$, and 52 at $243-345^{\circ} \mathrm{C} .47,48-51$ The loading conditions for these tests include $\mathrm{R}=0.1-0.75, \mathrm{~K}_{\max }=20-100 \mathrm{MPa} \cdot \mathrm{m}^{1 / 2}$, and rise time $=0.5-5000 \mathrm{~s}$. The results indicate very little effect of PWR environment on the fatigue CGRs of Ni-alloy weld metals. However, only about $10 \%$ of the data were obtained under conditions for which significant environmental enhancement would be expected.

The experimental CGRs obtained by Van Der Sluys et al. ${ }^{49}$ for Alloy 82 and by James and Mills 51 for Alloy 182 are plotted in Fig. 56 as a function of the CGRs predicted for Alloy 600 in air under the same loading conditions. The James and Mills ${ }^{51}$ data are for $243{ }^{\circ} \mathrm{C}$, where environmental effects would 
be expected to be small. Most of the data were obtained under loading conditions that result in CGRs greater than $1 \times 10^{-9} \mathrm{~m} / \mathrm{s}$ in air, i.e., load ratios $\leq 0.2$ and rise times $\leq 10 \mathrm{~s}$. Under these loading conditions, crack growth is primarily controlled by mechanical fatigue, and environmental effects are not expected to be significant even in materials susceptible to environmental enhancement. The data for Alloy 82 (Fig. 56a) extend into a loading region where strain-rate-dependent environmental enhancement would be expected in susceptible materials, although there are only a few data in the region where significant enhancement would be expected. The available data show very little frequency-dependent environmental enhancement and are best represented by the expression

$$
\mathrm{CGR}_{\mathrm{env}}=\mathrm{CGR}_{\mathrm{air} \mathrm{A} 600}+0.12\left(\mathrm{CGR}_{\mathrm{air} \mathrm{A} 600}\right)^{0.82} \text {, }
$$

where $\mathrm{CGR}_{\text {air }} \mathrm{A} 600$ is the growth rate predicted for Alloy 600 in air under the same loading conditions, although a simple constant multiplier would also represent the data almost as well.

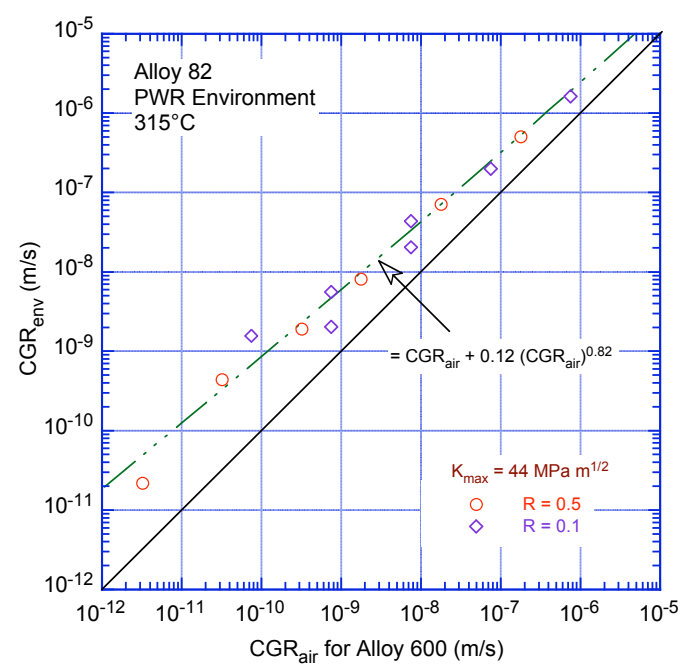

(a)

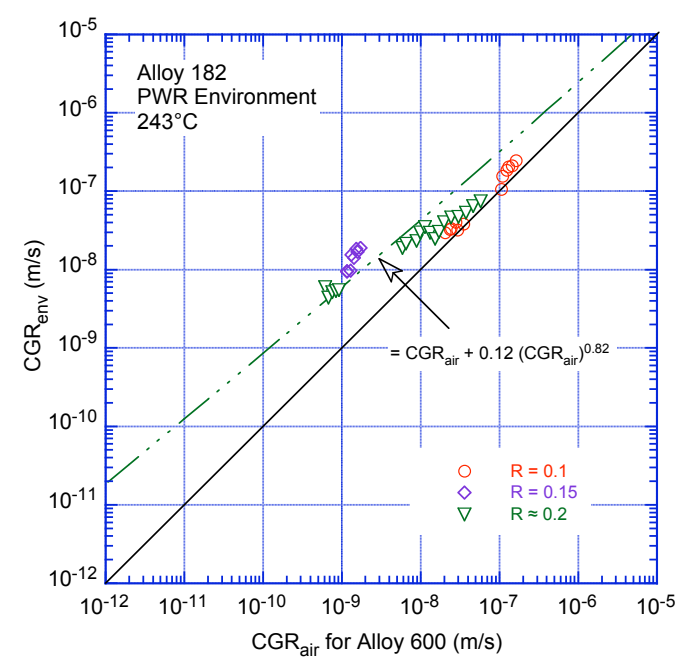

(b)

Figure 56. Fatigue CGR data for (a) Alloy 82 and (b) Alloy 182 weld metal in PWR environment as a function of the growth rate for Alloy 600 in air under the same loading conditions. Data obtained by VanDerSluys et al. (Ref. 49) and James and Mills (Ref. 51).

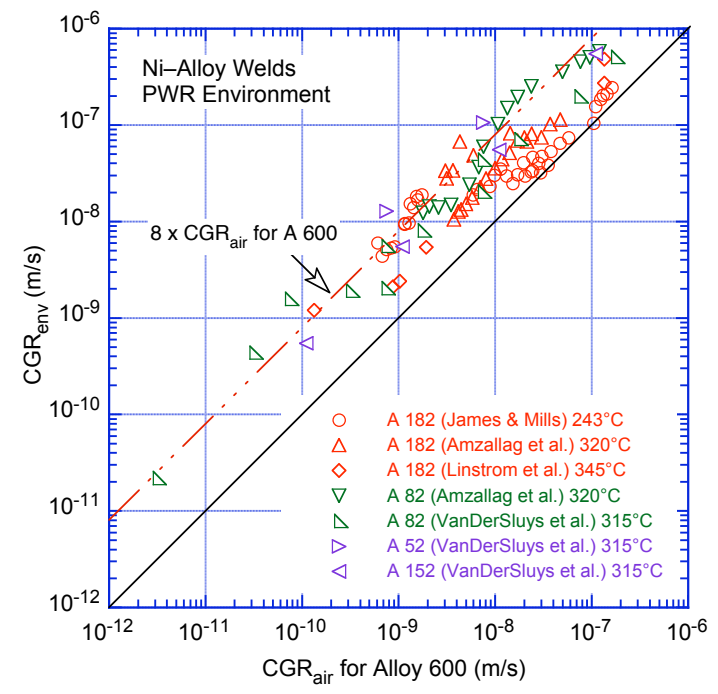

Figure 57.

Fatigue CGR data for $\mathrm{Ni}$-alloy welds in PWR environment as a function of the growth rate for Alloy 600 in air under the same loading conditions. Data from Refs. 47-51. 
Literature data on fatigue CGR for Ni-alloy welds in the PWR environment are shown in Fig. 57. The few data available for Alloys 52 and 152 are also included in the figure. Nearly $90 \%$ of the CGR data may be bounded by a curve that is a factor of eight greater than the growth rates predicted for Alloy 600 in air under the same loading conditions.

The ANL data on cyclic crack growth rates are shown in Fig. 58. They are consistent with the literature data as they also seem to show little or no environmental enhancement. Nevertheless, as with the data from the literature, Eq. 11 appears to be a good descriptor of the observed behavior. However, it also appears that most of the CGR data may be bounded by a curve that is a factor of ten greater than the growth rates predicted for Alloy 600 in air under the same loading conditions.

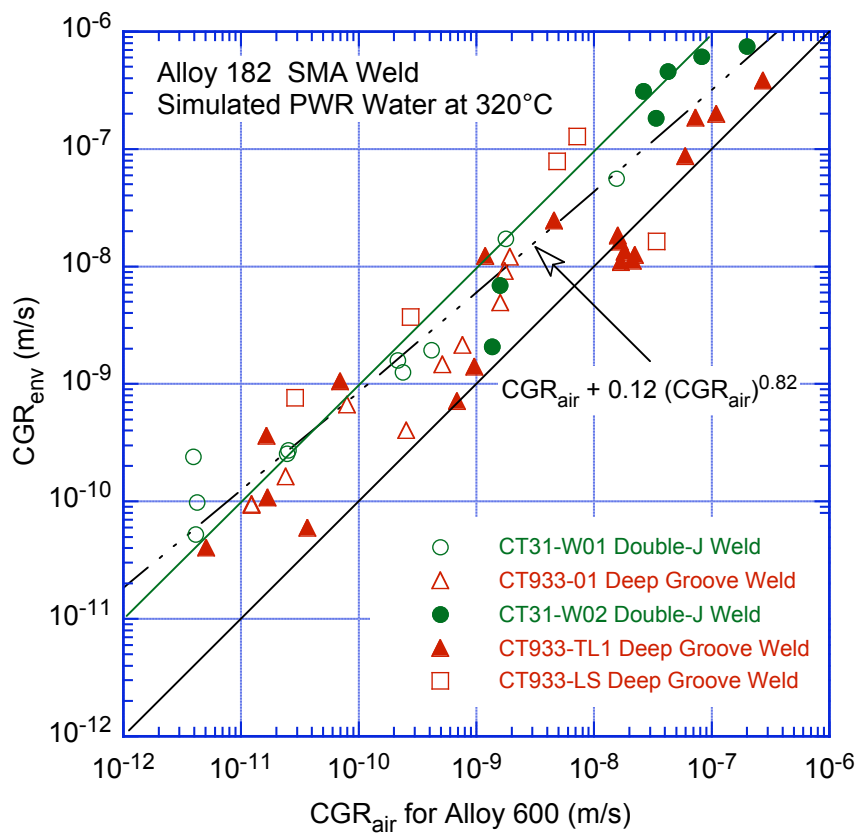

Figure 58.

CGR data for Alloy 182 SMA weld-metal specimen in simulated PWR environment at $320^{\circ} \mathrm{C}$ as a function of growth rates for Alloy 600 in air.

\subsection{Crack Growth Rates under Constant Load}

The effect of the stress intensity K on SCC crack growth for Ni-alloy welds in PWR environments has been represented by a modified ${ }^{52}$ relationship between crack growth rate CGR $_{\text {env }}(\mathrm{m} / \mathrm{s})$ and stress intensity factor $\mathrm{K}\left(\mathrm{MPa} \mathrm{m}{ }^{1 / 2}\right)$ originally developed by Scott to describe CGRs in steam generator tubing. However, unlike the CGR relationship for Alloy 600, the CGR relationship for Ni-alloy welds has no threshold value for the stress intensity factor K (in Alloy 600 the threshold is $9 \mathrm{MPa} \mathrm{m}^{1 / 2}$ ),

$$
\mathrm{CGR}_{\mathrm{env}}=\mathrm{A}(\mathrm{K})^{1.6}
$$

The term A depends on the heat of the material and the temperature. The temperature dependence is usually assumed to follow an Arrhenius behavior:

$$
A=\alpha \exp \left[-\frac{Q}{R}\left(\frac{1}{T}-\frac{1}{T_{\text {ref }}}\right)\right],
$$


where: $\mathrm{Q}=$ activation energy for crack growth

$$
\begin{aligned}
& =130 \mathrm{~kJ} / \mathrm{mol}(31.1 \mathrm{kcal} / \mathrm{mol}) \text { for Ni-alloy welds } \\
\mathrm{R} & =\text { universal gas constant } \\
& =8.314 \times 10^{-3} \mathrm{~kJ} / \mathrm{mol} \cdot \mathrm{K}\left(1.103 \times 10^{-3} \mathrm{kcal} / \mathrm{mol}{ }^{\circ} \mathrm{R}\right) \\
\mathrm{T} & =\text { absolute operating temperature in } \mathrm{K}\left(\text { or }{ }^{\circ} \mathrm{R}\right) \\
\mathrm{T}_{\text {ref }} & =\text { absolute reference temperature used to normalize the CGR data } \\
& =598 \mathrm{~K}\left(1076.67^{\circ} \mathrm{R}\right) \\
\alpha & =1.5 \times 10^{-12} \text { at } 325^{\circ} \mathrm{C} .
\end{aligned}
$$

The existing SCC CGR database on Ni-alloy welds in simulated PWR environments includes results from Westinghouse, ${ }^{53,54}$ Studsvik, ${ }^{47}$ Electricite de France (EdF), ${ }^{55}$ CEA, ${ }^{56}$ and ETH, ${ }^{57}$ on Alloy 182; from Westinghouse ${ }^{58}$ and Lockheed Martin ${ }^{59}$ on Alloys 182 and 82; from Bechtel Bettis ${ }^{60,61}$ on Alloy 82; and from Mitsubishi Heavy Industries (MHI) ${ }^{62}$ on Alloy 132. The data have been obtained at temperatures between 289 and $360^{\circ} \mathrm{C}$ and $\mathrm{K}_{\max }$ between 13 and $67 \mathrm{MPa} \mathrm{m}{ }^{1 / 2}$. A majority of the tests at EdF and all of the ETH tests were performed using wedge-opening-loaded (WOL) specimens with displacement control. The procedures for the EdF tests describe the need to check the loads at the completion of the test to determine the amount of relaxation that may have occurred, but the only data reported are for the stress intensity factors at the beginning of the test. Most of the tests at the other laboratories have been performed under active load control on specimens fatigue precracked in air.

The experimental CGRs obtained under constant load in the current tests are compared with available CGR data for Ni-alloy welds ${ }^{47,53-59}$ in Fig. 59. The industry proposed disposition CGR curve, based on Eq. 12 for Alloy $182^{52}$ in the PWR environment at $325^{\circ} \mathrm{C}$ is also plotted in the figure. The data were normalized to $325^{\circ} \mathrm{C}$ using Eq. 13 and an activation energy of $130 \mathrm{~kJ} / \mathrm{mol}$. Most of the existing data for Alloys 182 and 82 welds are between the Alloy 600 average curve and a factor of 10 above this curve.

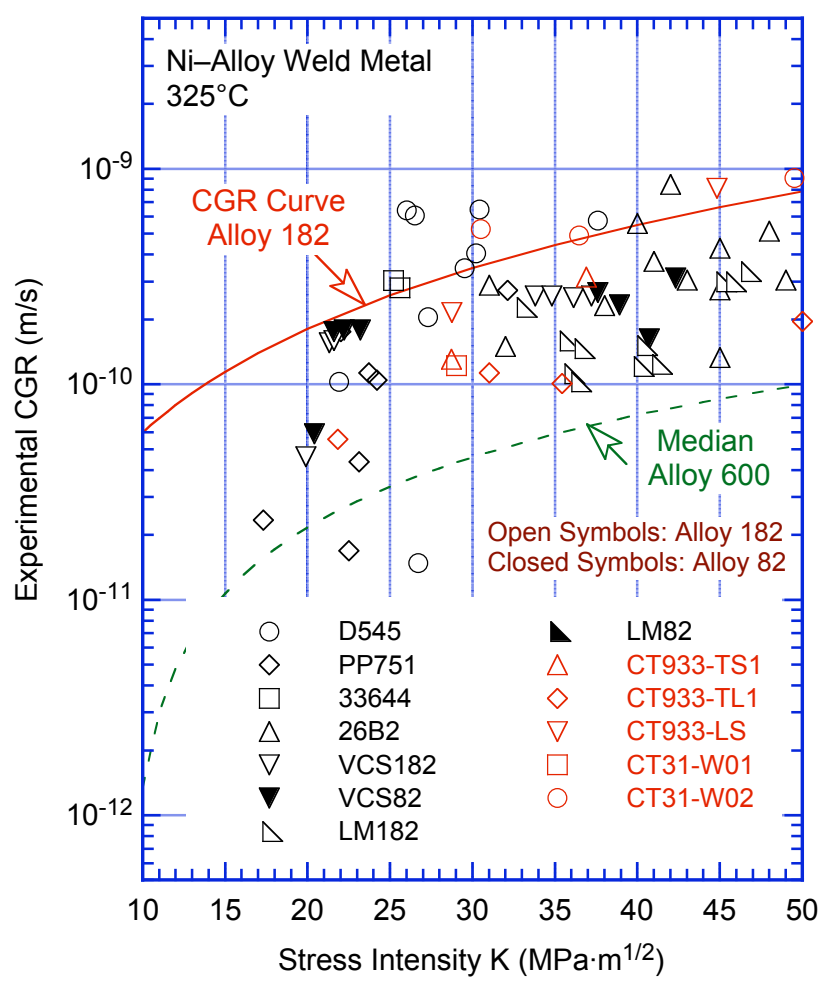

Figure 59.

Comparison of the SCC crack growth rate for the Argonne Alloy 182 weld with the available data for Alloy 182 and 82 welds in simulated PWR environment. All results normalized to $325^{\circ} \mathrm{C}$ using an activation energy of $130 \mathrm{~kJ} / \mathrm{mol}$. Data from Refs. 47,53-59. 
Some of the earlier studies used the DC potential drop technique to estimate crack extension during the test and shed load to maintain a constant $\mathrm{K}$. The presence of unbroken ligaments, time-dependent changes in the resistivity of $\mathrm{Ni}$-alloys exposed to a PWR environment, and shifts in $\mathrm{Ni} / \mathrm{NiO}$ stability regime with changes in dissolved hydrogen level, can result in significant uncertainties in crack length measurements. Many laboratories concluded that DC potential drop measurements of crack length were not reliable for Alloy 182,56,61 and recommendations were made to use potential drop only to detect initiation of active crack growth and to adhere to a "one set of conditions, one test specimen" protocol so that fractographic measurements could be used to determine the change in crack length. However, in some recent studies, including the present study, the reversed current DC potential drop technique has been successfully used to monitor crack extension in Ni alloys in PWR environments. ${ }^{47,58,62}$ The success may depend on the uniformity of the crack front. In addition, an internal reference sample made of the same material as the test specimen is commonly used to normalize the test results to compensate for possible changes in temperature, material resistivity, etc.

\subsection{Effect of Key Parameters on SCC Crack Growth Rates}

\subsubsection{Effect of Orientation of Dendrites}

Alloy 182 has a highly anisotropic structure. As the weld is deposited, dendrites grow transverse to the weld direction. Crack growth rates have been measured along the plane of the columnar grains/dendrites in a direction parallel to the columnar grains (designated TS orientation) and perpendicular to the columnar grains (designated TL orientation). Investigators at EdF concluded that although there is significant scatter, as evident in Fig. 60, the growth rates parallel to the dendrites are in general a factor 2 to 5 higher than the growth rates perpendicular to the dendrites. Similar behavior has also been observed in other studies, as shown in Fig 61. In interpreting the results in Fig. 61, note that the results for TS and LS orientations should be comparable. The crack plane for both orientations is along the columnar dendrites, although it is parallel to the direction of the weld deposit in the TS orientation and perpendicular to the direction of the weld deposit in the LS orientation. There is significant overlap in the experimental CGRs in the TL and TS orientations, e.g., the growth rates for Bechtel Bettis Alloy 82 weld $\mathrm{C}$ appear to be higher for the TL than TS orientation. Also, in the present study, the transition from a TG mode to IG SCC occurred sooner for the grains with dendrites perpendicular rather than parallel to the direction of crack growth.

Figure 62 shows CGR data obtained at ANL under constant load for laboratory-prepared weld alloys. Consistent with the other data in the literature, ${ }^{53,54,60,61}$ at high $\mathrm{K}$ values the CGRs for cracks propagating across the direction of dendrites (orientation TL) are about a factor of two smaller than the CGRs for crack propagation along the direction of dendrites (orientations TS and LS). 


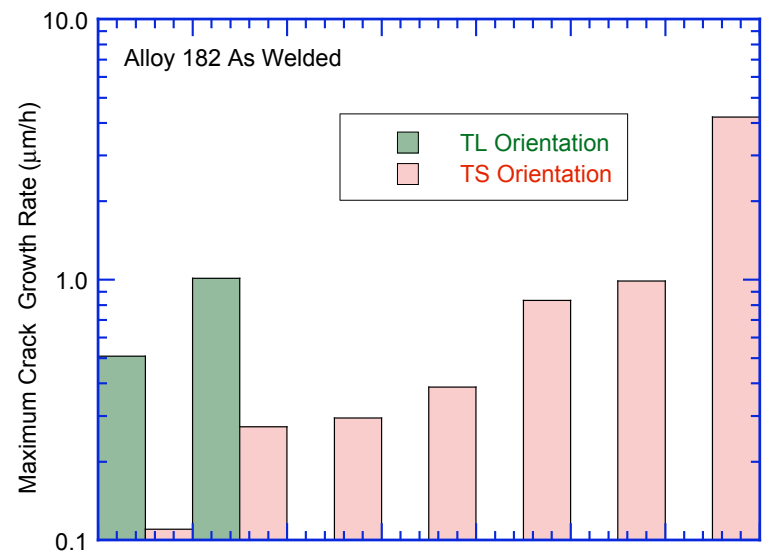

Figure 60.

Experimental crack growth rates in Alloy 182 weld in TL and TS orientations. Data from Ref. 55.

\subsubsection{Effect of Size of the Experimental Crack Advance}

As discussed in Section 4.2, both grain boundary type and grain orientation have an important effect on crack growth. Both Alloys 600 and 182 were found to contain increased proportions of HAB or

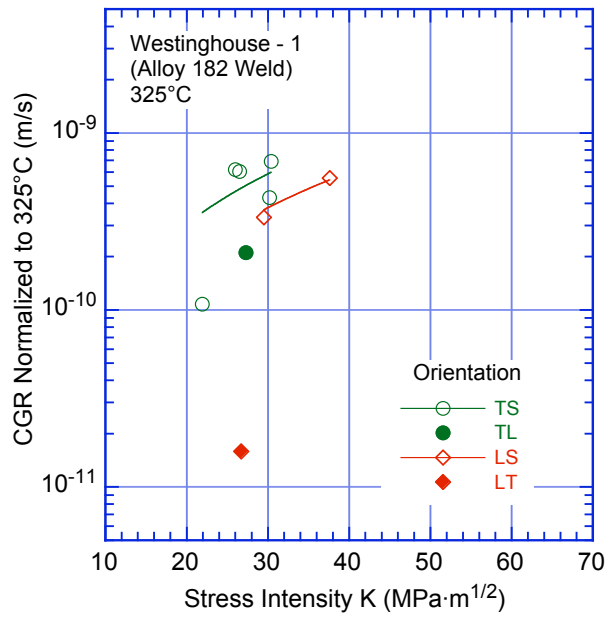

(a)

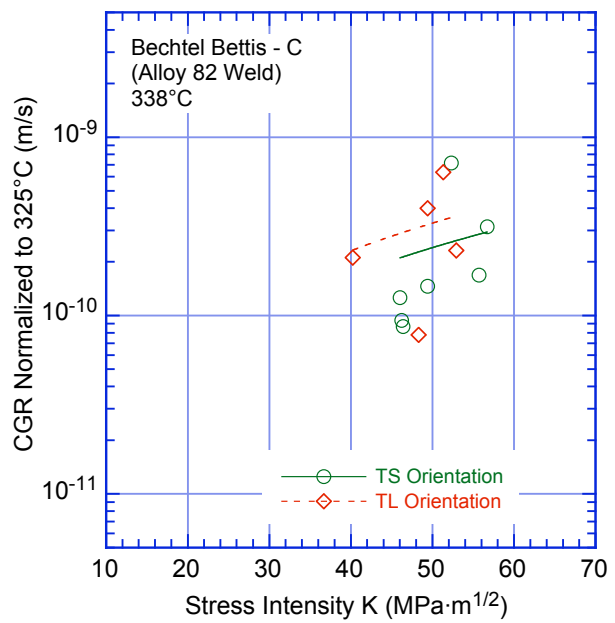

(c)

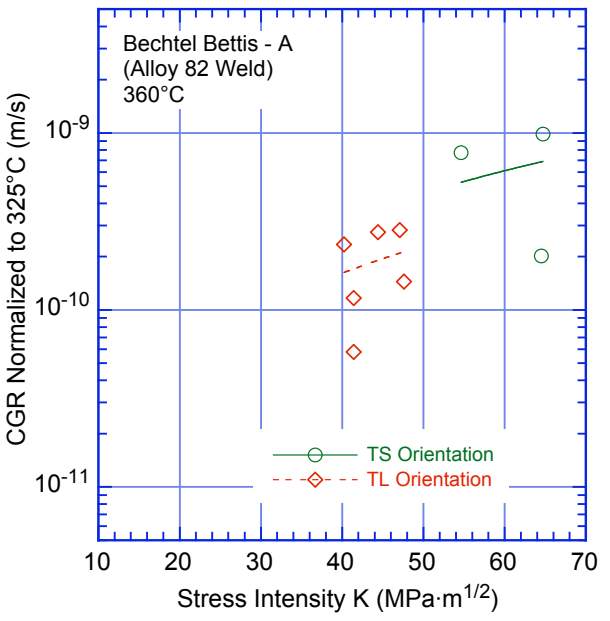

(b)

Figure 61.

Influence of the orientation of the dendrites on the crack growth rates in Alloy 182 and 82 welds in PWR environments. Note that differences in test temperatures preclude direct comparison of the Alloy 182 and 82 CGRs. Data from Refs. 53,54,60,61. 


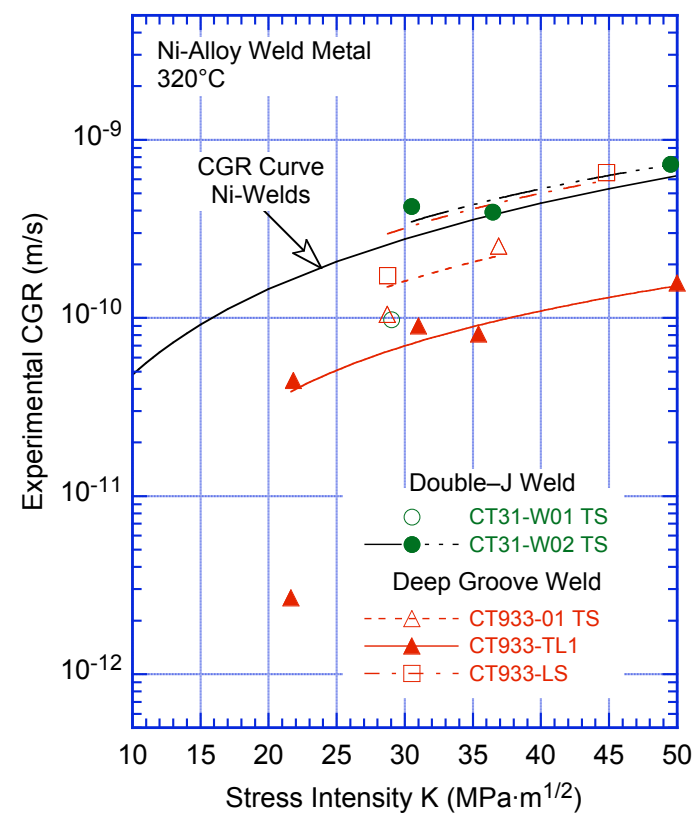

Figure 62.

SCC crack growth data for the Argonne

Alloy 182 weld specimens tested.

random boundaries $(\approx 60 \%$ in Alloy 600 , and $\approx 70 \%$ for weld Alloy 182$)$, well above the percolation threshold for a 2 -D plane in a 3 -D lattice $(\approx 22 \%),{ }^{63}$ as would be the case of a propagating SCC crack in an alloy. Therefore, one can safely assume for simplicity that only the random boundaries participate in the cracking process, and thus, it is the uncertainty in the fraction of random boundaries that it is most likely to affect the observed crack growth. Hence, in a CGR test, the crack advance must encompass a sufficient number of grain boundaries so that the resulting CGR is representative for the alloy being investigated.

The uncertainty in the fraction of random boundaries has two sources. The first is of statistical nature and depends on the number of boundaries based on which the fraction of random boundaries is calculated. The second is of physical nature, and reflects the fact that the grain boundary character distribution is inhomogenous for any metallic material. For this analysis, we estimated the potential difference between the fraction of the cracking-susceptible HAB boundaries cracked during a test and the average number of susceptible boundaries in the material. We assumed that: (a) only HABs cracked, and (b) the HABs are distributed homogeneously in the alloy. These assumptions provide a conservative estimate for the number of grain boundaries that must be sampled.

In Alloy 600, the grain size of the material varies from 30 to $100 \mu \mathrm{m}$, with an average size of $\approx 50 \mu \mathrm{m}$. As shown in Table 11 , a crack advance of $\approx 50 \mu \mathrm{m}$ would encounter $\approx 440$ grains across the net thickness of $\approx 22 \mathrm{~mm}$ for a $25.4-\mathrm{mm}$ thick $1-\mathrm{T}$ CT specimen. A simple statistical formalism by Alexandreanu and $\mathrm{Was}^{45}$ can be used to evaluate how representative is this sample for the material being investigated. Assuming, as previously stated, that only random boundaries are susceptible to cracking and that the random boundary fraction is $60 \%$ in Alloy 600 , the deviation in the fraction of susceptible random boundaries that would result from a sample of 440 grains from that typical of the material is $3.9 \%$. Increasing the crack advance to $500 \mu \mathrm{m}$ would reduce the deviation to $1.2 \%$. However, the inhomogeneity in the fraction of HAB boundaries is about $12 \%$. Thus, increasing the crack extension to $500 \mu \mathrm{m}$ to obtain an error of $1.2 \%$, in reality, provides no assurance that the number of boundaries tested is representative of the alloy of interest. 
Table 11. Fractional errors in the population of cracking susceptible HABs as a function of alloy, orientation, and crack advance.

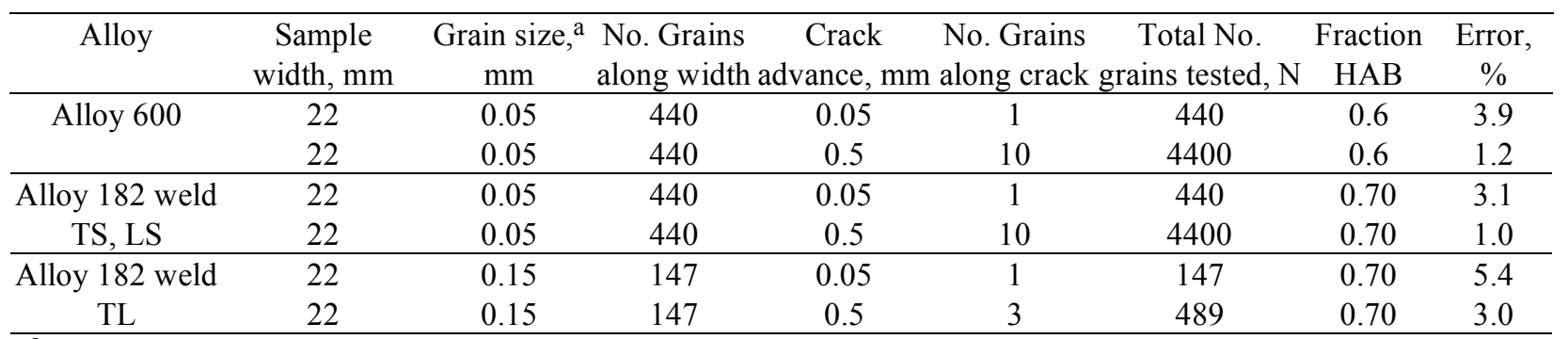

${ }^{\mathrm{a}}$ The grain size is as seen by the crack front.

A similar analysis can be made for Alloy 182 weld, the results are also given in Table 11. Although increasing the crack advance from 50 to $500 \mu \mathrm{m}$ would decrease the deviation of the fraction of HABs from that representative of the material, it is not clear whether the reduction would be significant in terms of the inhomogeneity of the alloy. Although the inhomogeneity of the HAB distribution in the weld alloy has not been analyzed in detail for weld Alloy 182, the results obtained from the three OIM scans presented in a Section 4.2 suggest that the inhomogeneity in the HAB fraction in the weld materials is about $5.5 \%$. Thus, the $5.4 \%$ difference in the fraction of HABs associated with a $50-\mu \mathrm{m}$ crack advance in a TL-oriented specimen in a homogeneous material, shown in Table 11, is comparable to the actual inhomogeneity of the weld. As with Alloy 600, increasing the crack length to $500 \mu \mathrm{m}$ to obtain an error of $3.0 \%$ provides little additional assurance that the material encountered is representative of the alloy tested.

\subsubsection{Effect of Gentle Cycling and Periodic Unloading}

Preferential growth along favorably oriented grains can lead to extremely uneven crack fronts. Even when crack advance is uniform, unbroken ligaments can be left behind the advancing crack. The ratio of maximum to average crack extension is often used to quantify the extent of engagement with the precrack. ${ }^{61}$ Typically crack fronts become more even for larger amounts of growth. For average crack extensions less than $1 \mathrm{~mm}$, the maximum crack extension is typically 2 to 4 times greater. For average crack extensions greater than $3 \mathrm{~mm}$, the ratio of maximum-to-average extension is 1.3.

In recent studies a partial unload/reload cycle is often introduced during SCC crack growth tests. This test condition tends to result in a more uniform crack front and more consistent growth rates than obtained from pure constant load (or constant displacement) tests. ${ }^{61}$ Also, specimens are often fatigue precracked in the water environment, and to assist the transition from a TG fatigue crack to IG SCC, the final precrack is performed with gentle cycling at $R \geq 0.5$ and rise times $\geq 1000 \mathrm{~s}$. A comparison of experimental CGRs obtained with and without periodic partial unloading is shown in Fig. 63. The results obtained at different temperatures were normalized to $325^{\circ} \mathrm{C}$ using the Arrhenius equation and an activation energy of $130 \mathrm{~kJ} / \mathrm{mol}$. Crack growth rates obtained with unloading period $\geq 1000 \mathrm{~s}$ appear to show good agreement with the data obtained with constant load. 


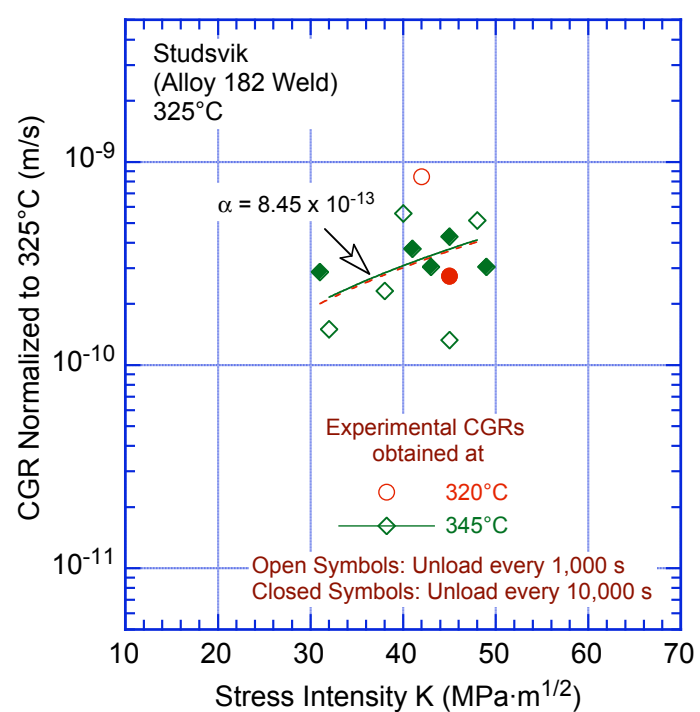

(a)

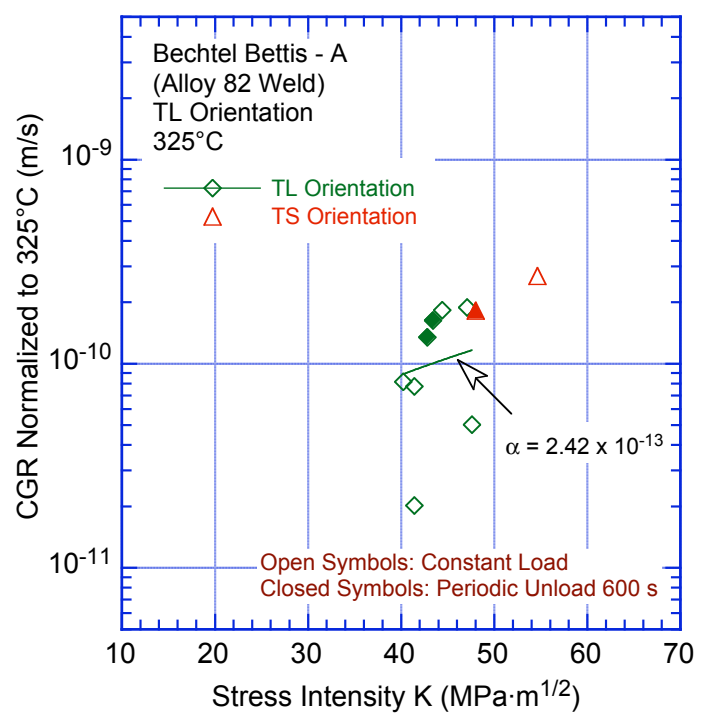

(c)

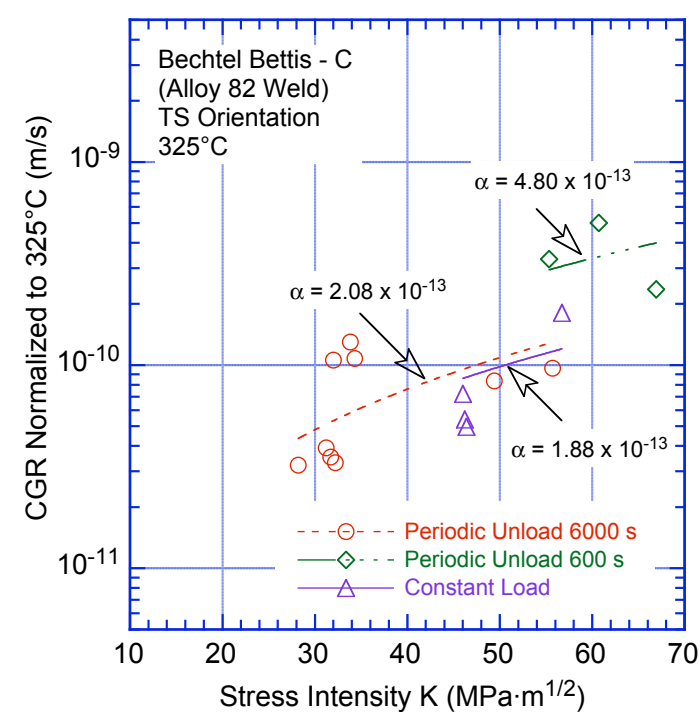

(b)

Figure 63.

Experimental crack growth rates of

Alloy 182 and 82 welds obtained with and without periodic partial unloading.

Data from Refs. 47,60,61.

\subsubsection{Effect of Water Chemistry}

The water chemistries used for the CGR tests at Westinghouse, ${ }^{53,54}$ Studsvik, ${ }^{47} \mathrm{EdF}^{55}$ and CEA ${ }^{56}$ on Alloy 182 are fairly similar, e.g., $1000-1200 \mathrm{ppm} \mathrm{B,} \approx 2 \mathrm{ppm} \mathrm{Li}$, and $20-35 \mathrm{cc} / \mathrm{kg}$ dissolved hydrogen, and are characteristic of the start of the fuel cycle. Tests by Tsutsumi et al. ${ }^{62}$ and Jacko et al. ${ }^{58}$ were performed in PWR water with $1800 \mathrm{ppm} \mathrm{B}, 3.5 \mathrm{ppm} \mathrm{Li}$, and $\approx 30 \mathrm{cc} / \mathrm{kg}$ dissolved hydrogen. The water chemistries for the tests at Lockheed Martin ${ }^{59}$ used hydrogen levels of $20-40 \mathrm{cc} / \mathrm{kg}$, and the tests at Bechtel Bettis ${ }^{61}$ used $150 \mathrm{cc} / \mathrm{kg}$ for the tests at $360^{\circ} \mathrm{C}$ and $40-60 \mathrm{cc} / \mathrm{kg}$ for the tests at lower temperatures.

The effect of dissolved hydrogen level on CGRs in Ni alloys has been investigated by Morton et al. in SCC studies. ${ }^{64}$ Several conclusions wee reached. A change in hydrogen level alters the electrochemical potential, and the growth rate exhibits a maximum at potentials in proximity to the $\mathrm{Ni} / \mathrm{NiO}$ phase transition. The dependency of growth rates on dissolved hydrogen level is best described in terms of the potential relative to the $\mathrm{Ni} / \mathrm{NiO}$ phase transition and not the dissolved hydrogen level. The 
peak CGR at different temperatures corresponds to the potential for the $\mathrm{Ni} / \mathrm{NiO}$ phase transition, which occurs at different hydrogen concentrations for different temperatures. The CGRs decrease as the electrochemical corrosion potential deviates from the corrosion potential of the $\mathrm{Ni} / \mathrm{NiO}$ phase transition.

Earlier studies on primary water SCC in steam generator tubing showed relatively little dependence on variations in primary water chemistry within the current PWR water chemistry guidelines. ${ }^{65}$ Some limited studies on Alloy 600 nozzle materials* show similar results. In most of these tests, the chemistry variables are changed one at a time, i.e., one variable is varied over the range of interest while the other variables are held at their nominal value. In the work reported in Ref. 65, a much larger effect of water chemistry was observed when several variables were changed simultaneously. However, in these tests $\mathrm{KOH}$ was used to vary $\mathrm{pH}$ so that the water chemistries were not truly prototypical of PWR primary chemistry. The effect of water chemistry on CGRs appears to be an area that requires additional study.

\subsubsection{Effect of Temperature}

Alloys 600 and 182 show a significant variation of CGR with temperature. For Alloy 600, activation energies for crack growth have been estimated as $130 \mathrm{~kJ} / \mathrm{mol}(31.1 \mathrm{kcal} / \mathrm{mol}){ }^{28}$ For Alloys 182 and 82 welds, the data sets with the most data on temperature variations are plotted in Figs. 64 as a function of $1000 / \mathrm{T}$, where $\mathrm{T}$ is the absolute temperature in Kelvin. In Fig. $64 \mathrm{c}$ because the $288^{\circ} \mathrm{C}$ data were obtained with a $600-$ s unload/reload cycle, which is shown in Section 5.3.3 to result in a factor of $\approx 2$ increase in CGRs, the data were decreased by a factor of 2 . The different data sets yield activation energies that are either comparable to that observed for Alloy 600, e.g., the Bechtel Bettis ${ }^{60,61}$ and ETH ${ }^{57}$ data sets, or a factor of $\approx 2$ higher, e.g., the Westinghouse, ${ }^{53,54}$ Lockheed Martin, ${ }^{59}$ and CEA ${ }^{56}$ data sets. The Bechtel Bettis tests were conducted within the Ni regime, i.e., above the hydrogen concentrations for the $\mathrm{Ni} / \mathrm{NiO}$ phase transition. However, the $360^{\circ} \mathrm{C}$ tests at $150 \mathrm{cc} / \mathrm{kg}$ hydrogen were farther removed from the $\mathrm{Ni} / \mathrm{NiO}$ phase transition than the $338^{\circ} \mathrm{C}$ tests conducted at $40-60 \mathrm{cc} / \mathrm{kg}$ hydrogen. As discussed above in Section 5.3.4, the CGRs are highest near the $\mathrm{Ni} / \mathrm{NiO}$ phase transition and decrease as the potential deviates from the $\mathrm{Ni} / \mathrm{NiO}$ potential. It is possible that the CGRs in the $360^{\circ} \mathrm{C}$ tests may have been reduced because of the high dissolved hydrogen levels. Thus, the activation energy for the Bechtel Bettis data may be slightly higher than that determined in Fig. 64c.

Although the measured activation energies have substantial uncertainy, it appears not unreasonable to adjust data when necessary using an activation energy of $130 \mathrm{~kJ} / \mathrm{mol}$. The data suggest the possibility that the activation energy for Alloys 182 and 82 welds may be slightly higher than that for Alloy 600 .

\footnotetext{
*"Crack Growth and Microstructural Characterization of Alloy 600 PWR Vessel Head Penetration Materials," Licensed Document, Electric Power Research Institute, Palo Alto, 1997.
} 


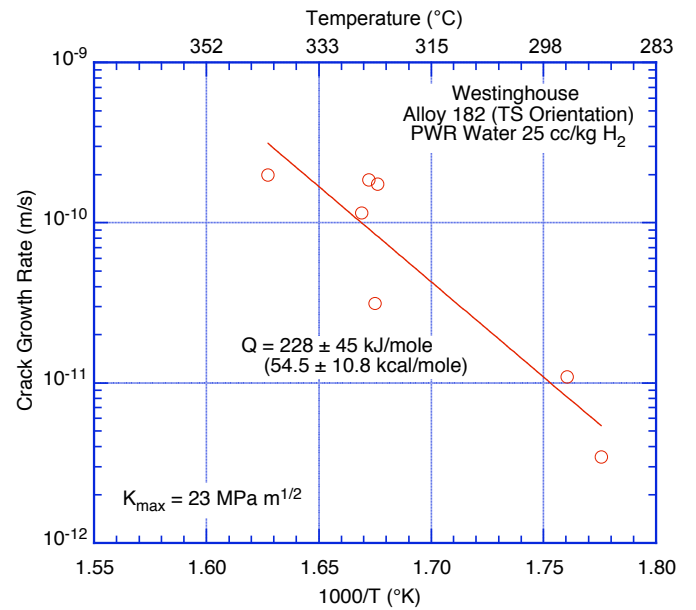

(a)

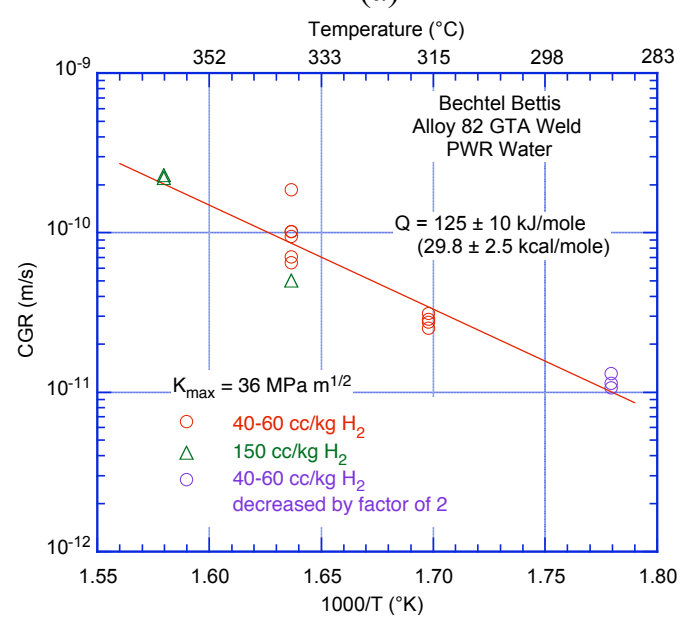

(c)

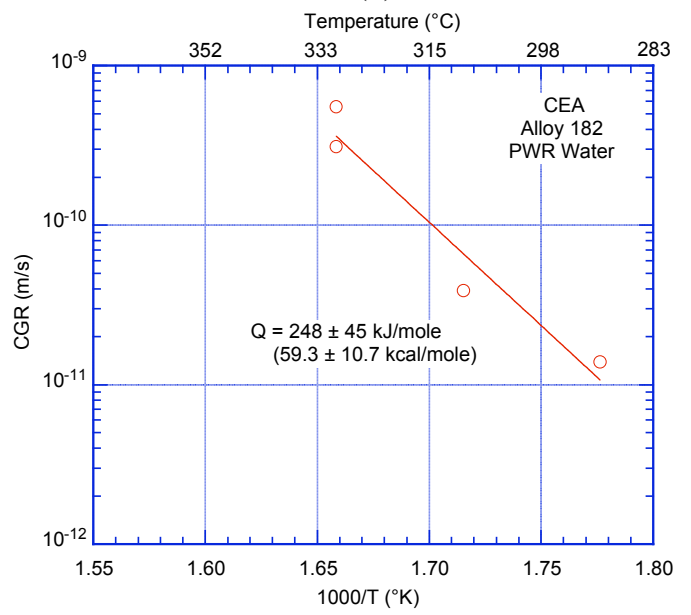

(e)

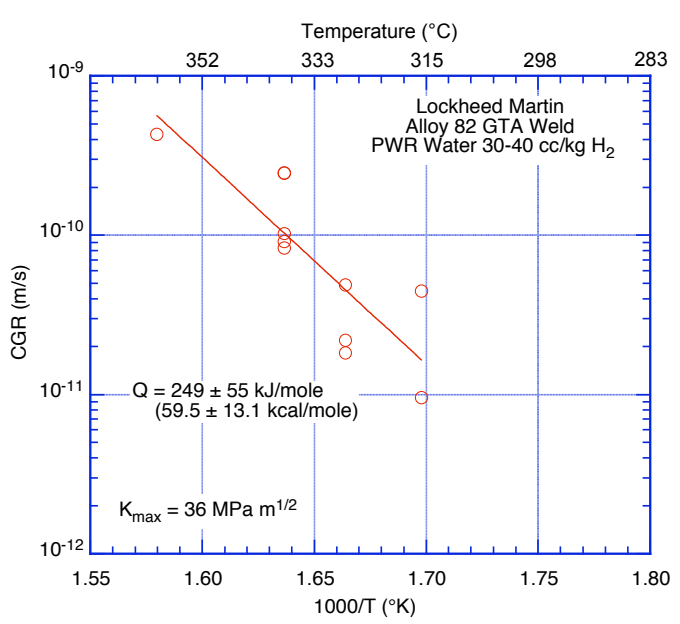

(b)

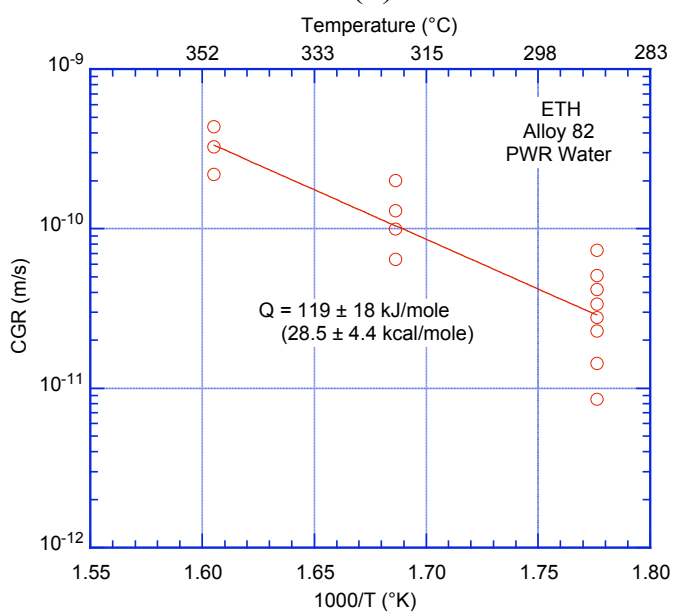

(d)

Figure 64.

Temperature dependence of the CGR data for Alloy 182 and 82 obtained at

(a) Westinghouse, (b) Lockheed Martin, (c) Bechtel Bettis, (d) ETH, and (e) CEA at temperatures between 290 and $360^{\circ} \mathrm{C}$.

(Refs. 53-61)

\subsubsection{Heat-to-Heat Comparisons of the CGR Data}

The CGR vs. K plots of some of the available CGR data sets for Alloys 182 and 82 are shown in Fig. 65. To allow for incomplete initiation of SCC across the crack front the reported CGR were modified by dividing by the engagement fraction. ${ }^{52}$ Also, the experimental CGRs were normalized to 
$325^{\circ} \mathrm{C}$ using Eq. 13, and then the best-fit parameter " $\alpha$ " was determined for each data set. The values of the parameter $\alpha$ range from $1.5 \times 10^{-11}$ to $9.0 \times 10^{-10}$ for Alloy 182, and $5.0 \times 10^{-12}$ to $3.5 \times 10^{-10}$ for Alloy 82. Thus, the CGRs of Alloy 182 are typically a factor of 2.5 higher than of Alloy 82.

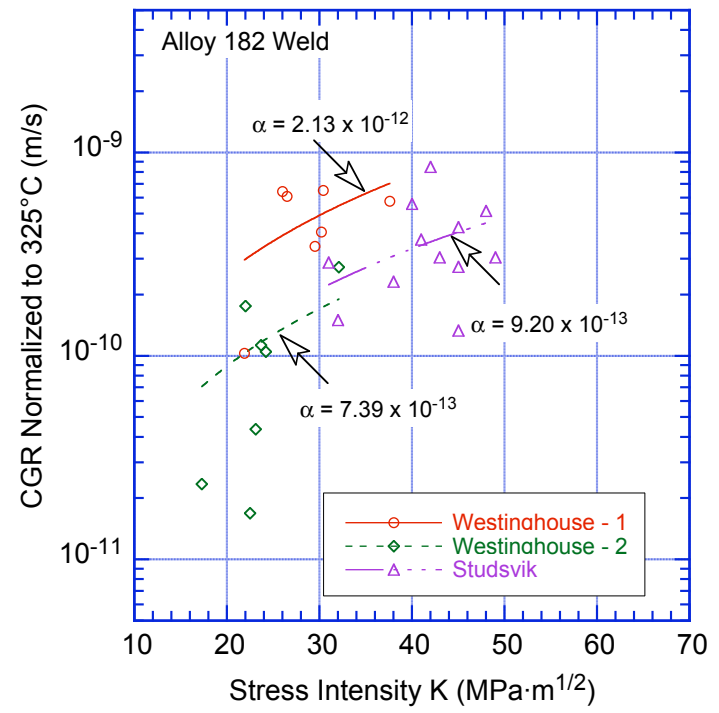

(a)

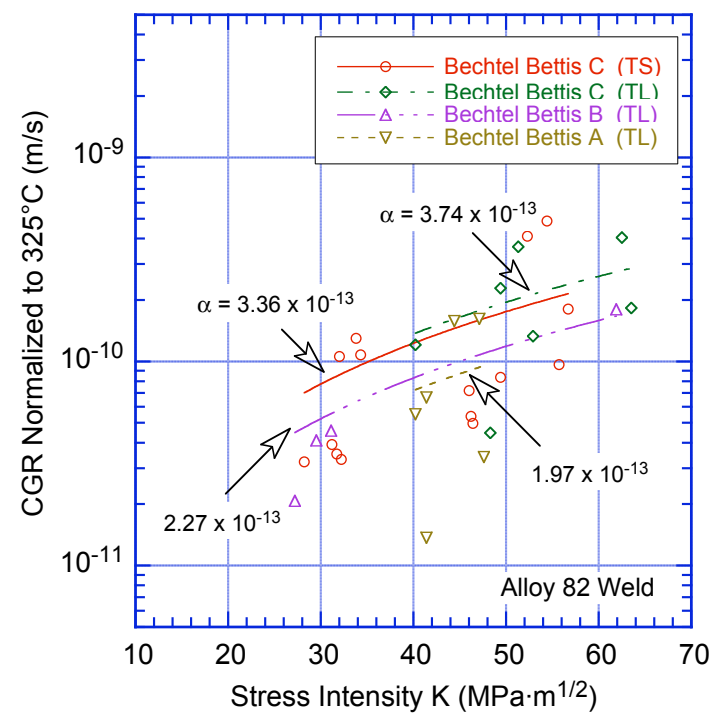

(c)

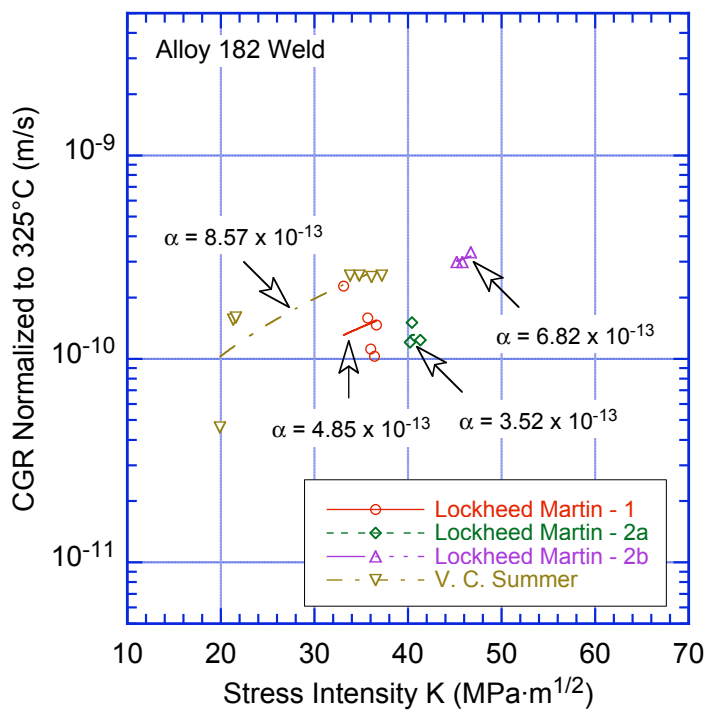

(b)

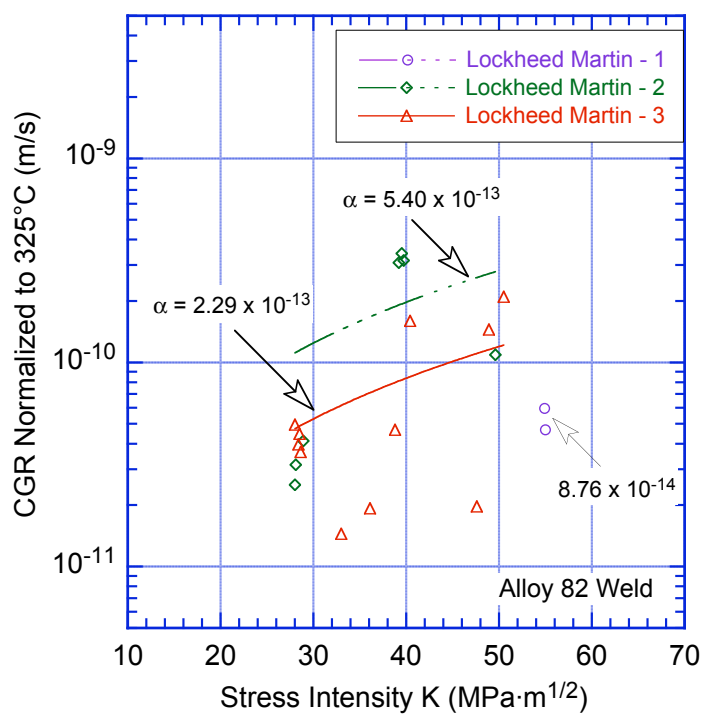

(d)

Figure 65. Experimental crack growth rate normalized to $325^{\circ} \mathrm{C}$ as a function of stress intensity factor $\mathrm{K}$

\subsubsection{Extrapolation of Available Data to the Population of Alloy 182 and 82 Weld Materials}

In the selection of a disposition curve, one must consider not only how well it describes the available test data, but how it is related to the CGRs that could occur in the much larger number of heats of material that are found in the field. To do this, the values of parameter $\alpha$ determined from the tests on the various welds were considered as a sample from a much larger population of heats of material of interest. The values were ordered and median ranks 66,67 were used to estimate the cumulative distribution of parameter $\alpha$ for the population. This distribution can be fit reasonably well by a lognormal distribution. However, the experimental CGRs were first adjusted for incomplete initiation of SCC, 
temperature, orientation, and alloy type, as follows: (a) divide by the engagement fraction to allow for incomplete initiation, (b) use Eq. 13 and an activation energy of $130 \mathrm{~kJ} / \mathrm{mole}$ to normalize the CGRs to common reference temperature of $325^{\circ} \mathrm{C}$, (c) multiply CGRs for TL orientations by 2 to account for orientation effects, and (d) multiply CGRs for Alloy 82 welds by 2.5 to account for the effects of alloy type. Also, studies at $\mathrm{CEA}^{56}$ generally report only the maximum values of CGR; the average CGRs were determined from the maximum values using the correlation proposed by Attanasio et al. ${ }^{59}$ The ratio between the maximum and average CGR was assumed to be the same as the ratio between maximum and average crack extension, i.e., $\mathrm{R}=\Delta \mathrm{a}_{\max } / \Delta \mathrm{a}_{\mathrm{ave}}$. The ratio $\mathrm{R}$ is expressed as

$$
\ln (\mathrm{R}-1)=2.48-0.762 \ln \left(\Delta \mathrm{a}_{\mathrm{ave}} / 0.051\right)
$$

where crack extension is in $\mathrm{mm}$. The normalized CGR data for the various Ni-alloy welds are presented in Table 12. The distributions for (a) the data that satisfy the screening criterion of Ref. 52 and (b) all the existing data are plotted with a log scale for $\alpha$ in Figs. 66a and b, respectively. The values of $\log$ mean and $\log$ standard deviation for the screened data and all the data are -27.795 and 0.650 , and -27.768 and 0.563 , respectively. Thus the median and 75th percentile values of parameter $\alpha$ are $8.55 \times 10^{-13}$ and 1.32 $\times 10^{-12}$ and, $8.72 \times 10^{-13}$ and $1.27 \times 10^{-12}$, respectively. The difference between the analyses with the screened data and all the data is insignificant. The estimated uncertainties for various data sets are also shown in the figure. The value of $\alpha$ that describes the 75 th percentile of this distribution would give a CGR model that would be expected to bound the CGRs of $75 \%$ of the heats of Alloy 182 welds in the population.
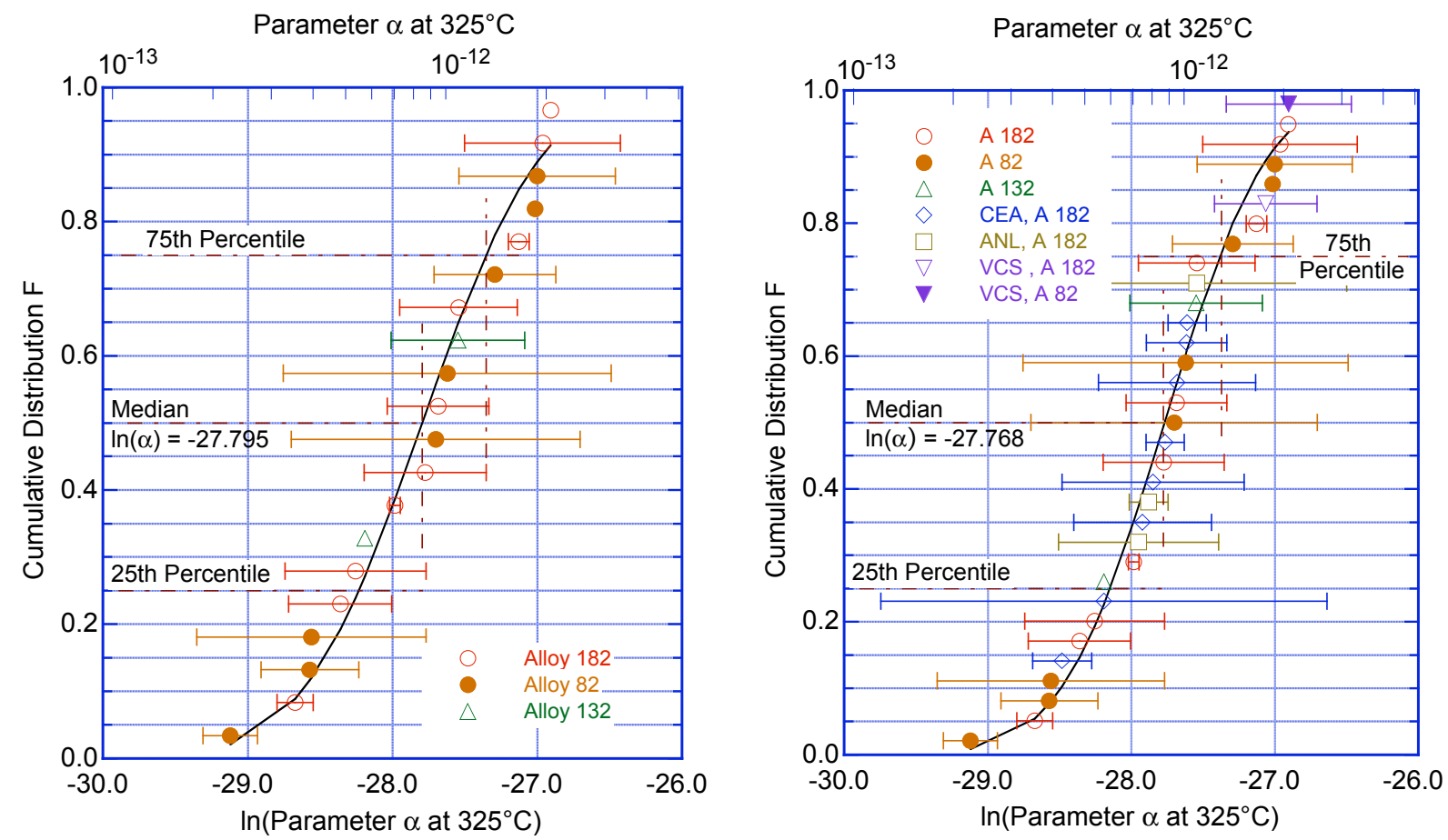

Figure 66. Estimated cumulative distribution of the normalized parameter $\alpha$ in the CGR relationship for Alloy 182 based on (a) data that satisfy the screening criterion of Ref. 52 and (b) all the data. 
Table 12. Values of the parameter $A$ in the Scott model for crack growth rate [Eq. (12)] for several Alloy 182,82 , and 132 welds.

\begin{tabular}{|c|c|c|c|c|c|c|}
\hline Heat No. & Alloy & Orientation & $\operatorname{Ln}($ Parameter $\alpha)$ & Std Deviation & Data Points & Reference \\
\hline WH $182-1^{*}$ & A 182 & TS & -25.964 & 0.538 & 7 & 53,54 \\
\hline WH $182-1^{*}$ & A 182 & TL & -26.908 & - & 1 & 46,47 \\
\hline WH $182-2^{*}$ & A 182 & TS & -27.685 & 0.351 & 3 & 53,54 \\
\hline WH $182-3^{*}$ & A 182 & TS & -27.128 & 0.072 & 2 & 53,54 \\
\hline Studsvik 26B2* & A 182 & TS & -27.544 & 0.405 & 5 & 12,47 \\
\hline Studsvik $6892^{*}$ & A 182 & TS & -27.775 & 0.422 & 2 & 12,47 \\
\hline Studsvik WC05F8* & A 182 & TS & -28.256 & 0.486 & 8 & 12,47 \\
\hline LM $182-1^{*}$ & A 182 & TS & -28.361 & 0.357 & 5 & 59 \\
\hline LM $182-2 a^{*}$ & A 182 & TS & -28.673 & 0.124 & 3 & 59 \\
\hline LM $182-2 b^{*}$ & A 182 & TS & -27.983 & 0.036 & 3 & 59 \\
\hline LM $82-2^{*}$ & A 82 & TS & -27.701 & 0.997 & 6 & 59 \\
\hline LM $82-3^{*}$ & A 82 & TS & -28.559 & 0.792 & 11 & 59 \\
\hline LM $82-1^{*}$ & A 82 & TS & -29.121 & 0.188 & 2 & 59 \\
\hline A-1 ${ }^{*}$ & A 82 & TL & -27.294 & 0.420 & 3 & 61 \\
\hline $\mathrm{C}-1^{*}$ & A 82 & TL & -27.002 & 0.540 & 3 & 61 \\
\hline $\mathrm{C}-2^{*}$ & A 82 & $\mathrm{TL}$ & -27.623 & 1.133 & 2 & 61 \\
\hline $\mathrm{C}-3^{*}$ & A 82 & TS & -27.016 & - & 1 & 61 \\
\hline $\mathrm{C}-4^{*}$ & A 82 & $\mathrm{TS}$ & -28.571 & 0.338 & 6 & 61 \\
\hline MHI MG7* & A 132 & TS/LS & -27.548 & 0.462 & 3 & 62 \\
\hline MHI $132^{*}$ & A 132 & LS & -28.191 & - & 1 & 62 \\
\hline CEA 182 D545 & A 182 & $\mathrm{TL}$ & -28.191 & 1.555 & 4 & 56 \\
\hline CEA 182 M1 & A 182 & TL & -27.848 & 0.634 & 2 & 56 \\
\hline CEA 182 M2 & A 182 & TL & -27.765 & 0.132 & 2 & 56 \\
\hline CEA 182 M4 & A 182 & TL & -27.611 & 0.133 & 2 & 56 \\
\hline CEA 182 D545 SR & A 182 & TL & -27.614 & 0.280 & 2 & 56 \\
\hline CEA 182 M1 SR & A 182 & $\mathrm{TL}$ & -28.482 & 0.205 & 2 & 56 \\
\hline CEA 182 M2 SR & A 182 & TL & -27.921 & 0.480 & 2 & 56 \\
\hline CEA 182 M4 SR & A 182 & $\mathrm{TL}$ & -27.682 & 0.547 & 2 & 56 \\
\hline VCS Weld & A 82 & TS & -26.903 & 0.436 & 8 & 58 \\
\hline VCS Butter & A 182 & TL & -27.062 & 0.356 & 8 & 58 \\
\hline ANL Double J* & A 182 & TS & -27.545 & 1.045 & 4 & This study \\
\hline ANL Deep Groove* & A 182 & TS & -27.948 & 0.558 & 5 & This study \\
\hline ANL Deep Groove* & A 182 & $\mathrm{TL}$ & -27.878 & 0.135 & 4 & This study \\
\hline
\end{tabular}

${ }^{*}$ Dataset satisfy the screening criterion of Ref. 52.

Two sources of error are possible in the distribution in Fig. 66. One is the difficulty of determining the parameters of the full lognormal distribution from only a few samples. We have determined a sample mean and sample standard deviation. We need the population mean and population standard deviation. ${ }^{68}$ Confidence bounds can be obtained on the population mean and standard deviation in terms of the sample mean and standard deviation. Even this, however, does not fully address the uncertainty in the distribution, because of the large uncertainties in the sample values themselves, i.e., the "horizontal" uncertainty in the actual value of parameter $\alpha$, as indicated by the error bars in Fig. 66. 
To assess the effect of these uncertainties on the population statistics, we performed a Monte Carlo analysis, in which a series of distributions was generated by sampling from the distributions for the value of $\alpha$ for each heat defined by the uncertainty for the particular heat. Each of these distributions was then used to estimate the mean value and standard deviation of the lognormal distribution for the population. Because the $\log$ of the mean and the $\log$ of the standard deviation of $\alpha$ are distributed normally, in the following discussion, the term "mean" and "standard deviation" will be used as shorthand for "log mean" and "log standard deviation", and the discussion will focus on properties of normal distributions. The sample means will be denoted as $\alpha_{\mathrm{s}}$, the population means as $\alpha_{t}$; the sample standard deviation is $\mathrm{s}$, the population standard deviation is $\sigma$.

For a normal distribution the quantity

$$
\frac{(\mathrm{n}-1) \mathrm{s}^{2}}{\sigma^{2}}
$$

where $\mathrm{n}$ is the number of samples, has a $\chi^{2}$ distribution with $\mathrm{n}-1$ degrees of freedom. ${ }^{68}$ The quantity

$$
\frac{\alpha_{\mathrm{s}}-\alpha_{\mathrm{t}}}{\mathrm{s}} \sqrt{\mathrm{n}}
$$

has a $\mathrm{t}$ distribution with $\mathrm{n}-1$ degrees of freedom. ${ }^{68}$ For each sample mean and standard deviation generated by the Monte Carlo analysis, an estimate of the population standard deviation and mean were obtained by sampling from the $\chi^{2}$ and $t$ distributions and using Eqs. 15 and 16. Values of the 95th, 90th, 75th, and 50th percentile values for each of the population distributions were calculated. Five-thousand Monte Carlo cases were run to develop distributions for 95th, 90th, 75th, and 50th percentile values. The results of the Monte Carlo analysis are summarized in Table 13 in terms of $\alpha$ values that bound the portion of the population we wish to consider and the confidence that we wish to have in the estimates of the bounds. With small sample sizes, demanding too high a confidence level can lead to very conservative estimates of the percentile values.

Table 13. Values of the parameter $\alpha$ for Alloy 182 and 82 at $325^{\circ} \mathrm{C}$ as a function of the percentage of the population bounded and the confidence level.

\begin{tabular}{ccccc}
\hline Confidence & \multicolumn{4}{c}{ Population Percentage } \\
\cline { 2 - 5 } Level & 95 & 90 & 75 & 50 \\
\hline 50 & $2.47 \times 10^{-12}$ & $1.95 \times 10^{-12}$ & $\mathbf{1 . 3 2} \times \mathbf{1 0}^{-12}$ & $8.55 \times 10^{-13}$ \\
75 & $3.41 \times 10^{-12}$ & $2.68 \times 10^{-12}$ & $1.78 \times 10^{-12}$ & $1.14 \times 10^{-12}$ \\
90 & $4.99 \times 10^{-12}$ & $3.84 \times 10^{-12}$ & $2.48 \times 10^{-12}$ & $1.53 \times 10^{-12}$ \\
95 & $5.93 \times 10^{-12}$ & $4.53 \times 10^{-12}$ & $2.88 \times 10^{-12}$ & $1.74 \times 10^{-12}$ \\
\hline
\end{tabular}

Cumulative distributions for these values can be obtained by rank ordering the values and then approximating the cumulative distribution by median ranks. ${ }^{66}$ These distributions are shown in Fig. 67. By considering, for example, the distribution for the 95th percentile values, one can determine the value at the desired confidence bounds corresponding to $\mathrm{F}=0.5,0.75,0.9$, and 0.95 . Order statistics ${ }^{69}$ can be used to show that with 5000 values, the confidence bounds on the percentile values determined from these distributions are quite narrow. The 75th percentile value of $\alpha$ at a $50 \%$ confidence level is $1.32 \times 10^{-12}$. 


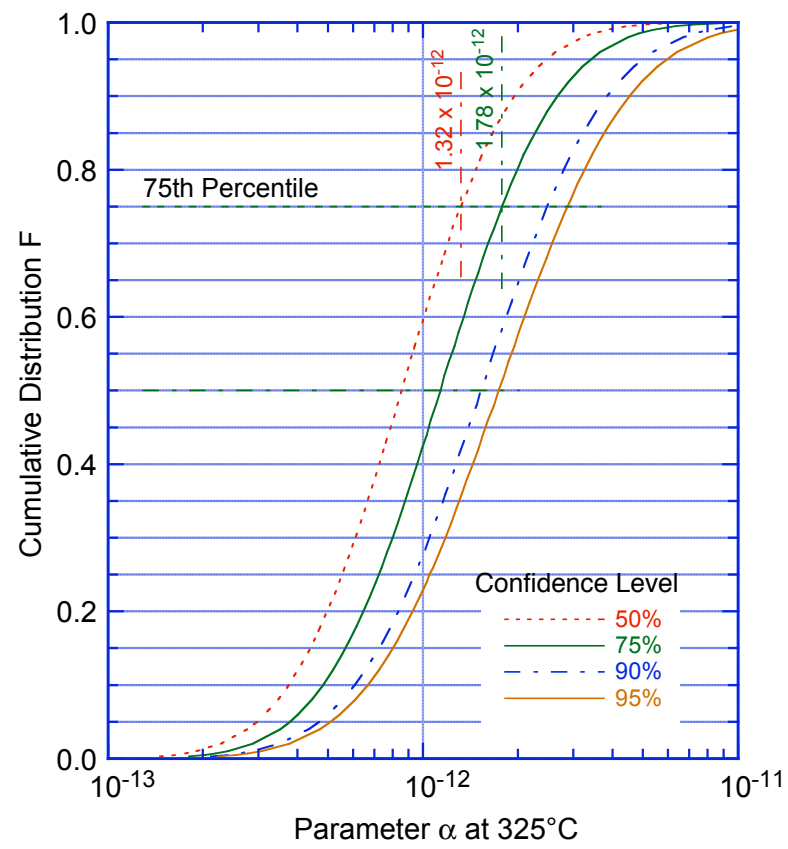

Figure 67.

Distributions of the 95th, 90th, 75th, and 50th confidence levels for parameter $\alpha$ for heats of Alloy 182 welds in PWR water at $325^{\circ} \mathrm{C}$.

This is a "best estimate" ( $50 \%$ confidence level) that it bounds $75 \%$ of the population. This curve is compared with the experimental CGR data for Alloy 182 (including ANL data) and Alloy 82 in Fig. 68a and $b$, respectively.

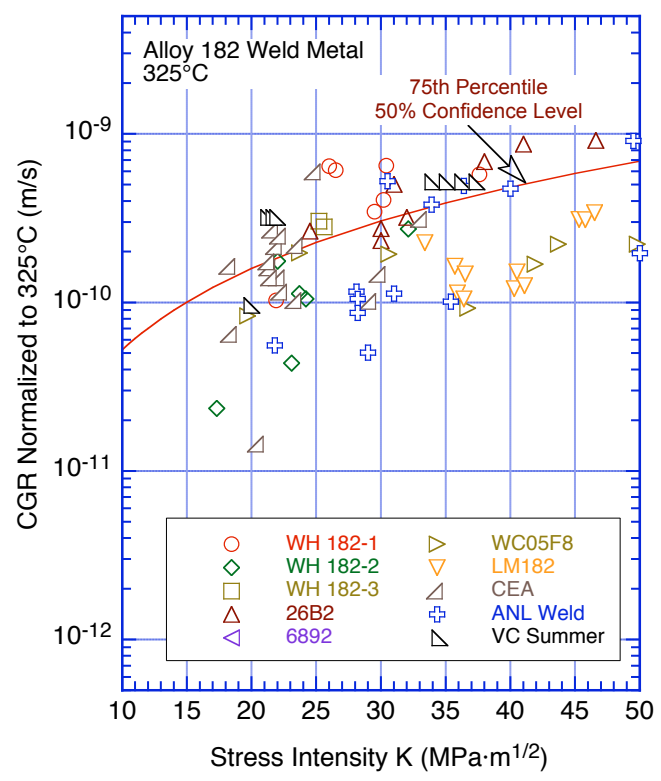

(a)

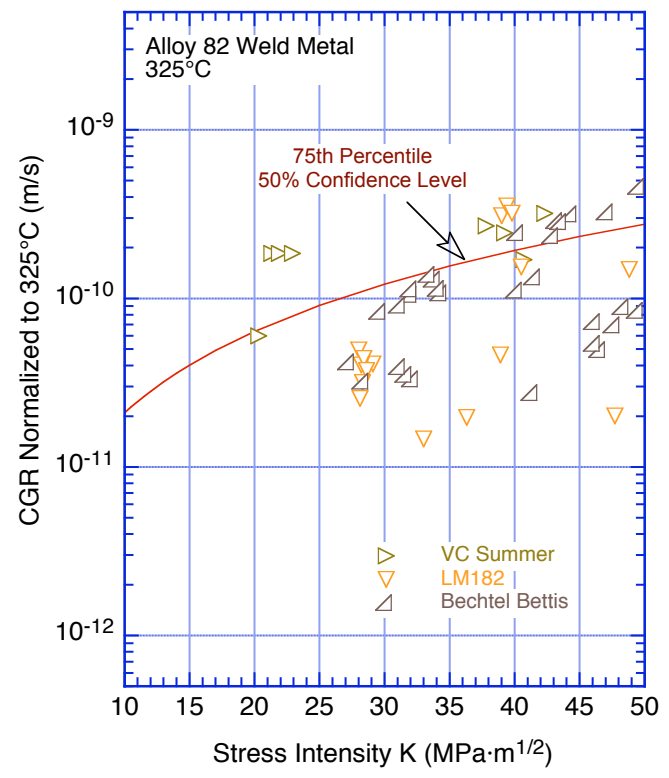

(b)

Figure 68. Comparison of the SCC crack growth rate for (a) Alloy 182 and (b) Alloy 82 welds in simulated PWR environment with the 75th percentile curve. 


\section{Summary}

Crack growth rate results are presented for Alloy 182 shielded metal arc (SMA) weld metal in the simulated PWR environment at $320^{\circ} \mathrm{C}$. The weld had either a double "J" joint or a deep-groove design.

Metallographic examinations were performed to characterize the microstructure of the weld. The weld structure consisted of vertically columnar grains and dendrites. The weld microstructure was also examined by orientation imaging microscopy to determine the orientations of the grains and the type of grain boundaries present. The results indicate that the intragranular dendrites are coherent and are, therefore, expected to be very resistant to cracking. The proportion of cracking-resistant coincident-site lattice boundaries in the weld was found to be relatively small $(\approx 30 \%)$ by comparison with that of Alloy 600 in a solution-annealed condition $(\approx 50 \%)$. The comparison suggests that Alloy 182 is more susceptible to cracking than Alloy 600, and this inference is supported by the findings presented in this report. However, the same OIM maps have revealed the clustering of grains with similar orientation in the weld alloy. In addition, an OIM analysis along the crack path in the weld specimens found that boundaries separating grains of similar orientation are more resistant to cracking than boundaries separating grains of different orientations. That is, the clustering of grains with similar orientations in weld alloys resulted in a different class of random boundaries that are more resistant to SCC. As such, it appears that grain orientation emerges as a SCC-determining parameter that should be included along with grain boundary misorientation for a better description of a weld alloy's susceptibility to SCC. A first necessary step would include a precise quantification of the prevalence of this class of boundaries in weld alloys.

Crack growth tests were conducted on 25.4-mm thick 1-T compact tension specimens with different orientations relative to the weld columnar grains. Crack extensions were monitored by the reversing DC potential difference method. The final crack extension estimated from the DC potential method was verified by physical measurements on the fracture surfaces.

The environmental enhancement of CGRs under cyclic loading was determined relative to the CGRs that would be expected under the same loading conditions for Alloy 600 in air. The results indicate little or no environmental enhancement of CGRs for Alloy 182 weld metal in the PWR environment. The CGRs of Alloy 182 in the PWR environment are a factor of $\approx 5$ higher than those of Alloy 600 in air under the same loading conditions.

The experimental CGR for the Alloy 182 weld obtained under essentially a constant load with periodic partial unloading is close to that expected for the median behavior of Alloy 600 in the PWR environment. Most of the existing CGR data for Alloy 182 and 82 welds are a factor of 1-10 greater than the median value for Alloy 600.

Metallographic examination of the fracture surface revealed a relatively straight crack front. The fracture mode correlated well with the test condition. Specifically, it was found that high rise times or long hold periods favor IG SCC. Also, IG cracking apparently advanced more readily along some grain orientations than others, resulting in a crack front with occasional unbroken ligaments and few regions of TG cracking.

The existing CGR data for Ni-alloy weld metals have been compiled and evaluated to establish the effects of key material, loading, and environmental parameters on CGRs in PWR environments. The 
results from the present study were compared with the existing CGR data to determine the relative susceptibility of the specific Ni-alloy weld to SCC and corrosion fatigue.

The limited data in the literature and results from the present study indicate very little frequencydependent environmental enhancement of fatigue CGRs of Alloy 182 and 82 welds in PWR environments. Under the same loading conditions, strain-rate-dependent environmental enhancement is observed in Alloy 600.

The SCC CGRs of Ni-alloy welds are influenced by several material and environmental parameters. In general, the CGRs are higher for Alloy 182 than Alloy 82. Although there is significant scatter in the results, the CGRs along the plane of the columnar grains are higher in a direction parallel than perpendicular to the columnar grains. The existing data suggest that the activation energy for the temperature dependence of SCC CGRs for Alloy 182 and 82 weld metals may be slightly higher than that for Alloy 600. Individual data sets yield activation energies between $120-250 \mathrm{~kJ} / \mathrm{mol}(28.5-$ $59.5 \mathrm{kcal} / \mathrm{mol}$ ). Studies on the effect of dissolved hydrogen on SCC CGRs in Alloy 182 and 82 welds indicate a maximum in proximity to the electrochemical potential of the $\mathrm{Ni} / \mathrm{NiO}$ phase transition. The CGRs decrease as the electrochemical corrosion potential deviates from the corrosion potential of the $\mathrm{Ni} / \mathrm{NiO}$ phase transition.

The effect of the stress intensity factor K on SCC crack growth for Ni-alloy welds is represented by the Scott model. Heat-to-heat comparisons of the CGR data were made. The cumulative distribution of the parameter A in the Scott model was used to estimate the heat-to-heat variability of the population of Alloy 182 and 82 welds. Values of the parameter A as a function of the percentage of the population bounded and the confidence level were determined. Under similar loading and environmental (PWR) conditions, the mean CGRs for $\mathrm{Ni}$-alloy welds appear to be a factor of $\approx 2$ higher than the mean CGRs for Alloy 600. 


\section{References}

1. Scott, P., "An Analysis of Primary Water Stress Corrosion Cracking in PWR Steam Generators," Proc. of the Specialists Meeting on Operating Experience with Steam Generators, Brussels, Belgium, pp. 5-6, 1991.

2. Cattant, F., "Lessons Learnt from the Examination of Tubes Pulled from Electricite de France Steam Generators," Nucl. Eng. Des. 168, pp. 241-253, 1997.

3. Diercks, D. R., W. J. Shack, and J. Muscara, "Overview of Steam Generator Tube Degradation and Integrity Issues,” Nucl. Eng. Des. 194, pp. 19-30, 1999.

4. USNRC Information Notice No. 90-10, "Primary Water Stress Corrosion Cracking (PWSCC) of Inconel 600," Feb. 1990.

5. USNRC Generic Letter 97-01, "Degradation of Control Rod Drive Mechanism and Other Vessel Closure Head Penetrations," April 1, 1997.

6. Economou, J., A. Assice, F. Cattant, J. Salin, and M. Stindel, "NDE and Metallurgical Examination of Vessel Head Penetrations," 3rd Intl. Symp. of Fontevraud, Sept. 12-16, 1994.

7. Robinson, M. R., Duke Power Company, "Oconee Unit 1 and Unit 3 Reactor Vessel Head Leakage, Cracking of RV Head Penetrations due to Primary Water Stress Corrosion Cracking," NRC Meeting with the NEI EPRI Material Reliability Program Regarding CRDM Nozzle Crackling Issues, Rockville, MD, April 12, 2001.

8. Frye, C. R., T. Alley, M. L. Arey, Jr., and M. R. Robinson, "Cracking in Alloy 600/182 Reactor Vessel Head Penetrations," PVP-Vol. 437, Service Experience and Failure Assessment Applications ASME 2002, P. S. Lam, ed., American Society of Mechanical Engineers, New York, pp. 171-178, 2002.

9. USNRC Information Notice 2001-05, “Through-Wall Circumferential Cracking of Reactor Pressure Vessel Head Control Rod Driver Mechanism Penetration Nozzle at Oconee Nuclear Station, Unit 3," April 30, 2001.

10. USNRC Bulletin 2001-01, "Circumferential Cracking of Reactor Pressure Vessel Head Penetration Nozzles," Aug. 3, 2001.

11. USNRC Information Notice 2000-17, "Crack in Weld Area of Reactor Coolant System Hot Leg Piping at V. C. Summer,” Oct. 18, 2000; Suppl. 1, Nov. 16, 2000; Suppl. 2, Feb. 28, 2001.

12. Jenssen, A., K. Norrgard, J. Lagerstrom, G. Embring, and D. Tice, "Assessment of Cracking in Dissimilar Metal Welds," in Proc. of the Tenth Intl. Conf. on Environmental Degradation of Materials in Nuclear Power Systems-Water Reactors, NACE International, Houston, TX, 2001.

13. Bennetch, J. I., G. E. Modzelewski, L. L. Spain, and G. V. Rao, "Root Cause Evaluation and Repair of Alloy 82/182 J-Groove Weld Cracking of Reactor Vessel Head Penetrations at North Anna Unit 2," PVP-Vol. 437, Service Experience and Failure Assessment Applications ASME 2002, P. S. Lam, ed., American Society of Mechanical Engineers, New York, pp. 179-185, 2002. 
14. USNRC Information Notice 2002-11, "Recent Experience with Degradation of Reactor Pressure Vessel Head," March 12, 2002.

15. USNRC Information Notice 2003-11, "Leakage Found on Bottom-Mounted Instrumentation Nozzles,” Aug. 13, 2003; Suppl. 1, Jan. 8, 2004.

16. USNRC Bulletin 2003-02, "Leakage from Reactor Pressure Vessel Lower Head Penetrations and Reactor Coolant Pressure Boundary Integrity," Aug. 21, 2003.

17. Ruther, W. E., W. K. Soppet, and T. F. Kassner, "Corrosion Fatigue of Alloys 600 and 690 in Simulated LWR Environments,” NUREG/CR-6383, ANL-95/37, April 1996.

18. Ruther, W. E., W. K. Soppet, and T. F. Kassner, "Environmentally Assisted Cracking of Alloys 600 and 690 in Simulated LWR Water," Environmentally Assisted Cracking in Light Water Reactors, Semiannual Report, July 1997-December 1997, NUREG/CR-4667, Vol. 25, ANL-98/18, pp. 4275, Sept. 1998.

19. Ruther, W. E., W. K. Soppet, T. F. Kassner, and W. J. Shack, "Environmentally Assisted Cracking of Alloys 600 and 690 in Simulated LWR Water," Environmentally Assisted Cracking in Light Water Reactors, Semiannual Report, January 1998-July 1998, NUREG/CR-4667, Vol. 26, ANL98/18, pp. 25-32, March 1999.

20. Ruther, W. E., W. K. Soppet, T. F. Kassner, and W. J. Shack, "Environmentally Assisted Cracking of Alloys 600 and 690 in Simulated LWR Water," Environmentally Assisted Cracking in Light Water Reactors, Semiannual Report, July 1998-December 1998, NUREG/CR-4667, Vol. 27, ANL-99/11, pp. 45-54, October 1999.

21. Soppet, W. K., O. K. Chopra, and W. J. Shack, "Environmentally Assisted Cracking of Alloys 600 and 690 in Simulated LWR Water," Environmentally Assisted Cracking in Light Water Reactors, Semiannual Report, July 1999-December 1999, NUREG/CR-4667, Vol. 29, ANL-00/23, pp. 3945, November 2000.

22. Chopra, O. K., W. K. Soppet, and W. J. Shack, "Effects of Alloy Chemistry, Cold Work, and Water Chemistry on Corrosion Fatigue and Stress Corrosion Cracking of Nickel Alloys and Welds," NUREG/CR-6721, ANL-01/07, April 2001.

23. Cassagne, T. B., and A. Gelpi, "Crack Growth Rate Measurements on Alloy 600 Steam Generator Tubes in Steam and Primary Water," Proc. of the Fifth Intl. Symp. on Environmental Degradation of Materials in Nuclear Power Systems-Water Reactors, American Nuclear Society, La Grange Park, IL, pp. 518-524, 1991.

24. Foster, J. P., W. H. Bamford, and R. S. Pathania, "Initial Results of Alloy 600 Crack Growth Rate Testing in a PWR Environment," Proc. of the Seventh Intl. Symp. on Environmental Degradation of Materials in Nuclear Power Systems-Water Reactors, NACE International, Houston, TX, pp. 25-39, 1995.

25. Magdowski, R., F. Vaillant, C. Amzallag, and M. O. Speidel, "Stress Corrosion Crack Growth Rates of Alloy 600 in Simulated PWR Coolant," Proc. of the 8th Intl. Symp. on Environmental Degradation of Materials in Nuclear Power Systems-Water Reactors, S. M. Bruemmer, ed., American Nuclear Society, La Grange Park, IL, pp. 333-338, 1997. 
26. Le Hong, S., C. Amzallag, and A. Gelpi, "Modeling of Stress Corrosion Crack Initiation on Alloy 600 in Primary Water of PWRs," Proc. of the Ninth Intl. Symp. on Environmental Degradation of Materials in Nuclear Power Systems-Water Reactors, F. P. Ford, S. M. Bruemmer, and G. S. Was, eds., The Minerals, Metals, and Materials Society, Warrendale, PA, pp. 115-122, 1999.

27. Raquet, O., and G. Santarini, "Stress Corrosion Crack Propagation Rate of Alloy 600 in the Primary Water of PWR Influence of a Cold Worked Layer," Proc. of the Ninth Intl. Symp. on Environmental Degradation of Materials in Nuclear Power Systems-Water Reactors, F. P. Ford, S. M. Bruemmer, and G. S. Was, eds., The Minerals, Metals, and Materials Society, Warrendale, PA, pp. 207-213, 1999.

28. White, G. A., Hickling, J., and Mathews, L. K., "Crack Growth Rates for Evaluating PWSCC of Thick-Wall Alloy 600 Material," Proc. of the 11th Intl. Symp. on Environmental Degradation of Materials in Nuclear Power Systems-Water Reactors, NACE International, Houston, TX, pp. 166-179, 2003.

29. Macdonald, D. D., A. C. Scott, and P. Wentrcek, "External Reference Electrodes for Use in High Temperature Aqueous Systems,” J. Electrochem. Soc. 126, pp. 908-911, 1979.

30. Andresen, P. L., and P. G. Campbell, "The Effects of Crack Closure in High-Temperature Water and its Role in Influencing Crack Growth Data," Proc. of the Fourth Intl. Symp. on Environmental Degradation of Materials in Nuclear Power Systems-Water Reactors, D. Cubicciotti, ed., NACE International, Houston, TX, pp. 4.86-4.111, 1990.

31. Briant, C. L., and E. L. Hall, "The Microstructural Causes of Intergranular Corrosion of Alloys 82 and 182," Corrosion, 43, pp. 539-548, 1987.

32. Palumbo, G., K. T. Aust, E.M. Lehockey, U. Erb, and P. Lin, "On a more Restrictive Geometric Criterion for 'Special' CSL Grain Boundaries,” Acta Metallurgica, 14, pp. 1685-1690, 1998.

33. Was, G., V. Thaveeprungsriporn, and D. C. Crawford, "Grain Boundary Misorientation Effects on Creep and Cracking in Ni-Based Alloys," Journal of Materials, 50 (2), pp. 44-49, 1998.

34. Alexandreanu, B., B. Capell, and G. S. Was, "Combined Effect of Special Grain Boundaries and Grain Boundary Carbides on IGSCC of Ni-16Cr-9Fe-xC Alloys," Materials Science and Engineering A, 300, pp. 94-104, 2001.

35. Lehockey, E. M., G. Palumbo, and P. Lin, "Improving the Weldability and Service Performance of Nickel- and Iron-Based Superalloys by Grain Boundary Engineering," Metallurgical and Materials Transactions, 29 (12), pp. 369-379, 1998.

36. Brandon D.G., "The structure of high-angle grain boundaries", Acta Metallurgica, 14, pp 1479$1484,1966$.

37. Palumbo, G., P.J. King, and K.T. Aust, "Grain Boundary Design and Control for Intergranular Stress Corrosion Resistance,” Scripta Metallugica et Materialia, 25 (8), pp. 1775-1780, 1991.

38. Cheung, C., U. Erb, and G. Palumbo, "Application of Grain Boundary Engineering Concepts to Alleviate Intergranular Cracking in Alloys 600 and 690," Materials Science and Engineering A, 185, pp. 39-43, 1994. 
39. Gertsman, V. I., and S.M. Bruemmer, "Study of Grain Boundary Character along Intergranular Stress Corrosion Crack Paths in Austenitic Alloys," Acta Materialia, 49, pp. 1589-1598, 2001.

40. Pan, Y., B. L. Adams, T. Olson, and N. Panayotou, "Grain-Boundary Structure Effects on Intergranular Stress Corrosion Cracking of Alloy X-750," Acta Materialia, 44 (12), pp. 4685-4695, 1996.

41. Lehockey, E. M., A.M. Brennenstuhl, and I. Thompson, "On the Relationship between Grain Boundary Connectivity, Coincident Site Lattice Boundaries, and Intergranular Stress Corrosion Cracking," Corrosion Science, 46, pp. 2383-2404, 2004.

42. Yi, Y. S., and J. S. Kim, "Characterization Methods of Grain Boundary and Triple Junction Distributions,” Scripta Materialia 50, pp. 855-859, 2004.

43. Schuh, C. A., R. W. Minich, and M. Kumar, "Connectivity and Percolation in Simulated GrainBoundary Networks,” Phil. Mag. 83 (6), pp. 711-726, Feb. 21, 2003.

44. Alexandreanu, B., and G. S. Was, "Grain Boundary Deformation-Induced Intergranular Stress Corrosion Cracking of Ni-16Cr-9Fe in 360 C Water," Corrosion 59 (8), 705, 2003.

45. Alexandreanu, B., and G. S. Was, "A Priori Determination of the Sampling Size for Grain Boundary Character Distribution and Grain Boundary Degradation Analysis," Phil. Mag. A, 81 (8), pp. 1951-1965, 2001.

46. Wright, S.I., and D.P. Field, "Recent Studies of Local Texture and its Influence on Failure," Materials Science and Engineering A, 257, pp. 165-170, 1998.

47. Lindstrom, R., P. Lidar, and J. Lagerstrom, "Crack Growth of Alloy 182 in Simulated Primary Side PWR Environment," Proc. of the 8th Intl. Symp. on Environmental Degradation of Materials in Nuclear Power Systems-Water Reactors, S. M. Bruemmer, ed., American Nuclear Society, La Grange Park, IL, pp. 422-429, 1997.

48. Amzallag, C., G. Baudry, and J. L. Bernard, "Effects of PWR Environment on the Fatigue Crack Growth of Different Stainless Steels and Inconel Type Alloy," Proc. IAEA-Specialists Meeting on Subcritical Crack Growth, NUREG/CP-0044, Vol. 1, pp. 263-294, 1983.

49. Van Der Sluys, W. A., B. A. Young, and D. Doyle, "Corrosion Fatigue Properties on Alloy 690 and some Nickel-Based Weld Metals," Assessment Methodologies for Preventing Failure: Service Experience and Environmental Considerations, PVP Vol. 410-2, R. Mohan, ed., American Society of Mechanical Engineers, New York, pp. 85-91, 2000.

50. Psaila-Dombrowski, M. J., C. S. Wade, J. M. Sarver, W. A. Van Der Sluys, and P. E. Doherty, "Evaluation of Weld Metals 82, 152, 52, and Alloy 690 Stress Corrosion Cracking and Corrosion Fatigue Susceptibility," Proc. of the 8th Intl. Symp. on Environmental Degradation of Materials in Nuclear Power Systems-Water Reactors, S. M. Bruemmer, ed., American Nuclear Society, La Grange Park, IL, pp. 412-421, 1997. 
51. James, L. A., and W. J. Mills, "Fatigue-Crack Propagation Behavior of Wrought Alloy 600 and Weld-Deposited EN82H in an Elevated Temperature Aqueous Environment," Service Experience, Structural Integrity, Severe Accident, and Erosion in Nuclear and Fossil Plants, PVP Vol. 303, The American Society of Mechanical Engineers, pp. 21-36, 1995.

52. White, G., J. Hickling, and C. Harrington, "MRP Development of Crack Growth Rate Disposition Curves for Primary Water Stress Corrosion Cracking (PWSCC) of Thick-Section Alloy 600 Components and Alloy 82, 182 and 132 Weldments," 2005 EPRI International PWSCC of Alloy 600 Conference, Santa Ana Pueblo, NM, March 7-10, 2005.

53. Bamford, W. H., J. P. Foster, and R. S. Pathania, "An Investigation of Alloy 182 Stress Corrosion Cracking in Simulated PWR Environment," Proc. of the Ninth Intl. Symp. on Environmental Degradation of Materials in Nuclear Power Systems-Water Reactors, F. P. Ford, S. M. Bruemmer, and G. S. Was, eds., The Minerals, Metals, and Materials Society, Warrendale, PA, pp. 279-294, 1999.

54. Bamford, W. H., J. P. Foster, K. R. Hsu, L. Tunon-Sanur, and A. McIlree, "Alloy 182 Weld Crack Growth, and its Impact on Service-Induced Cracking in Operating PWR Plant Piping," Proc. Tenth Intl. Conf. on Environmental Degradation of Materials in Nuclear Power Systems-Water Reactors, NACE International, Houston, TX, 2001.

55. Le Hong, S., J. M. Boursier, C. Amzallag, and J. Daret, "Measurement of Stress Corrosion Cracking Growth Rates in Weld Alloy 182 in Primary Water of PWR," Proc. Tenth Intl. Conf. on Environmental Degradation of Materials in Nuclear Power Systems-Water Reactors, NACE International, Houston, TX, 2001.

56. Cassagne, T., D. Caron, J. Daret, and Y. Lefevre, "Stress Corrosion Crack Growth Rate Measurements in Alloys 600 and 182 in Primary Loops Under Constant Load," Proc. of the Ninth Intl. Symp. on Environmental Degradation of Materials in Nuclear Power Systems-Water Reactors, F. P. Ford, S. M. Bruemmer, and G. S. Was, eds., The Minerals, Metals, and Materials Society, Warrendale, PA, pp. 217-224, 1999.

57. Magdowski, R., and M. Speidel, "Stress Corrosion Crack Growth of Weld Material Alloy 182 in Simulated PWR Environments," Institute of Metallurgy, Swiss Federal Institute, Internal Report No. 226, Zurich, Jan. 2001.

58. Jacko, R. J., R. E. Gold, G. V. Rao, K. Koyama, and A. Kroes, "Results of Accelerated SCC Testing of Alloy 82, Alloy 182 and Alloy 52M Weld Metals," The Vessel Penetration Inspection, Crack Growth and Repair Conference, Oct. 2, 2003, Gaithersburg, MD, 2003, Vol. 1, pp. 413426.

59. Attanasio, S., J. V. Mullen, J. W. Wuthrich, W. W. Wilkening, and D. S. Morton, "Stress Corrosion Crack Growth Rates (SCCGRs) for Alloy 182 and 82 Welds," The Vessel Penetration Inspection, Crack Growth and Repair Conference, Oct. 2, 2003, Gaithersburg, MD, 2003, Vol. 1, pp. 267296.

60. Brown, C. M., and W. J. Mills, "Effect of Water on Mechanical Properties and Stress Corrosion Behavior of Alloy 600, Alloy 690, EN82H Welds, and EN52 Welds," Corrosion, 55 (2), pp. 173186, 1999. 
61. Mills, W. J., and C. M. Brown, "Stress Corrosion Crack Growth Rates for Alloy 82H Welds in High Temperature Water," Proc. 11th Intl. Conf. on Environmental Degradation of Materials in Nuclear Power Systems-Water Reactors, NACE International, Houston, TX, 2003.

62. Tsutsumi, K., H. Kanasaki, K. Yoshimoto, Y. Nomura, S. Asada, and T. Yonezawa, "SCC Growth Rate of Nickel Based Alloy 132 Weld Metal in PWR Water," Proc. 11th Intl. Conf. on Environmental Degradation of Materials in Nuclear Power Systems-Water Reactors, NACE International, Houston, TX, 2003.

63. Frary, M., and C.A. Schuh, Connectivity and percolation behaviour of grain boundary networks in three dimensions, Phil.Mag. A 85 (11), pp. 1123-1143, April 2005.

64. Morton, D. S., S. A. Attanasio, and G. A. Young, "Primary Water SCC Understanding and Chraracterization through Fundamental Testing in the Vicinity of the Nickel/Nickel Oxide Phase Transition," Proc. Tenth Intl. Conf. on Environmental Degradation of Materials in Nuclear Power Systems-Water Reactors, NACE International, Houston, TX, 2001.

65. Lidar, P., M. Konig, J. Engstrom, and K. Gott, "Effect of Water Chemistry on Environmentally Assisted Cracking in Alloy 600 in Simulated PWR Environments," Proc. Ninth International Symposium on Environmental Degradation of Materials in Nuclear Power Systems-Water Reactors, The Minerals, Metals, and Materials Society (TMS), Warrendale, PA, pp. 125-130, 1999.

66. Johnson, L. G., "The Median Ranks of Sample Values in Their Population with an Application to Certain Fatigue Studies,” Ind. Math, 2, pp. 1-9, 1951.

67. Lipson, C., and N. J. Sheth, "Statistical Design and Analysis of Engineering Experiments," McGraw Hill, New York, 1973.

68. Beck, J., and K. Arnold, "Parameter Estimation in Engineering and Science," J. Wiley, New York, 1977.

69. Hogg, R. V., and A. T. Craig, "Introduction to Mathematical Statistics," Prentice Hall, New York, 1995. 
1. REPORT NUMBER

(Assigned by NRC. Add Vol., Supp., Rev., and Addendum Numbers, if any.)

BIBLIOGRAPHIC DATA SHEET

(See instructions on the reverse)

\section{TITLE AND SUBTITLE}

Crack Growth Rates of Nickel Alloy Welds in a PWR Environment
NUREG/CR-6907

ANL-04/3

3. DATE REPORT PUBLISHED

MONTH

May $2 p 06$

4. FIN OR GRANT NUMBER

Y 6388

5. AUTHOR(S)

B. Alexandreanu, O. K. Chopra, and W. J. Shack
6. TYPE OF REPORT

Technical

8. PERFORMING ORGANIZATION - NAME AND ADDRESS (If NRC, provide Division, Office or Region, U.S. Nuclear Regulatory Commission, and mailing address; if contractor, provide name and mailing address.)

Argonne National Laboratory

9700 South Cass Avenue

Argonne, IL 60439

9. SPONSORING ORGANIZATION - NAME AND ADDRESS (If NRC, type "Same as above": if contractor, provide NRC Division, Office or Region, U.S. Nuclear Regulatory Commission, and mailing address.)

Division of Fuel, Engineering and Radiological Research

Office of Nuclear Regulatory Research

U.S. Nuclear Regulatory Commission

Washington, DC 20555-0001

10. SUPPLEMENTARY NOTES

William H. Cullen, Jr., NRC Project Manager

11. ABSTRACT (200 words or less)

Reactor vessel internal components made of nickel-base alloys are susceptible to stress corrosion cracking (SCC). A program is being conducted at Argonne National Laboratory to evaluate the resistance of Ni-alloys and their welds to SCC in simulated LWR coolant environments. This report presents crack growth rate (CGR) results for Alloy 182 in simulated PWR environments. The results indicate little or no environmental enhancement of fatigue CGRs of Alloy 182 weld-metal. In addition, the cyclic CGRs of Alloy 182 ware found to be a factor of $\approx 5$ higher than of Alloy 600 in air under the same loading conditions. The SCC CGRs for weld alloy were close to the average behavior of Alloy 600. The sample orientation was found to have a profound effect on the magnitude of crack growth: cracking was found to propagate faster along the dendrites than across them. The existing CGR data for Ni-alloy weld metals have been compiled and evaluated to establish the effects of key material, loading, and environmental parameters on CGRs in PWR environments. The results from the present study are compared with the existing CGR data for $\mathrm{Ni}$-alloy welds to determine the relative susceptibility of the specific Ni-alloy weld to environmentally enhanced cracking.

12. KEY WORDS/DESCRIPTORS (List words or phrases that will assist researchers in locating this report.)

Crack Growth Rate

Ni-base welds

PWR Environment

13. AVAILABILITY STATEMENT
Unlimited
14. SECURITY CLASSIFICATION
(This Page)
Unclassified
(This Report)
Unclassified
15. NUMBER OF PAGES
16.ICE PR

